

\section{Propositions}

1. A multidisciplinary approach is needed to explore fate and effects of hydrophobic organic contaminants in shallow lakes.

(this thesis)

2. Organic contaminants that are more hydrophobic are more likely to trigger rather than being affected by an ecological regime shift. (this thesis)

3. Universal evaluation criteria for performance of environmental models do not exist.

4. Environmental scientists must focus more on changing than on interpreting the world.

5. Having a lot of information hampers conceiving great ideas.

6. Destiny is a useful concept to deal with the inevitable uncertainty of life.

Propositions belonging to the thesis entitled

Model studies on the dynamics of hydrophobic organic compounds in shallow lake ecosystems

Xiangzhen Kong

Wageningen, 30 November, 2018 


\section{Model studies on the dynamics of hydrophobic organic compounds in shallow lake ecosystems}

Xiangzhen Kong 


\section{Thesis committee}

\section{Promotors}

Prof. Dr W.M. Mooij

Special professor Aquatic Food Web Ecology

Wageningen University \& Research and Netherlands Institute of Ecology (NIOOKNAW)

Prof. Dr A.A. Koelmans

Personal Chair of Aquatic Ecology and Water Quality Mangement Wageningen University \& Research

\section{Other members}

Prof. Dr C. Kroeze, Wageningen University \& Research

Prof. Dr J. de Boer, VU Amsterdam

Prof. Dr A.J. Hendriks, Radboud University Nijmegen

Dr M.H.S. Kraak, University of Amsterdam

This research was conducted under the auspices of the C.T. de Wit Graduate School for Production Ecology \& Resource Conservation (PE\&RC) 


\title{
Model studies on the dynamics of hydrophobic organic compounds in shallow lake ecosystems
}

\author{
Xiangzhen Kong
}

Thesis

submitted in fulfilment of the requirements for the degree of doctor at Wageningen University by the authority of the Rector Magnificus

Prof. Dr A.P.J. Mol, in the presence of the

Thesis Committee appointed by the Academic Board to be defended in public on Friday 30 November 2018 at 4.p.m. in the Aula. 
Xiangzhen Kong

Model studies on the dynamics of hydrophobic organic compounds in shallow lake ecosystems, 253 pages

PhD thesis, Wageningen University, Wageningen, The Netherlands (2018)

With references, with summary in English

ISBN 978-94-6343-347-1

DOI https://doi.org/10.18174/458894 
To my father

\section{致我的父茶}




\section{Contents}

$\begin{array}{lr}\text { Foreword } & 9\end{array}$

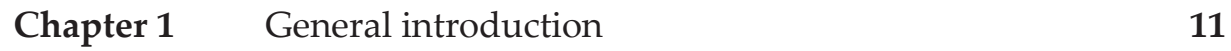

Chapter 2 Multimedia fate modeling of Polycyclic Aromatic 29 Hydrocarbons (PAHs) in Lake Small Baiyangdian, Northern China

Chapter 3 Simulation of the fate and seasonal variations of $\alpha-57$ hexachlorocyclohexane $(\alpha-\mathrm{HCH})$ in Lake Chaohu using a dynamic fugacity model

Chapter 4 Modeling the multimedia fate dynamics of $\gamma-\mathbf{8 3}$ Hexachlorocyclohexane in a large Chinese lake

Chapter 5 Multimedia fate modeling of perfluorooctanoic acid (PFOA) and perfluorooctane sulphonate (PFOS) in the shallow lake Chaohu, China

Chapter 6 Integrated ecological and chemical food web 155 accumulation modeling explains PAH temporal trends during regime shifts in a shallow lake

$\begin{array}{lll}\text { Chapter } 7 & \text { General discussion } & 201\end{array}$

$\begin{array}{ll}\text { References } & 225\end{array}$

$\begin{array}{ll}\text { Summary } & 241\end{array}$

$\begin{array}{lr}\text { Acknowledgements } & 245\end{array}$

$\begin{array}{ll}\text { About the author } & 248\end{array}$

$\begin{array}{lr}\text { List of publications } & 249\end{array}$

$\begin{array}{ll}\text { Training \& Education Statement } & 251\end{array}$ 
Foreword

\section{Foreword}

The twentieth century witnesses the widespread eutrophication and intensive organic contaminations in earth surface water systems located in highly populated areas, resulting in severe deterioration of water quality in freshwater ecosystems around the globe. This is particularly the case for many freshwater shallow lakes in China. The interaction between excess nutrient loading and enormous organic contaminants discharge has raised increasing attention from both scientists and lake managers, whereas accurate prediction for both substances cannot be properly predicted based on knowledge from either field alone. However, efforts in the related scientific research, particularly the development of relevant modeling tools, remains scarce. To this end, the aim of this thesis is to develop an integrated ecological and chemical modeling tool, which is composed of contaminant fate module (CF), food web accumulation module (FW) and ecological module (EM), in the hope to fulfill the research gap above. We collected three groups of HOCs, namely hexachlorocyclohexanes (HCHs), polycyclic aromatic hydrocarbons (PAHs) and Per- and polyfluoroalkyl substances (PFASs), in multiple compartments from two Chinese shallow lakes that are currently in distinct ecological states, i.e., Lake Small Baiyangdian (in clear state) and Lake Chaohu (in turbid state). In particular, paleo-records of PAHs residual levels in Lake Chaohu in two sediment cores covering the time span of over 60 years were obtained. We elaborated to explicitly investigate the fate, transport and transformation of these contaminants in these two shallow lakes using the developed modeling tool, with either steady state or dynamic simulations (in time scales of both short-term intra-annual (1-2 years) and long-term inter-annual (60 years)). The following issues were addressed: 1) fate of the chemicals in lake environment and the dominant processes; 2) seasonal patterns of chemicals in lakes and the driving factors; 3) long-term dynamics of chemicals in lakes and the driving factors; and 4) impact of abrupt changes in ecosystems on the distribution of contaminations in shallow lakes. For modeling techniques, we implemented uncertainty analysis on the model using both classic Monde Carlo and more advanced Bayesian Markov Chain Monte Carlo (MCMC) algorithm. We recommend to apply MCMC to contaminant modeling approach to make calibration possible and to remove the overestimated uncertainty in predictions. Furthermore, we 
compared the advantages and disadvantages of our model to other models with similar objectives, and we further proposed a more comprehensive modeling framework that incorporates hydrodynamic models to address spatial variations of contamination, which embraces the fruitful outcomes in aquatic ecosystem modeling. Finally, we advocate to add modeling approach as the third dimension for the 'contemporary \& paleoobservations' strategy, which together contribute to the 'golden triangle' framework. New insights and discoveries may emerge for the evaluation on the organic contaminants in shallow lake systems, which may contribute to ecological and human health risk assessment. This 'golden triangle' may serve as the multidiscipline framework for limnologic research in the future. 
Chapter 1

\section{General introduction}


General introduction

"Persistent pollutants, persistent threats."

-Jepson E Law, Science 2016, 352:1388-1389.

\section{Introduction}

Increasing contamination including excessive nutrients and toxic compounds are one of the most prevalent threats confronting freshwater ecosystems globally (Skei et al. 2000, Schwarzenbach et al. 2006). Increasing nutrient loads, together with many other human activities, can induce abrupt changes in aquatic ecosystems, which can in turn influence the environmental behavior of those toxic chemicals. Understanding the interactions between ecological processes and the behavior of toxic chemicals therefore becomes a relevant and urgent issue in the context of global change. In this chapter, I briefly introduce the current status of micropollutants contamination in global aquatic systems, and review the potential impact of ecological processes on the environmental behavior of many contaminants. Then, I provide a short review on the development of fugacity-based multimedia fate model for HOCs, which, in this thesis, has been further coupled to a food web accumulation model and an ecological model. In the last section, I introduce the two study sites and the three groups of target chemicals investigated in this thesis, and finally give the outline of this thesis.

\section{Hydrophobic organic contaminants in aquatic ecosystems}

It is well recognized that the contamination of global freshwater resources by micropollutants has become a key environmental issue raising major public concern (Millennium Ecosystem Assessment 2005). Around the globe, approximately one-third of the freshwater is currently affected by humans for agriculture, industrial and domestic activities (Schwarzenbach et al. 2006). As a consequence, annually c.a. 300 million tons of chemical compounds, including c.a. 140 million tons of fertilizers, pesticides, and various hazardous chemicals such as hydrophobic organic contaminants (HOCs), finally enter aquatic ecosystems including streams, rivers, lakes, groundwater and coastal seas (Larsson et al. 2000, Skei et al. 2000, Schwarzenbach et al. 2006). This is particularly the case in many catchments with high population densities and intensive human activities in China, such as Haihe Plain (Wang et al. 2011a, Wang et al. 2013) and lower Yangtze River floodplain in China (Qiu et al. 2008, He et al. 2012, Qin et al. 2013a). 
Some of these HOCs do not or very slowly degrade, such as lindane and polycyclic aromatic hydrocarbons (PAHs) (Walker et al. 1999, Breivik and Wania 2002, Schenker et al. 2009, Parajulee and Wania 2014). After these chemicals enter the aquatic environment, they are subject to environmental and ecological processes, and are distributed among various compartments in the lake, accumulate and biomagnify in the food chain, thereby threatening the ecological functions at various levels, from impairment of individuals (e.g. the survival and biomass of one or more core species) to ultimately the ecosystem level (biodiversity and functioning loss) due to their high toxicity at environmentally relevant concentrations (Qin et al. 2013b). A recent study indicates that polychlorinated biphenyls (PCBs) continue to threaten marine predators, such as orcas, even though the use and manufacture of PCBs have been banned in the early 1980s (Jepson and Law 2016). In addition, these persistent contaminants damage human health via consumption of aquatic products and environmental exposure (Wu et al. 2007). Those organic contaminants with low degradation rates are generally referred to as Persistent Organic Pollutants (POPs) (Jones and De Voogt 1999), and many of those causing high ecological or human health risks have been subject to legislative restrictions in the Stockholm convention (SCPOPs 2009, Vijgen et al. 2011).

\section{Alternative stable states in shallow lake ecosystems}

The environmental behavior of HOCs in aquatic systems is determined by biogeochemical and ecological processes within these systems (Koelmans et al. 2001). Therefore, understanding the ecology of these systems, e.g., shallow lakes that are distributed globally, is a prerequisite for evaluating the effects of HOCs on these systems.

Intensive studies have revealed that freshwater shallow lake ecosystems exhibit alternative stable states, i.e. a clear, macrophyte-dominated state, and a turbid, phytoplankton-dominated state (Scheffer et al. 1993). Such systems are stable in either of the states reinforced by multiple feedbacks, which center around the interaction between macrophytes and water turbidity (Scheffer et al. 1993). The alternative equilibria in shallow lakes have important implications, as they can shift from one state to another surprisingly when a threshold of a certain external condition is crossed, which is generally referred to as a 'regime shift' (Scheffer et al. 2001a, Scheffer and Carpenter 2003, Scheffer 2004, Scheffer and Jeppesen 2007).

Among all the potential mechanisms, crossing the threshold of a critical nutrient level in the water column is often considered as the dominant one (Scheffer 2004). Therefore, the world-wide water quality deterioration due to 
General introduction

eutrophication by excessive nutrient discharge will exhibit nonlinear rather than linear patterns and result in abrupt changes in ecosystems. In addition, many other factors may also play a role (Scheffer and van Nes 2007). Recent studies have highlighted the impact of extreme water levels on lakes ecosystems, demonstrating that frequent flooding and occasional droughts can induce regime shifts as well (Schooler et al. 2011). The significant role of hydrological disturbance by human activities (van Geest et al. 2007, LoverdeOliveira et al. 2009, Kong et al. 2017a), climate change (Scheffer et al. 2001b, Smol et al. 2005) in driving regime shifts in lakes have also been demonstrated. As a consequence, the risk of transgressing the 'planetary boundaries' and the occurrence of abrupt change in ecosystems such as lakes are increasing rapidly in the context of global change driven by multiple human activities in the coming future (Rockström et al. 2009, Dearing et al. 2014, Scheffer et al. 2015, Steffen et al. 2015).

\section{Potential impact of ecological state on the fate of HOCs in lakes}

The alternative stable states and abrupt changes occurring in shallow lake ecosystems could have a substantial impact on the fate of HOCs. The ecological structures in the alternative states are different (Downing et al. 2012, Kong et al. 2016). The ecological functions in ecosystems with different structure are substantially altered, leading to disturbed biogeochemical cycling (Jeppesen et al. 2011). Several studies have indicated that these changes may influence the environmental behavior of HOCs in these lake systems, including transport, partitioning, and bioavailability (Berglund et al. 2001, Koelmans et al. 2001, Moermond et al. 2005, Nizzetto et al. 2012). First, the differences in primary producers play a critical role. In a clear lake, the dominated submerged vegetation can act as a sink for HOCs and decrease the amount in other compartments (Roessink et al. 2010). For example, sediment-rooted macrophytes can substantially decrease the amount of pollutants in sediment by uptake (Diepens et al. 2014). On the other hand, in a turbid state lake dominated by suspended algae, the sink of vegetation is absent and the mobility of HOCs is enhanced. It has been reported that abundant algae in eutrophic lakes may act as a 'biological pump' that drives the exchange of HOCs between e.g. air-water and water-sediment interfaces, thereby largely influencing the fate and transport of HOCs in lakes and oceans (Dachs et al. 1999, Dachs et al. 2000, Nizzetto et al. 2012). Second, the altered food web structure and ecological functioning may also play a role. The importance of planktonic food webs in driving the fate of HOCs in lakes suggest the necessity to include zooplankton as a factor (Berrojalbiz et al. 2009). In addition, the 
changes in the fish community can result in, e.g. different intensity of sediment disturbance by benthivorous fish, which subsequently will affect the fate of HOCs (Roessink et al. 2010). Several studies addressed this issue with mesocosm experiments and field observations (Moermond et al. 2005, Roessink et al. 2010). However, only few studies have addressed the impact of regime shifts from one ecological state to the alternative state on the distribution and transport of HOCs in one system. This gap in knowledge is subject to the data paucity of HOC observations either in ecosystems of contrasting states, or in one ecosystem undergone abrupt changes.

\section{Fugacity-based multimedia fate model}

Multimedia fate model is a widely used modeling tool to investigate environmental behavior of chemicals, ecological risk assessment and environmental management of contaminants. Fugacity-based multimedia fate model is one of the derivatives, which is considered to be an important development of multimedia fate model (Mackay 2001). The word fugacity originates from the Latin fugere, which means to flee. This concept was firstly introduced to thermodynamics in 1901 by the American chemist Gilbert N. Lewis (Lewis and Randall 1961). Fugacity evaluates the equilibrium distribution and tendency of chemicals to escape between phases (Mackay and Paterson 1981). It was applied in multimedia fate modeling since the beginning of the 1980s (Mackay 1979, Mackay and Paterson 1981, 1982).

Fugacity-based multimedia fate model is developed based on the principle that both environmental conditions and physical-chemical properties of the chemicals determine their fate, transport and transformation in the environment. Four levels of fugacity model exist (Level I - IV) (Mackay and Paterson 1982):

- Level I model is for equilibrium, stable and non-flowing systems;

- Level II model is for equilibrium, stable and flowing systems;

- Level III model is for non-equilibrium, stable and flowing systems;

- Level IV model is for non-equilibrium, non-stable and flowing systems .

It is either Level III or Level IV model that could comprehensively describe the chemical's behavior after entering the environment. More compartments are included during the development of level III model with case studies of contaminants of prior attention (Edwards et al. 1999). The model accounts for chemicals in air, water, fish and sediment (aquatic systems)(Mackay et al. 1983a, Mackay et al. 1983b, Mackay and Hughes 1984, 
General introduction

Mackay et al. 1986, Mackay and Diamond 1989, Baek and Park 2000, Wang et al. 2012a), soil and plants systems (Paterson et al. 1990, Paterson et al. 1991), terrestrial systems (Wang et al. 2002, Wania et al. 2006, Parajulee and Wania 2014), as well as the whole environmental (Mackay and Paterson 1991, Mackay et al. 1992). In addition, incorporation of spatial heterogeneity at both regional (Tao et al. 2003) and global (Ballschmiter 1992, Wania and Mackay 1995) scales provides deeper insights into the characteristics of chemical's behavior in environment. Coupling to an atmospheric transportation model enables the model to address global distribution and health risk from inhalation exposure to the contaminants (Zhang et al. 2009, Wang et al. 2011a). Furthermore, a level IV fugacity-based multimedia fate model evaluates dynamics of fate, transport and transformation of chemicals, at temporal scales of either short-term with seasonal variations (Lang et al. 2007, Wang et al. 2011a) or long-term with changes in emission intensity (Tao et al. 2006, Cao et al. 2007, Liu et al. 2007, Ao et al. 2009, Dong et al. 2009). These studies generally observe a relative good fit of model predictions to measured data, and an evident response of contaminant residual levels to the changes in emission rates in the past. Prognoses of contaminant residual levels in the coming decades can also be indicated (Tao et al. 2006), which serves as critical implications for chemical managements. Overall, since the first report, fugacity-based multimedia fate model has been under continuous development and applications.

Fugacity-based multimedia fate model has also been utilized in investigations of the bioconcentration, bioaccumulation and biomagnification of contaminants in food chains and/or food webs in ecosystems (usually level III) to facilitate ecological and human health risk assessment. These approaches are based on the fact that the fugacity ratio between biota and abiotic phases, and between trophic levels, could be higher than one. As a result, fugacity gradient of chemicals is the key driver of bioconcentration, bioaccumulation and biomagnification (Connolly and Pedersen 1988). In addition, studies that quantitatively evaluate the relevant parameters also provide an important basis for these approaches, such as the relationship between the bioaccumulation factor $\left(K_{B}\right)$ and the octanol/water partition coefficient (Kow) (Mackay 1982). For food chains and food webs, fugacity-based model starts from modeling contaminants in both the digestive system of fish (Mackay and Hughes 1984, Gobas et al. 1993, Gobas et al. 1999, Hauck et al. 2011) and terrestrial vegetation (Calamari et al. 1987, Paterson et al. 1994, McKone and Maddalena 2007, Diepens et al. 2014), including agriculture crops (Hung and Mackay 1997). Next, the model is extended to whole food chains and/or food webs (Diamond et al. 1996, Binelli and Provini 2003, Arnot and Gobas 2004, Gobas and Arnot 2010) and ultimately to a general framework for food web accumulation model 
(Campfens and Mackay 1997), resulting in modeling tools with more systematic description on transport and transformation of chemicals, and a rapid risk assessment of commercial chemicals (Mackay and Fraser 2000). Overall, due to potential toxicity of the contaminants that may lead to species extinction (Gilbertson 1996) or human health risks (Thomas et al. 1998), understanding bioconcentration, bioaccumulation and biomagnification of contaminants using models is of great importance (Sharpe and Mackay 2000, Koelmans et al. 2001). However, models integrating ecosystem dynamics and contaminant fate models are still limited in both model availability and completeness of process description.

\section{PCLake as a lake ecological model}

PCLake model was initially developed as an integrated ecosystem model for temperate shallow non-stratifying lakes in the Netherlands (Janse and van Liere 1995). The model has a fully mixed water column and a subsurface sediment layer, and operates with closed nutrient cycles in the lake system (Janse 1997, Mooij et al. 2010). Three groups of phytoplankton (diatoms, greens and blue-green) and submerged vegetation are included in the model, as well as a simplified food web, consisting of zooplankton, zoobenthos, and three functional groups of fish (zooplanktivorous, benthivorous and piscivorous). Each compartment is modeled by three components, namely, dry weight as a surrogate for carbon, nitrogen and phosphorus. The model keeps track of the mass balances. In addition, the model is based on both mechanistic descriptions of biotic and abiotic processes (e.g. grazing, mortality, respiration and shade effects) and empirical relations (e.g. sediment resuspension, interactions between resuspension and vegetation). The main purpose of the model development is to simulate the critical transitions between the clear, vegetation-dominated state and the turbid, phytoplankton-dominated state in shallow lakes (Janse and van Liere 1995). A comprehensive and detailed descryption of PClake model can be found in Janse (2005).

To date, multiple studies have investigated the features of shallow lake ecosystem simulated by PCLake. The model is well-calibrated based on a large lake dataset in the Netherlands, and the most sensitive parameters and model uncertainties are addressed (Aldenberg et al. 1995, van Puijenbroek et al. 2004, Mooij et al. 2009, Janse et al. 2010, Nielsen et al. 2014). Some studies mainly focus on calculating the critical level of nutrient loading at which a transition may occur between the two alternative stable states in shallow lakes. These studies aim at revealing the associated influencing factors such as lake types or other features, and providing hints for lake management (Janse 1997, Janse et 
General introduction

al. 2008). In addition, the model can also be used to address the biological factors influencing the stability of macrophyte-dominate states in the lake (Janse et al. 1998). The effects of climate change on shallow lakes are also evaluated by the PCLake model in both temperate and subtropical regions (Mooij et al. 2007, Fragoso et al. 2011, Nielsen et al. 2014). The predictions from the model to future scenarios in the context of global warming depend on the location and the status of the lake. Nonetheless, evidence from model simulations has shown that changes in climate, nutrient and hydraulic loading, as well as enhanced input of terrestrial particulate organic matter, will decrease critical nutrient loadings and increase the probability of a shift from a clear to a turbid state (Mooij et al. 2007, Lischke et al. 2014). Several studies focus on modification and improvement of the PCLake model, including addition of vertical variations in the lake (Prokopkin et al. 2010), and incorporation of a 3D hydrodynamics model to describe the integrated hydrodynamic, water-quality, and biological processes in the lake (Fragoso et al. 2009, Fragoso et al. 2011).

PCLake model is considered as a powerful tool to simulate the longterm dynamics of Lake Chaohu ecosystem because this model is developed in the context of alternative stable states and regime shifts of shallow lakes between clear and turbid states. The model has a detailed submodel for submerged macrophytes and an explicit interpretation of the interactions between phytoplankton and submerged macrophytes. The most important mechanisms that lead to alternative stable states and hysteresis are considered in PCLake. The assumed regime shifts in Lake Chaohu during the last several decades, from a clear, submerged-dominated state (approximately 30\% coverage of submerged plants before the 1960s), to a turbid, phytoplanktondominated state, are within the scope and ability of the model, making it possible to simulate the dynamics and reveal the dominant driving factors. In this thesis, PCLake is coupled with a fugacity-based multimedia model developed for modeling HOCs in shallow lake Chaohu. Details can be found in a previous publication (Kong et al. 2017a).

\section{Research objectives and hypothesis}

In this thesis, I aim to address the following questions: What are the characteristics of fate, transport and bioaccumulation of HOCs for the distinct ecological states of shallow lake ecosystems, on both seasonal and annual temporary scales? What are the major factors influencing the patterns of HOC environmental behavior? Can an integrated contaminant fate \& ecosystem model for this approach be developed? Will the model be able to simulate the dynamics of fate, transport and bioaccumulation of HOCs during a regime 
Chapter 1

shift occurring in a lake? I hypothesize that the environmental behavior of HOCs in shallow lakes with alternative stable states (i.e. clear and turbid states) will be significantly different in terms of fate, transport and bioaccumulation. Therefore, regime shifts in shallow lakes would exert large impacts on HOCs cycling in shallow lakes and possibly their risks.

\section{Study systems}

\section{Study sites}

Two typical shallow lakes in China are selected (Fig. 1), one in a clear, macrophyte-dominant state (Lake Small Baiyangdian), and the other in a turbid, phytoplankton-dominant state (Lake Chaohu).

\section{- Lake Small Baiyangdian}

Lake Baiyangdian is located in the triangular region defined by three large cities, Beijing, Tianjin, and Baoding. It is the largest freshwater lake in northern China with a total area of $366 \mathrm{~km}^{2}$ with an average depth of approximately $1.9 \mathrm{~m}$. Lake Baiyangdian plays an important role in maintaining the ecological balance of north China and in providing domestic, agricultural, and industrial water sources for the lake catchment (Wang et al. 2013), which is regarded as the 'Pearl of North China'. It is also a critical natural wetland for groundwater replenishment, flood control and biodiversity preservation in this region (Li et al. 2012). Lake Baiyangdian is composed of 143 small lakes and ponds. Lake Small Baiyangdian is one of them with a total area of $13.3 \mathrm{~km}^{2}$. This lake is dominated by macrophytes whereas the lake has suffered from increasing nutrient loading and HOCs due to rapid population growth and economic development in the basin over the past several decades (Xu et al. 2011a).

\section{- $\quad$ Lake Chaohu}

Lake Chaohu is the fifth-largest shallow freshwater lake in China (surface area $780 \mathrm{~km}^{2}$ with an average depth of approximately $3 \mathrm{~m}$ ). The catchment area of the lake is $12,938 \mathrm{~km}^{2}$. Before the 1950s, the lake was well known for its scenic beauty and rich aquatic products. The macrophyte coverage was $25 \%-30 \%$ of the lake area and the water body was mesotrophic with a low phytoplankton concentration before 1960 (Xu et al. 1999b). Over the last several decades, the total human population living in the catchment increased from 3.1 million in 1950 to 7.4 million in 2013. In the same period the gross value of industrial output increased from 31 million RMB in 1950 to 
General introduction

165,525 million RMB in 2013 (Zhang et al. 2015a). Drastic changes have occurred in this lake, and nowadays the lake is highly eutrophic with frequent summer blooms of cyanobacteria (Kong et al. 2015, Zhang et al. 2015b). Previous studies combing ecosystem modeling and paleolimnological records have revealed that this lake has undergone several regime shifts since 1950s (Kong et al. 2016, Kong et al. 2017a). Moreover, the lake has been highly polluted with multiple HOCs over a long-term period (He et al. 2014). Therefore, this lake also serves as a good case for investigating the impact of regime shifts on environmental behavior of HOCs during a long-term time scale.

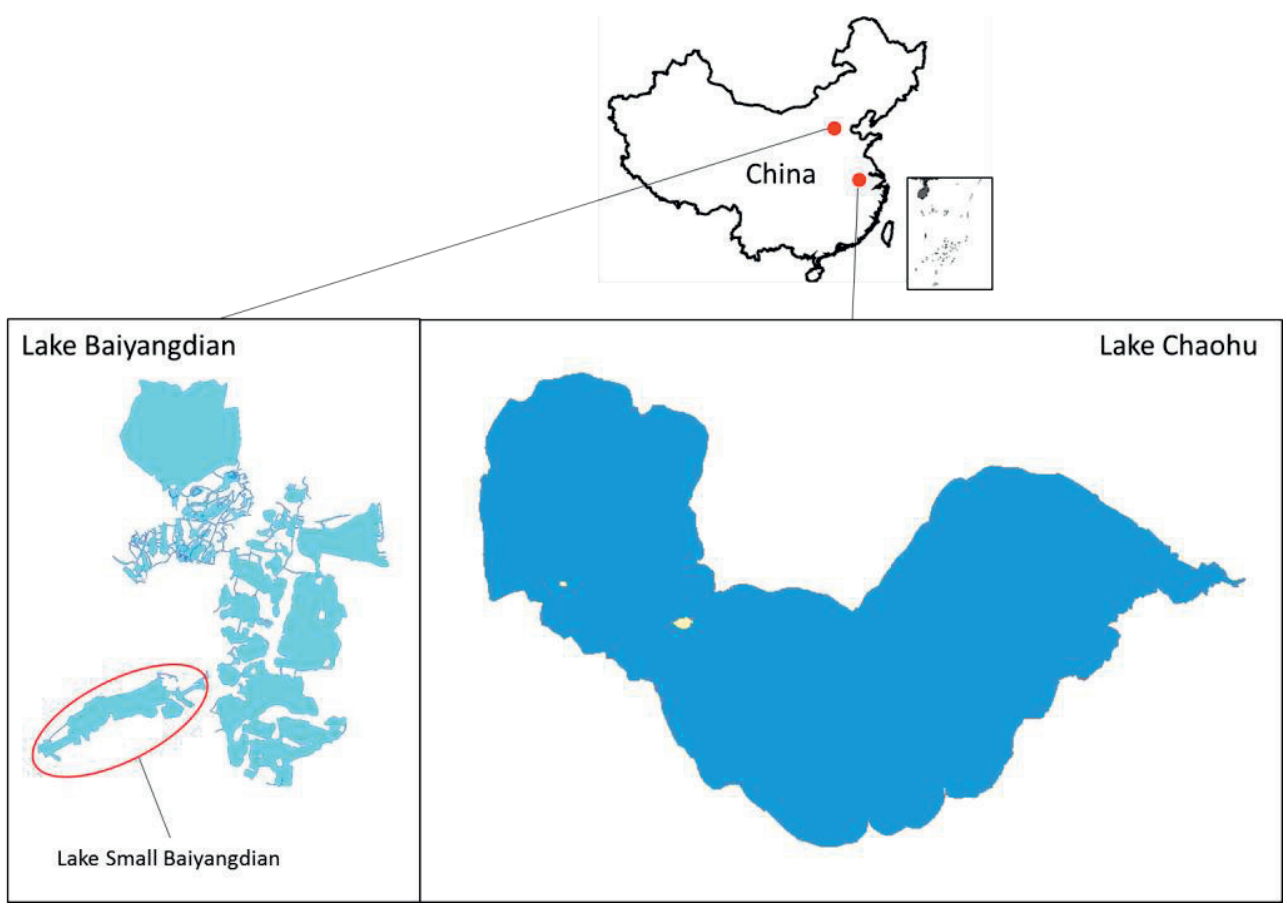

Fig. 1 Locations of Lake Small Baiyangdian and Lake Chaohu in China.

\section{Target HOCs}

- Hexachlorocyclohexanes (HCHs)

$\mathrm{HCH}$ are chemicals of any of several polyhalogenated organic compounds consisting of a six-carbon ring with one chlorine and one hydrogen attached to each carbon (Table 1). They are compounds of major concern 
among organochlorine pesticides (OCPs), which have been heavily used in the past around the world (Carson 2002). There are eight geometric isomers of $\mathrm{HCHs}$, which differ in the axial and equatorial positions of the chlorine atoms (Walker et al. 1999). $\mathrm{HCH}$ isomers $(\alpha-, \beta$ - and $\gamma-\mathrm{HCH})$ were recently added to the list of persistent organic pollutants (POPs) at the Stockholm Convention (Vijgen et al. 2011). The isomers of $\alpha-\mathrm{HCH}$ and $\gamma-\mathrm{HCH}$ are the main ingredients for the commercial product of technical HCHs (containing $60-70 \%$ $\alpha-\mathrm{HCH}$ and $10-15 \% \gamma-\mathrm{HCH}$ ), and $\gamma-\mathrm{HCH}$ is the active ingredient of the insecticide lindane (containing more than $99.9 \% \gamma-\mathrm{HCH}$ ). Studies showed that lindane may exert pressures on freshwater ecosystems (Qu et al. 2011, Matozzo et al. 2012). Among the isomers of $\mathrm{HCHs}, \alpha-\mathrm{HCH}$ can cause human neurological disorders and gastrointestinal discomfort, resulting in liver and kidney damage, human endocrine system disorders and immune system abnormalities (SCPOPs 2009). Furthermore, as the only isomer with specific insecticidal properties, $\gamma-\mathrm{HCH}$ is found to be a tumor promoter (Walker et al. 1999). One study indicated that subtle alterations in breast and prostate cells could be induced by environmental concentrations of lindane (Kalantzi et al. 2004b).

\section{Polycyclic aromatic hydrocarbons (PAHs)}

PAHs are hydrocarbons-organic compounds containing only carbon and hydrogen, which can be found in coal and tar deposits, and are also produced by the incomplete combustion of organic matter (Zhang and Tao 2009). PAHs are globally-concerned pollutants due to their widespread occurrence, strong persistence, long-range transport potential and carcinogenic toxicity (Qin et al. 2013b), and have been listed in Annex B of the Stockholm Convention (SCPOPs 2009). As one of the fastest growing countries in the world, China is suffering from severe contamination with PAHs from various sources (Zhang et al. 2007), where ecosystem and human health are threated. The atmospheric emissions of 16 priority PAHs in China in 2004 (114 Gg) accounted for about $22 \%$ of the total global emissions $(520 \mathrm{Gg}$ ) (Zhang et al. 2009). It was estimated that $5.8 \%$ of China's land area, where $30 \%$ of the population lives, exceeded the national ambient benzo[a]pyrene $(\mathrm{BaP})$ standard of $10 \mathrm{ng} / \mathrm{m}^{3}$, and that the overall population attributable fraction for lung cancer caused by inhalation exposure to PAHs was 1.6\% (Zhang et al. 2009).

- Poly - and perfluoroalkyl substances (PFASs)

PFASs are a group of chemicals that are widely applied in fire-fighting foams, carpets, paints, and oil-resistant coatings for food contact paper, etc. (Giesy and Kannan 2001, Liu et al. 2015b). These group of substances have 
General introduction

been produced since the 1950s, and are highly used from the 1970s at a global scale (Lindstrom et al. 2011). After the prohibition of application in 2002 (3M 2003), the countries around the world have still reported the continuous production and application of PFASs, and its production increases annually. Both perfluorooctanoic acid (PFOA) and perfluorooctane sulphonate (PFOS) are the dominant PFASs that have attracted public attention (Loos et al. 2010). PFOA, also known as "C8", is used in the process of making Teflon and similar chemicals. PFOS, on the other hand, is the key ingredient in Scotchgard, a fabric protector made by 3M, and numerous stain repellents. In 2009, PFASs were listed in Annex B of the Stockholm Convention (SCPOPs 2009).

Table 1 Basic information of the target HOCs

\begin{tabular}{|c|c|c|c|c|}
\hline Name & Abbreviation & Molecular structure & $\begin{array}{c}\text { Molecular } \\
\text { formula }\end{array}$ & CAS No. \\
\hline \multicolumn{5}{|c|}{ Hexachlorocyclohexane $(n=2)$} \\
\hline $\begin{array}{l}\alpha- \\
\text { hexachlorocyclohexane }\end{array}$ & $\alpha-\mathrm{HCH}$ & & $\mathrm{C}_{6} \mathrm{H}_{6} \mathrm{Cl}_{6}$ & $319-84-6$ \\
\hline $\begin{array}{l}\gamma- \\
\text { hexachlorocyclohexane }\end{array}$ & $\gamma-\mathrm{HCH}$ & & $\mathrm{C}_{6} \mathrm{H}_{6} \mathrm{Cl}_{6}$ & $58-89-9$ \\
\hline \multicolumn{5}{|c|}{ Polycyclic Aromatic Hydrocarbons $(n=16)$} \\
\hline Naphthalene & NAP & & $\mathrm{C}_{10} \mathrm{H}_{8}$ & $91-20-3$ \\
\hline Acenaphthylene & $\mathrm{ACY}$ & & $\mathrm{C}_{12} \mathrm{H}_{8}$ & $208-96-8$ \\
\hline Acenaphthene & ACE & & $\mathrm{C}_{12} \mathrm{H}_{10}$ & $83-32-9$ \\
\hline Fluorene & FLO & & $\mathrm{C}_{13} \mathrm{H}_{10}$ & $86-73-7$ \\
\hline Phenanthrene & PHE & & $\mathrm{C}_{14} \mathrm{H}_{10}$ & $85-01-8$ \\
\hline Anthracene & ANT & & $\mathrm{C}_{14} \mathrm{H}_{10}$ & $120-12-7$ \\
\hline Fluoranthene & FLA & & $\mathrm{C}_{16} \mathrm{H}_{10}$ & 206-44-0 \\
\hline Pyrene & PYR & & $\mathrm{C}_{16} \mathrm{H}_{10}$ & $129-00-0$ \\
\hline
\end{tabular}


Chapter 1

\begin{tabular}{|c|c|c|c|}
\hline Benzo(a)anthracene & $\mathrm{BaA}$ & $\mathrm{C}_{18} \mathrm{H}_{12}$ & $56-55-3$ \\
\hline Chrysene & CHR & $\mathrm{C}_{18} \mathrm{H}_{12}$ & $218-01-9$ \\
\hline Benzo(b)fluoranthene & $\mathrm{BbF}$ & $\mathrm{C}_{20} \mathrm{H}_{12}$ & $205-99-2$ \\
\hline Benzo(k)fluoranthene & $\mathrm{BkF}$ & $\mathrm{C}_{20} \mathrm{H}_{12}$ & 207-08-9 \\
\hline Benzo(a)pyrene & $\mathrm{BaP}$ & $\mathrm{C}_{20} \mathrm{H}_{12}$ & $50-32-8$ \\
\hline Indeno(1,2,3-cd)pyrene & IcdP & $\mathrm{C}_{22} \mathrm{H}_{12}$ & $193-39-5$ \\
\hline Dibenz(a,h)anthtacene & DahA & $\mathrm{C}_{22} \mathrm{H}_{14}$ & $53-70-3$ \\
\hline Benzo(ghi)perylene & BghiP & $\mathrm{C}_{22} \mathrm{H}_{12}$ & $191-24-2$ \\
\hline \multicolumn{4}{|c|}{ Poly - and perfluoroalkyl substances $(n=2)$} \\
\hline Perfluorooctanoic acid & PFOA & $\mathrm{C}_{8} \mathrm{HF}_{15} \mathrm{O}_{2}$ & $335-67-1$ \\
\hline $\begin{array}{l}\text { Perfluorooctanesulfonic } \\
\text { acid }\end{array}$ & PFOS & $\mathrm{C}_{8} \mathrm{HF}_{17} \mathrm{O}_{3} \mathrm{~S}$ & $1763-23-1$ \\
\hline
\end{tabular}

\section{Field sampling}

Monthly samples over two years were collected in the two lakes, including gaseous, aerosol particles, water and suspended solids samples. Concentrations of target HOCs were measured. Other field data included HOCs in multiple groups of biota (fish and benthos) for human consumption, phytoplankton, submerged vegetation, surface sediment and soil in the catchment. Lipid fractions were measured for all organisms. In addition, PAH profiles were measured in two sediment cores in Lake Chaohu from the centers 
General introduction

of the west and the east part of Lake Chaohu. Chronologies were obtained by measuring ${ }^{210} \mathrm{~Pb}$ and ${ }^{137} \mathrm{Cs}$ radionuclide activities in contiguous samples in the first $30 \mathrm{~cm}$ of the cores. The time series of historical PAHs records in sediment cores were used for the validation of the long-term model simulation.

\section{Model development}

The model developed in this project is composed of three modules, i.e., a contaminant fate module (CF), a food web accumulation module (FW) and an ecological module (EM).

\section{- $\quad$ CF module}

The CF module focuses on the fate and transport of contaminants in the abiotic compartments in lake ecosystems (Koelmans et al. 2001). In this thesis, the CF was developed from the fugacity-based Quantitative Water, Air, Sediment Interaction (QWASI) model (Mackay et al. 1983b), with the major difference being the inclusion of the soil compartment, and atmospheric advection input and output from the modelled system. The CF has four main compartments (atmosphere, water, soil and sediment). The atmospheric phase is comprised of two sub-phases: gaseous and particulate matter. The aqueous, soil and sediment phases all comprise two sub-phases: water (pore water for sediment) and solids (suspended solids for aqueous phase). It is assumed that the fugacities for all of the sub-phases in each compartment are the same (Mackay and Paterson 1991), i.e., equilibrium exists within all four main compartments.

\section{- $\quad F W$ module}

The FW module describes the contaminant uptake, depuration and transformation in aquatic biota, and transfer through the trophic levels of the lake food web. The structure of the FW in this project was designed based on previous studies focusing on food web structure in typical Chinese lakes such as Lake Chaohu (Zhang et al. 2012, Kong et al. 2016). For fish and invertebrates (zooplankton and zoobenthos), the exchange with water was modelled following Arnot and Gobas (2004). For both macrophytes and phytoplankton, the approach was similar to that used for the fish and invertebrates, however with modifications based on the uptake model from Dachs et al. (1999). The metabolic transformation rates for fish and invertebrates were similar to those in Moermond et al. (2007). Bioaccumulation modeling accounted for predation or grazing on different types of food, and loss by being predated or grazed 
Chapter 1

according to the interactions defined in Arnot and Gobas (2004) and the diet composition defined in Kong et at. (2016) for Lake Chaohu.

\section{- $\quad$ EM module}

The EM module was developed to account for biogeochemical cycling in a lake ecosystem, including the dynamics of nutrient and organisms, and to subsequently provide external inputs of biomass for the FW module. Therefore, EM serves as the basis for the integrated modeling approach. PCLake was used as the EM in this thesis. PCLake is a well-developed ecosystem model with a detailed coverage of the interactions between phytoplankton and submerged macrophytes. The most important mechanisms that lead to alternative stable states and hysteresis in shallow lakes are modelled explicitly. In addition, PCLake has been adapted for Chinese lakes and fitted to field observations (including nutrient levels, water quality indicators and biomass of various biota components) (Kong et al. 2017a). PCLake has a food web module that is similar to the module used in FW. Therefore, the biomass for different organism groups as simulated by EM (PCLake) was used as external inputs for FW.

\section{Model analysis}

Model analysis included both sensitivity analysis and uncertainty analysis, in order to evaluate the robustness of the model. All parameters were initiated using empirical values from literature or field observations from the laboratory.

\section{- Sensitivity analysis}

Sensitivity analysis was applied by implementing a 'perturbation' near the best estimate value of a parameter, and the variation of model outputs was studied under the condition that other parameters remained unchanged. The Morris classification screening method, a widely applied local sensitivity analysis method (Morris 1991), was used.

\section{- Uncertainty analysis}

For uncertainty analysis of environmental models, basic Monte Carlo simulation is commonly used, which relies on user-defined probability distributions for the model input parameters. Due to data limitations, the distributions of certain parameters are difficult to determine, which might lead to an unsatisfactory fit between the model output and the observed data and over-estimated uncertainty of the model results in the Monte Carlo simulation. 
General introduction

Therefore, a Bayesian Markov Chain Monte Carlo (MCMC) method associated with the adapted Metropolis-Hastings algorithm was used in this thesis, which combines the uncertainty analysis and the calibration of the fugacity model (Saloranta et al. 2008).

\section{- $\quad$ Model simulation and validation}

The model runs on different time scales, i.e., steady state, short-term seasonal variations and long-term dynamics starting from the early 1950s. The steady state model serves as the first step in model development and evaluation. The short-term simulation aimed at evaluating the robustness of the model and the ability of the model to predict the seasonality of HOC concentrations in lakes. The long-term simulation is designed to investigate the impact of a catastrophic regime shift on the fate and dynamics of HOCs. External conditions including water inflow and outflow, depth, wind speed, water temperate and precipitation were collected. The model was validated by field observations from both multiple compartments in the lake and also the data from sediment cores.

\section{Thesis outline}

\section{Chapter 2}

This chapter aimed to develop a basic version of the model including the CF module and a very simple FW module, which was applied in modeling the fate and transport of PAHs under steady state assumption in Lake Small Baiyangdian, a typical macrophyte-dominated shallow lake. The sensitivity of parameters and model uncertainty was investigated.

\section{Chapter 3}

Based on the previous developed model (Chapter 2), seasonal variations of $\alpha-\mathrm{HCH}$ in Lake Chaohu, a typical phytoplankton-dominated shallow lake, were modelled. Sensitivity analysis was conducted for both stable and dynamic parameters. Uncertainty of the model in dynamics simulations was evaluated using basic Monte Carlo simulations.

\section{Chapter 4}

Seasonal variations of $\gamma-\mathrm{HCH}$ in Lake Chaohu were simulated using the model in Chapter 3, but slightly different in structure. Uncertainty analysis 
Chapter 1

was conducted by both basic Monte Carlo and Bayesian Markov Chain Monte Carlo (MCMC) methods, and the results were compared and discussed.

\section{Chapter 5}

Two per- and polyfluoroalky substances (PFASs), including perfluorooctanoic acid (PFOA) and perfluorooctane sulphonate (PFOS), were explicitly investigated in the turbid Lake Chaohu based on a two-year field observation. A similar modeling tool as that in Chapter $3 \& 4$ was applied, with essential adaptations in both structure and parameterizations for both contaminants. Uncertainty of the model in dynamical simulations was evaluated and the major sources of uncertainty will be identified.

\section{Chapter 6}

The model was updated by including a full FW module, and further linked to an EM module using PCLake. This modified model was utilized in simulating long-term dynamics of representative polycyclic aromatic hydrocarbons (PAHs) in Lake Chaohu during a long term period covering regime shifts in the lake ecosystem. Historical records of PAHs from sediment cores were used for model validation. 


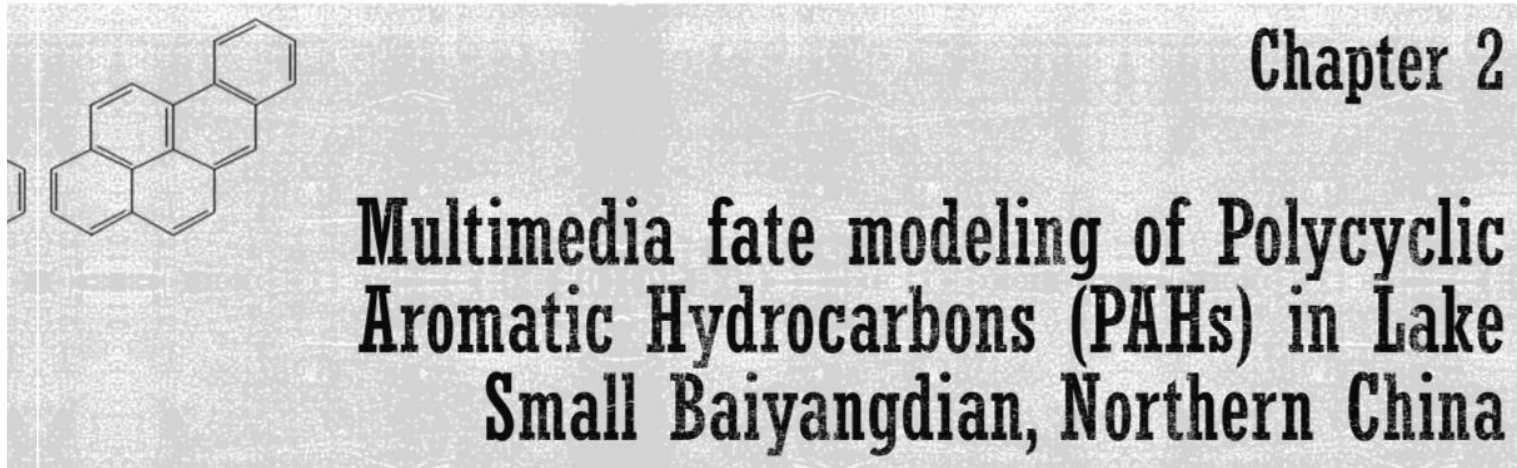

Fuliu Xu, Ning Qin, Ying Zhu, Wei He, Xiangzhen Kong, Michael T.

Barbour, Qishang He, Yan Wang, Huiling Ouyang, Shu Tao

Published in Ecological Modelling (2013) 252, 246-257 in a slightly different form 
Chapter 2

\section{Abstract}

A QWASI (Quantitative Water Air Sediment Interaction) fugacity model was developed to characterize the fate and transfer of fifteen priority PAHs in Lake Small Baiyangdian. The PAH concentrations in the air (air, particulates), water (water, suspended solids, plants and fishes) and sediment (water and solids) as well as the transfer fluxes between adjacent compartments were derived under the steady-state assumption. Sensitivities of the model estimates to input parameters were tested. Monte Carlo simulation was conducted for the uncertainty analysis. The results indicated that there was generally good agreement between the modeled and measured concentrations with the differences within an order of magnitude for the majority of PAH components. The fluxes into and out of the lake as well as each compartment were well-balanced. The average bioaccumulation flux of PAHs by plants was four times higher than that by fishes. The transfer directions of PAHs were from air to water and to sediment. Temperature was the most influential parameter, and was more sensitive to the modeled concentrations of middle- and high-molecular-weight PAHs that were considered as the source of the model uncertainty. The model developed in this study could well characterize the fate and transfer of PAHs in the lake. 
Modeling PAHs in a macrophyte-dominated shallow lake

\section{Introduction}

Polycyclic aromatic hydrocarbons (PAHs) are globally-concerned pollutants due to their widespread occurrence, strong persistence, long-range transportation potential and carcinogenic toxicity (Xu et al. 2011b). As one of the fastest growing countries in the world, China is suffering from severe contamination of PAHs from various sources (Zhang et al. 2007). The threat of $\mathrm{PAH}$ pollution to ecosystems and human health have become serious in China. It was reported that the atmospheric emissions of 16 priority PAHs in China in 2004 (114 Gg) accounted for about $22 \%$ of the total global emissions ( $520 \mathrm{Gg}$ ) of 16 priority PAHs set by USEPA (Zhang and Tao 2009). It was estimated that $5.8 \%$ of China's land area, where $30 \%$ of the population lives, exceeded the national ambient benzo[a]pyrene (BaP) standard of $10 \mathrm{ng} / \mathrm{m}^{3}$, and that the overall population attributable fraction for lung cancer caused by inhalation exposure to PAHs was $1.6 \%$ (Zhang et al. 2009). Therefore, it is very meaningful to understand and predict the fate and transport of PAHs in various environmental media in China.

Multimedia modeling is required to predict the fate and transport of PAHs, since they occur in every media including air, water, soil, sediment and various organisms. Among various multimedia models, fugacity model proposed by Mackay (1979) is the most popular model with many successful case studies on the fate of organic chemicals such as PAHs at regional scales (Wang et al. 2002, Tao et al. 2003, Lang et al. 2008). In the developed fugacity models, two case studies included all 16 principal PAHs (Lang et al. 2008, Wang et al. 2011a); only limited PAH components such as BaP and phenanthrene (Phe) were considered in other studies (Wang et al. 2002, Tao et al. 2003). However, the fate of PAH components in water and sediments were not well modeled in such studies at regional scales (Wang et al. 2002, Tao et al. 2003, Lang et al. 2008, Wang et al. 2011a). To solve this limitation, a more specific approach consisting of the quantitative water, air, sediment interaction (QWASI) fugacity model can be used. The QWASI fugacity model developed first by Mackay and his colleagues (Mackay et al. 1983a, Mackay et al. 1983b) has been successively applied to predict the fate of heavy metals and organic chemicals such as lead $(\mathrm{Pb})$, mercury $(\mathrm{Hg})$, nickel $(\mathrm{Ni})$, copper $(\mathrm{Cu})$, polychlorinated biphenyls (PCBs), linear alkylbenzenesulphonates (LAS) and $\mathrm{BaP}$ in lake or river ecosystems (Mackay et al. 1983a, Mackay et al. 1983b, Holysh et al. 1986, Ling et al. 1993, Diamond et al. 2000, Woodfine et al. 2000). However, priority PAH components other than BaP have not been included in the QWASI fugacity models. In order to understand properly and to compare 
the behaviors of individual PAH components in aquatic ecosystems, it is critical to include other priority $\mathrm{PAH}$ components excluding $\mathrm{BaP}$, because the behaviors and physical-chemical features are varied for different PAH components (Harvey 1991, Lohmann et al. 2011). For BaP, more case studies on using QWASI fugacity model are still needed to understand and predict its fate behaviors in lake ecosystems, especially in such a lake as Small Baiyangdian that has abundant aquatic plants. In the previous studies on the development and application of QWASI fugacity model, aquatic plants were never included. It was suggested that plant bioaccumulation potential was one of the major limitations of the fugacity model (Calamari et al. 1987).

In this study, a QWASI fugacity model was developed to characterize the environmental fate and transfer processes of PAHs in Lake Small Baiyangdian. Aquatic plants were included in the model, and the fifteen priority PAH components were modeled. The reliability of the model estimates was evaluated by various means including concentration validation, sensitivity and uncertainty analysis.

\section{Materials and methods}

\section{Study area and measurements}

Lake Baiyangdian, the largest freshwater lake in Northern China, is located at the central place of three big cities, Beijing, Tianjing and Shijiazhuang, one of the most seriously polluted areas in China for PAHs (Zhang et al. 2007) (Fig. 1). Lake Baiyangdian is one of the important locations of fish production in China. However, during the last decades, with the rapid economic development and population growth in the watershed and neighbor regions, the lake receives an increased loading of PAHs (Xu et al. 2011b). The lake with total area of $366 \mathrm{~km}^{2}$ is composed of 134 interconnected small lakes with different size areas. Lake Small Baiyangdian, with the area of $13.3 \mathrm{~km}^{2}$, is the biggest one among 134 interconnected small lakes.

Sampling for water, suspended solids, sediment and macrophytes at six sites (Fig. 1), and for fish at one site in Lake Small Baiyangdian was performed once on October $7^{\text {th }}, 2007$. Air sampling including gaseous, particulate and dust samples at two sites was carried out four times seasonally during autumn 2007 to summer 2008. Gaseous and particulate samples were collected using passive air sampler (Tao et al. 2009). Dust samples were collected by dust tank. Macrophyte samples included two species of floating plants, three species of submerged plants, and three species of emergent plant. Four species of commonly consumed freshwater fish including 15 individuals 
Modeling PAHs in a macrophyte-dominated shallow lake

of crucian carp, and 10 individuals each of snakehead fish, grass carp and silver fish were collected. Fifteen priority PAHs included Acenaphthylene (Acy), Acenaphthene (Ace), fluorene (Flo), Phe, anthracene (Ant), fluoranthene (Fla), pyrene (Pyr), Chrysene (Chr), benzo[a]anthracene (BaA), benzo[b] fluoranthene $(\mathrm{BbF})$, benzo[k]fluoranthene $(\mathrm{BkF}), \mathrm{BaP}$, indeno[1,2,3-cd]pyrene (IcdP), benzo[ghi]perylene (BghiP), dibenz[a,h]anthracene (DahA), and were measured by GC-MS. Organic carbon contents in water, suspended solids and sediments, and lipid contents in fish and macrophytes were also analyzed. The mean contents of PAHs, lipid and organic carbon in the studied multimedia were calculated for the parameters and calibrated for the model.

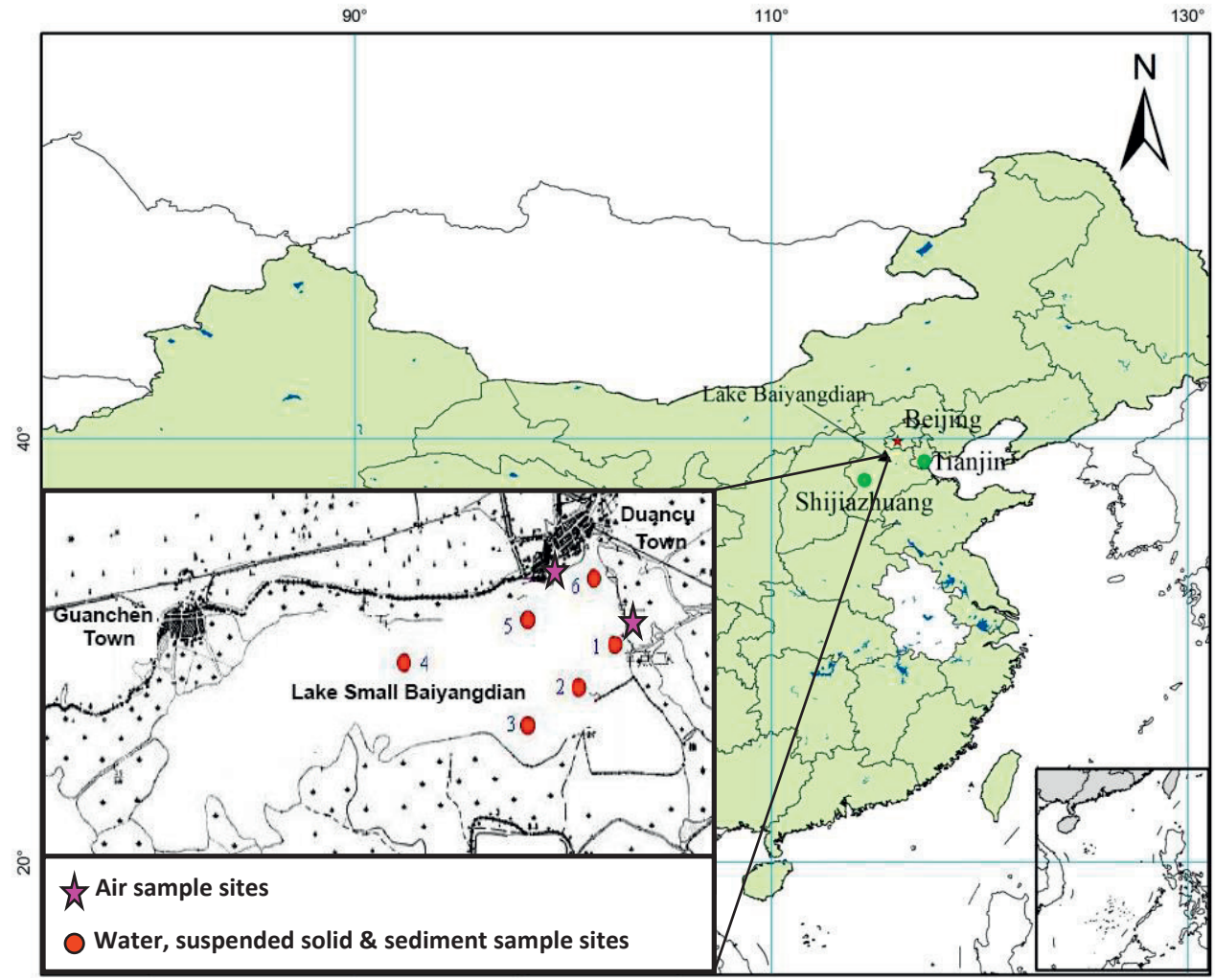

Fig. 1. Location of Lake Small Baiyangdian and sampling sites in China

\section{Model development}

\section{Conceptual framework}


A QWASI (Quantitative Water Air Sediment Interaction) fugacity model was developed to characterize the multimedia fate of PAHs in Lake Small Baiyangdian based on the approaches of Mackay and his colleagues (Mackay et al. 1983a, Mackay et al. 1983b, Mackay and Diamond 1989, Mackay and Paterson 1991). The conceptual diagram of the model is presented in Fig. 2. Air, water and sediment were defined as three bulk compartments. Eight subcompartments included in the three bulk compartments are as follows: air and particles in air; water, suspended solids, plants and fish in water; and water and solids in sediment. The processes taken into consideration are defined in Fig. 2, and additional details are given in the Appendices (Table 1).

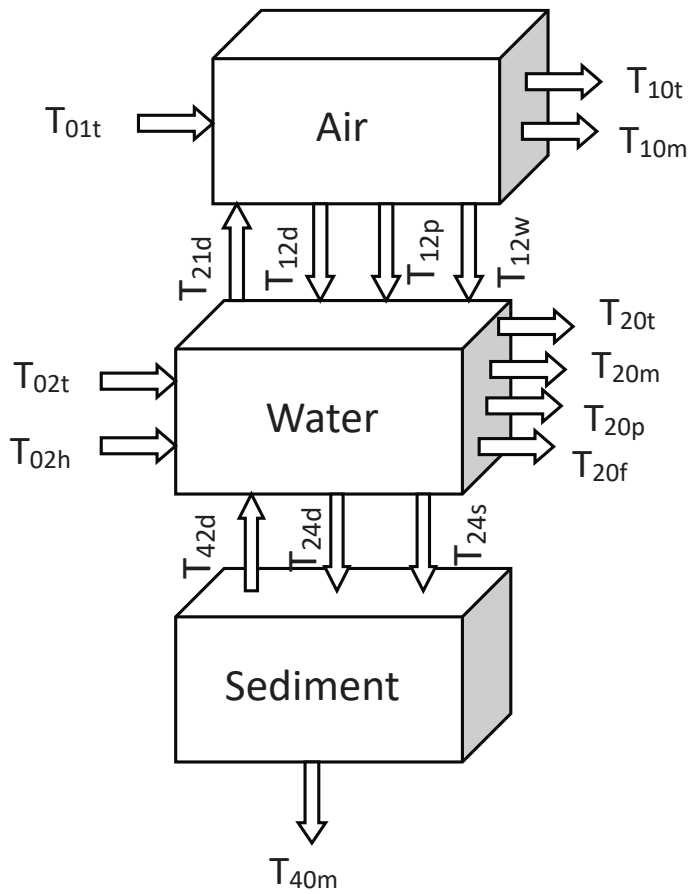

Fig. 2. Conceptual diagram of the QWASI fugacity model for modeling multimedia fates of PAHs in Lake Small Baiyangdian. Transfer processes are designated as $\mathrm{T}_{\mathrm{ijk}}$. The subscripts $\mathrm{i}$ and $\mathrm{j}$ represent various media ( 0 for outside of the area including local emission and discharge from human activities and 1 , 2 and 4 for compartments of air, water and sediment, respectively). The subscript $\mathrm{k}$ indicates process category $(\mathrm{t}, \mathrm{h}, \mathrm{d}, \mathrm{p}, \mathrm{w}, \mathrm{s}$ and $\mathrm{m}$ for advective flow, human discharge, diffusion, dry and wet precipitation, sedimentation and degradation, respectively). 
Modeling PAHs in a macrophyte-dominated shallow lake

Table 1 Transfer and transformation processes defined in the QWASI fugacity model

\begin{tabular}{|c|c|}
\hline Symbol & Transfer process \\
\hline $\mathrm{T}_{01 \mathrm{t}, \mathrm{T}} \mathrm{T}_{10 \mathrm{t}}$ & Advective air flows into/out of the lake air bulk \\
\hline $\mathrm{T}_{02 \mathrm{t},} \mathrm{T}_{20 \mathrm{t}}$ & Advective water flows into/out of the lake water bulk \\
\hline $\mathrm{T}_{02 \mathrm{~h}}$ & Local wastewater discharge to the lake water bulk \\
\hline $\mathrm{T}_{10 \mathrm{~m}}, \mathrm{~T}_{20 \mathrm{~m}}, \mathrm{~T}_{40 \mathrm{~m}}$ & Degradation in air, water and sediment \\
\hline $\mathrm{T}_{20 \mathrm{p}}, \mathrm{T}_{20 \mathrm{f}}$ & Bioaccumulation in aquatic plants and fishes \\
\hline $\mathrm{T}_{12 \mathrm{~d}}, \mathrm{~T}_{12 \mathrm{p}}, \mathrm{T}_{12 \mathrm{w}}$ & Diffusion, dry deposition and wet precipitation from air to water \\
\hline $\mathrm{T}_{21 \mathrm{~d}}$ & Diffusion from water to air \\
\hline $\mathrm{T}_{24 \mathrm{~d}}, \mathrm{~T}_{42 \mathrm{~d}}$ & Diffusion between water column and bottom sediment \\
\hline $\mathrm{T}_{24 \mathrm{~s}}$ & Sedimentation from column and bottom sediment \\
\hline
\end{tabular}

- Model equations

The mass balance equations with fugacities as variables for air, water and sediment bulk compartments are tabulated in the Appendices (Table 2). The equations for the transfer rate coefficients of the modeled processes and for the fugacity capacity of each bulk phase and sub-phase are listed in Tables 3 and 4 in the Appendices, deriving from the approaches of Mackay and his colleagues (Mackay et al. 1983a, Mackay et al. 1983b, Mackay and Diamond 1989, Mackay and Paterson 1991).

Table 2 Mass balance equations in the QWASI fugacity model

\begin{tabular}{lll}
\hline Phase & Mass balance equation* & Mass balance equation in detail \\
\hline \multirow{2}{*}{ Air } & $T_{01 t}+T_{21 d}=T_{10 t}+T_{10 m}+T_{12 d}+T_{12 p}+T_{12 w}$ & $\begin{array}{l}Q_{01 t} C_{01 t}+D_{21 d} f_{2}=\left(D_{10 t}+D_{10 m}+D_{12 d}+D_{12 p}+\right. \\
\left.D_{12 w}\right) f_{1}\end{array}$ \\
\multirow{2}{*}{ Water } & $T_{02 t}+T_{02 h}+T_{12 d}+T_{12 p}+T_{12 w}+T_{42 d}=T_{20 t}+T_{20 m}+$ & $Q_{02 t} C_{02 t}+Q_{02 h} C_{02 h}+\left(D_{12 d}+D_{12 p}+D_{12 w}\right) f_{1}+D_{42 d} f_{4}=$ \\
& $T_{20 f}+T_{20 r}+T_{21 d}+T_{24 d}+T_{24 s}$ & $\left(D_{20 t}+D_{20 m}+D_{20 f}+D_{20 r}+D_{21 d}+D_{24 d}+D_{24 s}\right) f_{2}$ \\
\multirow{2}{*}{ Sediment } & $T_{24 d}+T_{24 s}=T_{42 d}+T_{40 m}$ & $\left(D_{24 d}+D_{24 s}\right) f_{2}=\left(D_{42 d}+D_{40 m}\right) f_{4}$ \\
\hline
\end{tabular}

${ }^{*} \mathrm{~T}_{\mathrm{ijk}}$ are transfer processes, defined in Table $1 . \mathrm{D}_{\mathrm{ijk}}$ are transfer rate coefficients for major transfer processes from the $i^{\text {th }}$ bulk phase to the $j^{\text {th }}$ bulk phase (see Table 3 for details). For system input, $\mathrm{T}_{01 \mathrm{t}}=\mathrm{Q}_{01 \mathrm{t}} \times \mathrm{C}_{01 \mathrm{t}}, \mathrm{T}_{02 \mathrm{t}}=\mathrm{Q}_{02 \mathrm{t}} \times \mathrm{C}_{02 \mathrm{t}}, \mathrm{T}_{02 \mathrm{~h}}=\mathrm{Q}_{02 \mathrm{~h}} \times \mathrm{C}_{02 \mathrm{~h}}$. For system output, $T_{10 \mathrm{t}}=\mathrm{D}_{10 \mathrm{t}} \times \mathrm{f}_{1}, \mathrm{~T}_{20 \mathrm{t}}=\mathrm{D}_{20 \mathrm{t}} \times \mathrm{f}_{2}, \mathrm{~T}_{10 \mathrm{~m}}=\mathrm{D}_{10 \mathrm{~m}} \times \mathrm{f}_{1}, \mathrm{~T}_{20 \mathrm{~m}}=\mathrm{D}_{20 \mathrm{~m}} \times \mathrm{f}_{2}, \mathrm{~T}_{40 \mathrm{~m}}=\mathrm{D}_{40 \mathrm{~m}} \times \mathrm{f}_{4}, \mathrm{~T}_{20 \mathrm{p}}$ $=D_{20 r} \times f_{2}, T_{20 f}=D_{2 f} \times f_{2}$. For air-water transfer, $T_{12 d}=D_{12 d} \times f_{1}, T_{21 d}=D_{21 d} \times f_{2}, T_{12 p}=D_{12 p} \times f_{1}$, $\mathrm{T}_{12 \mathrm{w}}=\mathrm{D}_{12 \mathrm{w}} \times \mathrm{f}_{1}$. For water-sediment transfer, $\mathrm{T}_{24 \mathrm{~d}}=\mathrm{D}_{24 \mathrm{~d}} \times \mathrm{f}_{2}, \mathrm{~T}_{42 \mathrm{~d}}=\mathrm{D}_{42 \mathrm{~d}} \times \mathrm{f}_{4}, \mathrm{~T}_{24 \mathrm{~s}}=\mathrm{D}_{24 \mathrm{~s}} \times \mathrm{f}_{2}$. 
Chapter 2

Table 3 Equations for calculating transfer rate coefficients $(D)$

\begin{tabular}{|c|c|c|c|}
\hline Process & & Equations & Remarks \\
\hline $\begin{array}{l}\text { Air(1)- } \\
\text { Water(2) }\end{array}$ & $\begin{array}{l}\text { Diffusion } \\
\text { Dry deposition } \\
\text { Wet precipitation }\end{array}$ & $\begin{array}{l}\mathrm{D}_{12 \mathrm{~d}}=\mathrm{A}_{2} /\left[1 /\left(\mathrm{K}_{12} \times \mathrm{Z}_{11}\right)+\right. \\
\left.1 /\left(\mathrm{K}_{21} \times \mathrm{Z}_{22}\right)\right] \\
\mathrm{D}_{12 \mathrm{p}}=\mathrm{A}_{2} \times \mathrm{K}_{\mathrm{p}} \times \mathrm{X}_{13} \times \mathrm{Z}_{13} \\
\mathrm{D}_{12 \mathrm{w}}=\mathrm{A}_{2} \times \mathrm{K}_{\mathrm{w}} \times \mathrm{S}_{\mathrm{c}} \times \mathrm{X}_{13} \times \mathrm{Z}_{13}\end{array}$ & $\mathrm{D}_{21 \mathrm{~d}}=\mathrm{D}_{12 \mathrm{~d}}$ \\
\hline $\begin{array}{l}\text { Water(2)- } \\
\text { Sediment(4) }\end{array}$ & $\begin{array}{l}\text { Diffusion } \\
\text { Deposition }\end{array}$ & $\begin{array}{l}\mathrm{D}_{24 \mathrm{~d}}=\mathrm{A}_{2} /\left[1 /\left(\mathrm{K}_{24} \times \mathrm{Z}_{22}\right)+\mathrm{L}_{4} /\left(\mathrm{B}_{4} \times \mathrm{Z}_{22}\right)\right] \\
\mathrm{D}_{24 \mathrm{~s}}=\mathrm{A}_{2} \times \mathrm{K}_{\mathrm{s}} \times \mathrm{Z}_{23} ;\end{array}$ & $\mathrm{D}_{42 \mathrm{~d}}=\mathrm{D}_{24 \mathrm{~d}}$ \\
\hline Reaction & $\begin{array}{l}\text { Degradation in air } \\
\text { Degradation in water } \\
\text { Degradation in } \\
\text { sediment }\end{array}$ & $\begin{array}{l}\mathrm{D}_{40 \mathrm{~m}}=\mathrm{K}_{\mathrm{m} 1} \times \mathrm{A}_{1} \times \mathrm{h}_{1} \times \mathrm{Z}_{1} \\
\mathrm{D}_{20 \mathrm{~m}}=\mathrm{K}_{\mathrm{m} 2} \times \mathrm{A}_{2} \times \mathrm{h}_{2} \times\left(\mathrm{Z}_{22}+\mathrm{Z}_{23}\right) \\
\mathrm{D}_{40 \mathrm{~m}}=\mathrm{K}_{\mathrm{m} 4} \times \mathrm{A}_{4} \times \mathrm{h}_{4} \times \mathrm{Z}_{4}\end{array}$ & - \\
\hline Advection & $\begin{array}{l}\text { Advective air flows } \\
\text { Advective water flows }\end{array}$ & $\begin{array}{l}D_{011}=Q_{01 t} \times Z_{1} \\
D_{02 t}=Q_{02 t} \times Z_{2}\end{array}$ & - \\
\hline Biota & $\begin{array}{l}\text { Fish harvest } \\
\text { Plants harvest }\end{array}$ & $\begin{array}{l}D_{20 \mathrm{f}}=Y_{\mathrm{f}} \times Z_{2 \mathrm{f}} / \rho_{2 \mathrm{f}} \\
\mathrm{D}_{20 \mathrm{p}}=Y_{\mathrm{p}} \times \mathrm{Z}_{2 \mathrm{p}} / \rho_{2 \mathrm{p}}\end{array}$ & - \\
\hline
\end{tabular}

${ }^{*} D_{\mathrm{ijk}}$ are transfer rate coefficients for major transfer processes from the $\mathrm{i}^{\text {th }}$ bulk phase to the $j^{\text {th }}$ bulk phase $(1,2$, and 4 for air, water, and sediment, respective, 0 for outside of the area). The subscript $k$ indicates process category $(t, d, p, w, f, r, s$, and $\mathrm{m}$ for advective flow, diffusion, dry deposition, wet precipitation, fish bioaccumulation, pant bioaccumulation, sedimentation, and degradation, respectively). $\mathrm{Z}$ is fugacity capacity (see Table 4 for details). See Table 5 for the meanings of other parameters.

Table 4 Equations for calculating fugacity capacities ( $Z$ )

\begin{tabular}{|c|c|c|c|}
\hline Bulk phase & Sub-phase & \multicolumn{2}{|c|}{ Equations for calculating $\mathrm{Z}\left(\mathrm{mol} / \mathrm{m}^{3} \cdot \mathrm{Pa}\right)^{*}$} \\
\hline Air & $\begin{array}{l}\text { Air } \\
\text { Particle }\end{array}$ & $\begin{array}{l}\mathrm{Z}_{11}=1 / \mathrm{RT} \\
\mathrm{Z}_{13}=6 \mathrm{E} 6 /(\mathrm{PsRT}) / \mathrm{BPs}\end{array}$ & $Z_{1}=X_{11} Z_{11}+X_{13} Z_{13}$ \\
\hline Water & $\begin{array}{l}\text { Water } \\
\text { Suspended } \\
\text { solids } \\
\text { Fish } \\
\text { Plant }\end{array}$ & $\begin{array}{l}\mathrm{Z}_{22}=1 / \mathrm{H} \\
\mathrm{Z}_{23}=\mathrm{O}_{23} \rho_{23} \mathrm{~K}_{\mathrm{oc}} / \mathrm{H} \\
\mathrm{Z}_{2 \mathrm{f}}=\mathrm{BCF}_{\mathrm{f}} / \mathrm{H} \\
\mathrm{Z}_{2 \mathrm{p}}=\mathrm{BCF}_{\mathrm{p}} / \mathrm{H}\end{array}$ & $\begin{array}{l}Z_{2}=X_{222} Z_{22}+X_{23} Z_{23}+X_{2 f} Z_{2 f} \\
+X_{2 p} Z_{2 p}\end{array}$ \\
\hline Sediment & $\begin{array}{l}\text { Pore water } \\
\text { Solids }\end{array}$ & $\begin{array}{l}\mathrm{Z}_{42}=1 / \mathrm{H} \\
\mathrm{Z}_{43}=\mathrm{O}_{43} \rho_{43} \mathrm{~K}_{\mathrm{oc}} / \mathrm{H}\end{array}$ & $Z_{4}=X_{42} Z_{42}+X_{43} Z_{43}$ \\
\hline
\end{tabular}

* $Z_{1}, Z_{2}$, and $Z_{4}$ are fugacity capacity for air, water and sediment bulk compartments, respectively. $Z_{11}, Z_{13}, Z_{22}, Z_{23}, Z_{24}, Z_{2 p}, Z_{42}$, and $Z_{43}$ are fugacity capacity for air and particle sub-phases in air, water, suspended solids, fish, plant sub-phases in water, pore water and solids sub-phases in sediment, respectively. See Table 5 for the meanings of other parameters. 
Modeling PAHs in a macrophyte-dominated shallow lake

- Model parameters

The model parameters including environmental, physical, chemical and process kinetic ones were determined in three different ways -- literature review, laboratory experiments and model calibration. The symbols, descriptions, values and sources of all model parameters are presented in Tables 5. The mean values of collected data are used for the parameters after abnormal values are excluded. The Henry's law constant, saturation vapor pressure and fugacity ratio is the value under the temperature of $25^{\circ} \mathrm{C}$. However, the average annual temperature in Lake Small Baiyangdian is $12.1^{\circ} \mathrm{C}$. The necessary corrections for these parameters are performed by the equation in literature (Paasivirta et al. 1999).

Table 5 Parameters for the QWASI fugacity model

\begin{tabular}{|c|c|c|c|c|}
\hline Symbo & IUnit & Parameters & Value & Reference \\
\hline $\begin{array}{l}\mathrm{A}_{1} \\
\mathrm{~A}_{2}, \mathrm{~A}_{4}\end{array}$ & $\mathrm{~m}^{2}$ & $\begin{array}{l}\text { Interface areas of air/water and } \\
\text { water/sediment }\end{array}$ & $1.366 \times 10^{7}$ & [1] \\
\hline$h_{1}$ & $\mathrm{~m}$ & Thickness of air & $7.00 \times 10^{2}$ & {$[2],[3]$} \\
\hline $\mathrm{h}_{2}$ & $\mathrm{~m}$ & Thickness of water & 1.87 & {$[2],[3]$} \\
\hline $\mathrm{h}_{4}$ & $\mathrm{~m}$ & Thickness of sediment & $1.00 \times 10^{-1}$ & {$[2],[3]$} \\
\hline $\mathrm{X}_{13}$ & $\mathrm{v} / \mathrm{v}$ & Volume fractions of solids in air & $9.84 \times 10^{-11}$ & [4], Note A \\
\hline $\mathrm{X}_{23}$ & $\mathrm{v} / \mathrm{v}$ & Volume fractions of solids in water & $4.29 \times 10^{-6}$ & [4], Note A \\
\hline$X_{43}$ & $\mathrm{v} / \mathrm{v}$ & $\begin{array}{l}\text { Volume fractions of solids in } \\
\text { sediment }\end{array}$ & $3.00 \times 10^{-1}$ & [4], Note A \\
\hline L4 & $\mathrm{m}$ & Diffusion path lengths in sediment & $5.00 \times 10^{-3}$ & [4] \\
\hline$X_{2 f}$ & $\mathrm{v} / \mathrm{v}$ & Volume fractions of fish in water & $4.08 \times 10^{-5}$ & [5], [6] \\
\hline$X_{2 p}$ & $\mathrm{v} / \mathrm{v}$ & Volume fractions of plants in water & $8.20 \times 10^{-4}$ & [5], [6] \\
\hline $\mathrm{X}_{42}$ & $\mathrm{v} / \mathrm{v}$ & $\begin{array}{l}\text { Volume fractions of water in } \\
\text { sediment }\end{array}$ & $7.00 \times 10^{-1}$ & [4] \\
\hline $\mathrm{O}_{23}$ & $\%$ & $\begin{array}{l}\text { Contents of organic carbon in solids } \\
\text { in water }\end{array}$ & $4.41 \times 10^{-1}$ & Note A \\
\hline $\mathrm{O}_{43}$ & $\%$ & $\begin{array}{l}\text { Contents of organic carbon in solids } \\
\text { in sediment }\end{array}$ & $2.89 \times 10^{-2}$ & Note A \\
\hline$\rho_{23}$ & $\mathrm{t} / \mathrm{m}^{3}$ & Densities of solids in water & 1.89 & Note A \\
\hline$\rho_{43}$ & $\mathrm{t} / \mathrm{m}^{3}$ & Densities of solids in sediment & 2.49 & Note A \\
\hline$\rho_{2 f}$ & $\mathrm{t} / \mathrm{m}^{3}$ & Densities of fish in water & 1.05 & [7], Note A \\
\hline$\rho_{2 p}$ & $t / m^{3}$ & Densities of plants in water & $8.83 \times 10^{-1}$ & [7], Note A \\
\hline$Q_{01 t}$ & $\mathrm{~m}^{3} / \mathrm{h}$ & Air advection flow into lake area & $1.13 \times 10^{10}$ & [2],calculated \\
\hline $\mathrm{Q}_{10 \mathrm{t}}$ & $\mathrm{m}^{3} / \mathrm{h}$ & $\mathrm{Ai}$ & $1.13 \times 10^{10}$ & [2],calculated \\
\hline$Q_{02 t}$ & $\mathrm{~m}^{3} / \mathrm{h}$ & ction flow into the lake & $3.00 \times 10^{4}$ & [8] \\
\hline $\mathrm{Q}_{20 \mathrm{t}}$ & $\mathrm{m}^{3} / \mathrm{h}$ & Water advection flow out of the lake & $2.50 \times 10^{4}$ & [8] \\
\hline
\end{tabular}


Chapter 2

\begin{tabular}{|c|c|c|c|c|}
\hline $\mathrm{Q}_{02 \mathrm{~h}}$ & $\mathrm{~m}^{3} / \mathrm{h}$ & Rate of local wastewater discharge & 500 & [2],calculated \\
\hline $\mathrm{C}_{02 \mathrm{t}}$ & $\mathrm{mol} / \mathrm{m}^{3}$ & $\begin{array}{l}\text { PAHs concentration in water } \\
\text { advection flow }\end{array}$ & Note B & [9], Note A \\
\hline $\mathrm{C}_{02 \mathrm{~h}}$ & $\mathrm{~mol} / \mathrm{m}^{3}$ & PAHs concentration in wastewater & Note B & Note A \\
\hline $\mathrm{Y}_{\mathrm{f}}$ & $\mathrm{T} / \mathrm{h}$ & Harvest rate of fish & 3.00 & [5], [6] \\
\hline $\mathrm{Y}_{\mathrm{p}}$ & $\mathrm{T} / \mathrm{h}$ & Harvest rate of plants & $6.00 \times 10^{1}$ & [5], [6] \\
\hline $\mathrm{T}$ & K & Local average temperature & $3.00 \times 10^{2}$ & {$[1]$} \\
\hline $\mathrm{PS}_{25}$ & $\mathrm{~Pa}$ & Local vapor pressure & Note B & {$[10] \sim[14]$} \\
\hline $\mathrm{R}$ & \multicolumn{2}{|c|}{$\mathrm{Pa} \cdot \mathrm{m}^{3} / \mathrm{mol} \cdot \mathrm{KThe}$ gas constant } & 8.314 & {$[10],[11],[15]$} \\
\hline $\mathrm{F}_{25}$ & - & Fugacity ratio at $25^{\circ} \mathrm{C}$ & Note B & [11] \\
\hline $\mathrm{H}_{25}$ & $\mathrm{~Pa} \cdot \mathrm{m}^{3} / \mathrm{mol}$ & Henry's constant & Note B & {$[11] \sim[14],[16]$} \\
\hline $\mathrm{BF}_{\mathrm{F}}$ & - & $\begin{array}{l}\text { Fugacity ratio temperature } \\
\text { correction factor }\end{array}$ & Note B & {$[17]$} \\
\hline $\mathrm{B}_{\mathrm{H}}$ & - & $\begin{array}{l}\text { Henry's law constant temperature } \\
\text { correction factor }\end{array}$ & Note B & {$[17]$} \\
\hline $\mathrm{BPs}$ & - & $\begin{array}{l}\text { Saturation vapor pressure } \\
\text { temperature correction factor }\end{array}$ & Note B & [17] \\
\hline Koc & $\mathrm{m}^{3} / \mathrm{t}, 1 / \mathrm{h}$ & Adsorption coefficient & Note B & $\begin{array}{c}{[11],[14],[18],} \\
{[19]}\end{array}$ \\
\hline $\mathrm{K}_{\mathrm{m} 1}$ & $1 / \mathrm{h}$ & of PAHs in air & Note B & {$[20],[21]$} \\
\hline $\mathrm{K}_{\mathrm{m} 2}$ & $1 / \mathrm{h}$ & Degradation rate of PAHs in water & Note B & {$[20],[21]$} \\
\hline $\mathrm{K}_{\mathrm{m} 4}$ & $1 / \mathrm{h}$ & $\begin{array}{l}\text { Degradation rate of PAHs in } \\
\text { sediment }\end{array}$ & Note B & [20], [21] \\
\hline $\mathrm{BCF}_{f}$ & $\mathrm{~m}^{3} / \mathrm{t}$ & Bioconcentration factor of fish & Note B & $\begin{array}{l}\text { [21] [23], Note } \\
\text { A (calculated) }\end{array}$ \\
\hline $\mathrm{BCF}_{\mathrm{p}}$ & $\mathrm{m}^{3} / \mathrm{t}$ & Bioconcentration factor of plants & Note B & $\begin{array}{l}\text { [21] [23], Note } \\
\text { A (calculated) }\end{array}$ \\
\hline $\mathrm{B}_{1}$ & $\mathrm{~m}^{2} / \mathrm{h}$ & Molecular diffusiviti & Note B & [24] [27] \\
\hline $\mathrm{B}_{2}$ & $\mathrm{~m}^{2} / \mathrm{h}$ & Molecular diffusivities in water & Note B & [24] [27] \\
\hline $\mathrm{B}_{4}$ & $\mathrm{~m}^{2} / \mathrm{h}$ & Molecular diffusivities in sediment & Note B & [24] [27] \\
\hline $\mathrm{K}_{12}$ & $\mathrm{~m} / \mathrm{h}$ & $\begin{array}{l}\text { Air-side molecular transfer } \\
\text { coefficient over water }\end{array}$ & 3.00 & [28], [29] \\
\hline $\mathrm{K}_{21}$ & $\mathrm{~m} / \mathrm{h}$ & $\begin{array}{l}\text { Water-side molecular transfer } \\
\text { coefficient over air }\end{array}$ & $3.00 \times 10^{-2}$ & [28], [29] \\
\hline $\mathrm{K}_{24}$ & $\mathrm{~m} / \mathrm{h}$ & $\begin{array}{l}\text { Water-side molecular transfer } \\
\text { coefficient over sediment }\end{array}$ & $1.00 \times 10^{-2}$ & [28], [29] \\
\hline Kp & $\mathrm{m} / \mathrm{h}$ & Dry deposition velocity & $5.69 \times 10^{-1}$ & {$[2],[4],[30],[31]$} \\
\hline $\mathrm{K}_{w}$ & $\mathrm{~m} / \mathrm{h}$ & Wet deposition velocity & $6.51 \times 10^{-5}$ & {$[2],[4],[30],[31]$} \\
\hline Ks & $\mathrm{m} / \mathrm{h}$ & Water sedimentation rates & $4.60 \times 10^{-6}$ & [32], [33] \\
\hline $\mathrm{Sc}_{\mathrm{C}}$ & $\mathrm{m} / \mathrm{h}$ & Rain scavenging rate & $2.00 \times 10^{5}$ & {$[34]$} \\
\hline
\end{tabular}

Note A: Data determined in our lab. 
Modeling PAHs in a macrophyte-dominated shallow lake

Note B: Presented in Table S1.

Reference: [1] Zhao et al., 2007; [2] HPEPB, 2001; [3] Ma et al., 2007; [4] Mackay and Paterson, 1991; [5] Zhao et al., 2005; [6] Zhao, 1995; [7] Davenport, 1999; [8] Yin, 2008; [9] Bai, 2008; [10] Van Agreren et al., 1998; [11]Mackay et al., 1997; [12] Wang, 1991; [13] Wang, 1993; [14] Jin, 1990; [15] Karickhoff, 1981; [16] Ten Hulscher et al., 1992; [17] Passivirta et al., 1999; [18] STF, 1991; [19] US-EPA, 1996a; [20] Mackay, 2001; [21] Lang et al., 2008; [22] Duan, 2005; [23] Tang et al., 2006; [24] Perry and Chilton, 1973; [25] US-EPA, 1996b; [26] Shor et al., 2003; [27] Xu, 1991; [28] Thibodeaux, 1996; [29] Banks and Herrera, 1997; [30] Beijing Statistics Bureau, 2005; [31] Tainjin Environment Protection Bureau, 1991, 1996, 2001; [32] Chen et al., 2006; [33] Hu et al., 1998; [34] Mackay and Paterson, 1986 (See SI for details of references).

\section{- Multimedia modeling}

The concentrations of PAHs in the compartments and the transfer fluxes between adjacent compartments were modeled under a steady-state assumption. Measured concentrations in this study were used for model validation. Modeling was performed using Matlab v.6.5 (MathWorks 2002). SPSS v.10.0 and MS Excel were employed for statistical analysis and data manipulation.

\section{- Sensitivity analysis}

A good overview of the most sensitive components of the model can be determined through sensitivity analysis. This analysis provides a measure of the sensitivity of parameters, forcing functions or sub-models to the state variables of greatest interest in the model. In practical modeling, the sensitivity analysis is carried out by changing the parameters, forcing functions and submodels, and the corresponding response of the selected state variables is observed (Jorgensen, 1994). In this study, the sensitivity analysis was performed only for the parameters. A change for the parameter at $\pm 10 \%$ was chosen, and the sensitivity coefficient $(S)$ was calculated by the following formula (Jørgensen 2011):

$$
S=\left(Y_{1.1}-Y_{0.9}\right) /(0.2 * Y)
$$

The terms, $\mathrm{Y}_{1.1}$ and $\mathrm{Y}_{0.9}$, represent the estimated concentrations when the tested parameter was changed at $+10 \%$ and $-10 \%$, respectively. The greater the absolute value of sensitivity coefficient, the more sensitive the parameter.

\section{Uncertainty analysis}


Both concentrations and fluxes estimated by the multimedia model are inherently variable (McKone 1996). In addition to the inherent variability, there are also uncertainties in the parameters and estimates (Tao et al. 2003). For assessing the overall uncertainty and variability in predictions, Monte Carlo simulation was used to illustrate collective variance of the inputs through the model. Each input parameter was represented as a probability density function that defined both the range of values and the likelihood of the parameter having that value. All of the parameters were assumed to follow the lognormal distribution. The simulation was undertaken repeatedly 3000 times, with new values randomly selected for all parameters within the range of mean \pm standard deviation. A built-in function of "randn" in Matlab was used to select the values randomly for each parameter (MathWorks 2002). The model uncertainty was ascertained by statistical analysis on the output result. To quantify the differences, coefficients of variation (CVs) were calculated based on log-transformed data.

\section{Results and discussion}

\section{Modeled concentration distributions}

The levels and distributions of calculated PAHs concentrations in the three bulk and seven sub-phases are presented in the Appendices (Table S2). The highest PAHs concentrations were found in the sediment phase, followed by the water and air phases (Fig. 3). The percentage ratios of individual PAH congeners ranged from $58.9 \%$ to $88.5 \%, 11.5 \%$ to $26.8 \%$, and 0 to $14.3 \%$ for the sediment, water and air phases, respectively (Fig. 3). This implies that the sediment would serve as the sink of PAHs. Among different PAHs congeners, low-molecular-weight PAHs (LMW-PAHs) predominated the distribution in three bulk phases. From LMW-PAHs to middle- and high-molecular-weight PAHs (MMW- and HMW-PAHs), the average percentage were increased from $64.8 \%$ to $66.1 \%$ and $87.0 \%$ in the sediment, and decreased from $26.3 \%$ to $22.9 \%$ and $13.0 \%$ in the water, and $11.0 \%$ to $8.9 \%$ and 0 in the air. This means that LMW-PAHs were in higher proportion in the water and air, while HMWPAHs were in higher proportion in the sediment. 

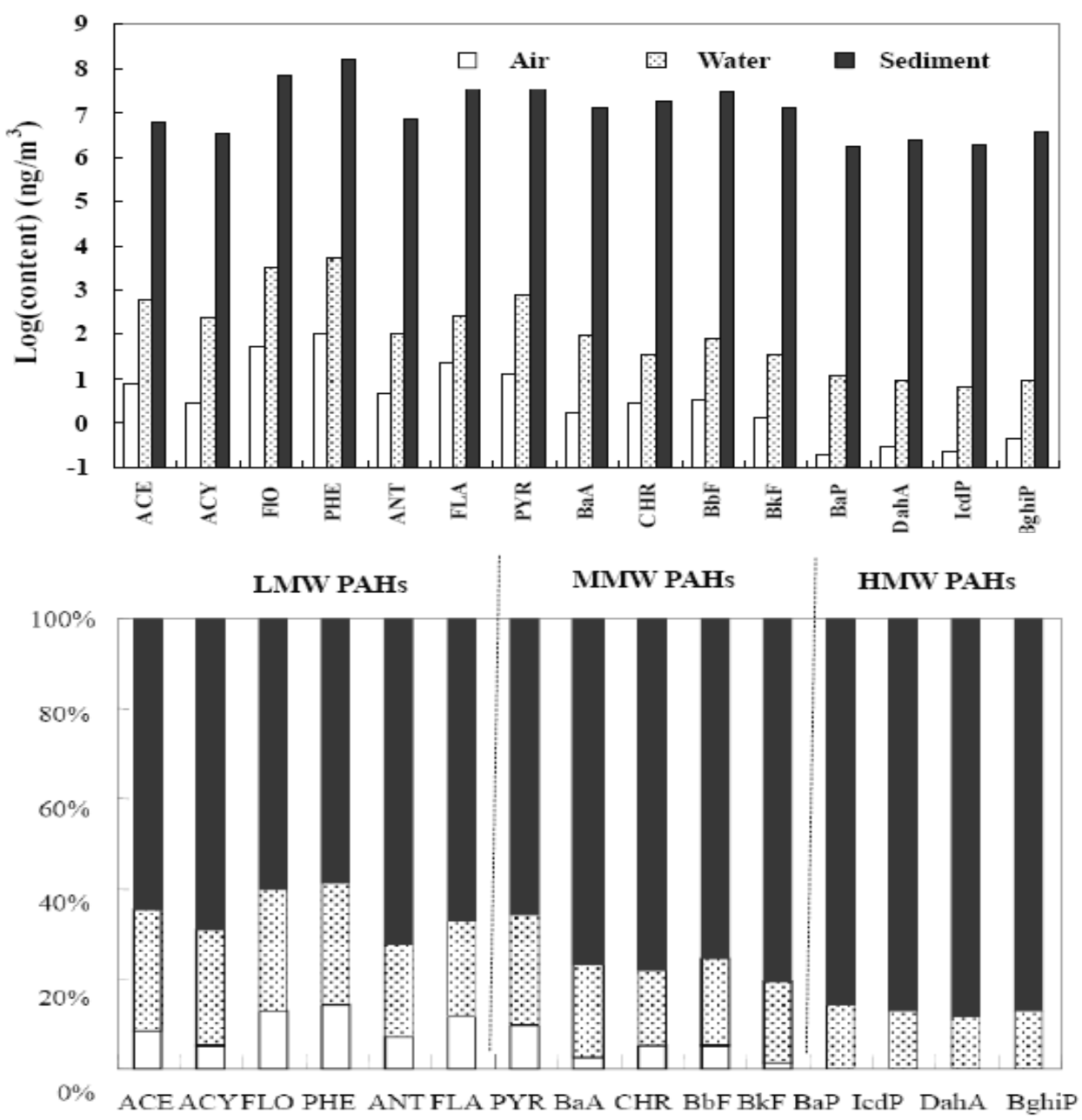

Fig. 3. Distributions of calculated PAHs concentration and their percentage in three bulks. LMW-, MMW- and HMW-PAHs are low-molecular- weight PAHs with 2-3 ring (Nap, Acy, Ace, Flo, Phe, Ant, Fla), moderate-molecularweight PAHs with 4 ring (Pyr, Baa, $\mathrm{Chr}, \mathrm{Bbf}, \mathrm{Bkf}$ ) and high-molecular-weight PAHs with 5-6 ring (Bap, Icdp, Daha, Bghip). 
Chapter 2
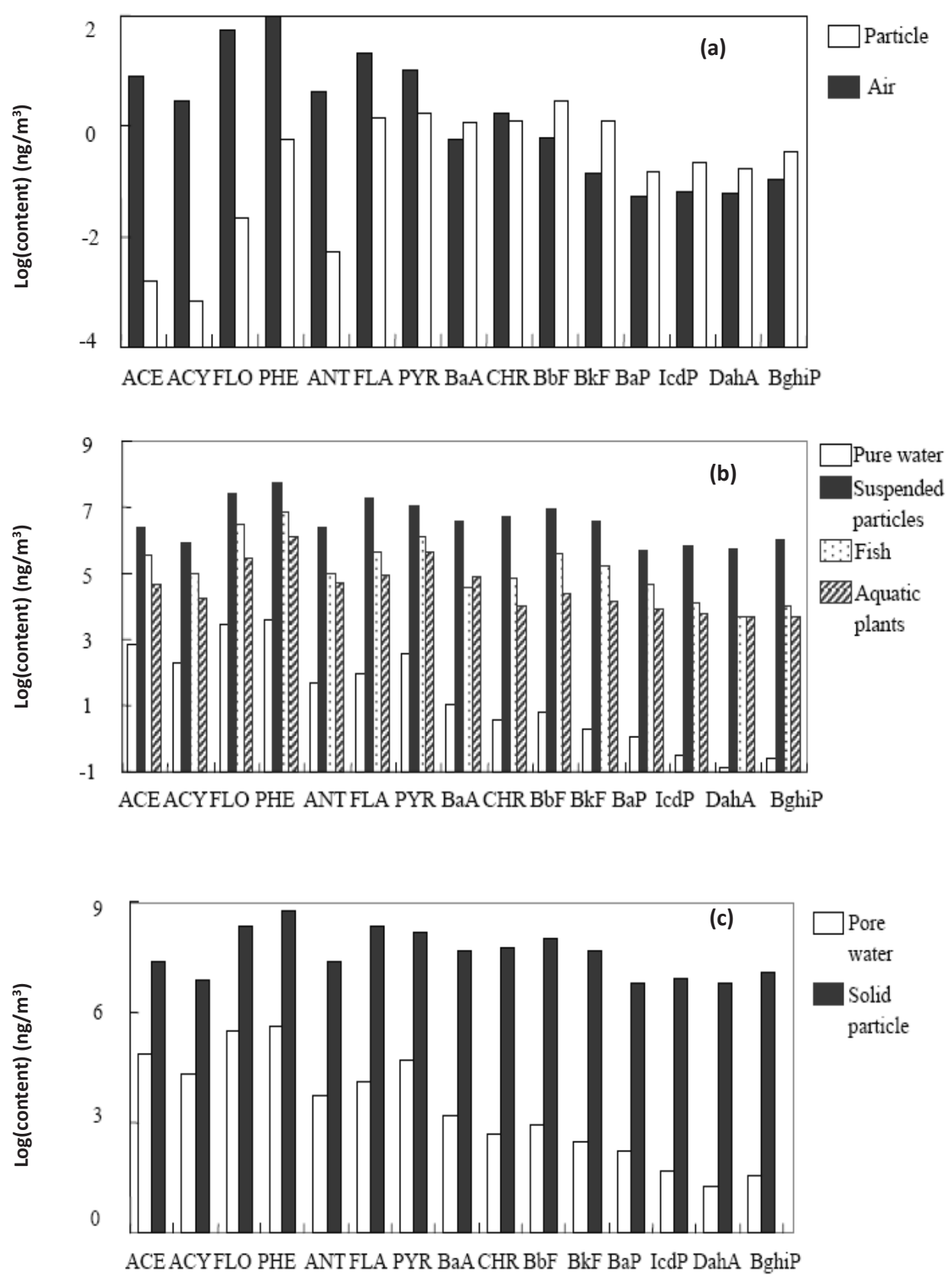

Fig. 4. Calculated PAHs concentrations in the sub-phases in Lake Small Baiyangdian 
Modeling PAHs in a macrophyte-dominated shallow lake

Fig. 4 illustrates that the different distribution patterns of LMW-, MMW- and HMW-PAHs in seven sub-phases. In the air, LMW-PAHs predominated in the gaseous sub-phase, while HMW-PAHs were dominant in solid-particle sub-phase (Fig. 4a). In the water, the PAHs contents in subphases were in the declining order of suspended solids (C23) > fish (C2f) $>$ aquatic plants $(\mathrm{C} 2 \mathrm{p})>$ dissolved sub-phase (C22); and PAHs contents in the dissolved phase were much lower than these in the suspended solid, fish and aquatic plant sub-phases. From LMW-PAHs to MMW- and HMW-PAHs, the contents were decreased in the dissolved sub-phase, and similar in the suspended solids, fish and plant sub-phases (Fig. 4b). In the sediment, PAHs contents in the solid sub-phase (C43) were significantly higher than these in pore water sub-phase (C42) (Fig. 4c).

The different fate behaviors of LMW-, MMW- and HMW-PAHs in the water, air and sediment may be attributed to the difference in their physical and chemical properties. LMW-PAHs with higher vapor pressure and Henry's law constant are more volatile than HMW-PAHs with lower vapor pressure and Henry's law constant. On the other hand, LMW-PAHs are less lipophilic due to their lower Koc values, so that their ability in binding to organic matter in suspended solids and sediments is obviously weaker than that of HMWPAHs. The dissolved PAHs concentrations in the water and pore water were decreased with the increase of their molecular weight, probably due to the decreasing solubility.

\section{Model validation}

The model was validated by the comparisons between calculated and measured PAHs concentrations in the sub-phases. As shown in Fig. 5, very similar distribution patterns in the sub-phases of the water and sediment would be found in both calculated and measured PAHs concentrations. The simulated values for the most of PAHs congeners were lower than their measured values, which may be attributed to the neglect of some input process such as soil erosion. The difference between the calculated and measured PAHs concentrations were different for both the sub-phases and PAH congeners. Among seven sub-phases, the best agreements with the difference less than one order of magnitude could be found for the PAHs concentrations in the solid sub-phase in the sediment (C43), while the worst agreements with the difference around two orders of magnitude were for the PAHs concentrations in the dissolved and solid sub-phase in water (C22 and C23). Among fifteen PAH congeners, LMW-PAHs maintain better agreements in all sub-phases than HMW- PAHs. The best agreements with the difference less 
than one order of magnitude could be found for the LMW-PAHs except for Acy and ANT in the suspended solid sub-phases (C23) and ANT in the fish sub-phases (C2f). The worst agreements with the difference around two orders of magnitude were for the HMW-PAHs in the suspended solid and fish subphases (C23 and C2f). The Icdp and Daha in the suspended solid and fish subphases as well as the Bghip in the suspended solid sub-phase were undetectable; however, their modeled values were relatively high.
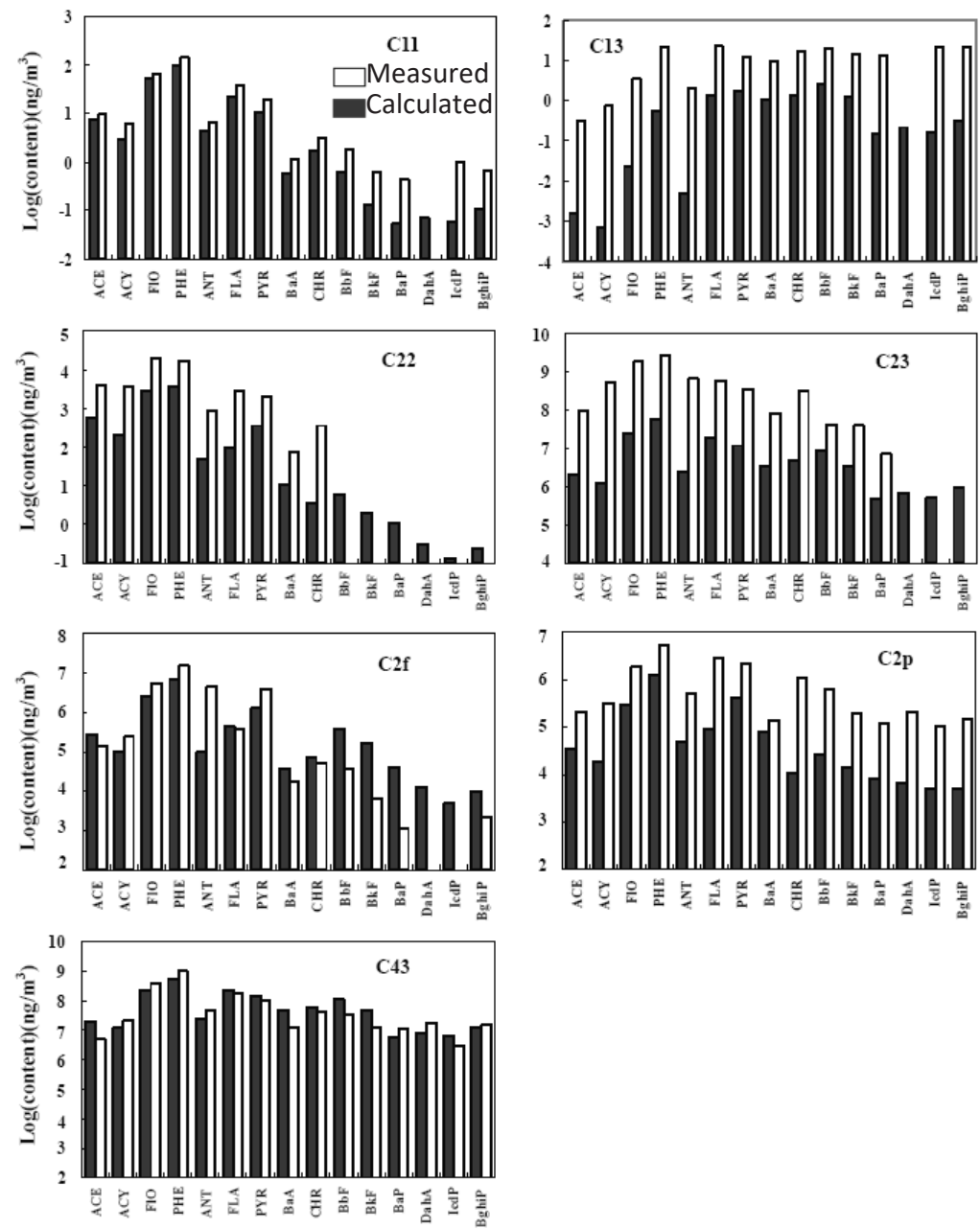

Fig. 5. Comparisons between the calculated and measured concentration of PAHs in seven sub-phases. C11, C13, C22, C23, C2f, C2p and C43 are the PAHs contents in the gaseous and particulate sub-phases in air, the dissolved, suspended solid, fish and plant sub-phases in water, and the solid sub-phase in sediment, respectively. 
Modeling PAHs in a macrophyte-dominated shallow lake

The calculated transfer fluxes of PAHs across the air-water and watersediment interfaces are shown in Fig. 6 and Table S3. The transfer fluxes from air to water across the air-water interface and from water to sediment across the water-sediment interface were much higher than these from water to air and from sediment to water, respectively. This indicated that, in the air-watersediment system, the transfer directions of PAHs were from air to water and to sediment. Air was the source of PAHs, while sediment could serve as the sink of PAHs. Among fifteen PAH congeners, the highest transfer fluxes from air to water $\left(\mathrm{T}_{12}\right)$ and from water to sediment $\left(\mathrm{T}_{24}\right)$ could be found for LMW-PAHs (including 2- and 3-ring PAHs), followed by MMW- and HMW- PAHs.

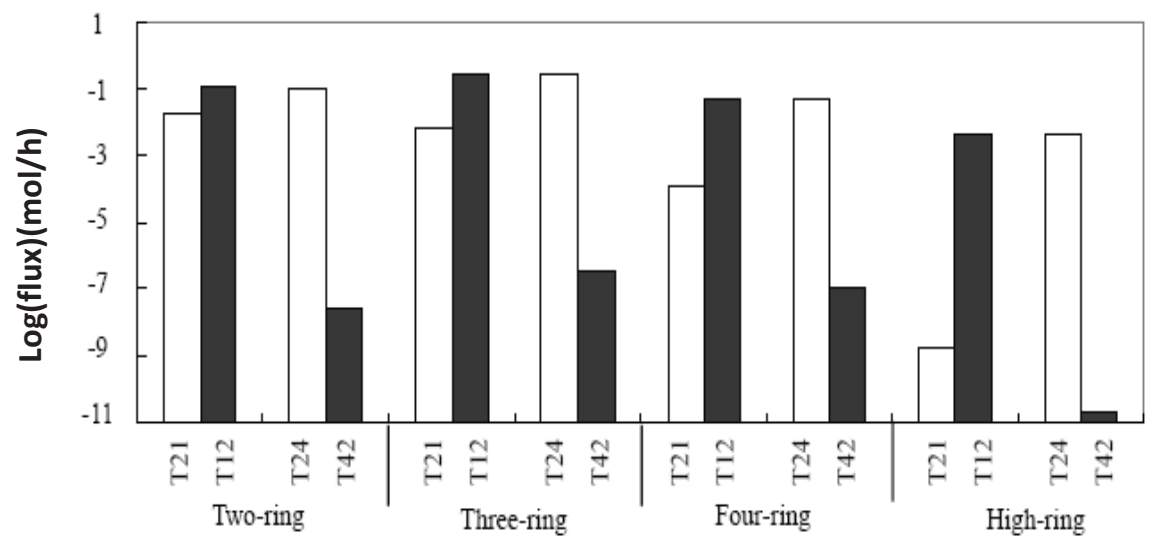

Fig. 6. Transfer fluxes of PAHs across the air-water and water-sediment interfaces in Lake Small Baiyangdian. T21 and T12 are transfer fluxes from water to air and from air to water across the air-water interface, respectively; T24 and T42 are transfer fluxes from water to sediment and from sediment to water across the water-sediment interface, respectively.

Fig. 7 illustrates that contributions of the transfer fluxes of PAHs from air to water and from water to sediment though different processes were changed. From air to water (Fig. 7a), the transfer of LMW-PAHs by the diffuse process (T12d) contributed the highest fluxes, followed by wet and dry precipitation processes ( $\mathrm{T}_{12 \mathrm{p}}$ and $\mathrm{T}_{12 \mathrm{w}}$ ). For MMW- and HMW-PAHs, the wet precipitation had the highest contribution of transfer fluxes $\left(\mathrm{T}_{12 \mathrm{w}}\right)$, followed by the diffuse and dry precipitation ( $\mathrm{T}_{12 \mathrm{~d}}$ and $\left.\mathrm{T}_{12 \mathrm{p}}\right)$. From LMW-PAHs (including 2- and 3-ring PAHs) to MMW- and HMW-PAHs, the transfer fluxes through diffuse process $\left(\mathrm{T}_{12 \mathrm{~d}}\right)$ were decreased. The transfer fluxes through dry and wet precipitations ( $\mathrm{T}_{12 \mathrm{p}}$ and $\mathrm{T}_{12 \mathrm{w}}$ ) were increased from 2-ring PAHs to 3- and 4-ring PAHs. From water to sediment (Fig. 7b), the transfer fluxes of PAHs were 
Chapter 2

mainly depended on the sedimentation process $\left(\mathrm{T}_{24 \mathrm{~s}}\right)$. The diffuse process $\left(\mathrm{T}_{24 \mathrm{~d}}\right)$ could only have some contributions for 2-, 3- and 4-ring PAHs.
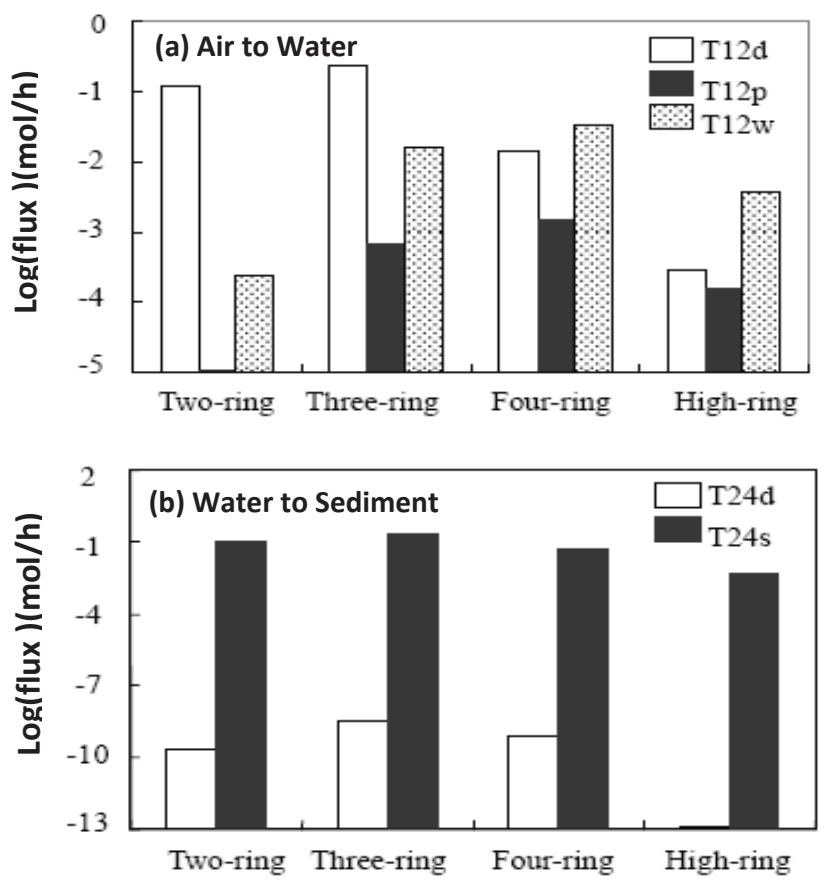

Fig. 7. Transfer fluxes of PAHs through different processes from air to water (a) and from water to sediment (b) in Lake Small Baiyangdian. T12d, T12p and $\mathrm{T} 12 \mathrm{w}$ are the transfer fluxes from air to water through the diffuse, dry and wet precipitation processes, respectively; $\mathrm{T} 24 \mathrm{~d}$ and $\mathrm{T} 24 \mathrm{~s}$ are the transfer fluxes from water to sediment through the diffuse and sedimentation processes.

\section{Sensitivities of modeled concentrations to input parameters}

The parameters with sensitivity coefficients higher than 0.5 are considered as more influential parameters in the model (Table S4). Four compounds, Ace, Phe, Chr and BaP, were chosen to represent two-, three-, four- and high-ring PAHs. The model outputs included the concentrations of four representative PAH compounds in the four sub-phases in the water including dissolved phase (C22), suspended solids (C23), fish (C2f) and aquatic plants $(\mathrm{C} 2 \mathrm{p})$, and in solids sub-phase in the sediment (C43). The results were summarized in Table S9 in the Appendices. Among 54 parameters, there were only 17 parameters with sensitivity coefficients higher than 0.5 . Temperature $(\mathrm{T})$ was the most influential parameter in the model, and was more sensitive to the model concentrations for $\mathrm{Chr}$ and $\mathrm{BaP}$ than those for Ace and Phe in all the 
Modeling PAHs in a macrophyte-dominated shallow lake

studied sub-phases (C22, C23, C2f, C2p and C43). The number of sensitive parameters for $\mathrm{BaP}$ in the studied sub-phases was nine to thirteen; however, that for Ace and Phe was only three to seven. There were only three parameters, T, Ks and $\mathrm{K}_{12}$, that were sensitive to Ace and Phe in C23. For the modeled concentration in a specific studied sub-phase, the parameters for $\mathrm{BaP}$ and $\mathrm{Chr}$ were more sensitive than those for Ace and Phe.

\section{Uncertainty of the modeled Concentrations}

3000 Monte Carlo simulations were performed to simulate the concentrations of four representative PAHs (Ace, Phe, Chr and $\mathrm{BaP}$ ) in the seven sub-phases. Coefficients of variation (CVs) for Ace, Phe, Chr and $\mathrm{BaP}$ in the seven sub-phases are shown in Fig. 8 and the heights of the bars indicate the perturbations of the calculated concentrations.

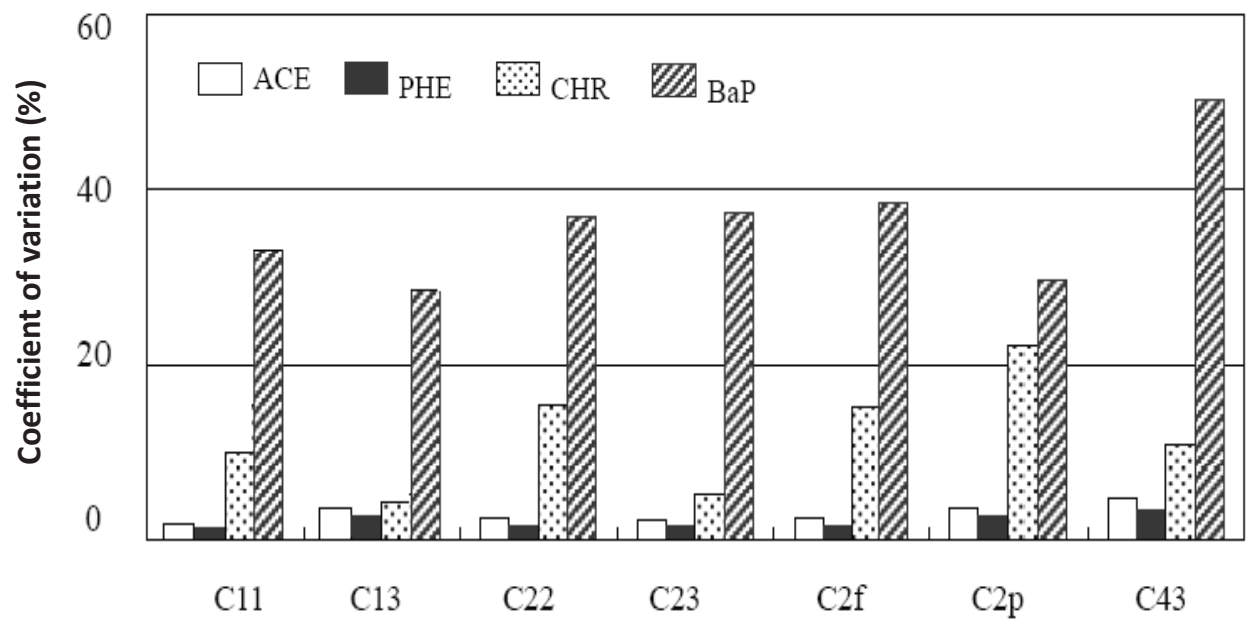

Fig. 8. Comparisons of $\mathrm{CV}$ values for the four representative PAHs in the seven sub-phases.

Fig. 8 illustrates that, among four representative $\mathrm{PAH}$ components, $\mathrm{BaP}$ had the highest CV values of $29 \%$ in the particulate sub-phase in air (C13) to $50 \%$ in the sediments (C43), followed by $\mathrm{Chr}$ with the $\mathrm{CV}$ ranging from about $4 \%$ in the particulate sub-phase in the air (C13) to $22 \%$ in the plant sub-phase in the water (C2p); however, all the CV values for Ace and Phe in seven sub-phases were less than $5 \%$. This indicated that there were the highest uncertainty for the modeled $\mathrm{BaP}$ concentration, and very low uncertainty for the modeled Ace and Phe concentrations. In seven sub-phases studied, the variabilities for the modeled Ace and Phe concentrations were relatively similar to each other, and 
those for the modeled $\mathrm{Chr}$ and $\mathrm{BaP}$ concentrations were in a descending order of $\mathrm{C} 2 \mathrm{p}>\mathrm{C} 22 \approx \mathrm{C} 2 \mathrm{f}>\mathrm{C} 43 \approx \mathrm{C} 11>\mathrm{C} 23 \approx \mathrm{C} 13$, and of $\mathrm{C} 43>\mathrm{C} 2 \mathrm{f}>\mathrm{C} 23 \approx \mathrm{C} 22>\mathrm{C} 11>\mathrm{C} 2 \mathrm{p} \approx \mathrm{C} 13$, respectively. The largest uncertainties of the calculated $\mathrm{BaP}$ concentrations were related to the most influential parameters identified in the sensitivity analysis (Table S4).

\section{The ecological implications of the proposed model}

Ecotoxicological models are increasingly applied to assess the fate and effect of chemical emissions to the environment, and they can be divided into three types, fate models, effect models and fate-transport-effect models (FTEmodels) (Jørgensen 2011). Fate models provide the concentration of a chemical in one or more environmental compartments; effect models translate a concentration or body burden in a biological compartment to an effect either on an organism, a population, a community, an ecosystem, a landscape, or the entire ecosphere; and fate-transport-effect models are the merging of fate models with effect models (Jørgensen 2011). So far, many fate models, fewer effect models, and only a few FTE-models have been applied to solve ecotoxicological problems and perform ecological risk assessments; however, the development is toward a wider application of effect and FTE-models (Jørgensen 2011).

Through the QWASI fugacity model developed in the present study, the PAHs concentrations in main environmental compartments including the air (air, particulates), water (water, suspended solids, plants and fishes) and sediment (water and solids) were derived. These results could be used for the ecological risk assessments of PAHs in the Lake Small Baiyangdian. The proposed multimedia fate model could serve as a fundamental for developing an effect model and FTE-model to solve ecotoxicological problems and perform ecological risk assessments of PAHs in the Lake Small Baiyangdian. Furthermore, the applications of the effect model and FTE-model in the lake would promote the development of eco-toxicological model.

The modeling results in the present study point out that macrophytes play an very important role in maintaining a healthy lake ecosystem by taking up toxic substances and by creating a favorable environment for a variety of complex chemical, biological and physical processes that contribute to the removal and degradation of toxic pollutants (Xu et al. 1999b). Macrophytes growing in a lake are also crucial to regulate lake biological structure, because they limit algal growth by shading and competing for nutrients with algae and because they increase herbivorous fish biomass by providing food, and a refuge (Xu et al. 1999b). 
Modeling PAHs in a macrophyte-dominated shallow lake

\section{Conclusions}

A QWASI fugacity model was developed to characterize the fate and transfer of fifteen priority PAHs in Lake Small Baiyangdian. The reliability of the model estimates was evaluated by various means including concentration validation, sensitivity and uncertainty analysis. There was generally good agreement between the modeled and measured concentrations with the differences within an order of magnitude for the majority of PAHs. The fluxes into and out of the lake as well as each compartment were well-balanced. The average bioaccumulation of PAHs by plants was four times higher than that by fishes. The transfer directions of PAHs were from air to water and to sediment. Temperature was the most influential parameter, and was more sensitive to the modeled concentrations of middle- and high-molecular-weight PAHs that were considered as the source of the model uncertainty. The model developed in this study could well characterize the fate and transfer of PAHs in the lake.

\section{Acknowledgements}

Funding was provided by the National Science Fund for Distinguished Young Scholars (No. 40725004) and by the National Natural Science Foundation of China (40671165 and 41030529). 


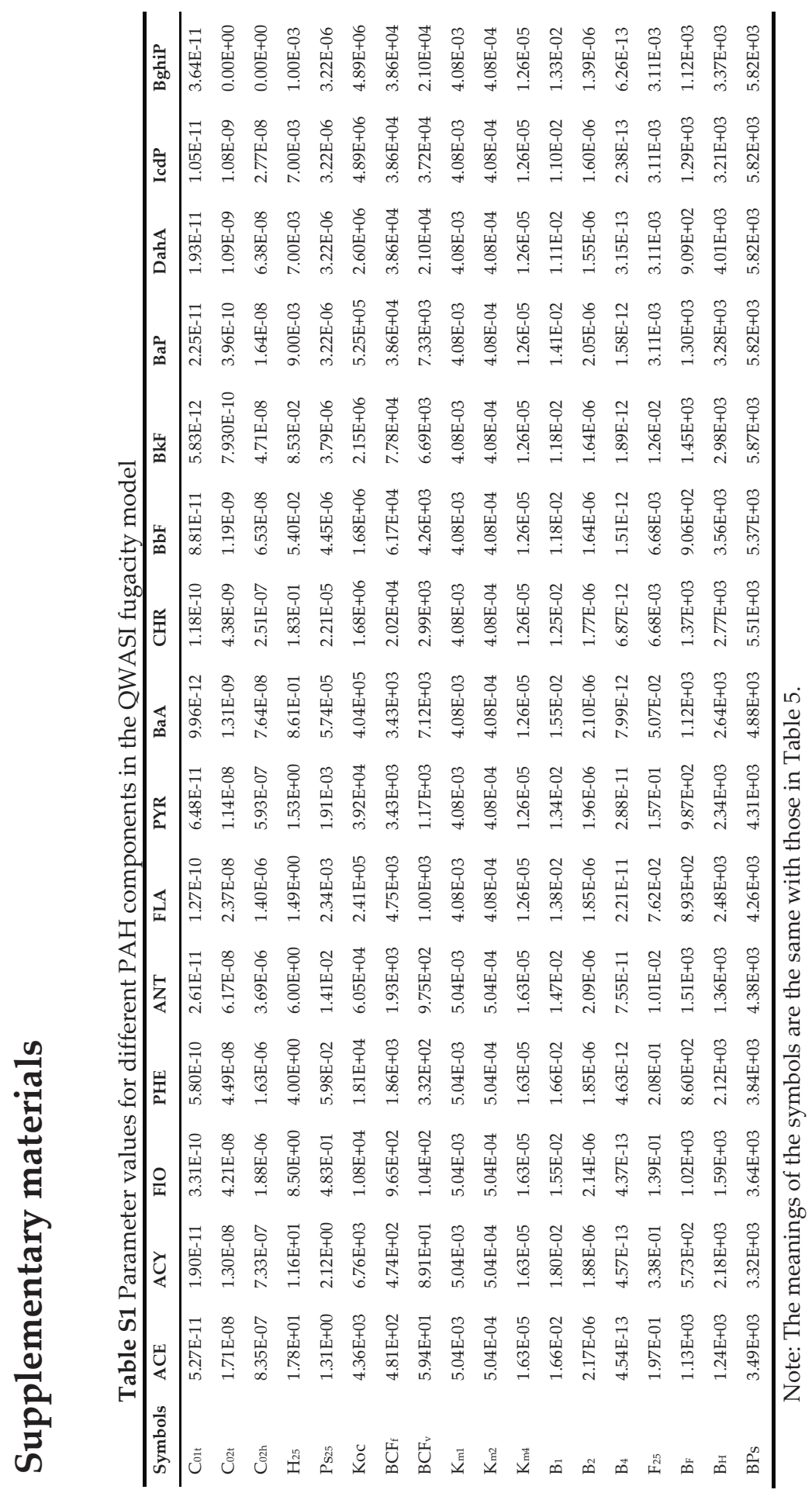




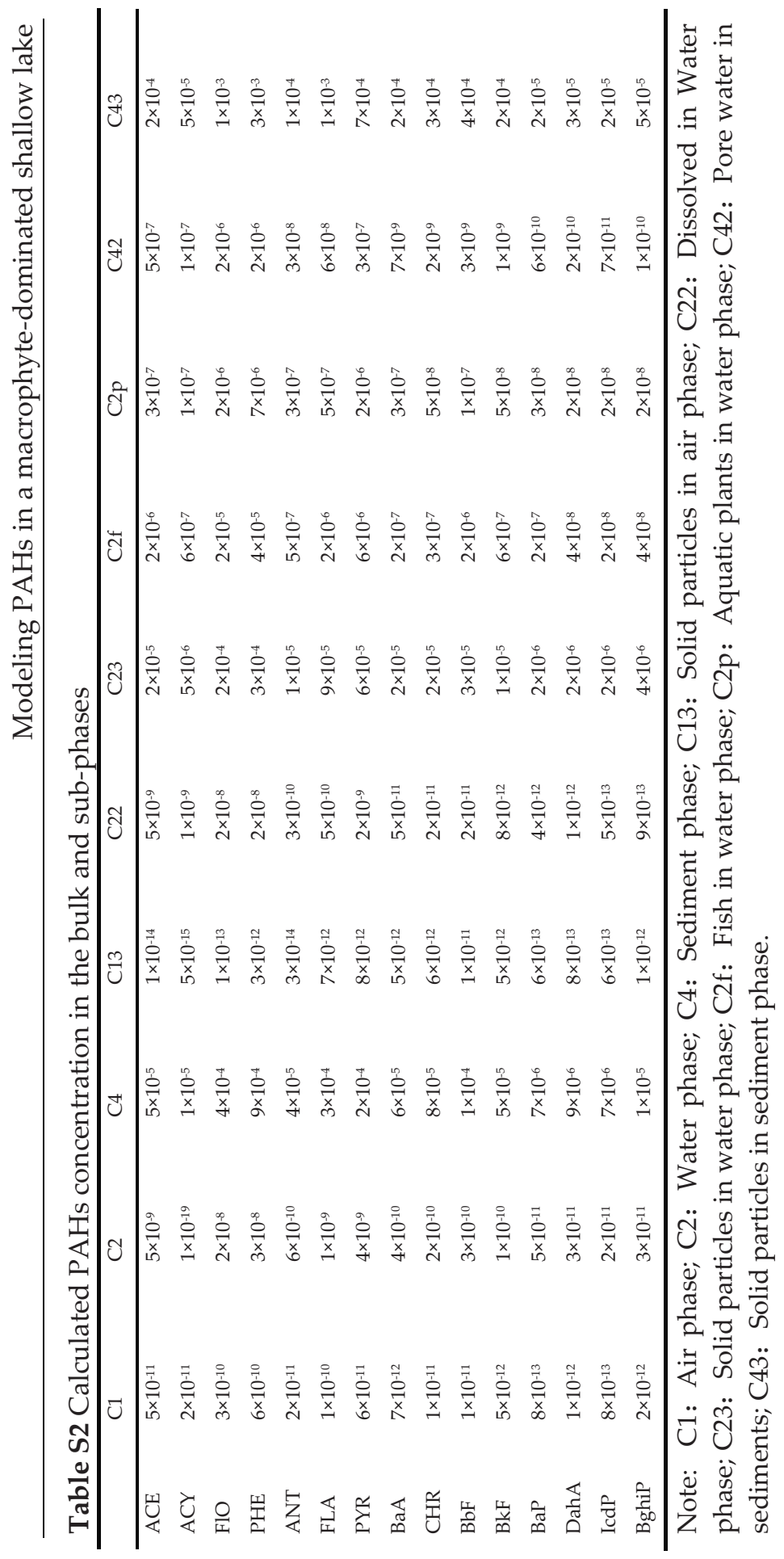




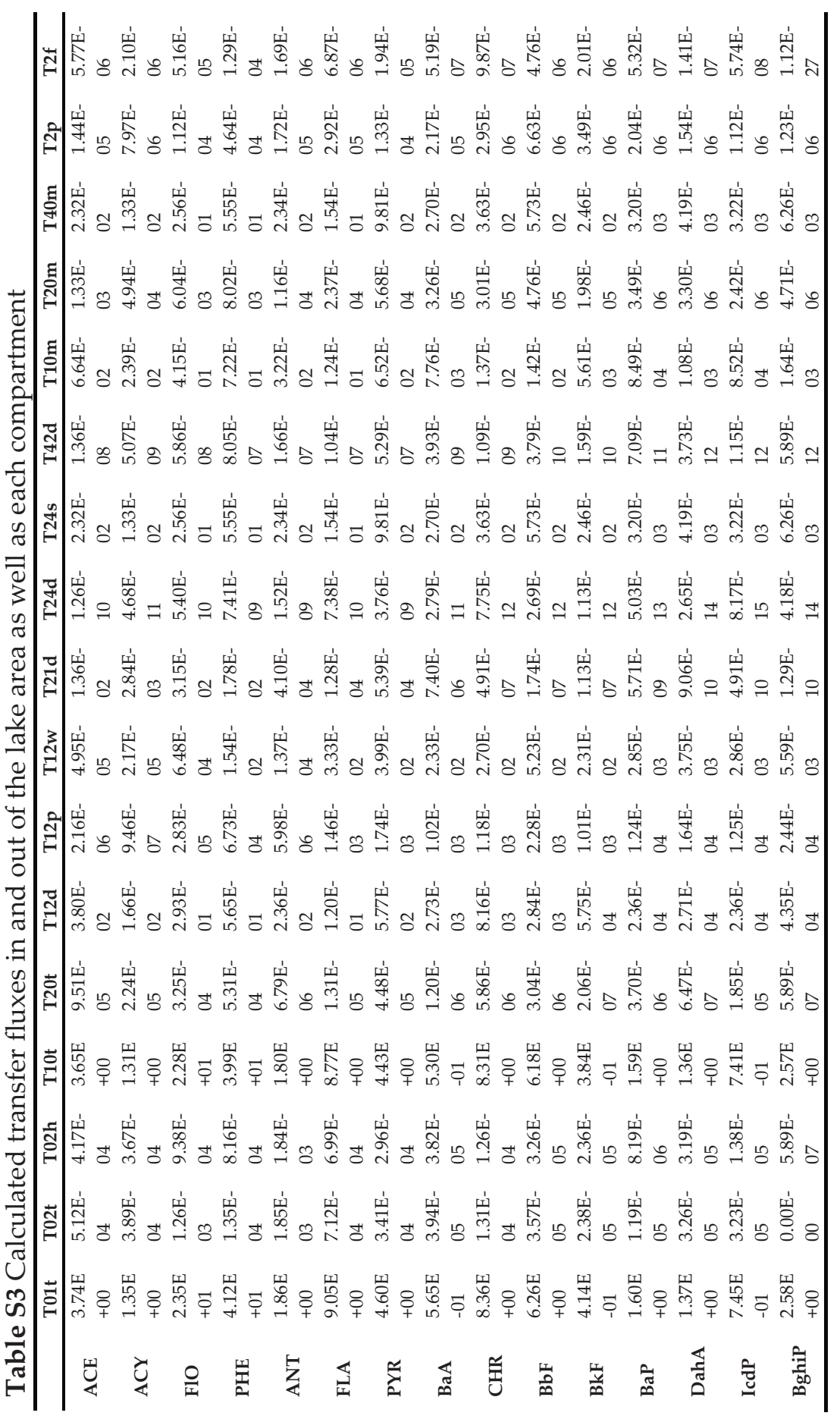




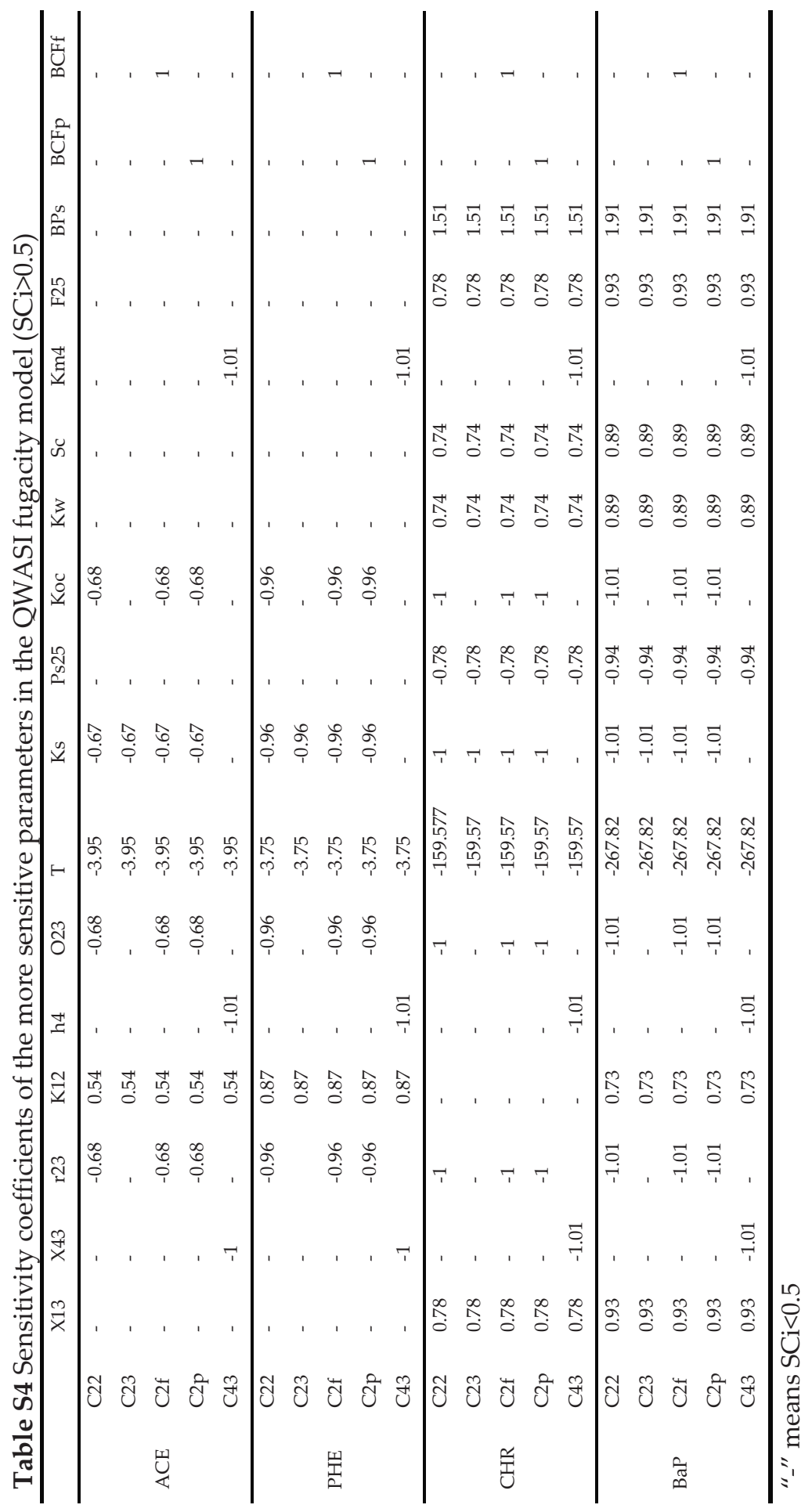




\section{References list for Table 5}

1) Zhao, Y.H, Lian, J.Y., Zhao, X.P., 2007. Protection for habitat security of biological resources in wetland of Baiyangdian Natural Reserve. Journal of Shijiazhuang Vocational Technology Institute 17 (2), 1-4.

2) HPEPB (Hebei Provincial Environmental Protection Bureau), 2001. Environmental Quality Statement 1996-2000. Hebei Provincial Environmental Protection Bureau, Hebei.

3) Ma, Z.P., Zhao, J.H., Kang, X.J., Jing, A.Q., 2007. The wind-driven water circulation in Baiyangdian Lake, China and the implication to environmental remediation. Oceanologia et Limnologia Sinica 38 (5), 405-410.

4) Mackay, D., Paterson, S., 1991. Evaluating the multimedia fate of organic chemicals: A level III fugacity model. Environ. Sci. Technol, 25, 427-436.

5) Zhao, X., Cui, B.S., Yang, Z.F., 2005. A study of the lowest ecological water level of Baiyangdian Lake. Acta Ecologica Sinica, 25, 1033-1040.

6) Zhao, F., 1995. Baiyangdian large aquatic resource survey and the impact of eutrophication. J. Environ. Sci., 16, 21-24.

7) Davenport, J., 1999. Swimbladder volume and body density in an armoured benthic fish, the streaked gurnard. Journal of Fish Biology 55, 527-534.

8) Yin, J.M., 2008. Chaos characterization of water level and adding solution of water in Lake BaiYang-Dian. Masters Thesis. Agricultural University of Hebei.

9) Bai, Y.J., 2008. Pollution characteristics of polycyclic aromatic hydrocarbons (PAHs) in surface water in western area around Bohai Bay. Ph.D. Thesis. Peking University, Beijing.

10) Van Agreren, M.H., Sytze, K., Dick, B.J., 1998. Handbook on Biodegradation and Biological Treatment of Hazardous Organic Compounds. Kluwer Academic Publishers, New York.

11) Mackay, D., Shiu, W.Y., Ma, K.C., 1997. Illustrated Handbook of Physical-Chemical Properties and Environmental Fate for Organic Chemicals, Volume V, Pesticide Chemicals. Lewis Publishers, Boca Raton, FL.

12) Wang, L.S., 1991. Chemistry of Organic Pollutant; Sci. Press: Beijing.

13) Wang, L.S., 1993. Chemical Carcinogens. Chinese Environment Science Press: Beijing.

14) Jin, X.C., 1990. Chemistry of Organic Compound Pollutant. Tsinghua University Press: Beijing.

15) Karickhoff, S.W., 1981. Semi-empirical estimation of sorption of hydrophobic pollutants on natural sediments and soils. Chemosphere 10, 833-846.

16) Ten Hulscher, T.E.M., Vandervelde, L.E., Bruggeman, W.A., 1992. Temperature dependence of Henry's law constants for selected chlorobenzenes,polychlorinated biphenyls and polycyclic aromatic hydrocarbons. Environmental Toxicology and Chemistry 11 (11), 1595-1603.

17) Paasivirta, J., Sinkkonen, S., Mikkelson, P., Rantio, T., Wania, F., 1999. Estimation of vapor pressures, solubilities and Henry's law constants of selected persistent organic pollutants as functions of temperature. Chemosphere 39 (5), 811-832.

18) STF (Soil Transport and Fate Database and Model Management System), 1991. Environmental Systems and Technologies, Blacksburg, USA.

19) US EPA, 1996. Soil Screening Guidance: Technical Background Document. US Environmental Protection Agency, Office of Emergency and Remedial Response, Washington, 9355.4-17A.

20) Mackay, D., 2001. Multimedia environmental models: the fugacity approach. Lewis Pub., Chelsen, MI.

21) Lang, C., Tao, S., Wang, X.J., Zhang, G., Fu, J.M., 2008. Modeling polycyclic aromatic hydrocarbon composition profiles of sources and receptors in the Pearl River Delta, China. Environmental Toxicology and Chemistry 27 (1), 4-9.

22) Duan, Y.H., 2005. Distribution and source-sink relationship of polycyclic aromatic hydrocarbons in topsoil from Tianjin. Ph.D. Thesis. Peking University, Beijing. 
23) Tang, M.J., Xu, Z.X., Zuo, Q., Huang, M.H., Tao, S., 2006. Multimedia fate modeling of PAHs in Guangdong Hong Kong, and Macao. Ecology and Environment 15 (4), 670-673.

24) Perry, R.H., Chilton, C.H., 1973. Chemical Engineers' Handbook, 5th edition. McGraw-Hill, New York, pp. 230-235.

25) US EPA, 1996. Soil Screening Guidance: Technical Background Document. US Environmental Protection Agency, Office of Emergency and Remedial Response, Washington, 9355.4-17A.

26) Shor, L.M., Rockne, K.J., Taghon, G.L., Young, L.Y., Kosson, D.S., 2003. Desorption kinetics for field-aged polycyclic aromatic hydrocarbons from sediments. Environ. Sci. Technol. 37 (8), 15351544.

27) Xu, Z.H., Mao, Z.X., Wang, L.S., Pang, Y.L., 1991. Handbook of Chemistry Property Estimate Method (Environmental Property of Organic Compound). Chemical Industry Press, Beijing.

28) Thibodeaux, L.J., 1996. Environmental Chemodynamics: Movement of Chemicals in Air, Water, and Soil. John Wiley \& Sons, INC.

29) Banks, R.B., Herrera, F.F., 1997. Effect of Wind and Rain on Surface Reaeration. J. Environ. Engr. Div. ASCE 103 (EE3), 489-504.

30) Beijing Statistics Bureau, 2005. Beijing Statistics Year Book. Chinese Statistics Press, Beijing.

31) Tianjin Environmental Protection Bureau (TJEPB), 2001. Environmental Quality Statement (19912000). Tianjin Environmental Protection Bureau, Tianjin.

32) Chen, J.G., Zhou, W.H., Deng, A.J., Sun, G.H., 2006. Formation and evolution of the longitudinal profile of the Lower Yellow River in modern times. Sediment Study 2 (1), 1-8.

33) Hu, C.H., Ji, Z.W., Huang, Y.J., Chen, D., 1998. Analysis on dredging practice in rivers, lakes and reservoirs. J. Sed. Res. 12 (4), 47-55.

34) Mackay, D., Paterson, S., Schroeder, W.H., 1986. Model describing the rates of transfer processes of organic-chemicals between atmosphere and water. Environmental Science and Technology 20, 810-816. 
Chapter 2 
CI

\section{Chapter 3}

Simulation of the fate and seasonal variations of $\alpha$-hexachlorocyclohexane ( $\alpha$ $\mathrm{HCH}$ ) in Lake Chaohu using a dynamic fugacity model

Xiangzhen Kong, Wei He, Ning Qin, Qishuang He, Bin Yang,

Huiling Ouyang, Qingmei Wang, Chen Yang, Yujiao Jiang, Fuliu Xu

Published in Scientific World Journal (2012) doi:10.1100/2012/691539 


\section{Abstract}

Fate and seasonal variation of $\alpha$-hexachlorocyclohexane $(\alpha-\mathrm{HCH})$ were simulated using a dynamic fugacity model in Lake Chaohu, China. Sensitivity analyses were performed to identify influential parameters and Monte Carlo simulation was conducted to assess model uncertainty. The calculated and measured values of the model were in good agreement except for suspended solids, which might be due to disregarding the plankton in water. The major source of $\alpha-\mathrm{HCH}$ was input from atmospheric advection, while the major environmental outputs were atmospheric advection and sediment degradation. The net annual input and output of $\alpha-\mathrm{HCH}$ was approximately $0.294 \mathrm{t}$ and $0.412 \mathrm{t}$, respectively. Sediment was an important sink for $\alpha-\mathrm{HCH}$. Seasonal patterns in various media were successfully modeled and factors leading to this seasonality were discussed. Sensitivity analysis found that parameters of source and degradation were more important than the other parameters. The sediment was influenced more by various parameters than air and water were. Temperature variation had a greater impact on the dynamics of the model output than other dynamic parameters. Uncertainty analysis showed that the model uncertainty was relatively low, but significantly increased in the second half of the simulation period due to the increase in the gas-water diffusion flux variability. 
Modeling $\alpha-\mathrm{HCH}$ in a phytoplankton-dominated shallow lake

\section{Introduction}

Organochlorine pesticides (OCPs) have been under increasing scrutiny due to their refractory qualities and high ecotoxicity. Hexachlorocyclohexanes (HCHs), a type of OCPs, have already been listed by the Stockholm Convention on Persistent Organic Pollutants in the first batch of control compounds (SCPOPs 2009). During the 1960s and 1970s, there was a substantial amount of production and usage of $\mathrm{HCH}$ pesticides in China, resulting in high level of residues in the soil (Cao et al. 2004). Through surface runoff, undercurrent, osmosis, leaching and other transport mechanisms from the soil into the surface water, the water bodies, such as lakes, have also been severely polluted by $\mathrm{HCH}$ pesticides. According to historical data, the quantity of emitted OCPs in the Lake Chaohu water bodies amounted to 1.16 tons in 1984. Among the isomers of $\mathrm{HCHs}, \alpha-\mathrm{HCH}$ can cause human neurological disorders and gastrointestinal discomfort, resulting in liver and kidney damage, human endocrine system disorders and immune system abnormalities (SCPOPs 2009). Therefore, an understanding of the distribution and dynamics of $\alpha-\mathrm{HCH}$ in lake environments is extremely crucial.

The multi-media model is a mathematical model developed in the 1980s based on the concept that the physical and chemical properties of environmental systems and pollutants synergistically determine the concentration distribution and migration of contaminants throughout the transformation process between environmental compartments (Mackay 2001). Mackay (1979) and Mackay and Patterson $(1981,1982)$ proposed a fugacity model to simplify the structure of the multi-media model and the calculation process. This model has been widely used in describing the environmental behaviors of pollutants in global, regional and local environments (Wania and Mackay 1995, Tao et al. 2003, Liu et al. 2007). There are four levels in the fugacity model. A level IV fugacity model is appropriate when continuous changes in the concentrations of particular pollutants are studied over a period of time (Tao et al. 2006, Liu et al. 2007).

Few studies have been conducted that focus on the seasonal variation in $\alpha-\mathrm{HCH}$ using the level IV fugacity model. In this study, the fate and seasonal variation of $\alpha-\mathrm{HCH}$ in the air, water and sediment of Lake Chaohu was examined. Since the usage of industrial HCHs was banned in 1983 and lindane was applied instead (Tao et al. 2006), the $\alpha-\mathrm{HCH}$ emissions can be assumed to be zero. The results of this model can reveal the main source, the migration and transformation processes and the most influential parameters on the fate and seasonal variations of $\alpha-\mathrm{HCH}$ in the of Lake Chaohu environment. 
The uncertainty of the model was also assessed using a Monte Carlo simulation.

\section{Materials and methods}

\section{Model development}

The framework of the model in this study was based on the Quantitative Water, Air, Sediment Interaction (QWASI) fugacity model (Mackay et al. 1983a), with the major difference being the inclusion of atmospheric advection input and output of the system. This model included three main compartments: atmosphere, water, and sediment, which were represented by the subscripts 1,2 and 4 , respectively. The atmospheric phase was comprised of two sub-phases: gaseous and particulate matter. The aqueous phase also comprised two sub-phases: water and suspended solids. The sediment phase consisted of porewater and a solid phase. The model framework is shown in Figure 1. The basic characteristics of the model for Lake Chaohu are shown in Table 1.

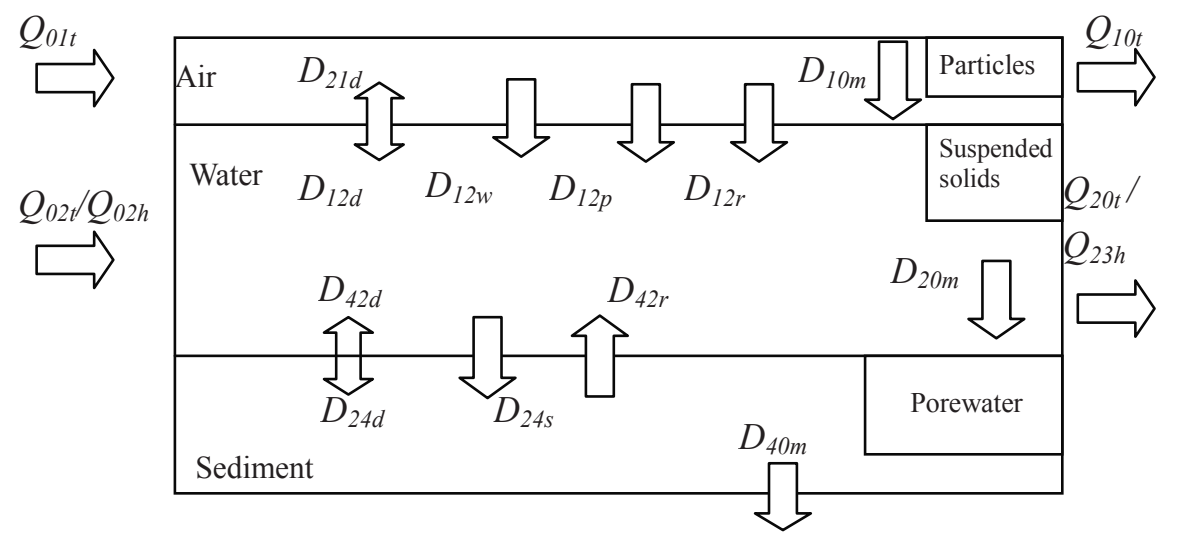

Fig. 1. Transport fluxes of $\alpha-\mathrm{HCH}$ in and out of the Lake Chaohu area and between the adjacent compartments. $D_{12 d,} D_{21 d,} D_{24 d}$ and $D_{42 d}$ represent the diffusion processes between air/water and water/sediment. $D_{12 p}$ and $D_{12 w}$ represent the dry and wet deposition from air to water, respectively. $D_{12 r}$ represents scavenging by precipitation. $Q_{01 t}, Q_{02 t}$ and $Q_{02 h}$ represent the input from air advection, water inflows and waste water discharge, respectively. $Q_{10 t}$ $Q_{20 t}$ and $Q_{23 h}$ represent the output from air advection, water outflows and water reuse by industry and agriculture, respectively. $D_{10 \mathrm{~m}}, D_{20 \mathrm{~m}}$ and $D_{40 \mathrm{~m}}$ represent the degradation occurring in the air, water and sediment, respectively. 
Modeling $\alpha-\mathrm{HCH}$ in a phytoplankton-dominated shallow lake

Table 1 Volume and properties of the phases and sub-phases

\begin{tabular}{|c|c|c|c|c|c|c|}
\hline \multirow[b]{2}{*}{ Main phase } & \multirow[b]{2}{*}{ Area $\left(m^{2}\right)$} & \multirow[b]{2}{*}{ Depth $(\mathrm{m})$} & \multirow{2}{*}{$\begin{array}{l}\text { Organic } \\
\text { Carbon } \\
(\%)\end{array}$} & \multicolumn{3}{|c|}{ Sub-phases and volume fraction $(X i j)$} \\
\hline & & & & Air (1) & Water (2) & $\begin{array}{l}\text { Solid } \\
\text { Particles (3) }\end{array}$ \\
\hline$\overline{\text { Air (1) }}$ & $7.5810 \mathrm{E}+08$ & $1.0000 \mathrm{E}+02$ & - & $1.0000 \mathrm{E}+00$ & - & $7.6278 \mathrm{E}-11^{\mathrm{b}}$ \\
\hline Water (2) & $7.5810 \mathrm{E}+08$ & $3.0124 \mathrm{E}+00$ & $\begin{array}{l}1.6700 \mathrm{E}- \\
01\end{array}$ & - & $1.0000 \mathrm{E}+00$ & $1.2631 \mathrm{E}-05^{\mathrm{b}}$ \\
\hline Sediment (3) & $7.5810 \mathrm{E}+08$ & 1.0000E-01 & $\begin{array}{l}4.6077 \mathrm{E}- \\
03\end{array}$ & - & 7.0000E-01 & $3.0000 \mathrm{E}-01$ \\
\hline
\end{tabular}

Model parameter symbols, units, values and data sources are shown in Tables S1 and S2 in Supplementary Materials. The model had a total of 46 parameters, including 23 environmental parameters, 12 interface mass transfer parameters and 11 physicochemical parameters for the pollutant. The environmental parameters included temperature, lake area, height and subphase volume fraction determined by the literature or laboratory measurements. The physicochemical parameters, such as the gas constant, Henry's constant and saturated vapor pressure, were obtained from the literature. The environmental kinetics of the process parameters, including the rate of degradation, the rate of diffusion, migration constant, molecular diffusion path length, atmospheric wet and dry deposition rates, deposition rate and cleaning coefficients, were obtained from the relevant literature. Fifteen parameters had annually changing values, including the environmental parameters ( $h_{2}, X_{13}, Q_{01 t} Q_{10 t}, Q_{02 t}, Q_{20 t}, Q_{23 h}, Q_{02 h}, T, C_{1}$ and $\left.X_{23}\right)$ and the mass transfer parameters $\left(\mathrm{K}_{12}, \mathrm{~K}_{21}, \mathrm{~K}_{42 \mathrm{r}}\right.$ and $\left.\mathrm{K}_{\mathrm{w}}\right)$. The parameter $\mathrm{h}_{2}$ included hourly data; $T, K_{12}, K_{21}, K_{42 r}$ and $K_{w}$ had daily data, and $X_{13}$, Q01t $\left(Q_{10 t}\right), Q_{02 t}, Q_{20 t}, Q_{23 h}$, Q $02 h, C_{1}$ and $X_{23}$ had monthly data. Other parameters were used in terms of annual average values, and they remained constant during the simulation. In addition, Henry's constant, saturated vapor pressure and the fugacity rate of the pollutant were primarily obtained using a temperature of $25{ }^{\circ} \mathrm{C}$. The temperature correction required for these parameters and the correction equation are shown in Equation 1 (Paasivirta et al. 1999):

$$
\log _{10} P_{T}=\log _{10} P_{25}+A \times\left(\frac{1}{298}-\frac{1}{T+273}\right)
$$

where $P_{T}$ is the physical and chemical parameter values at $T\left({ }^{\circ} \mathrm{C}\right)$ (Henry's constant, the saturation vapor pressure or fugacity rate); $P_{25}$ is the physical and chemical parameters at $25^{\circ} \mathrm{C}$; $A$ is the temperature correction coefficient (for Henry's constant, saturated vapor pressure and fugacity 
rate).To obtain the total river inflows of Lake Chaohu from May 2010 to February 2011, monthly data from May 1987 to April 1988 were collected (Tu et al. 1990) along with the corresponding daily precipitation data from the China Meteorological Data Sharing Service System. There was a significant linear relationship between the river inflow and the precipitation data. Using this linear relationship and the monthly precipitation data from May 2010 to February 2011 for Lake Chaohu, the river inflow (Q ${ }_{02 t}$ ) for the simulation period was easily calculated. This calculation was based on the assumption that there were no significant landscape level changes which largely modifying fate of precipitation at catchment area since 1980s. In addition, the values of water inflow were not important to the fate of $\alpha-\mathrm{HCH}$ in the lake, which will be revealed in the sensitive analysis (section 3.3). The average monthly river outflow ( $\mathrm{Q}_{20 \mathrm{t}}$ ) of Lake Chaohu was based on the water balance calculation of inflow and water level in addition to the rates of industrial and agricultural water consumption $\left(\mathrm{Q}_{23 \mathrm{~h}}\right)$ (Tu et al. 1990).Taking into consideration that industrial HCHs were banned in 1983 and lindane $(\gamma-\mathrm{HCH})$ was applied instead (Tao et al. 2006), emissions of $\alpha-\mathrm{HCH}$ in the vicinity of Lake Chaohu were assumed to be zero during the simulation. Atmospheric $\alpha-\mathrm{HCH}$ input originated from atmospheric advection. The $\alpha-\mathrm{HCH}$ concentration in the advection within the study area $\left(\mathrm{C}_{1}\right)$ was determined according to the sampled values on the lake side (four samples in total). The daily average wind speed and direction during the simulation period in Lake Chaohu area was obtained from the China Meteorological Data Sharing Service System. The volumes of atmospheric advections ( $\left.\mathrm{Q}_{01 t}, \mathrm{Q}_{10 \mathrm{t}}\right)$ were calculated according to the corresponding atmospheric height, the area of Lake Chaohu and the wind speed. $\alpha-\mathrm{HCH}$ input originated from water inflows were determined by the summation of the input amount from all the rivers around the lake.

The mass transfer coefficients of both sides of the gas-water interface ( $\mathrm{K}_{12}$ and $\mathrm{K}_{21}$ ) were calculated according to the method proposed by Southworth (1979). The resuspension coefficient (K42r) was calculated according to the formula from $\mathrm{Tu}$ et al. (1990). The specific equations are as follows:

$$
\begin{aligned}
& \mathrm{K}_{12}=11.375 \cdot(\mathrm{WS}+\mathrm{RS}) \cdot(18 / \mathrm{MW})^{0.5}
\end{aligned}
$$

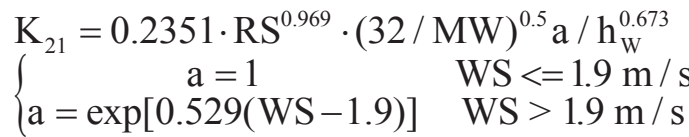


$\mathrm{K}_{42 \mathrm{r}}=3 \times 10^{-8} \cdot \mathrm{WS} / \mathrm{h}_{\mathrm{w}}$

where WS is the average wind speed $(\mathrm{m} / \mathrm{s})$; RS is the surface flow velocity $(\mathrm{m} / \mathrm{s})$; $\mathrm{MW}$ is the molecular weight $(\mathrm{g} / \mathrm{mol})$; and $\mathrm{hw}$ is the water depth (m).

The transfer and transformation processes defined in the model are shown in Table S3 (Supplementary Materials). Details can be found in Mackay and Patterson (1991). The level IV fugacity model can be expressed by equation (5), where fugacity is symbolized by $f(\mathrm{~Pa})$. The processes considered in the model included the advection of the air and water phases, diffusion and dry/wet deposition between the air and water, diffusion, sedimentation and resuspension between the water and sediment, and the degradation process during the main phase. In this study, the fourth-order Runge-Kutta method was applied to solve the differential equations by simulating step of 1-hour. The time period of the dynamic simulation was from May 1, 2010 to February 28 , 2011. The seasonal variation of the $\alpha-\mathrm{HCH}$ concentration for each compartment of the environment was simulated and compared to the measured values. Validation data were obtained from the monthly samples of atmospheric aerosols on an island in the lake, water and suspended solids (four sample sites in total) collected from May 2010 to February 2011 (Liu et al. 2012, Ouyang et al. 2012) and from the 14 sediment samples collected in August 2008 from Lake Chaohu (Wang et al. 2012c).

$$
\left\{\begin{aligned}
V_{1} Z_{1} d f_{1} / d t= & T_{01 t}-\left(D_{12 d}+D_{12 p}+D_{12 r}+D_{12 w}+D_{10 m}-D_{10 t}\right) f_{1}+D_{21 d} f_{2} \\
V_{2} Z_{2} d f_{2} / d t= & T_{02 t}+\left(D_{12 d}+D_{12 p}+D_{12 g}+D_{12 w}\right) f_{1}- \\
& \left(D_{21 d}+D_{24 d}+D_{24 s}+D_{20 m}+D_{20 t}+D_{23 h}\right) f_{2}+\left(D_{42 d}+D_{42 r}\right) f_{4} \\
V_{4} Z_{4} d f_{4} / d t= & \left(D_{24 d}+D_{24 s}\right) f_{2}-\left(D_{42 d}+D_{42 r}+D_{40 m}\right) f_{4}
\end{aligned}\right.
$$

\section{Sensitivity analysis}

When a system error of the model cannot be eliminated, the accuracy of the parameters is the most important factor in model accuracy, particularly regarding some sensitive parameters (Cao et al. 2004). Therefore, a sensitivity analysis was conducted for all parameters involved in the model (except the gas constant, $R$ ). For constant parameters, a local sensitivity analysis was applied which implemented a "perturbation" near the best estimate value of a parameter, and the variation of model outputs was studied under the condition that other parameters remained unchanged. The Morris classification screening method, a widely applied local sensitivity analysis method, was used 
(Morris 1991). A variable was selected, and the value changed to the fixed step size, while the other parameters remained the same. The sensitivity index of the parameter was the average of the multiple disturbance calculated Morris coefficient:

$$
S=\sum_{i=0}^{n-1} \frac{\left(Y_{i+1}-Y_{i}\right) / Y_{0}}{\left(P_{i+1}-P_{i}\right) / 100} /(n-1)
$$

where $S$ is the Morris coefficient; $Y_{i}$ is the model output value in the $i^{\text {th }}$ simulation; $Y_{0}$ is the model calculation result when the parameter is set at the initial value; $P_{i}$ is the percentage change of the parameter value the for the $i$-th simulation; and $n$ is the number of runs.

Cao et al. (2004) proposed that when the step size is small enough, the nonlinear effects of the parameters of the model output are negligible. In this study, it was assumed that the parameters increased and decreased by $10 \%$ on the basis of the original value. $Y_{0.9}, Y_{0}$ and $Y_{1.1}$ are the output results when the parameter was multiplied by $0.9,1$ and 1.1, respectively. The sensitivity coefficient $\left(C_{s}\right)$ is as follows:

$$
C s=A b s\left(\frac{Y_{1.1}-Y_{0.9}}{0.2 \times Y_{0}}\right)
$$

The effect of the parameters on the model output was not only associated with corresponding $C_{s}$ values of the parameters but was also related to the fluctuation range of the parameters in the environment (Cao et al. 2004). With the same $C_{s}$ value, those parameters with higher variability have greater impacts on the model than those with lower variability. In this study, the sensitivity coefficient after the correction of the coefficient of variation $\left(C_{n}\right)$ for the parameters was also calculated by (Cao et al. 2004), such that $C n=C s \times C V$, where $C V$ is the coefficient of variation of the parameter.

For the dynamic parameters in the model, the dynamic sensitivity coefficient (SCV) is calculated as follows (Lang et al. 2007):

$S C V_{i}=\frac{\Delta C V_{i}^{Y} / C V_{i}^{Y}}{\Delta C V_{i}^{X} / C V_{i}^{X}}$

where $C V_{i}{ }^{X}$ and $C V_{i}^{Y}$ indicate the corresponding coefficients of variation of the $i^{\text {th }}$ input parameter and the output parameter, respectively, and $\Delta C V_{i}{ }^{X}$ and $\Delta C V_{i}^{Y}$ represent the variations of the corresponding coefficients of variation of the $i$-th input parameter and the output parameter, respectively. 
Modeling $\alpha-\mathrm{HCH}$ in a phytoplankton-dominated shallow lake

\section{Uncertainty analysis}

A Monte Carlo simulation was utilized to study the impact of the simultaneous changes in the parameters on the model results, i.e., the uncertainty of the model. Based on an analysis of the collected parameter values, all of the parameters except for temperature $(T)$ were assumed to follow the lognormal distribution (Lang et al. 2007).

A total of 2200 Monte Carlo simulation runs were conducted. Both static and dynamic parameters with higher sensitivity coefficients were selected and the original values were retained for the remaining parameters in the simulation process. The geometric mean and standard deviation could be calculated for static parameters with multiple values. Conversely, if only one value was obtained, the corresponding coefficients of variation for the parameters were assigned using values based on the literature (Cao et al. 2004, Lang et al. 2007). For dynamic parameters, the monthly geometric mean and standard deviation were calculated from hourly or daily data. When only monthly data were available, the coefficients of variation were manually assigned. Each run was implemented with values for each parameter that were randomly selected in the range of the mean \pm standard deviation. Semiinterquartile ranges for the monthly model output were obtained for the uncertainty analysis.

\section{Results and discussion}

\section{Concentrations of $\alpha-\mathrm{HCH}$ in various media and model validation}

The simulated annually average concentrations of $\alpha-\mathrm{HCH}$ in the air, water and sediment are shown in Figure 2 and were found to be in agreement with the measured data. The differences in the main phases were $0.21,0.06$ and 0.07 logarithmic units for the air, water and sediment, respectively, which were all within $0.5 \log$ units during the simulation. The air concentrations were underestimated, which might be due to various factors. On the other hand, in addition to the uncertainty of the model, the underestimation in the sediment may be due to fact that the samples were collected in 2008, while the model simulation period was 2010-2011. The overestimation of the concentration in the water may have been due to the absence of a biological phase. Aquatic organisms, especially plankton, can substantially affect the fate of Persistent Organic Pollutants (POPs) in the water environment (Dachs et al. 1999). It can be observed that the $\alpha-\mathrm{HCH}$ concentration in the sediment particles was much higher than that in the atmosphere or in the water bodies. It was concluded 
that sediment is an important sink of $\alpha-\mathrm{HCH}$ (Walker et al. 1999).

The simulation results for the atmospheric particulates and the suspended solids in the water were not satisfactory. The differences between the measured and simulated data are 0.6 and 1.69 orders of magnitude, respectively. The underestimation of the $\alpha-\mathrm{HCH}$ concentration in atmospheric particulates may be associated with the underestimation of the organic carbon content or the volume ratio of the atmospheric particulates. It was always acceptable if the deviations between the simulated and observed data were less than 0.5 or 0.7 orders of magnitude for multimedia fugacity model (Cao et al. 2004). Thereby, the results in the air particles should be acceptable. The underestimation of the $\alpha-\mathrm{HCH}$ concentration in the suspended solids in the water may be related to similar processes as those that caused the overestimation in the water.

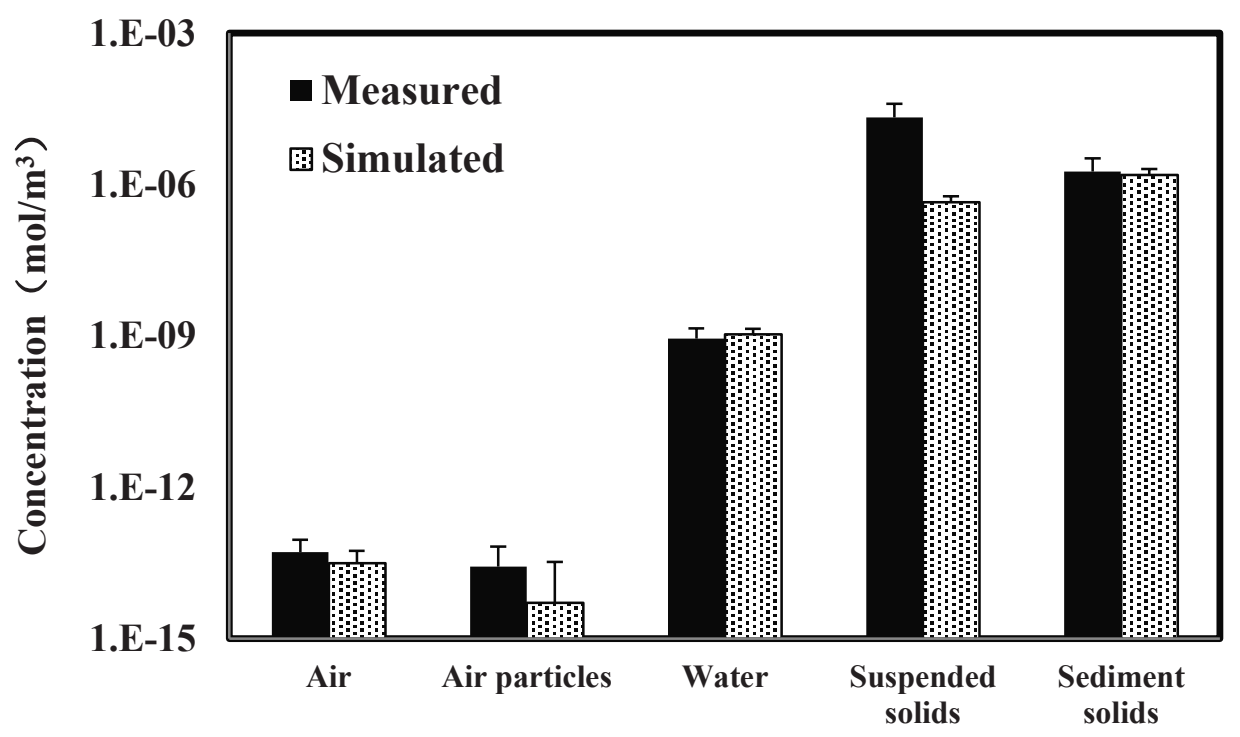

Fig. 2. Comparison between the simulated and measured $\alpha-\mathrm{HCH}$ concentrations in the air, water and sediment of Lake Chaohu. The error bars included in this figure represent the standard deviations.

The simulation results regarding the monthly $\alpha-\mathrm{HCH}$ concentration in different compartments are shown in Figure 3. The model output of the $\alpha$ $\mathrm{HCH}$ concentrations in the atmosphere and the atmospheric particles was consistent with the measured values. However, the $\alpha-\mathrm{HCH}$ concentration in 
Modeling $\alpha-\mathrm{HCH}$ in a phytoplankton-dominated shallow lake

the atmospheric particles peaked in November according to the measured values, while the calculated value peaked in December, which corresponded to the peak of gaseous $\alpha-\mathrm{HCH}$ concentration but failed to capture the November peak. This discrepancy may due to higher concentrations of $\alpha-\mathrm{HCH}$ in the remote input of atmospheric particulate matter in November. The specific mechanisms underlying this difference require further study.

Gaseous $\alpha-\mathrm{HCH}$ concentrations in the summer and winter, notably in August and December, were higher than in other seasons. Ridal et al. (1996) also observed relatively high concentrations of gaseous $\alpha-\mathrm{HCH}$ in Lake Ontario in August. The most likely cause of higher $\alpha-\mathrm{HCH}$ concentrations in the summer may be the higher temperatures in summer months (Zheng et al. 2010), which favor volatilization. High values in the winter may be due to remote inputs from the atmosphere ( $\mathrm{Li}$ et al. 2002). Haugen et al. (1998) suggested that when the regression coefficient $R^{2}$ for $\ln P$ and $1 / T$ is high, local gaseous $\alpha-\mathrm{HCH}$ is mainly derived from surface volatilization. Otherwise, remote input is typically the dominant source of gaseous $\alpha-\mathrm{HCH}$. In this study, the regression coefficient for $\ln P$ and $1 / T$ was 0.004 , indicating that the gaseous $\alpha-\mathrm{HCH}$ in Lake Chaohu was influenced to a greater extent by remote input than by lake volatilization. Agricultural land accounted for $61.12 \%$ of the total land area in the Lake Chaohu watershed (Tu et al. 1990). Consequently, large amounts of $\alpha-\mathrm{HCH}$ residues remain in the soils. After volatilization, the $\alpha$ $\mathrm{HCH}$ is able to be transported to the lake by air advection. In addition, there was a slight decline of gaseous $\alpha-\mathrm{HCH}$ in July (Figure 3), which corresponded to a marked increase in the wet deposition flux ( $\left.\mathrm{T}_{12 r}\right)$ during this period. The reason for the slight decline may be increased precipitation. It can be concluded that both temperature and precipitation are key factors affecting gaseous $\alpha-\mathrm{HCH}$. This conclusion was quantitatively verified using the sensitivity analysis. It is worth noting that wet deposition ( $\left.\mathrm{T}_{12 \mathrm{w}}\right)$ was higher in the summer, particularly in August, and lower during the other seasons. In contrast, dry deposition ( $\mathrm{T}_{12 \mathrm{p}}$ ) was higher in the winter, notably in December, and lower during the other seasons. 

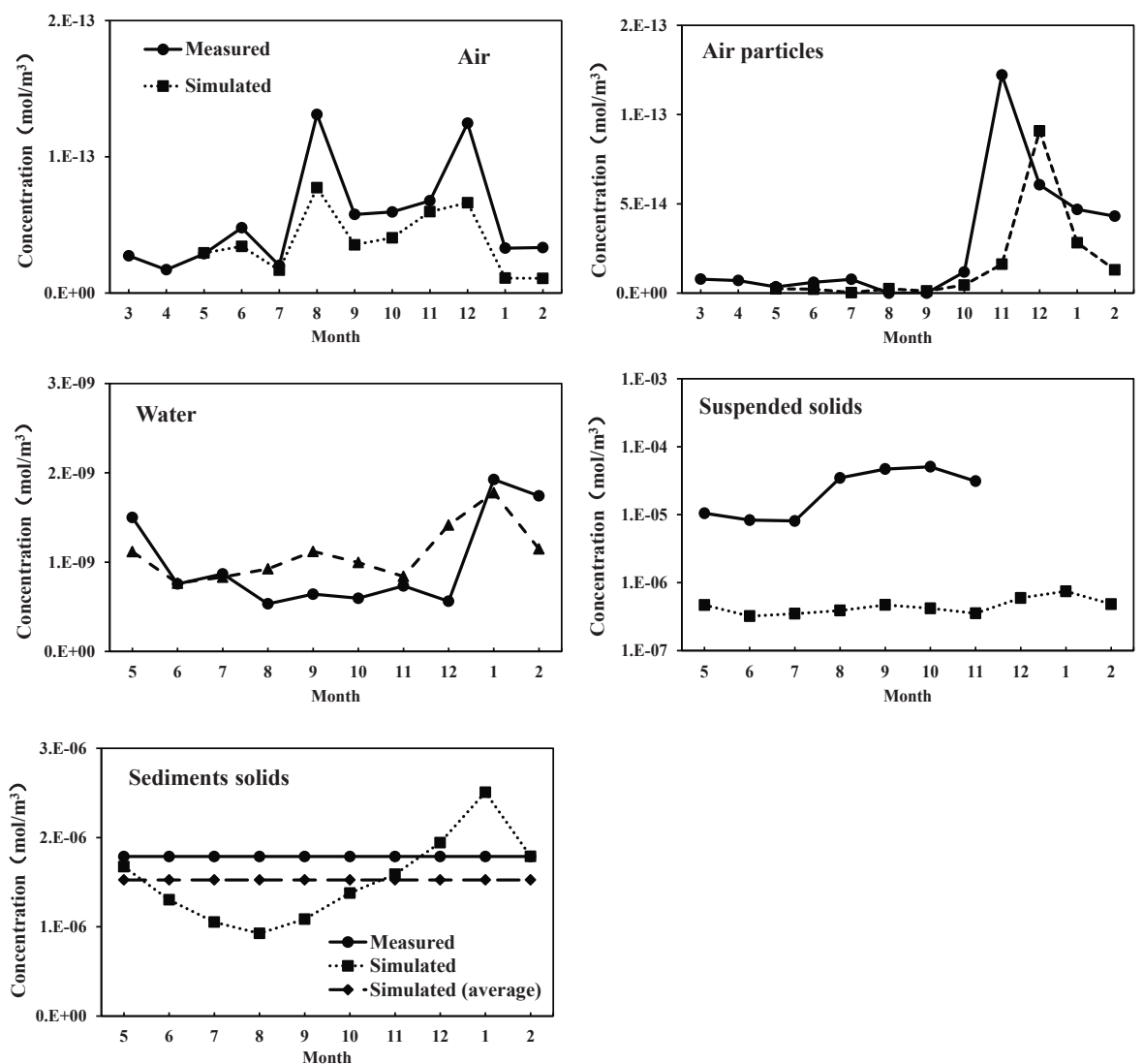

Fig. 3. Seasonal variations of $\alpha-\mathrm{HCH}$ concentrations in the various environmental media. Both the simulated and measured concentrations are presented for comparison and model validation.

$\alpha-\mathrm{HCH}$ in atmospheric particulate matter was lower in the summer and higher in the winter. The primary reason behind this difference may be that as the temperature rises in the summer, the gas-solid balance of $\alpha-\mathrm{HCH}$ in the air shifts toward the gaseous phase. The situation is opposite in the winter (Carlson et al. 2004). In addition, the atmospheric particulate matter content in the summer is lower due to a decrease in the remote inputs when compared to winter.

The measured and simulated values of $\alpha-\mathrm{HCH}$ in the water were also in good agreement. The model captured the high value in the winter and the variation in the other seasons, which was also consistent with the data Ridal et al. (1996) observed in Lake Ontario. The peak in the winter values may be attributed to several causes. First, although the winter temperatures are lower, 
Modeling $\alpha-\mathrm{HCH}$ in a phytoplankton-dominated shallow lake

leading to reduced water fugacity capacity (Carlson et al. 2004), the precipitation and water inflow are also lower in the winter, resulting in a significant decrease in water levels, which may cause a concentration effect. Furthermore, the gas-to-water diffusion process flux (T12d) is higher in the winter, which may also be important. Conversely, lower concentrations were simulated in the summer and the autumn. A noticeable decline occurred in June, which may be due to the dilution effect caused by the rising water levels and elevated water-to-air diffusion ( $\mathrm{T}_{21 \mathrm{~d}}$ ) caused by increasing temperatures. The $\alpha-\mathrm{HCH}$ concentrations in water begin to be overestimated from August through December, which coincides with an observed increase in the seasonal distribution of cyanobacteria in Lake Chaohu (Xie 2009). In addition, the calculated value of the $\alpha-\mathrm{HCH}$ concentration in the suspended solids was much less than the measured value by a factor of more than one order of magnitude every month. It can be speculated that disregarding aquatic organisms, particularly the phytoplankton phase, can lead to a significant deviation between the measured data and simulation results. Phytoplankton uptake is strongly affecting the fate of persistent organic pollutants (POPs) in aquatic environments (Dachs et al. 1999), which was not included in this model. Only absorption by the organic matter in the suspended solids was considered in the model. Dachs et al. (1999) proposed a model combining POPs in the airwater exchange and phytoplankton absorption processes. However, currently there is no data on the parameters of $\mathrm{HCH}$ exchange between water and phytoplankton (Del Vento and Dachs 2002, Berrojalbiz et al. 2011). A modification in the model structure and further research are needed in the future.

The annual averages of the sampled values of $\alpha-\mathrm{HCH}$ content in the sediment particles were consistent with the simulated results. Similar seasonal variation in the water bodies was obtained, showing the trends of higher values in the summer and lower values in the winter. With smaller seasonal changes, the $\alpha-\mathrm{HCH}$ content in the sediment was relatively stable compared to that in the water.

\section{Transfer fluxes of $\alpha-\mathrm{HCH}$ between compartments}

As shown in Figure 4, the net input of $\alpha-\mathrm{HCH}$ into the Lake Chaohu environment is approximately $0.115 \mathrm{~mol} / \mathrm{h}$ (approximately $0.294 \mathrm{t} / \mathrm{a}$ ), while the net output is $0.162 \mathrm{~mol} / \mathrm{h}$ (approximately $0.412 \mathrm{t} / \mathrm{a}$ ). It can be observed that the $\alpha-\mathrm{HCH}$ content in the Lake Chaohu watershed is diminishing. The atmospheric advection input was found to be the main source (T01t) $(0.278 \mathrm{t} / \mathrm{a})$, which corresponded to the atmospheric advection output ( $\left.\mathrm{T}_{10 \mathrm{t}}\right)(0.277 \mathrm{t} / \mathrm{a})$. By 
contrast, the $\alpha-\mathrm{HCH}$ input from water inflows was very small (0.016 t/a). An important output was the degradation in the sediments $(0.119 \mathrm{t} / \mathrm{a})$, which accounted for $89.05 \%$ of the total degradation in the environment, while the degradation in the water was $0.015 \mathrm{t} / \mathrm{a}$, which accounted for $10.86 \%$ of the total degradation.

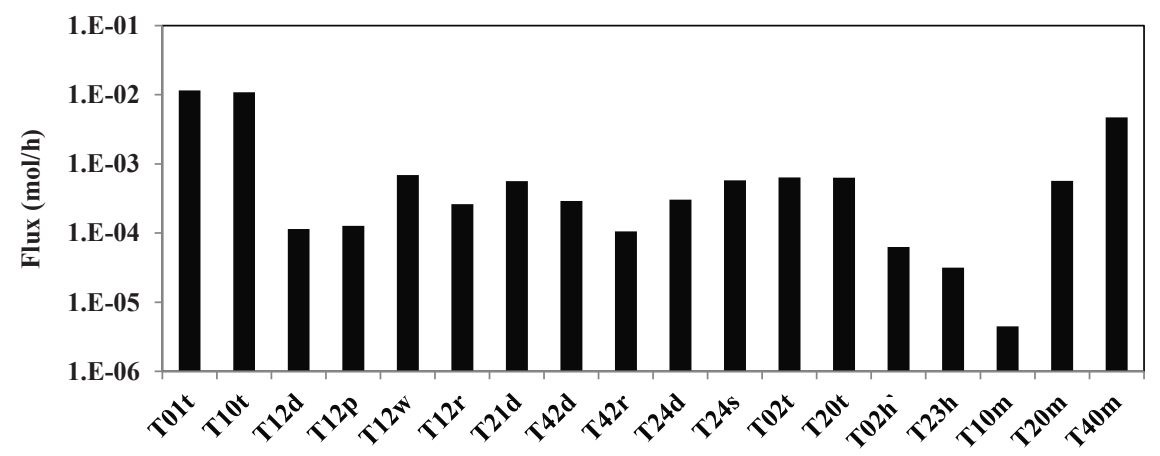

Fig. 4. $\alpha-\mathrm{HCH}$ fluxes in and out of the Lake Chaohu area and between the adjacent compartments. T01t: Air advection flows into the area; T10t: Air advection flows out of the area; T12d: Diffusion from air to water; T12p: Dry deposition from air to water; T12w: Wet deposition from air to water; T12r: Rain scavenging; T21d: Diffusion from water to air; T42d: Diffusion from sediment to water; T42r: Resuspension from sediment to water; T24d: Diffusion from water to sediment; T24s: Sedimentation from water to sediment; T02t: Water advection flows into the area; T20t: Water advection flows out of the area; T02h: Locative wastewater discharge; T23h: Industry and agriculture water usage; T10m: Degradation in air; T20m: Degradation in water; T40m: Degradation in sediment.

For interface processes, the atmospheric input to the water was 0.030 $\mathrm{t} / \mathrm{a}$, and the dominant process of atmospheric input to the water was precipitation scavenging ( $\left.\mathrm{T}_{12 \mathrm{w}}\right)$, which accounted for $57.80 \%$ of the gas-to-water flux. The flux of diffusion from the water to the atmosphere (T21d) was $0.014 \mathrm{t} / \mathrm{a}$. Therefore, there was an annual net input from the atmosphere to the water. The seasonal variations in the air-water exchange were shown in Figure 5. There was a net volatilization from the water into the atmosphere in May, which was consistent with the results obtained by Taihu (Qiu et al. 2008). During the other seasons, however, there is a net input from the atmosphere to the water, which is the converse of the results observed in Lake Taihu. The 
Modeling $\alpha-\mathrm{HCH}$ in a phytoplankton-dominated shallow lake

main cause of this difference may be that the research in Lake Taihu did not include deposition from air to water. It is also worth noting that the $\alpha-\mathrm{HCH}$ concentrations in the Lake Taihu atmosphere and water are $32 \pm 28 \mathrm{pg} / \mathrm{m}^{3}$ and $1887 \pm 1372 \mathrm{pg} / \mathrm{L}$, respectively, while in Lake Chaohu, the corresponding concentrations are $16 \pm 11 \mathrm{pg} / \mathrm{m}^{3}$ and $423 \pm 395 \mathrm{pg} / \mathrm{L}$, which are $50.0 \%$ and $22.4 \%$ of the values of Lake Taihu, respectively. The lower $\alpha-\mathrm{HCH}$ concentration in the water of Lake Chaohu may be due to historically lower $\mathrm{HCH}$ pesticide usage. The results are also opposite from the findings for Lake Ontario (Ridal et al. 1996). Ridal et al. (1996) proposed that, due to a reduction in the atmospheric concentration, the $\alpha-\mathrm{HCH}$ flux in Lake Ontario has shifted from net settlement to net volatilization when compared with the years prior to 1990. For Chaohu, however, due to a reduction in the water $\alpha-\mathrm{HCH}$ concentration, the air-water interface may have still been net settlement. Therefore, despite the net volatile flux in the summer, the annual net flux is from the gas to the water.
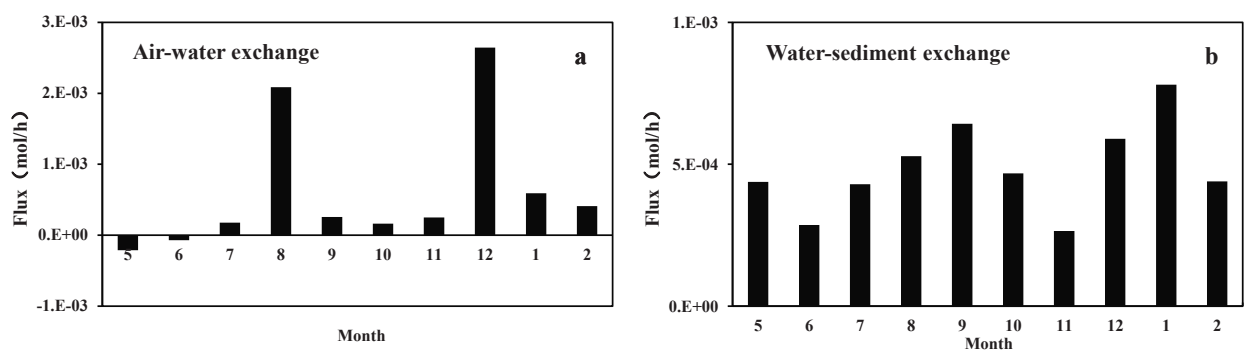

Fig. 5. $\alpha-\mathrm{HCH}$ fluxes over the air-water interface (a) and the water-sediment interface (b). The positive values indicate net inputs from air to water or from water to sediment.

The flux from the water to the sediment was $0.022 \mathrm{t} / \mathrm{a}$, and sedimentation $\left(\mathrm{T}_{24 \mathrm{~s}}\right)$ accounted for $65.49 \%$ of this flux. In addition, the flux from the sediment to the water was $0.010 \mathrm{t} / \mathrm{a}$, and diffusion flux ( $\mathrm{T}_{42 \mathrm{~d}}$ ) accounted for $73.28 \%$ of this flux. There was a net input from the water to the sediment (Figure 5). Although the sediment resuspension flux was $0.003 \mathrm{t} / \mathrm{a}$, which accounted for $26.72 \%$ of the flux from the sediment to the water, this flux still reflects the strong resuspension process in Lake Chaohu (Tu et al. 1990). In the sensitivity analysis, those parameters related to relatively important processes will always be observed with higher sensitivity (see next section). 

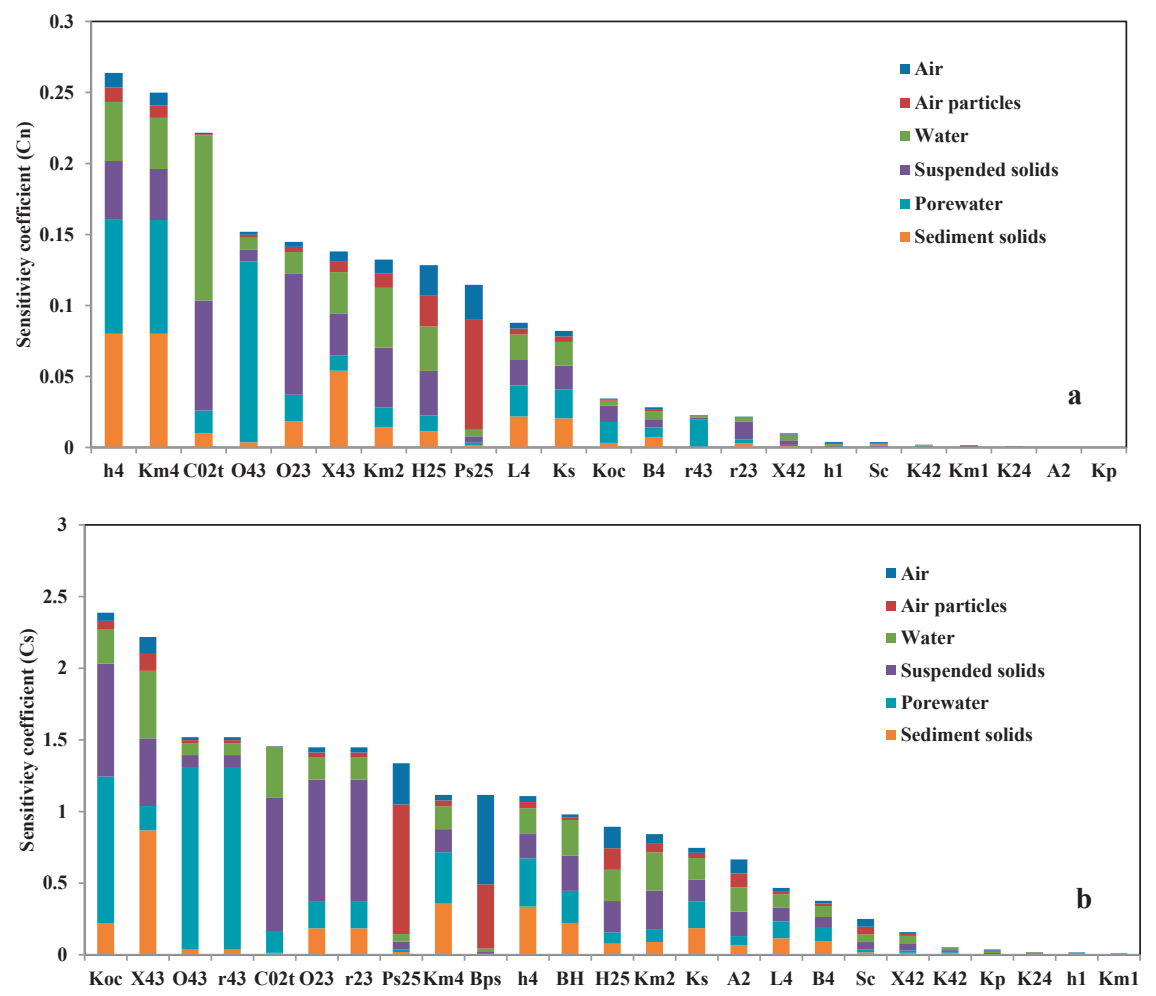

Fig. 6. Coefficients of sensitivity of the calculated concentrations of the environmental compartments to the input static parameters with $(\mathrm{Cn})(\mathrm{a})$ and without (Cs)(b) CV normalization.

\section{Sensitivity analysis}

For the static parameters, the sensitivity coefficients changed significantly after correction with the coefficients of variation (Figure 6). Thus, despite the high sensitivities regarding $\mathrm{K}_{\mathrm{oc}}, \mathrm{r}_{23}, \mathrm{r}_{43}, \mathrm{~B}_{\mathrm{ps}}, \mathrm{BH}_{\mathrm{H}}, \mathrm{A}_{2}$ and $\mathrm{Sc}$, the corrected sensitivity coefficients for those parameters with lower variability were significantly reduced, such that these eight parameters were considered to be insensitive. The sensitivity reductions in $\mathrm{K}_{\mathrm{oc}}$ and $\mathrm{A}_{2}$ were also observed by Cao et al. (2004). In contrast, due to higher variability, the sensitivity coefficients of $\mathrm{h}_{4}, \mathrm{~km}_{4}, \mathrm{~km}_{2}$ and $\mathrm{L}_{4}$ increased after correction, and they were found to be important parameters. $\mathrm{h}_{4}$ is related to sediment volume, and sediment is found as the sink for $\alpha-\mathrm{HCH}$ in lakes; $\mathrm{km} 4$ is directly related to the degradation of $\alpha-\mathrm{HCH}$ in the sediments, which has been found to be the most important degradation process in the environment (section 3.2). Thus, the two static parameters exerted considerable influence on the model results. $\mathrm{L}_{4}$ and 
Modeling $\alpha-\mathrm{HCH}$ in a phytoplankton-dominated shallow lake

$\mathrm{k}_{\mathrm{m} 2}$ become more important parameters due to their high variability. Other parameters, including $\mathrm{C}_{02 t}, \mathrm{O}_{23}, \mathrm{O}_{43}, \mathrm{X}_{43}, \mathrm{Ps}_{25}$ and $\mathrm{H}_{25}$, had relatively similar high sensitivity coefficients before and after correction. C $02 t$ strongly affects the $\alpha-\mathrm{HCH}$ content in the water and suspended matter. $\mathrm{O}_{23}$ and $\mathrm{O}_{43}$ determine the adsorption capacity of the particles in the suspended solids and sediments, while $X_{43}$ is related to the amount of sediment adsorption. Therefore, these parameters exert a great influence on the model output. Ps25 determines the fugacity capacity of the atmospheric particulates (Mackay et al. 1986), and $\mathrm{H}_{25}$ plays a decisive role on the fate of POPs in the environment (Odabasi et al. 2008). Although the variability of these two parameters is negligible, the collected values in this study are based on the results from different time periods using different methods. Therefore, the sensitivities of these two parameters remain high after the correction.

Each of the parameters has a different influence on the various environmental compartments. For example, $\mathrm{km}_{\mathrm{m}}$ has a higher sensitivity coefficient for the sediment than for the water or atmosphere, while $\mathrm{k}_{\mathrm{m}}$ has the highest sensitivity coefficient for the water. Overall, the average values of $\mathrm{Cn}$ for the air, water and sediment were $1.17 \%, 2.78 \%$ and $3.42 \%$, respectively. Although water contains the most parameters among the three main phases (Tao et al. 2006), the sediment serves as an important sink for $\alpha-\mathrm{HCH}$ and is influenced by all of the parameters to a greater extent than either the air or the water.

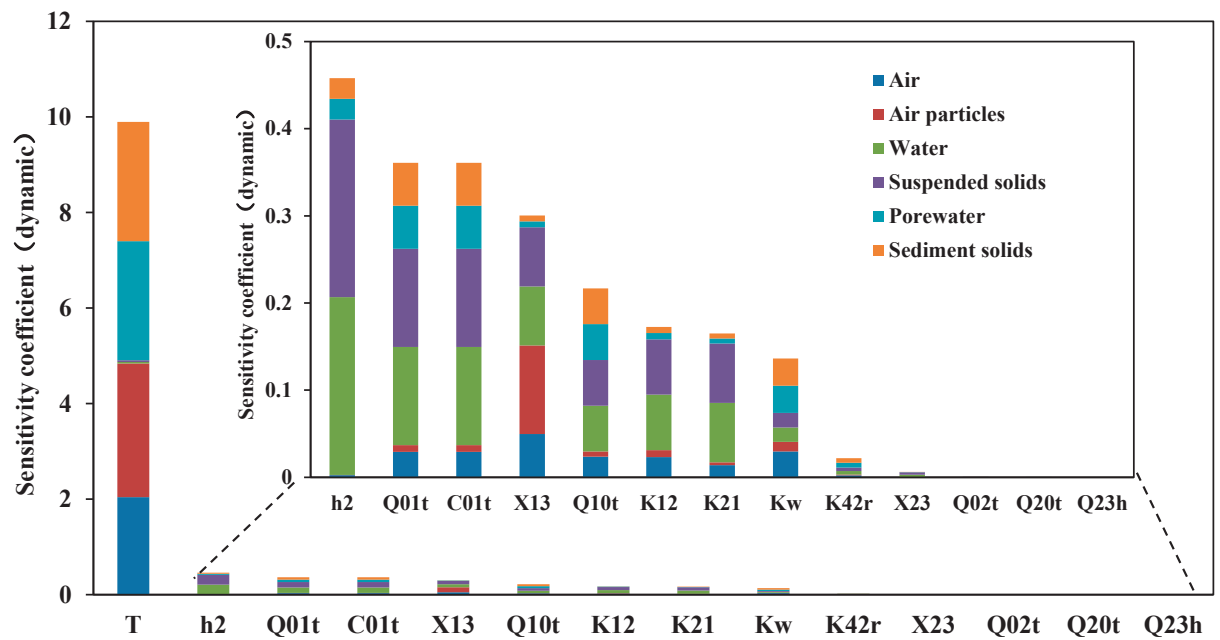

Fig. 7. Dynamic coefficients of sensitivity of the calculated concentrations of the environmental compartments to the input dynamic parameters. 
The dynamic sensitivity coefficients (SCV) are shown in Figure 7. The model output was much more sensitive to temperature $(T)$ than to the other parameters because temperature had very strong effects on $P s$ and $H$, the two important parameters in the model. Consequently, temperature played a decisive role in the distribution of $\alpha-\mathrm{HCH}$ between the gaseous and particulate phases as well as between the air and water (Walker et al. 1999). In addition, h2, $\mathrm{Q}_{011}, \mathrm{Q}_{10 t}, \mathrm{C}_{011}, \mathrm{X}_{13}, \mathrm{~K}_{12}, \mathrm{~K}_{21}$ and $\mathrm{K}_{\mathrm{w}}$ also had strong influences on the dynamic changes of the model output. h2 strongly affected the variation of $\alpha-\mathrm{HCH}$ concentrations in the water and suspended solids; $\mathrm{Q}_{011}, \mathrm{Q}_{10 t}$ and $\mathrm{C}_{01 t}$ were associated with the atmospheric advection, which was the main source of the $\alpha-\mathrm{HCH}$ in Lake Chaohu. Thus, the seasonal variations in these three parameters also had significant impacts. Cao et al.(2004) found that the parameters related to source and degradation in the fugacity model were relatively more important, which was consistent with the relatively high sensitivities of $\mathrm{Q}_{011}, \mathrm{Q}_{10 \mathrm{t}}, \mathrm{C}_{011}, \mathrm{k}_{\mathrm{m}}$ and $\mathrm{km}_{\mathrm{m}}$. $\mathrm{X}_{13}$ had a relatively strong influence on the seasonal changes in the concentration in the atmosphere and the water bodies as well as the particulate and suspended matter content, which is in agreement with the conclusion of the Pearl River Delta study (Lang et al. 2007); $K_{12}, K_{21}$ and $K_{w}$ were the main parameters influencing the air-water interface flux due to their direct impacts and significant seasonal variations, and these three parameters are also important parameters generally. In addition, due to the insignificant effect of water inflows on the model, parameters such as Q02t, $\mathrm{Q}_{20 t}$ and $\mathrm{Q}_{23 \mathrm{~h}}$ had little effect on the variability of the model output. Without considering the biological phase, the importance of $X_{23}$ was also reduced. The low sensitivity coefficient of $\mathrm{K}_{42 \mathrm{r}}$ was due to the corresponding low resuspension flux.

\section{Uncertainty analysis}

The results of the uncertainty analysis for each phase are shown in Figure 8. It was found that the uncertainty of the model was relatively small from May to September, as represented by the small semi-interquartile ranges of the Monte Carlo simulation results. The uncertainty of the model output began to increase in October and peaked in December or January. This increase was attributed to our finding that from October to December, the coefficients of variation in the gas-water diffusion rate $\left(K_{12}\right.$ and $\left.K_{21}\right)$ significantly increased, leading to an increase of variation in the air-water diffusion flux. This also contributed to a significant increase in the uncertainty of the other phases. Lang et al. (2007) similarly found that the coefficient of variability of diffusion is associated with wide variability in the gaseous PAHs concentrations. The 
Modeling $\alpha-\mathrm{HCH}$ in a phytoplankton-dominated shallow lake

rates of diffusion across the gas-water interface $\left(\mathrm{K}_{12}\right.$ and $\left.\mathrm{K}_{21}\right)$ were related to wind speed and water depth, and the coefficient of variation of water depth $\left(\mathrm{h}_{2}\right)$ did not increase during October-December. It can be speculated that elevated variation in the wind speed in this period causes the increasing uncertainty.
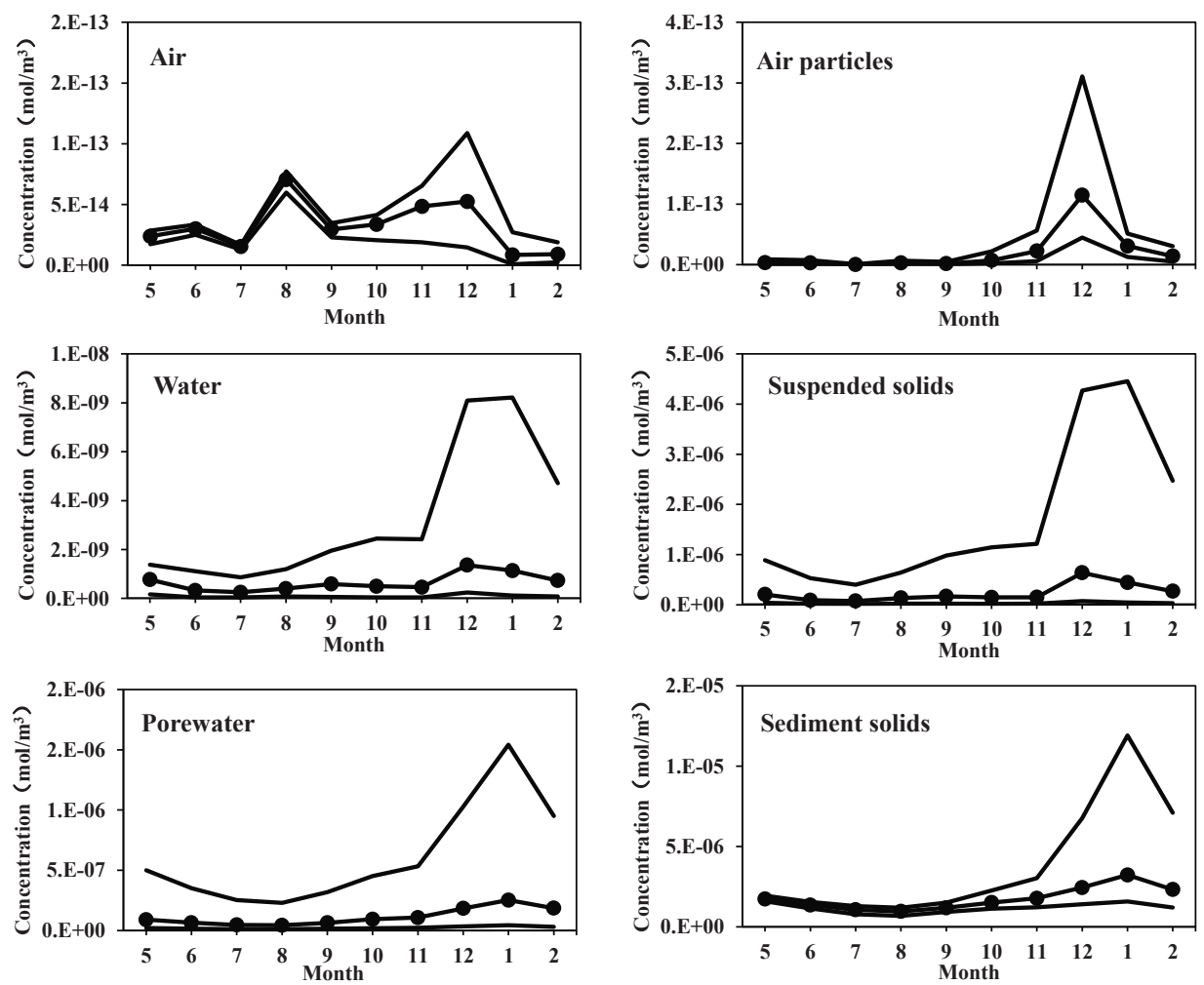

Fig. 8. Uncertainties of the predicted seasonal variations of $\alpha-\mathrm{HCH}$ concentrations in the air, water and sediment. The results are presented as median values (lines with dots) and semi-quartile ranges (solid lines).

\section{Conclusion}

A dynamic Quantitative Water, Air, and Sediment Interaction (QWASI) fugacity model was utilized to simulate the fate and seasonal variation of $\alpha$ $\mathrm{HCH}$ in the air, water and sediment, as well as various environmental fluxes in Lake Chaohu. The calculated and measured values of the model were in good agreement. However, disregarding the effects of aquatic organisms resulted in large deviations between the simulated and measured values of $\alpha-\mathrm{HCH}$ in 
suspended solids in water. The major source of $\alpha-\mathrm{HCH}$ in Lake Chaohu was input from atmospheric advection, while the major environmental outputs were atmospheric advection and sediment degradation. The net annual input of $\alpha-\mathrm{HCH}$ into the lake area was approximately $0.294 \mathrm{t}$, while the net output was approximately 0.412 t. The factors leading to the seasonal variations of $\alpha$ $\mathrm{HCH}$ in various compartments were revealed. For the fluxes at the air-water interface, atmospheric inputs into the water were dominant for most of the year with the deposition processes included, while the water and sediment interface was mainly influenced by the net input from the water to the sediment. Thus, sediment is an important sink for $\alpha-\mathrm{HCH}$. Sensitivity analysis found that parameters of source and degradation were more important than the other parameters. The sediment was influenced more by the combined effects of the various parameters than air and water were. In addition, temperature variation had a much greater impact on the dynamics of the model output than other dynamic parameters. Uncertainty analysis showed that the model uncertainty was relatively low, especially in the first half of the simulation period. Due to the increase in the gas-water diffusion flux variability, uncertainty of the model significantly increased for all of the compartments.

\section{Acknowledgments}

Funding for this study was provided by the National Foundation for Distinguished Young Scholars (40725004), the National Science Foundation of China (NSFC) (41030529, 41271462), and the National Project for Water Pollution Control (2012ZX07103-002). 
Modeling $\alpha-\mathrm{HCH}$ in a phytoplankton-dominated shallow lake

\section{Supplementary materials}

Table S1 Environmental parameters for the model

\begin{tabular}{|c|c|c|c|c|c|c|c|c|}
\hline Symbol & Unit & Parameters & Reference & $\begin{array}{c}\text { Data } \\
\text { Numbers }\end{array}$ & $\begin{array}{l}\text { Allocate } \\
\text { mean }\end{array}$ & $\begin{array}{l}\text { Allocate } \\
\text { SD }\end{array}$ & $\begin{array}{c}\text { Geometric } \\
\text { mean }\end{array}$ & $\begin{array}{c}\text { cGeometric } \\
\text { SD }\end{array}$ \\
\hline$\overline{\mathrm{A}_{2}}$ & $\mathrm{~m}^{2}$ & Interface areas of air/water & 1,2 & 2 & $7.58 \mathrm{E}+08$ & $2.69 \mathrm{E}+06$ & $7.58 \mathrm{E}+08$ & $1.00 \mathrm{E}+00$ \\
\hline $\mathrm{h}_{1}$ & $\mathrm{~m}$ & Thickness of air & 1 & 1 & $1.00 \mathrm{E}+02$ & $-\mathrm{b}$ & $1.00 \mathrm{E}+02$ & $1.00 \mathrm{E}+00$ \\
\hline $\mathrm{h}_{2^{\mathrm{a}}}$ & $\mathrm{m}$ & Depth of water & 3 & - & - & - & - & - \\
\hline $\mathrm{h}_{4}$ & $\mathrm{~m}$ & Thickness of sediment & 1 & 1 & $1.00 \mathrm{E}-01$ & $-b$ & $1.00 \mathrm{E}-01$ & $5.78 \mathrm{E}-01$ \\
\hline$X_{13^{2}}, X_{23}$ & $\mathrm{v} / \mathrm{v}$ & $\begin{array}{l}\text { Volume fractions of solids } \\
\text { in air and water }\end{array}$ & 4 , Note A & - & - & - & - & - \\
\hline $\mathrm{X}_{43}$ & $\mathrm{v} / \mathrm{v}$ & $\begin{array}{l}\text { Volume fractions of solids } \\
\text { in sediment }\end{array}$ & 4 & 1 & $3.00 \mathrm{E}-01$ & $-b$ & 3.00E-01 & $1.08 \mathrm{E}+00$ \\
\hline $\mathrm{X}_{42}$ & $\mathrm{v} / \mathrm{v}$ & $\begin{array}{l}\text { Volume fractions of water } \\
\text { in sediment }\end{array}$ & 4 & 1 & 7.00E-01 & $-b$ & 7.00E-01 & $1.02 \mathrm{E}+00$ \\
\hline $\mathrm{O}_{23}$ & $\%$ & $\begin{array}{l}\text { Contents of organic carbon } \\
\text { in solids in water }\end{array}$ & 4 & 1 & 1.67E-01 & $-b$ & 1.67E-01 & $1.20 \mathrm{E}+00$ \\
\hline $\mathrm{O}_{43}$ & $\%$ & $\begin{array}{l}\text { Contents of organic carbon } \\
\text { in solids in sediment }\end{array}$ & $\begin{array}{c}1,2,5 \\
\text { Note A }\end{array}$ & 61 & 5.27E-03 & 2.92E-03 & 4.61E-03 & $1.72 \mathrm{E}+00$ \\
\hline$\rho_{23}$ & $\mathrm{t} / \mathrm{m}^{3}$ & Densities of solids in water & 1 & 1 & $1.50 \mathrm{E}+00$ & $-b$ & $1.50 \mathrm{E}+00$ & $1.06 \mathrm{E}+00$ \\
\hline$\rho 43$ & $\mathrm{t} / \mathrm{m}^{3}$ & $\begin{array}{l}\text { Densities of solids in } \\
\text { sediment }\end{array}$ & 1 & 1 & $2.76 \mathrm{E}+00$ & $-b$ & $2.76 \mathrm{E}+00$ & $1.16 \mathrm{E}+00$ \\
\hline $\mathrm{Q}_{01 t^{\mathrm{a}}}, \mathrm{Q}_{10 \mathrm{t}^{\mathrm{a}}}$ & $\mathrm{m}^{3} / \mathrm{h}$ & $\begin{array}{l}\text { Air advection flow in and } \\
\text { out of the area }\end{array}$ & Calculated & - & - & - & - & - \\
\hline $\mathrm{Q}_{02 \mathrm{t}^{\mathrm{a}}}, \mathrm{Q}_{20 \mathrm{t}^{\mathrm{a}}}$ & $\mathrm{m}^{3} / \mathrm{h}$ & $\begin{array}{l}\text { Water advection flow in } \\
\text { and out of the area }\end{array}$ & Calculated & - & - & - & - & - \\
\hline $\mathrm{Q}_{02 \mathrm{~h}^{\mathrm{a}}}$ & $\mathrm{m}^{3} / \mathrm{h}$ & $\begin{array}{l}\text { Rate of local wastewater } \\
\text { discharge }\end{array}$ & 1 & - & - & - & - & - \\
\hline $\mathrm{C}_{1}^{\mathrm{a}}$ & $\mathrm{mol} / \mathrm{m}^{3}$ & $\begin{array}{l}\alpha-\mathrm{HCH} \text { concentration in } \\
\text { air }\end{array}$ & Note A & - & - & - & - & - \\
\hline $\mathrm{C}_{02 \mathrm{t}}$ & $\mathrm{mol} / \mathrm{m}^{3}$ & $\begin{array}{l}\alpha-\mathrm{HCH} \text { concentration in } \\
\text { water advection flow }\end{array}$ & 1,6 & 1 & $1.34 \mathrm{E}-08$ & $-b$ & $1.34 \mathrm{E}-08$ & $1.63 \mathrm{E}+00$ \\
\hline $\mathrm{C}_{02 \mathrm{~h}}$ & $\mathrm{~mol} / \mathrm{m}^{3}$ & $\begin{array}{l}\alpha-\mathrm{HCH} \text { concentration in } \\
\text { wastewater }\end{array}$ & 1 & 1 & $1.56 \mathrm{E}-08$ & $-b$ & $1.56 \mathrm{E}-08$ & $1.82 \mathrm{E}+00$ \\
\hline $\mathrm{T}^{\mathrm{a}}$ & K & Local average temperature & 7 & - & - & - & - & - \\
\hline
\end{tabular}

References:

[1]Tu, 1990; [2]Yin, 2011; [3] AHTIS (http://61.191.22.154/yc web/yc index frame.aspx). [4] Mackay, 2001; [5] Zhou et al., 2007; [6] Zhang, 2009. [7] CMDSSS (http://www.cma.gov.cn/2011qxfw/2011qsigx/index.htm) .

Note A: Measured in Laboratory.

a dynamic parameters (Values not shown)

${ }^{\mathrm{b}}$ One value only; Geometric SD assigned manually (Log-normal distribution assumed)

1) Tu, Q.Y., Gu, D.X., Yi, C.Q., Xu, Z.R., Han, G.Z., 1990. The Researches on the Lake Chaohu Eutrophication. , Publisher of University of Science and Technology of China, Hefei (in Chinese).

2) Yin, F.C., 2011. A study on evaluation and control instruments of Chao lake eutrophication, China Environmental Science Press Beijing (in Chinese).

3) Anhui Hydrological Telemetry Information System (AHTIS), 2010-2011. Hourly water level report. http://61.191.22.154/yc_web/yc index frame.aspx 


\section{Chapter 3}

4) Mackay, D., 2001. Multimedia Environmental Models: The Fugacity Approach, second ed., Lewis Publishers, NewYork, USA.

5) Zhou, Z.H., Liu, C.Q., Li, J., Zhu, Z.Z., 2007. Record of ecosystem evolvement processes provided by 813 Corg and $\delta 15 \mathrm{~N}$ Values in Chaohu Lake sediments, Environmental Science, 28, 1338-1343 (in Chinese).

6) Zhang, M., 2009. Distribution characteristic and assessment of typical persistent organic pollutions-Organochlorine pesticides in water of Chaohu Lake watershed. Anhui Agriculture University, Hefei (in Chinese).

7) China Meteorological Data Sharing Service System (CMDSSS), 2010-2011. Daily Meteorological Data. http://www.cma.gov.cn/2011qxfw/2011qsjgx/index.htm 
Modeling $\alpha-\mathrm{HCH}$ in a phytoplankton-dominated shallow lake

Table S2 Mass transfer kinetic and physical-chemical parameters for the model

\begin{tabular}{|c|c|c|c|c|c|c|c|c|}
\hline \multicolumn{2}{|c|}{ SymbolUnit } & \multirow{2}{*}{$\begin{array}{l}\text { Parameters } \\
\text { Local vapor } \\
\text { pressure }\end{array}$} & \multirow{2}{*}{$\frac{\text { Reference }}{1-6}$} & \multirow{2}{*}{$\begin{array}{c}\begin{array}{c}\text { Data } \\
\text { Numbers }\end{array} \\
6\end{array}$} & \multirow{2}{*}{$\begin{array}{l}\begin{array}{l}\text { Allocate } \\
\text { mean }\end{array} \\
4.92 \mathrm{E}-02\end{array}$} & \multirow{2}{*}{$\begin{array}{l}\begin{array}{l}\text { Allocate } \\
\text { SD }\end{array} \\
1.08 \mathrm{E}-01\end{array}$} & \multicolumn{2}{|c|}{$\begin{array}{l}\text { Geometric Geometric } \\
\text { mean } \quad \text { SD }\end{array}$} \\
\hline Ps & $\mathrm{Pa}$ & & & & & & 9.01E-03 & $1.50 \mathrm{E}+00$ \\
\hline $\mathrm{R}$ & $\begin{array}{l}\mathrm{Pa} \cdot \mathrm{m}^{3} / \mathrm{mol} \cdot \\
\mathrm{K}\end{array}$ & The gas constant & 1 & 1 & $8.31 \mathrm{E}+00$ & $0.00 \mathrm{E}+00$ & $8.31 \mathrm{E}+00$ & $1.00 \mathrm{E}+00$ \\
\hline $\mathrm{F}_{25}$ & - & $\begin{array}{l}\text { Fugacity ratio at } \\
25^{\circ} \mathrm{C}\end{array}$ & 7 & 1 & $1.21 \mathrm{E}-02$ & $-b$ & $1.21 \mathrm{E}-02$ & $1.00 \mathrm{E}+00$ \\
\hline $\mathrm{H}$ & $\mathrm{Pa} \cdot \mathrm{m}^{3} / \mathrm{mol}$ & $\begin{array}{l}\text { Henry's constant } \\
\text { Fugacity ratio }\end{array}$ & $1,3,5,6$ & 4 & $6.12 \mathrm{E}-01$ & 4.18E-02 & $6.11 \mathrm{E}-01$ & $1.07 \mathrm{E}+00$ \\
\hline $\mathrm{BF}_{\mathrm{F}}$ & - & $\begin{array}{l}\text { temperature } \\
\text { correction factor } \\
\text { Henry's law }\end{array}$ & 7 & 1 & $1.62 \mathrm{E}+03$ & $-\mathrm{b}$ & $1.62 \mathrm{E}+03$ & $1.00 \mathrm{E}+00$ \\
\hline $\mathrm{B}_{\mathrm{H}}$ & - & $\begin{array}{l}\text { constant } \\
\text { temperature } \\
\text { correction factor }\end{array}$ & 7 & 1 & $1.71 \mathrm{E}+03$ & $-b$ & $1.71 \mathrm{E}+03$ & $1.00 \mathrm{E}+00$ \\
\hline BPs & - & $\begin{array}{l}\text { Saturation vapor } \\
\text { pressure } \\
\text { temperature } \\
\text { correction factor }\end{array}$ & 7 & 1 & $4.95 \mathrm{E}+03$ & $-b$ & $4.95 \mathrm{E}+03$ & $1.00 \mathrm{E}+00$ \\
\hline Кос & $\mathrm{m}^{3} / \mathrm{t}, 1 / \mathrm{h}$ & $\begin{array}{l}\text { Adsorption } \\
\text { coefficient }\end{array}$ & $1,3,5$ & 3 & $1.69 \mathrm{E}+03$ & $1.86 \mathrm{E}+02$ & $1.68 \mathrm{E}+03$ & $1.11 \mathrm{E}+00$ \\
\hline $\mathrm{K}_{\mathrm{m} 1}$ & - & $\begin{array}{l}\text { Degradation rate } \\
\text { of } \alpha-\mathrm{HCH} \text { in air }\end{array}$ & $1,2,5,8,9$ & 4 & $2.43 \mathrm{E}-03$ & $3.70 \mathrm{E}-03$ & 1.09E-03 & $3.86 \mathrm{E}+00$ \\
\hline $\mathrm{K}_{\mathrm{m} 2}$ & - & $\begin{array}{l}\text { Degradation rate } \\
\text { of } \alpha-\mathrm{HCH} \text { in water }\end{array}$ & $1,2,5,10$ & 4 & 3.17E-04 & 3.33E-04 & 2.18E-04 & $2.63 \mathrm{E}+00$ \\
\hline $\mathrm{K}_{\mathrm{m} 4}$ & - & $\begin{array}{l}\text { Degradation rate } \\
\text { of } \alpha-\mathrm{HCH} \text { in } \\
\text { sediment }\end{array}$ & $1,2,3,5,10$ & 5 & 4.87E-04 & 7.37E-04 & $1.22 \mathrm{E}-04$ & $5.52 \mathrm{E}-01$ \\
\hline $\mathrm{B}_{1}$ & $\mathrm{~m}^{2} / \mathrm{h}$ & $\begin{array}{l}\text { Molecular } \\
\text { diffusivities in air } \\
\text { Molecular }\end{array}$ & $2,10,11,12$ & 4 & 2.49E-02 & $1.03 \mathrm{E}-02$ & 2.36E-02 & $1.44 \mathrm{E}+00$ \\
\hline $\mathrm{B}_{2}$ & $\mathrm{~m}^{2} / \mathrm{h}$ & $\begin{array}{l}\text { diffusivities in } \\
\text { water }\end{array}$ & $2,10,11,12$ & 4 & $2.86 \mathrm{E}-06$ & 1.17E-06 & 2.68E-06 & $1.54 \mathrm{E}+00$ \\
\hline $\mathrm{B}_{4}$ & $\mathrm{~m}^{2} / \mathrm{h}$ & $\begin{array}{l}\text { Molecular } \\
\text { diffusivities in } \\
\text { sediment } \\
\text { Air-side molecular }\end{array}$ & 2,12 & 2 & $1.43 \mathrm{E}-05$ & $1.09 \mathrm{E}-05$ & $1.20 \mathrm{E}-05$ & $2.34 \mathrm{E}+00$ \\
\hline $\mathrm{K}_{12^{\mathrm{a}}}$ & $\mathrm{m} / \mathrm{h}$ & $\begin{array}{l}\text { transfer coefficient } \\
\text { over water } \\
\text { Water-side }\end{array}$ & Calculated & - & - & - & - & - \\
\hline $\mathrm{K}_{21^{\mathrm{a}}}$ & $\mathrm{m} / \mathrm{h}$ & $\begin{array}{l}\text { molecular transfer } \\
\text { coefficient over air } \\
\text { Water-side }\end{array}$ & Calculated & - & - & - & - & - \\
\hline $\mathrm{K}_{24}$ & $\mathrm{~m} / \mathrm{h}$ & $\begin{array}{l}\text { Water-side } \\
\text { molecular transfer } \\
\text { coefficient over } \\
\text { sediment }\end{array}$ & 2 & 1 & $1.00 \mathrm{E}-02$ & $-b$ & $1.00 \mathrm{E}-02$ & $1.17 \mathrm{E}+00$ \\
\hline $\mathrm{K}_{42}$ & $\mathrm{~m} / \mathrm{h}$ & $\begin{array}{l}\text { Water-side } \\
\text { molecular transfer }\end{array}$ & 10,14 & 1 & $\begin{array}{l}5.39415 \mathrm{E}- \\
06\end{array}$ & $-b$ & 5.39E-06 & $1.52 \mathrm{E}+00$ \\
\hline
\end{tabular}


Chapter 3

\begin{tabular}{|c|c|c|c|c|c|c|c|c|}
\hline $\mathrm{K}_{42 \mathrm{r}^{\mathrm{a}}}$ & $\mathrm{m} / \mathrm{h}$ & $\begin{array}{l}\text { coefficient over } \\
\text { sediment } \\
\text { Sediment } \\
\text { resuspension rate } \\
\text { Diffusion path }\end{array}$ & Calculated & - & - & - & - & - \\
\hline $\mathrm{L}_{4}$ & $\mathrm{~m}$ & $\begin{array}{l}\text { lengths in } \\
\text { sediment }\end{array}$ & 2 & 2 & $3.50 \mathrm{E}-02$ & 2.12E-02 & $3.16 \mathrm{E}-02$ & $1.91 \mathrm{E}+00$ \\
\hline$K_{P}$ & $\mathrm{~m} / \mathrm{h}$ & $\begin{array}{l}\text { Dry deposition } \\
\text { velocity }\end{array}$ & 2,10 & 2 & $1.04 \mathrm{E}+01$ & $5.66 \mathrm{E}-01$ & $1.04 \mathrm{E}+01$ & $1.06 \mathrm{E}+00$ \\
\hline Ks & $\mathrm{m} / \mathrm{h}$ & $\begin{array}{l}\text { Water } \\
\text { sedimentation } \\
\text { rates }\end{array}$ & 14,15 & 5 & $3.62 \mathrm{E}-06$ & $4.34 \mathrm{E}-06$ & $1.66 \mathrm{E}-06$ & $4.32 \mathrm{E}+00$ \\
\hline $\mathrm{K}_{w^{a}}$ & $\mathrm{~m} / \mathrm{h}$ & $\begin{array}{l}\text { Wet deposition } \\
\text { velocity }\end{array}$ & 16 & - & - & - & - & - \\
\hline $\mathrm{S}_{\mathrm{c}}$ & - & Scavenging Ratio & 2,10 & 2 & $1.34 \mathrm{E}+05$ & $9.33 \mathrm{E}+04$ & $1.17 \mathrm{E}+05$ & $2.14 \mathrm{E}+00$ \\
\hline
\end{tabular}

References: [1] Cao,et al., 2007; [2]Mackay D., 2001; [3] Cao et al., 2003; [4]Cao et al., 2005; [5]Ao et al., 2009; [6]Dong et al., 2009; [7] Paasivirta et al.,1999; [8] Prinn et al., 2001; [9] Brubaker et al., 1998; [10] Breivik and Wania., 2002; [11] Mackay and Patterson, 1991; [12] Cao et al., 2004; [13]Tu, 1990; [14] Gu, 2007;[15] CDMSSS （http://www.cma.gov.cn/2011qxfw/2011qsjgx/index.htm）.

a dynamic parameters (Values not shown)

b One value only; Geometric SD assighed manually (Log-normal distribution assumed)

1) Cao, H.Y., Liang, T., Tao, S., Zhang, C. S., 2007. Simulating the temporal changes of OCP pollution in Hangzhou, China. Chemosphere, 67, 1335-1345,.

2) Mackay, D., 2001. Multimedia Environmental Models: The Fugacity Approach, second ed., Lewis Publishers, NewYork, USA.

3) Cao, H.Y., Cao, J., Xu, F.L., Li, B.G., 2003. Fate and transfer flux of HCHs in Tianjin," Environmental Chemistry, 22, 548-554 (in Chinese).

4) Cao, H.Y., Liang, T., Tao, S., 2005. Dynamic simulation and prediction of BHC transfer and residues in Beijing during 50 years. SCIENCE IN CHINA Ser. D Earth Sciences, 35, 980-988 (in Chinese).

5) Ao, J.T., Chen, J.W., Tian, F.L., Cai, X.Y., 2009. Application of a level IV fugacity model to simulate the long-term fate of hexachlorocyclohexane isomers in the lower reach of Yellow River basin, China. Chemosphere, 74, 370-376.

6) Dong, J.Y., Gao, H., Wang, S.G., Yao H.J., Ma, M.Q., 2009. Simulation of the transfer and fate of HCHs since the 1950s in Lanzhou, China. Ecotoxicology and Environmental Safety, 72, 1950-1956.

7) Paasivirta, J., Sinkkonen, S., Mikkelson, P., Rantio T., Wania, F., 1999. Estimation of vapor pressures, solubilities and Henry's law constants of selected persistent organic pollutants as functions of temperature. Chemosphere, $39,811-832$. 
Modeling $\alpha-\mathrm{HCH}$ in a phytoplankton-dominated shallow lake

8) Prinn, R.G. et al., 2001. Evidence for substantial variations of atmospheric hydroxyl radicals in the past two decades. Science, 292, 1882-1888.

9) Brubaker, W.W., Hites, R.A., 1998. OH reaction kinetics of gas-phase alphaand gamma-hexachlorocyclohexane and hexachlorobenzene," Environmental Science \& Technology, 32, 766-769.

10) Breivik, K., Wania, F., 2002. Evaluating a model of the historical behavior of two hexachlorocyclohexanes in the Baltic sea environment, Environmental Science \& Technology, 36. 1014-1023.

11) Mackay, D., Paterson, S., 1991. Evaluating the multimedia fate of organicchemicals - a Level-III fugacity model, Environmental Science \& Technology, 25, 427-436.

12) Cao, H. Y. et al., 2004. Multimedia fate model for Hexachlorocyclohexane in Tianjin, China, Environmental Science \& Technology, 38, 2126-2132.

13) Tu, Q.Y., Gu, D.X., Yi, C.Q., Xu, Z.R., Han, G.Z., 1990. The researches on the Lake Chaohu eutrophication. Publisher of University of Science and Technology of China, Hefei (in Chinese).

14) Gu, C.J., 2005. Historical sedimentary records and environmental changes in Chaohu lake. East China Normal University, Shanghai.

15) China Meteorological Data Sharing Service System (CMDSSS), 2010-2011. Daily Meteorological Data.

http://www.cma.gov.cn/2011qxfw/2011qsigx/index.htm 
Chapter 3

Table S3 Definitions of the transfer and transformation processes

\begin{tabular}{|c|c|c|}
\hline Symbol & Formula & Explanation \\
\hline \multicolumn{3}{|c|}{ System input: } \\
\hline $\mathrm{T}_{01 \mathrm{t}}$ & $\mathrm{Q}_{01 \mathrm{t}} \times \mathrm{C}_{01 \mathrm{t}}$ & Air advection flows into the area \\
\hline $\mathrm{T}_{02 \mathrm{t}}$ & $\mathrm{Q}_{02 t} \times \mathrm{C}_{02 t}$ & Water advection flows into the area \\
\hline $\mathrm{T}_{02 \mathrm{~h}}$ & $\mathrm{Q}_{02 \mathrm{~h}} \times \mathrm{C}_{02 \mathrm{~h}}$ & Locative wastewater discharge \\
\hline \multicolumn{3}{|c|}{ System output: } \\
\hline $\mathrm{T}_{10 \mathrm{t}}$ & $D_{10 t} \times f_{1}$ & Air advection flows out of the area \\
\hline $\mathrm{T}_{20 \mathrm{t}}$ & $\mathrm{D}_{20 \mathrm{t}} \times \mathrm{f}_{2}$ & Water advection flows out of the area \\
\hline $\mathrm{T}_{10 \mathrm{~m}}$ & $D_{10 m} \times f_{1}$ & Degradation in air \\
\hline $\mathrm{T}_{20 \mathrm{~m}}$ & $\mathrm{D}_{20 \mathrm{~m}} \times \mathrm{f}_{2}$ & Degradation in water \\
\hline $\mathrm{T}_{40 \mathrm{~m}}$ & $\mathrm{D}_{40 \mathrm{~m}} \times \mathrm{f}_{4}$ & Degradation in sediment \\
\hline $\mathrm{T}_{23 \mathrm{~h}}$ & $\mathrm{D}_{23 \mathrm{~h}} \times \mathrm{f}_{2}$ & Industry and agriculture water usage \\
\hline \multicolumn{3}{|c|}{ Air-water transfer: } \\
\hline $\mathrm{T}_{12 \mathrm{~d}}$ & $D_{12 d} \times f_{1}$ & Diffusion from air to water \\
\hline $\mathrm{T}_{21 \mathrm{~d}}$ & $\mathrm{D}_{21 \mathrm{~d}} \times \mathrm{f}_{2}$ & Diffusion from water to air \\
\hline $\mathrm{T}_{12 \mathrm{p}}$ & $D_{12 p} \times f_{1}$ & Dry deposition from air to water \\
\hline $\mathrm{T}_{12 \mathrm{w}}$ & $\mathrm{D}_{12 \mathrm{w}} \times \mathrm{f}_{1}$ & Wet deposition from air to water \\
\hline $\mathrm{T}_{12 \mathrm{r}}$ & $D_{12 r} \times f_{1}$ & Rain scavenging \\
\hline \multicolumn{3}{|c|}{ Water-sediment transfer } \\
\hline $\mathrm{T}_{24 \mathrm{~d}}$ & $\mathrm{D}_{24 \mathrm{~d}} \times \mathrm{f}_{2}$ & Diffusion from water to sediment \\
\hline $\mathrm{T}_{42 \mathrm{~d}}$ & $\mathrm{D}_{42 \mathrm{~d}} \times \mathrm{f}_{4}$ & Diffusion from sediment to water \\
\hline $\mathrm{T}_{24 \mathrm{~s}}$ & $\mathrm{D}_{244} \times \mathrm{f}_{2}$ & Sedimentation from water to sediment \\
\hline $\mathrm{T}_{42 \mathrm{r}}$ & $\mathrm{D}_{42 \mathrm{r}} \times \mathrm{f}_{4}$ & Resuspension from sediment to water \\
\hline
\end{tabular}




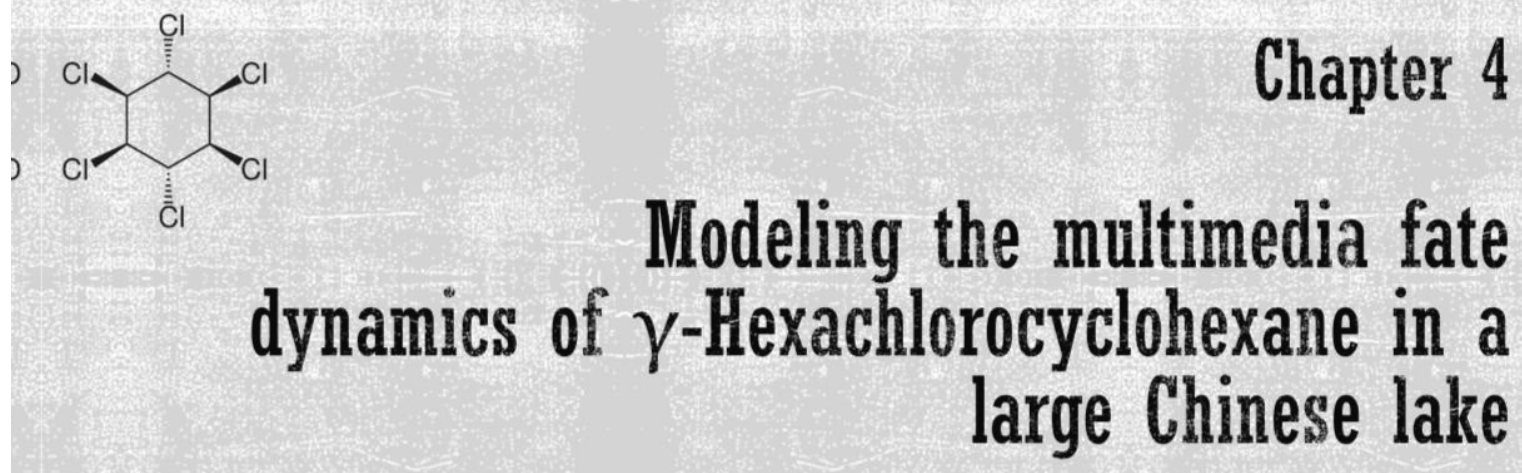

Xiangzhen Kong, Wei He, Ning Qin, Qishuang He, Bin Yang, Huiling Ouyang, Qingmei Wang, Chen Yang, Yujiao Jiang, Fuliu Xu

Published in Ecological Indicators (2014) 41, 65-74 
Chapter 4

\section{Abstract}

Long-term annual dynamics from 1984-2020 (simulation \#1) and seasonal variation from May 2010 to February 2011 (simulation \#2) of $\gamma$ Hexachlorocyclohexane $(\gamma-\mathrm{HCH})$ in various environmental media in Lake Chaohu, China was simulated with a previous developed fugacity-based level IV Quantitative Water Air Sediment Interaction (QWASI) model (Kong et al. 2012). The model was modified as a fish sub-phase was included. Also the emission flux was added to study the impact of the lindane prohibition in simulation \#1. Sensitivity analysis was conducted for both static and dynamic parameters, while in uncertainty analysis, both basic Monte Carlo and Bayesian Markov Chain Monte Carlo (MCMC) method were undertaken for simulation \#2 and the results were compared. Simulated data were consistent with the observations in simulation \#1. Seasonal patterns in various media were also successfully modeled in simulation $\# 2$ and factors leading to this seasonality were discussed. Atmospheric advection input was the main source. In simulation \#2, approximately 36 kilogram $(\mathrm{kg})$ of $\gamma-\mathrm{HCH}$ in Lake Chaohu was removed per year. In addition, $31 \mathrm{~kg}$ of $\gamma-\mathrm{HCH}$ was added to Lake Chaohu by air-water interface fluxes, and $13 \mathrm{~kg}$ of $\gamma-\mathrm{HCH}$ was added to the sediment by water-sediment interface. Sensitivity of static and dynamic parameters was discussed. Uncertainty analysis by the basic Monte Carlo method for simulation \#1 showed that the dispersion for each media was less than two orders of magnitude. Higher dispersions in fish and two sub-phases of the sediment were attributed to a larger variation in the relevant parameters. The MCMC method for simulation $\# 2$ eliminated $77 \%$ of the model true uncertainty in water ascertained by basic Monte Carlo method and significant elimination in other phases can be speculated. It is suggested that rather than calibrating the model, the main function of the MCMC for fugacity model should be to avoid overestimating uncertainty in model prediction. 
Modeling $\gamma-\mathrm{HCH}$ in a phytoplankton-dominated shallow lake

\section{Introduction}

Hexachlorocyclohexane $(\mathrm{HCH})$ isomers $(\alpha-, \beta$ - and $\gamma-\mathrm{HCH})$ were recently added to the list of persistent organic pollutants (POPs) at the Stockholm Convention (Vijgen et al. 2011). The isomer of $\gamma-\mathrm{HCH}$ is one of the main ingredients for the technical $\mathrm{HCH}$ (containing $10-15 \% \gamma-\mathrm{HCH}$ ), and the absolute ingredient of lindane (containing more than $99.9 \% \gamma-\mathrm{HCH}$ ). The ratios of $\alpha-\gamma-\mathrm{HCH}$ and $\beta-/(\alpha+\gamma)-\mathrm{HCH}$ are frequently used as the indicators to identify the source of the HCHs (Iwata et al., 1993, 1995; Walker et al., 1999; Law et al., 2001; Liu et al., 2012, 2013; Ouyang et al., 2012, 2013; Xu et al., 2013). For technical HCHs, the ratios of $\alpha-\gamma-\mathrm{HCH}$ and $\beta-/(\alpha+\gamma)-\mathrm{HCH}$ are approximately 4-7 and 0.06-0.17, respectively; while for lindane, the ratios of $\alpha$ $/ \gamma-\mathrm{HCH}$ and $\beta-/(\alpha+\gamma)-\mathrm{HCH}$ are less than 0.1 and 0.06 , respectively (Iwata et al., 1993, 1995; Walker et al., 1999). Additionally, the $\alpha / \gamma-\mathrm{HCH}$ ratio can serve as an indicator to identify the atmospheric source of $\mathrm{HCHs}$, since $\alpha-\mathrm{HCH}$ with the high vapor pressures is the main isomer in the air and could be transported for long distances (Iwata et al., 1993, 1995; Walker et al., 1999).

In China, there was extensive use of technical HCHs from 1953 until 1983 (Li et al. 2001), when lindane began to be applied instead, and HCHs were totally prohibited by the government in 1992 (Tao et al., 2006). Anhui Province, where Lake Chaohu is located, was among the regions with the highest usage of pesticides in China (Cai 2010). The application rate of technical HCHs in Anhui was close to Jiangxi Province, with a total usage of nearly 200 kilotons between 1952 and 1984 (Li et al. 2001). High levels of HCHs could persist in the environment under such intensive application, but $\mathrm{HCH}$ residue has been decreasing rapidly since its prohibition. It has been reported that the levels of $\mathrm{HCHs}$ in the topsoil in Anhui have dropped from $0.349 \mathrm{mg} / \mathrm{kg}$ (Xia et al. 1987) to $0.150 \mathrm{mg} / \mathrm{kg}$ (Yue et al. 1990) and $0.0286 \mathrm{mg} / \mathrm{kg}$ (Wang et al. 2011b).

Lake Chaohu is known as the fifth largest shallow freshwater lake in China. The lake has been severely polluted by $\mathrm{HCH}$ pesticides through surface runoff, undercurrent, osmosis and leaching from the soil into surface water. According to historical data, the OCP emissions in Chaohu water bodies amounted to 1.16 tons in 1984 (Zhang and Lu 1986). Due to persistence, the concentrations of $\mathrm{HCHs}$ in the soil and sediment of Lake Chaohu basin were $1.4 \mu \mathrm{g} / \mathrm{kg}$ (Gao and Zhao 2012) and $0.58 \mu \mathrm{g} / \mathrm{kg}$ (Wang et al. 2012c), respectively. In addition, according to our measurement, the level of $\gamma-\mathrm{HCH}$ in fish, which might be consumed by human beings, was $11.42 \pm 29.98 \mu \mathrm{g} / \mathrm{kg} \mathrm{dw}$ (Wang, 2012, unpublished data). Study showed that pesticides like lindane have been posing pressures on the freshwater ecosystem (Qu et al., 2011; Matozzo et al., 2012). In 
addition, as the only isomer with specific insecticidal properties, $\gamma-\mathrm{HCH}$ was found to be a tumor promoter (Dich et al. 1997). One study indicated that subtle alterations in breast and prostate cells could be induced by environmental concentrations of lindane (Kalantzi et al. 2004a). Therefore, understanding the behavior of $\gamma-\mathrm{HCH}$ in a lake environment is of great concern.

Multimedia models were usually applied in assessment of the fate and transport of organic pollutants in the environment (von Waldow et al., 2008). Fugacity-based multimedia model proposed by Mackay and Paterson (1982) has been widely used to describe the environmental behavior of organic pollutants in global, regional and local environments (Liu et al., 2007; Tao et al., 2003; Wania and Mackay, 1995; Xu et al., 2012; Xia et al., 2011). Among them, the fugacity-based Quantitative Water Air Sediment Interaction (QWASI) model by Mackay and Diamond (1989) should be considered for a lake system (Diamond et al. 2005, Xu et al. 2012). To date, few studies have focused on seasonal variations in pollutants (i.e., $\gamma-\mathrm{HCH}$ ) in subtropical aquatic systems using the dynamic fugacity model (Diamond et al., 2005; Tao et al., 2006; Lang et al., 2007; Liu et al., 2007; Ao et al., 2009; Xia et al., 2011; Xu et al., 2012). In our previous study, a fugacity-based level IV Quantitative Water Air Sediment Interaction (QWASI) model was developed to simulate the seasonality of $\alpha$ $\mathrm{HCH}$ in Lake Chaohu (Kong et al., 2012). As the measured data of $\gamma-\mathrm{HCH}$ in 1984 have been collected in this study, it is also interesting to use the model to simulate the long-term annual dynamics of $\gamma-\mathrm{HCH}$ (Wania and Mackay 1995, Cao et al. 2007, Xia et al. 2011) in Lake Chaohu. For $\gamma-\mathrm{HCH}$, other than the seasonal variation, it is also important to simulate the long-term dynamics and predict the residue level of the lindane in the environment in the future. Therefore, long-term annual dynamics of $\gamma-\mathrm{HCH}$ (from 1984 to 2020) in Lake Chaohu was also investigated by the model in this study. The measured data of $\gamma-\mathrm{HCH}$ in water and fish in 1984 have been collected for model validation. We also have modified the model by adding a fish sub-phase and an emission flux to air. In addition, in studies that focused on the uncertainty of the fugacity model (Tao et al., 2006; Ao et al., 2009), the basic Monte Carlo simulation was commonly used, which relies on user-defined probability distributions for the model input parameters. Due to data limitations, the distribution of certain parameters were difficult to determine, which might lead to an unsatisfactory fit between the model output and the observed data and over-estimated uncertainty of the model results in the Monte Carlo simulation (Saloranta et al. 2008). A Bayesian Markov Chain Monte Carlo $(\mathrm{MCMC})$ method was proposed to combine the uncertainty analysis and the calibration of the fugacity model by Saloranta et al. (2008). However, Salortanta 
Modeling $\gamma-\mathrm{HCH}$ in a phytoplankton-dominated shallow lake

et al. (2008) did not clearly show an improved fit of the model output to the observations or a better estimate of model uncertainty (two advantages of the MCMC method), which can be illustrated by a data set with more frequent observations, such as the seasonal variation simulation in this study, instead of the long-term simulation for yearly observations.

The main goals of this study were 1) to simulate the long-term dynamics of $\gamma-\mathrm{HCH}$ in Lake Chaohu from 1984 to 2020; 2) Using the results of 1) as initial values to model the seasonal variations of $\gamma-\mathrm{HCH}$ in Lake Chaohu from May 2010 to February 2011; 3) to evaluate the sensitivity of the parameters in seasonal variability simulation; and 4) to evaluate the advantages of the MCMC method by comparing the uncertainty of seasonal variations simulation determined by the basic Monte Carlo and MCMC methods.

\section{Materials and methods}

\section{Model development}

The framework of the fugacity-based QWASI model in the previous study was applied (Kong et al., 2012), which is present in Fig. S1 (supplementary materials). The volume and properties of the phases and subphases are presented in Table 1 (Chapter 3). The transfer fluxes included in the framework were originally from Mackay and Paterson (1991) and named after Cao et al. (2004). As fish play a very important role in aquatic environment and also in human daily food ( $\mathrm{Xu}$ et al. 2011), a fish sub-phase was included in the water to account for the bioconcentration effect, while the corresponding process of fish production $\left(T_{2 f}\right)$ was also added in the model framework. Emission (To1h) was added in the model because lindane was still in application before 1992. Table S3 (Chapter 3) provides a detailed description of all the processes in the model. It was assumed that the fugacities for all of the subphases in each compartment were the same (Mackay and Paterson 1991), i.e., equilibrium exists within all three main compartments. The differential mass balance equations with fugacities $\left(f_{i}, i=1,2\right.$, and 4$)$ as variables are illustrated in supplementary materials, S1.

\section{Simulations and model validation}

Two simulation phases were conducted in this study. Simulation \#1 modeled the dynamic of $\gamma-\mathrm{HCH}$ in Lake Chaohu annually from 1984 to 2020. As lindane was used instead of technical HCHs from 1983 and was prohibited in 1992, the steady state was assumed for $\gamma-\mathrm{HCH}$ in Lake Chaohu environment 
system in 1984. In 1993, emissions ceased and the corresponding application and discharge parameters were set to zero. Seasonal variations were not considered in this simulation. Simulation \#2 started from May 2010 to February 2011. Seasonally varying data for several parameters were applied instead, which will be demonstrated in section 2.3. The seasonality of $\gamma-\mathrm{HCH}$ in various media of Lake Chaohu was focused in this simulation. The fourth-order Runge-Kutta method was applied to solve differential equations with a simulation time step of 1 hour. The available observations of $\gamma-\mathrm{HCH}$ in water and fish in 1984 (Zhang and Lu 1986), fish data of 2010 (Wang, 2012, unpublished data), sediment data from August, 2009 (Wang et al. 2012c), and the sampled monthly data in our laboratory from May 2010 to February 2011 for air, air particles (Ouyang et al. 2012), water (He et al., 2012) and suspended solids (Liu et al., 2012) were used for model validation in the two simulations. Details of the sampling and measuring of the data can be found in the relevant references. Particularly, the measurement method for fish can be also found in Xu et al. (2012) and Wu et al. (2013).

\section{Parameter determination}

Model parameters symbols, units, values and data sources are provided in Table S1-S2 in the supplementary materials S2. Totally, 50 parameters were included, including 24 environmental parameters, 16 mass transfer parameters and 10 physicochemical parameters of the pollutant. Environmental and physicochemical parameters were determined by the literature or measured in the laboratory. Henry's constant, the saturated vapor pressure and the fugacity rate of the pollutant were corrected by the equation provided by Paasivirta et al. (1999) under different temperatures. The environmental kinetics of the process parameters were obtained from the relevant literature or calculated based on the conditions in Lake Chaohu.

For simulation \#1, the emissions rate to the air was not available for 1984. Although the discharge value from rivers to the lake was obtained, it was found that the output of the model underestimated the concentration in the water and fish by approximately 1.5 and 1 orders of magnitude in 1984, respectively, without emission input. Therefore, the value of the emissions rate to the air in 1984 was back calculated using the corresponding concentration in water. The rapid response of the water concentration to changes in loading allowed for the calibration of the inflow concentrations (Helm et al. 2002, Diamond et al. 2005). Due to high-level interactions between air and water, it was also possible to calibrate the emissions rate to air from the water concentration in Lake Chaohu. In addition, the observed $\gamma-\mathrm{HCH}$ concentration 
Modeling $\gamma-\mathrm{HCH}$ in a phytoplankton-dominated shallow lake

in fish could validate the results of the calibrated emissions rate. To be noticed, the emissions were assumed to move directly into the air above the lake (Fig. S1) due to deficiency of air advection data. For simulation \#2, there were 16 parameters with seasonal values, which can be found in Kong et al. (2012). $\mathrm{O}_{23}$ (organic carbon fraction in suspended solids in water) was a newly added dynamic parameter. Determination of these dynamic parameters was illustrated in the supplementary materials, S3. Other parameters used annual average values and remained constant during the simulation.

\section{Sensitivity analysis}

A similar sensitivity analysis was conducted for simulation \#2 as that in Kong et al. (2012). All 50 parameters were involved except the gas constant (R). For the constant parameters, the Morris classification screening method (Morris 1991) was used. Based on this method, a sensitivity coefficient (Cn) corrected by the coefficient of variation (CV) and applied by Tao et al. (2006) was chosen in this study. Moreover, for the 16 dynamic parameters in the model, the variability-based sensitivity coefficient (SCV) (Lang et al., 2007) was calculated to assess their influence on the variation of the model outputs.

\section{Uncertainty analysis}

Basic Monte Carlo simulation was applied to assess the uncertainty of the model both in simulation \#1 and \#2. The distributions of these parameters were obtained from prior knowledge and the data collected in this study. Based on the analysis of the collected parameter values and the modeling experience (Tao et al. 2006), all of the static parameters, except for temperature (normal distribution), were assumed to obey the lognormal distribution. More details can be found in Kong et al. (2012). Furthermore, Bayesian MCMC simulation method associated with the adapted Metropolis-Hastings algorithm (Saloranta et al. 2008) was conducted on simulation \#2. The density of observations in time and various media in this period provided sufficient information for the MCMC simulation. 15 parameters without seasonal variations and the standard deviation of the normal distribution of observations in log-scale (sigma0) were studied, which were primarily based on the results of the sensitivity analysis (see supplementary materials, S6 for details). The statistical characteristics of the 16 parameters with seasonal variations were not updated during the simulation. The remaining parameters were fixed to their original distributions. The length of the Markov chain was set as $10^{5}$. The convergence of the chain was judged by visual inspection and the first 20000 runs were discarded (considered as the burn-in period). The 
Chapter 4

uncertainty results obtained from random sampling (2200 runs) from the chain were compared with the former results derived from the basic Monte Carlo simulation. The $D_{R p}$ proposed by Tao et al. (2006) was considered as the indicator for the ascertained uncertainty and used for the comparison (see section 3.5 for details).

\section{Results and discussion}

\section{Simulation \#1: Dynamics of $\gamma-\mathrm{HCH}$ from 1984 to 2020}

The concentration dynamics of $\gamma-\mathrm{HCH}$ in each compartment from 1984-2020 are indicated in Fig. 1, along with the estimated uncertainty dispersion, which will be discussed in section 3.5. From 1984-1993, before lindane was completely prohibited in China, the concentrations of $\gamma-\mathrm{HCH}$ were in steady state for all the compartments. The model calculated $\gamma-\mathrm{HCH}$ concentration in water was in agreement with the observation. The estimated emissions rate to air was $30 \mathrm{~mol} / \mathrm{h}$, which was almost half of the determined emissions rate of $73.1 \mathrm{~mol} / \mathrm{h}$ in Hangzhou (Cao et al. 2007). Li et al. (2001) found that the application rate of technical HCHs in Zhejiang Province was twice as high as that in Anhui Province in the 1980s, which raised our confidence in the estimated emissions rate. In addition, the simulated $\gamma-\mathrm{HCH}$ concentration in fish also fit well with the observed data, suggesting the accuracy of the determined parameters. After the ban of lindane usage in 1993, concentrations of $\gamma-\mathrm{HCH}$ in all compartments decreased rapidly by more than three orders of magnitude, and the rate of change became slower after approximately 10 years. All of the simulated results were consistent with the observed data in 2010 and 2011, with deviations generally of less than one order of magnitude. The model predicted that till 2020, the residue level of $\gamma-\mathrm{HCH}$ in Lake Chaohu will keep slowly decreasing but still at the similar level as that at present. To be noticed, the model outputs of the suspended solids in water were almost two logarithmic units lower than the observations. This underestimation might be attributed to sample collection. The suspended solids were filtered from the water samples with a $0.45 \mu \mathrm{m}$ glass fiber filter (GFF) (He et al., 2013), which included the phytoplankton in the water. As a heavily eutrophic shallow lake, the phytoplankton was dominant in the lake, especially in the summer when algae were blooming. In addition, phytoplankton uptake strongly affects the fate of persistent organic pollutants (POPs) in aquatic environments (Dachs et al. 1999), which was not included in this study. Only absorption by the organic matter in the suspended solids was considered in the model, resulting in the underestimation of $\gamma-\mathrm{HCH}$ concentrations. Further studies are needed to 
Modeling $\gamma$-HCH in a phytoplankton-dominated shallow lake ascertain the relative uptake coefficient constants for $\gamma-\mathrm{HCH}$ in phytoplankton, which are not available at present.
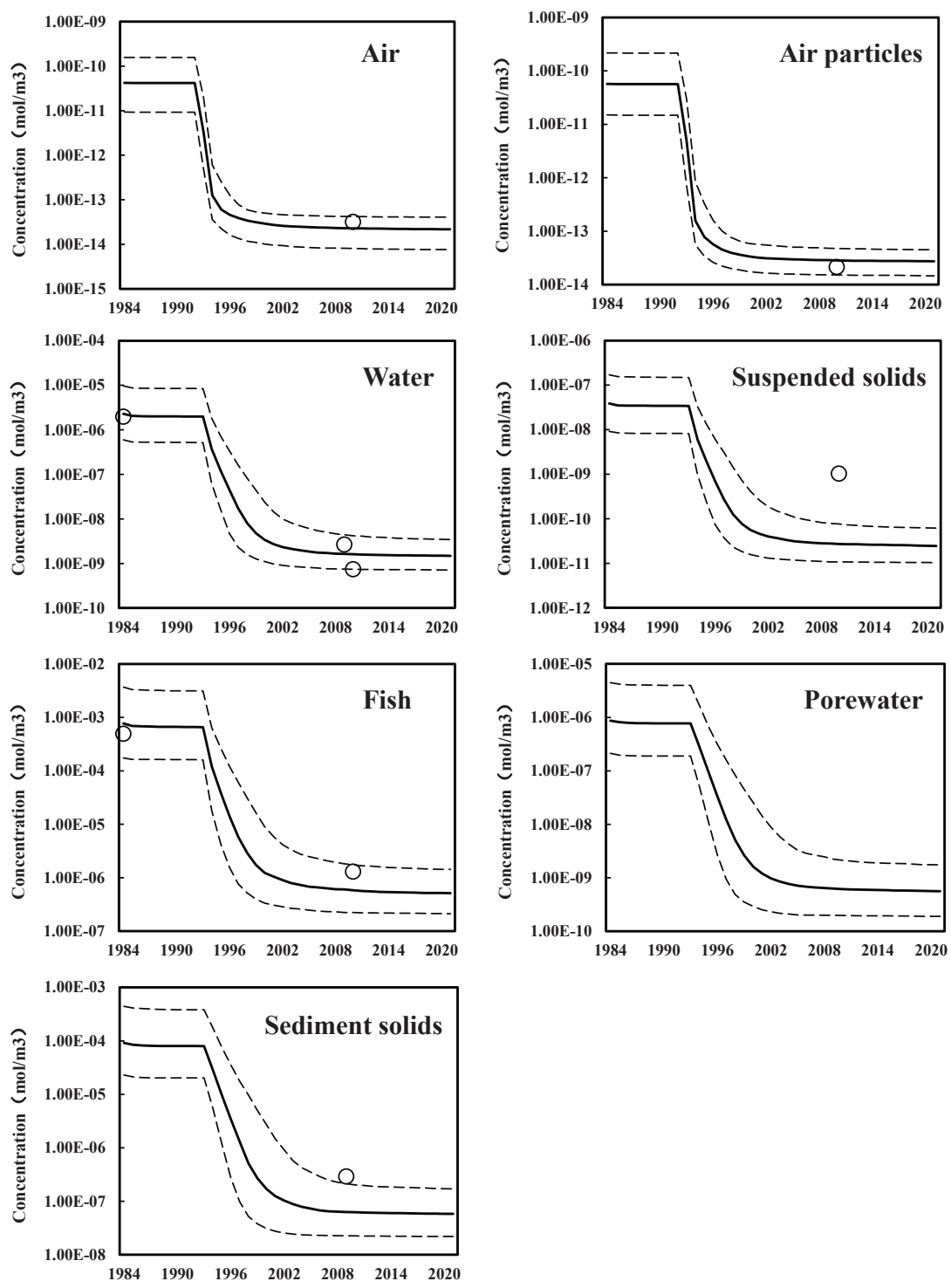

Fig. 1. Dynamics of the calculated $\gamma-\mathrm{HCH}$ concentration results in simulation \#1 for various environmental media in the lake as well as the uncertainty determined by the basic Monte Carlo simulation from 1984 to 2020. The results are depicted as the 0.25 (dashed line at the bottom) and 0.75 (dashed line on the top) percentiles, and the simulated data (solid line in the middle) in log-scale. Circles are the corresponding observations. 
The simulated results of the fugacity in the three main compartments on May 1 ${ }^{\text {st }}, 2010$ in simulation \#1 were set as the initial values for the simulation \#2. The average simulated results agreed well with the average observed data, which are presented in Fig. 2. The deviations were 0.36, 0.25, $0.12,1.36,0.66$ and 0.13 logarithmic units for air, air particles, water, suspended solids, fish and sediment solids, respectively, which were all within one logarithmic unit, except for suspended solids in water, which was also found for $\alpha-\mathrm{HCH}$ in Kong et al. (2012). Similar reasons to those presented in section 3.1 might account for the relatively large deviation in suspended solids. The relatively high level of $\gamma-\mathrm{HCH}$ concentration in fish should be the result of the bioconcentration effect (Hargrave et al. 2000), while the sediment might act as a sink of HCHs (Walker et al. 1999), resulting in high concentration.

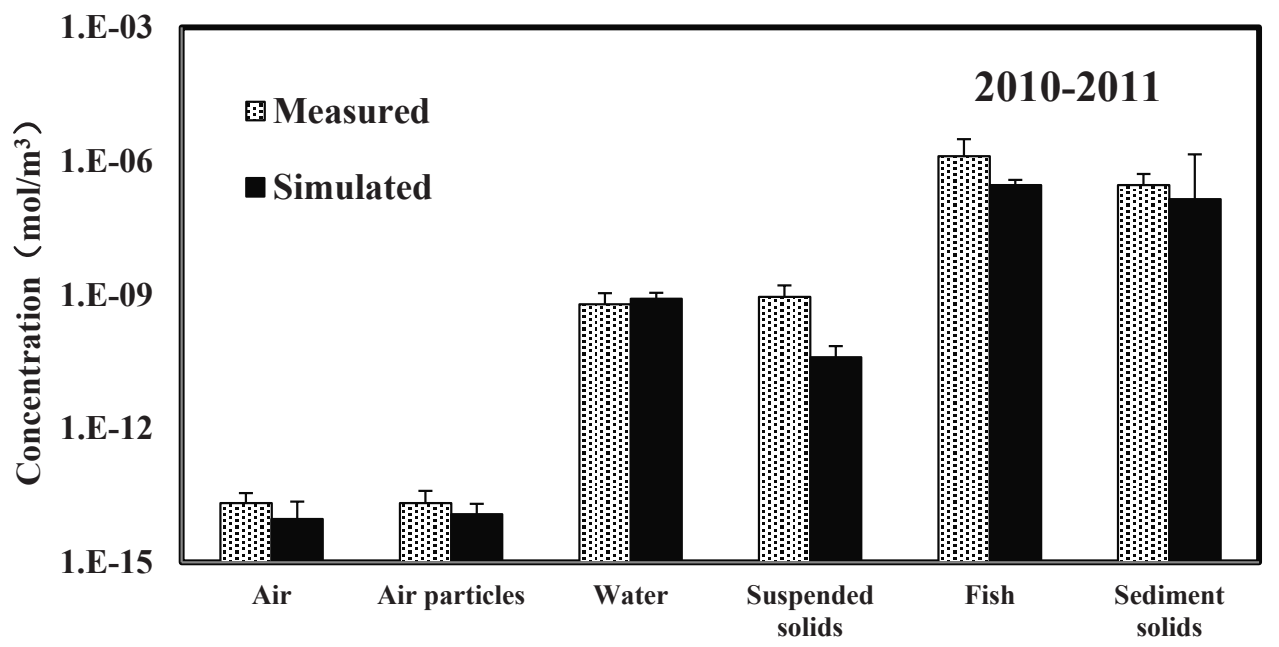

Fig. 2. Comparison of the measured and simulated $\gamma-\mathrm{HCH}$ concentration results in simulation \#2 for various environmental media in Lake Chaohu. Annual average values are presented and the standard deviations are also provided as little bars for both measured and simulated results.

\section{Simulation \#2: Seasonal variations of $\gamma-\mathrm{HCH}$ from 2010.5 to 2011.2}

Seasonal variations in the modeled $\gamma-\mathrm{HCH}$ concentrations in various media compared with the observations are indicated in Fig. 3. The model successfully simulated the seasonal patterns in air and water phases. The gaseous $\gamma-\mathrm{HCH}$ concentration was significantly higher in the summer (JuneAugust) than in other seasons, which was primarily attributed to increased input from air advection during the summer (Fig. S4). Possible reasons for this 
Modeling $\gamma-\mathrm{HCH}$ in a phytoplankton-dominated shallow lake

pattern were as follows: First, Haugen et al. (1998) proposed that the regression slope between $\ln P$ (air partial pressure; in atm) and $1 / T\left(\mathrm{~K}^{-1}\right)$ indicated that atmospheric concentrations were controlled by either re-evaporation from surfaces in the vicinity of the sampling site (steep) or air advection (shallow). It was found that the regression coefficients $\left(R^{2}\right)$ were 0.4317 and 0.0007 for $\gamma$ $\mathrm{HCH}$ and $\alpha-\mathrm{HCH}$ (Fig. S5), respectively, which indicated that the gaseous $\gamma$ $\mathrm{HCH}$ concentration was strongly affected by local emissions. Second, it was found that the $\alpha / \gamma$ ratio was much lower in both air and water in the summer (Fig. S6), indicating possible recent illegal applications of lindane around Lake Chaohu. It was reported that agricultural land accounted for $61.1 \%$ of the total land area in the Lake Chaohu basin (Tu et al. 1990), resulting in high levels of $\gamma-\mathrm{HCH}$ residues in the soil. The soil could be converted from a major sink to an important emissions source of OCPs after the ban (Tao et al. 2008). Higher precipitation levels and optimized plant growth in the summer also resulted in more rapid release of $\mathrm{HCHs}$ from soil (Waliszewski 1993). Third, high temperatures in the summer favored volatilization from fields to the atmosphere (Crosley et al. 1998), which was also the case in this study (T21d), with a lesser contribution to the seasonal pattern in comparison with the input from air advection ( $\left.\mathrm{T}_{01 t}\right)$. The $\gamma-\mathrm{HCH}$ concentration in air particulates showed a relatively high level in winter, which peaked in November (Fig. 3). Similar results for $\alpha-\mathrm{HCH}$ (Kong et al., 2012) and for $\gamma-\mathrm{HCH}$ in the Great Lakes (Carlson et al., 2004) were also provided. The atmospheric vapor pressure (Ps) for $\gamma-\mathrm{HCH}$ was lower in the winter due to lower temperatures, resulting in a higher fugacity capacity of the air particles. Therefore, temperature was the key factor controlling the partition of $\gamma-\mathrm{HCH}$ between the air vapor and particulate phases (Carlson et al. 2004). Similar results for $\alpha-\mathrm{HCH}$ (Kong et al., 2012) and for $\gamma-\mathrm{HCH}$ in the Great Lakes in United States (Carlson et al., 2004) were also reported. The atmospheric vapor pressure (Ps) of $\gamma-\mathrm{HCH}$ was lower in the winter due to lower temperatures, resulting in a higher fugacity capacity of the air particles. Therefore, temperature was the key factor controlling the partition of $\gamma-\mathrm{HCH}$ between the air vapor and particulate phases, which was also indicated in other study (Carlson et al., 2004). In the water phases, the $\gamma$ $\mathrm{HCH}$ concentration peaked in late winter (February) and was lower in other seasons for several reasons. Reasons for this are as follows. First, the low temperature in the winter, especially the lowest in February, led to low Henry's law constants and high fugacity capacities of the water phase. Moreover, the precipitation and water inflow were both low in the winter, resulting in a concentrated effect due to decreased water volume. A lower peak value was also observed in the summer (July). The significantly higher gaswater interface processes in summer (Fig. S4), especially wet deposition (T12w), 
might lead to the relatively higher concentration than those in late spring or autumn. However, the level in the winter was almost twice as high as that in the summer. The simulated results for suspended solids in water were consistent with the seasonal pattern of the observations but were underestimated by nearly one and half orders of magnitude. The observed data were relatively higher in August, which might correspond to the annual algae bloom in Lake Chaohu (Xu et al. 1999a). The simulated results captured the higher values during the summer due to relatively higher organic carbon fraction $\left(\mathrm{O}_{23}\right)$. However, further research was still required to introduce the process of phytoplankton uptake and ascertain the corresponding parameters. The average of the model results for fish and sediment agreed with the observations. The concentration in fish had relatively small seasonal variations. Similar seasonal variations in water bodies were observed for sediment solids. Although the sedimentation $\left(\mathrm{T}_{24 \mathrm{~s}}\right)$ had an elevated level in summer rather than winter, the much lower Henry's law function might have had a higher influence, leading to the peak value of the concentration in sediment solids in winter time.

\section{Transfer fluxes of $\gamma-\mathrm{HCH}$}

The simulated annual average transfer fluxes of $\gamma-\mathrm{HCH}$ in Lake Chaohu are depicted in Fig. S2. The amount of the fluxes had been estimated to account for a year in the following discussion. The net input of $\gamma-\mathrm{HCH}$ into Lake Chaohu was estimated at approximately $0.160 \mathrm{t} / \mathrm{a}$, while the net output was approximately $0.196 \mathrm{t} / \mathrm{a}$. Therefore, the total quantity of $\gamma-\mathrm{HCH}$ in Lake Chaohu had decreased by 0.036 tons, which was about one third of $\alpha-\mathrm{HCH}$ (Kong et al., 2012). Specifically, the main source of input was atmospheric advection of $0.151 \mathrm{t} / \mathrm{a}$, which corresponded to an advection output of $0.171 \mathrm{t} / \mathrm{a}$. On the contrary, the input from water inflow was relatively small $(0.008 \mathrm{t} / \mathrm{a})$, while the output from water outflow was 0.013 t/a. Degradation processes were significantly lower than $\alpha-\mathrm{HCH}$ (Kong et al., 2012), as the value were estimated as $0.001,0.002$ and 0.009 t/a for air, water and sediment, respectively, which could be attributed to the persistence of $\gamma-\mathrm{HCH}$ (Cao et al. 2004) and low levels of $\gamma-\mathrm{HCH}$ in the environment. The degradation in sediment accounts for $76.3 \%$ of the total degradation in the environment. For interface processes between air and water, the dominant process was rain scavenging $\left(\mathrm{T}_{12 \mathrm{w}}\right)$, which accounted for $72.3 \%$ of the air-to-water fluxes. Except for dry deposition $\left(\mathrm{T}_{12 \mathrm{p}}\right)$, all fluxes between air and water had a seasonal pattern of relatively higher in summer and lower in winter (Fig. S4). Diffusion from air to water $\left(\mathrm{T}_{12 \mathrm{~d}}\right)$ was $0.002 \mathrm{t} / \mathrm{a}$, while the corresponding process from water to air 
Modeling $\gamma-\mathrm{HCH}$ in a phytoplankton-dominated shallow lake

amounted to $0.007 \mathrm{t} / \mathrm{a}$. This result was close to the estimated annual average of net volatilization in Lake Taihu (4.1 kg; Qiu et al., 2008). However, net input from atmosphere to water was ascertained if deposition and rain scavenging fluxes were considered (Fig. S3). It was estimated that approximately 0.031 tons of $\gamma-\mathrm{HCH}$ was added to Lake Chaohu by air-water interface fluxes in one year. The large quantities of $\gamma-\mathrm{HCH}$ cycling through air-water interface fluxes indicated that this pathway might be a major factor in determining $\mathrm{HCH}$ concentrations in large lakes (Ridal et al. 1996). The interface between water and sediment provided a net input of 0.013 t/a (Fig. S3). Sedimentation accounted for $82.8 \%$ of the processes from water to sediment, while resuspension dominated the fluxes from sediment to water $(85.4 \%)$.
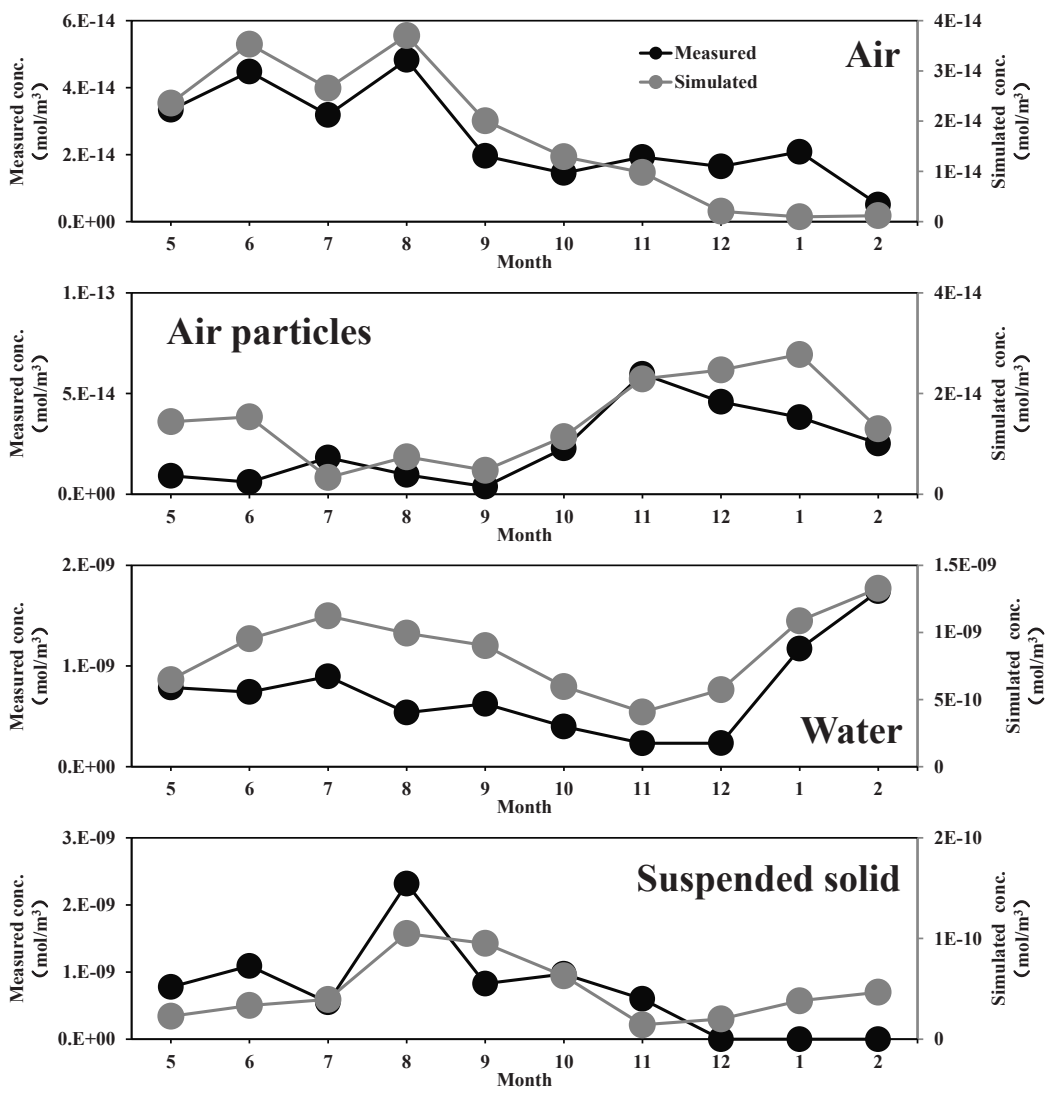

Fig. 3. Seasonal variations of $\gamma-\mathrm{HCH}$ concentrations in the air, air particles, water and suspended solids. Both simulated and measured concentrations are presented for model validation. 

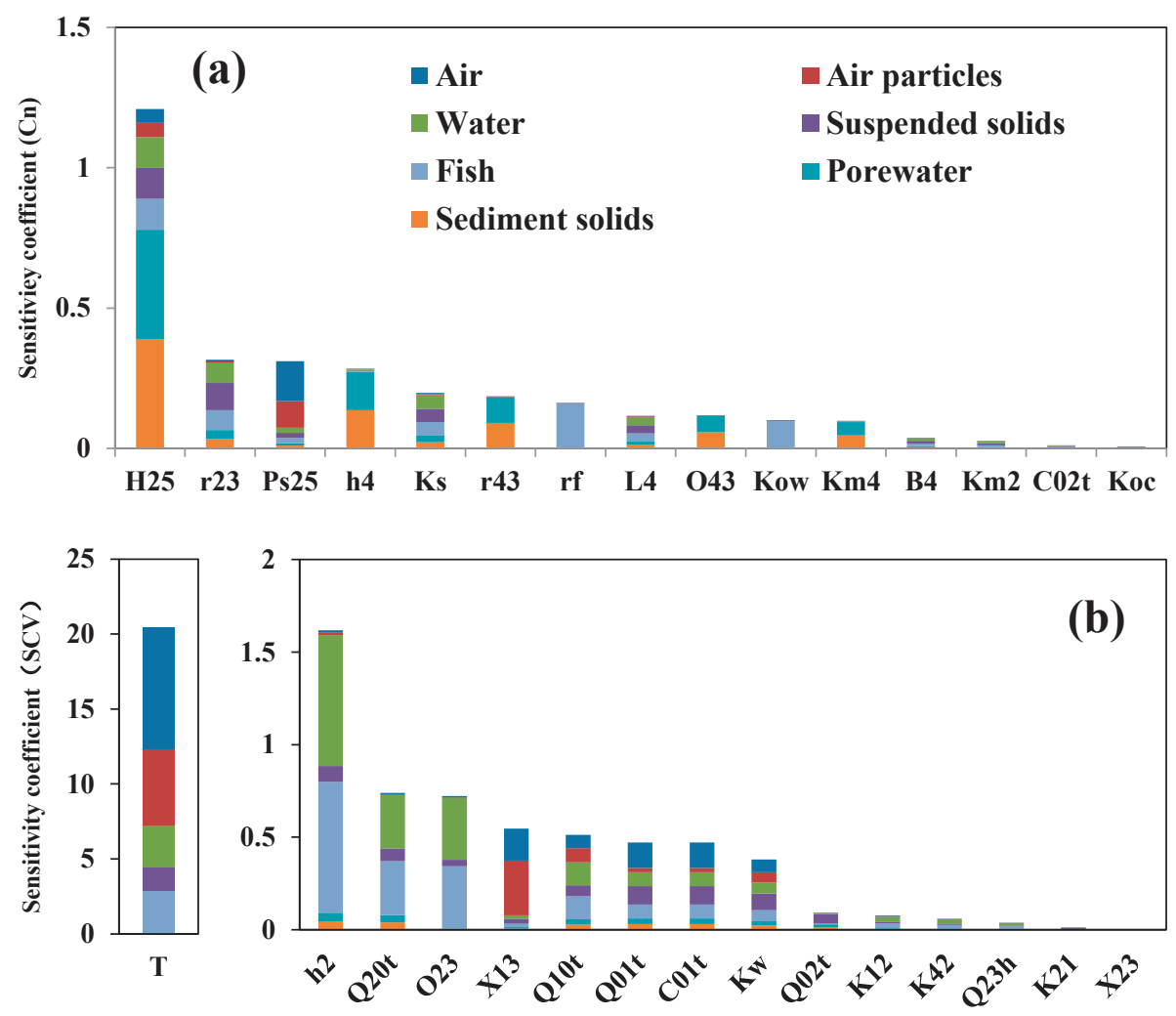

Fig. 4. Coefficient of variability normalized sensitivity coefficients $(\mathrm{Cn})$ of static parameters (a) and variability-based sensitivity coefficient (SCV) of the dynamic parameters (b) to the model outputs in various environmental media.

\section{Sensitivity of the model parameters}

The $\mathrm{CV}$ corrected sensitivity coefficients $(\mathrm{Cn})$ for the fifteen most sensitive parameters are displayed in Fig. $4 \mathrm{a}$, and the original coefficients $(C s)$ are presented in Fig. S7. Many of them were similar to the results for $\alpha-\mathrm{HCH}$ (Kong et al., 2012) so that only the different parts were discussed here. $\mathrm{H}_{25}$ (Henry's law constant at $25^{\circ} \mathrm{C}$ ) was determined to be the most sensitive parameter, which mainly resulted from its large variation (Table S2). In addition, all of the calculations of the fugacity capacity in the water and sediment phases were related to this parameter (Mackay and Paterson 1991). It was also suggested by Odabasi et al. (2008) that $\mathrm{H}_{25}$ played a fundamental role in predicting the environmental behavior of POPs. $\mathrm{K}_{\mathrm{s}}$ had a relatively stronger influence on the concentration of $\gamma-\mathrm{HCH}$ than $\alpha-\mathrm{HCH}$ probably due to the addition of fish sub-phase. This addition also resulted in the high sensitivity of 
Modeling $\gamma-\mathrm{HCH}$ in a phytoplankton-dominated shallow lake

Kow and $\mathrm{r}$, which were important parameters for fish. It was worth noted that parameters associated with degradation, such as $\mathrm{km}_{4}$ and $\mathrm{km}_{2}$, had relatively lower sensitivity for $\gamma-\mathrm{HCH}$ than $\alpha-\mathrm{HCH}$ due to less importance of degradation processes. It was found in section 3.3 that degradation fluxes of $\gamma$ $\mathrm{HCH}$ in all media were significantly lower than those of $\alpha-\mathrm{HCH}$. In general, the average values of $\mathrm{Cn}$ for air, water and sediment were $1.42 \%, 4.59 \%$ and $6.23 \%$, respectively. Although the water compartment was the center of the system and had the largest number of parameters in the model (Tao et al. 2006), sediment was under the greatest influence of the parameters. Variability-based sensitivity coefficients $(S C V)$ for the sixteen dynamic parameters were indicated in Fig. 4b. Similar to $\alpha$-HCH (Kong et al., 2012), temperature (T) was found to have a much greater influence on the variation of the model output than the other parameters. $h_{2}$ strongly affected the variations in $\gamma-\mathrm{HCH}$ concentrations in water and fish, which might be associated with the apparent seasonality of high water in the summer and the drought period in the winter. The SCV for $\mathrm{Q}_{20 t}$ was much higher than for Q $02 t$, which might be attributed to the nearly one and half times higher quantity of water outflow ( $\left.\mathrm{T}_{20 t}\right)$ than inflow (To2t) (Fig. S2). Lower concentration in the water inflow resulted in the higher influence of $\mathrm{Q}_{20 t}$ on the variation than $\mathrm{Q}_{02 t}$. $\mathrm{O}_{23}$ was relatively influential on the sub-phases in water with lower $S C V$ on the suspended solids, which might be due to the significant underestimation of this phase. In contrast to $\alpha$ $\mathrm{HCH}, \mathrm{K}_{12}$ and $\mathrm{K}_{21}$ were both considered to be unimportant to seasonality of $\gamma$ $\mathrm{HCH}$, probably because of lower diffusion fluxes for $\gamma-\mathrm{HCH}$ than $\alpha-\mathrm{HCH}$ between air and water.

\section{Uncertainty of the model simulation}

The results of the uncertainty analysis for simulation \#1 in various environmental media are illustrated in terms of the semi-inter-quartile range (i.e., the range between $25^{\text {th }}$ and $75^{\text {th }}$ percentiles) in Fig. 1 . The dispersion for each media was no more than two orders of magnitude. Moreover, the observations in various media in 1984 and 2010 were all within the range of dispersion (except for suspended solids), suggesting that the model was reliable. The large deviation between the observed and simulated data (where even the observed data fell far from the dispersion range) in suspended solids indicated that underestimation in this sub-phase originated not only from the uncertainty of the model prediction but also from model error, which in turn from the simplification of the model to the real environment (as discussed in section 3.1). The structure of this model requires modification so that predictions of the suspended solids might be more accurate. Comparatively 
speaking, the dispersions in the fish and the two sub-phases in sediment were larger than the other compartments. This trend might be attributed to larger variation in the relevant parameters. $\mathrm{C} n$ was a good indicator and provided information regarding the influence of parameter variation on the model. It was concluded in section 3.4 that sediment was under the largest influence of the parameters in this study, with an average $\mathrm{Cn}$ of $6.23 \%$ (3.11\% and $3.12 \%$ for porewater and sediment solids, respectively), while the corresponding value for fish was $2.16 \%$. These average $\mathrm{Cn}$ values were all higher than the other phases $(0.8 \%$ for air, $0.6 \%$ for air particles, $1.1 \%$ for water and $1.3 \%$ for suspended solids). It can be speculated that the larger dispersion for fish might come from the larger variation of $\mathrm{H}_{25}, \mathrm{r}_{23}, \mathrm{~K}_{\mathrm{s}}, \mathrm{r}_{\mathrm{f}}$ and $\mathrm{K}_{\mathrm{ow}}$, while the corresponding parameters for porewater and sediment solids were $\mathrm{H}_{25}, \mathrm{~h}_{4}, \mathrm{r}_{43}$, $\mathrm{O}_{43}$ and $\mathrm{K}_{\mathrm{m}}$ (Fig. 4). Due to insufficient observations, the MCMC method was not applied in this simulation.

The basic Monte Carlo and MCMC simulation were both undertaken for simulation \#2. 15 parameters determined to be influential to model outputs in the sensitivity analysis in section 3.4 were selected to be estimated and updated in the MCMC simulation. The results of the uncertainty analysis are presented simultaneously in Fig. 5. For the basic simulation, a similar characteristic as those for $\alpha-\mathrm{HCH}$ (Kong et al., 2012) was obtained. In the MCMC simulation, after the first 20000 runs, the chains for all of the parameters converged, which were judged by visual inspection (Fig. S8). Subsequently, 2200 runs of the model were performed, and the fifteen parameters (excluding sigma0) were randomly resampled from the last 80000 parameter chains. The results of the uncertainty analysis for all media are illustrated by the solid line in Fig. 5. The dispersion of the model output, shown as semi-inter-quartile ranges, was significantly reduced in this simulation. This difference was primarily attributed to the reduced dispersion of the fifteen parameters after the MCMC simulation. Details of the statistical characteristics for these parameters before and after the MCMC are listed in Table 1. The prior and posterior probability distributions of $\mathrm{r}_{23}$ and $\mathrm{H}_{25}$ are also shown in Fig. S9 (see supplementary materials, S6 for more details). The estimations of these parameters based on their posterior distributions were relatively close to the original values, while the semi-inter-quartiles ranges were all remarkably reduced. However, $\mathrm{K}_{\mathrm{s}}$ was estimated to be approximately two orders of magnitude lower compared to its original value. During the simulation, the model could be trying to fit the largely underestimated simulated data of suspended solids to the corresponding observations by decreasing the output of this sub-phase, such as sedimentation, which was strongly affected by $K_{s}$ (Fig. 4). However, the model error was too high to be 
reduced by simply updating the parameters. Moreover, this simulation also led to an incorrect continuous decrease in this parameter, resulting in an unreasonably low value for $\mathrm{K}_{\mathrm{s}}$ after the simulation. Therefore, $\mathrm{K}_{\mathrm{s}}$ retrieved its original distribution during the reproduction of the model uncertainty after the MCMC simulation.
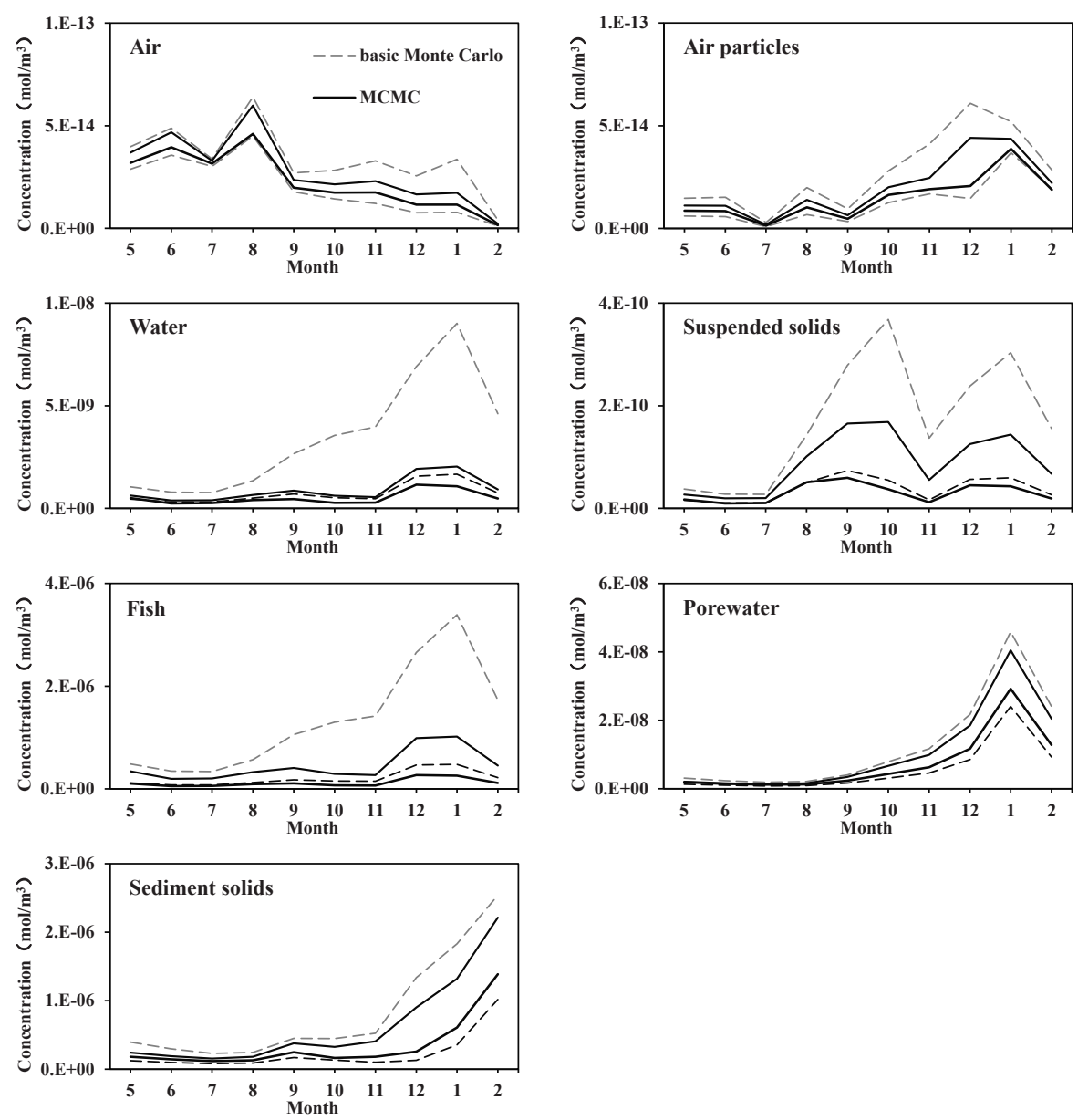

Fig. 5. The dynamics of the simulated dispersions of $\gamma-\mathrm{HCH}$ concentrations in various media from 2010.5-2011.2, which are presented as the 0.25 (dashed line at the bottom) and 0.75 (dashed line on the top) percentiles, determined by the basic Monte Carlo simulation and the 0.25 (solid line at the bottom) and 0.75 (solid line on the top) percentiles, determined by MCMC simulation. 
On the other hand, it was revealed that the uncertainty of the model included both inherent variability and true uncertainty of the model estimates (McKone 1996). Tao et al. (2006) proposed that $D_{R p}$, which was defined as the difference between the concentration ranges in which a given percentage $(p)$ of the simulated and the measured results fall, could be considered the indicator for the true uncertainty. Because the multi-site monthly samples were only available for water and suspended solids in this study, while the simulated data did not provide rational results for the suspended solids, the results in water were selected for uncertainty reduction estimation. For $p, 95 \%$ was used as the criteria. The annual averages of $D_{R 95}$ for the water phase in the basic Monte Carlo and MCMC simulations were 3.208 and 0.741, respectively. The true uncertainty provided by the basic Monte Carlo was unreasonably high, which might give a wrong impression of the model reliability (Saloranta et al. 2008). The MCMC simulation decreased the ascertained true uncertainty to $23 \%$ of the original, indicating that $77 \%$ of the model true uncertainty in water had been eliminated. A significant decrease of the true uncertainty of model prediction in other media could be speculated. The model simulation results with the updated parameter estimations for various media were not indicated because the output did not significantly fit the observation better. For the multimedia fugacity model, it was always acceptable if the differences between the simulated and observed data were less than 0.5 or 0.7 orders of magnitude (Cao et al. 2004). The patterns of variation were more valuable than the prediction accuracy for seasonal modeling by the level IV fugacity model (Lang et al. 2007). Thus, model calibration might not be important for the fugacity model. The calibration in the MCMC simulation was aimed at avoiding improbable parameter combinations, which led to a poor fit between the model results and observed data and the subsequent overestimation of model uncertainty, instead of fitting the model results as close as possible to the observations. As a result, rather than calibrating the model, it was suggested that the main functions of the MCMC in this study should be to conduct a proper uncertainty analysis, disregard improbable parameter combinations, and avoid the overestimation of the confidence bands in model prediction (Saloranta et al. 2008). 
Modeling $\gamma-\mathrm{HCH}$ in a phytoplankton-dominated shallow lake

Table 1 Statistical characteristics of prior and posterior distribution for the sixteen parameters in the MCMC simulation.

\begin{tabular}{lllllll}
\hline \multirow{2}{*}{ Parameters } & \multicolumn{1}{l}{ Prior } & & \multicolumn{5}{l}{ Posterior } \\
\cline { 2 - 7 } & $\mathbf{2 5 \%}$ & $\mathbf{5 0} \%$ & $\mathbf{7 5} \%$ & $\mathbf{2 5} \%$ & $\mathbf{5 0} \%$ & $\mathbf{7 5 \%}$ \\
\hline $\mathrm{h}_{4}$ & $6.907 \mathrm{E}-02$ & $1.000 \mathrm{E}-01$ & $1.448 \mathrm{E}-01$ & $1.255 \mathrm{E}-01$ & $1.350 \mathrm{E}-01$ & $1.452 \mathrm{E}-01$ \\
$\mathrm{~L}_{4}$ & $2.042 \mathrm{E}-02$ & $3.162 \mathrm{E}-02$ & $4.896 \mathrm{E}-02$ & $2.850 \mathrm{E}-02$ & $3.393 \mathrm{E}-02$ & $4.039 \mathrm{E}-02$ \\
$\mathrm{~K}_{\text {ow }}$ & $2.605 \mathrm{E}+03$ & $4.600 \mathrm{E}+03$ & $8.124 \mathrm{E}+03$ & $4.561 \mathrm{E}+03$ & $4.601 \mathrm{E}+03$ & $4.641 \mathrm{E}+03$ \\
$\mathrm{~K}_{\mathrm{oc}}$ & $1.441 \mathrm{E}+03$ & $1.619 \mathrm{E}+03$ & $1.818 \mathrm{E}+03$ & $1.475 \mathrm{E}+03$ & $1.588 \mathrm{E}+03$ & $1.710 \mathrm{E}+03$ \\
$\mathrm{~B}_{4}$ & $6.785 \mathrm{E}-06$ & $1.205 \mathrm{E}-05$ & $2.140 \mathrm{E}-05$ & $1.096 \mathrm{E}-05$ & $1.372 \mathrm{E}-05$ & $1.718 \mathrm{E}-05$ \\
sigma0 $_{5}$ & $1.141 \mathrm{E}+00$ & $1.500 \mathrm{E}+00$ & $1.972 \mathrm{E}+00$ & $5.265 \mathrm{E}-01$ & $5.476 \mathrm{E}-01$ & $5.696 \mathrm{E}-01$ \\
$\mathrm{r}_{23}$ & $2.264 \mathrm{E}+00$ & $2.500 \mathrm{E}+00$ & $2.760 \mathrm{E}+00$ & $2.545 \mathrm{E}+00$ & $2.552 \mathrm{E}+00$ & $2.559 \mathrm{E}+00$ \\
$\mathrm{r}_{43}$ & $2.474 \mathrm{E}+00$ & $2.760 \mathrm{E}+00$ & $3.079 \mathrm{E}+00$ & $2.514 \mathrm{E}+00$ & $2.555 \mathrm{E}+00$ & $2.596 \mathrm{E}+00$ \\
$\mathrm{r}_{\mathrm{f}}$ & $1.436 \mathrm{E}+00$ & $1.500 \mathrm{E}+00$ & $1.567 \mathrm{E}+00$ & $1.636 \mathrm{E}+00$ & $1.706 \mathrm{E}+00$ & $1.779 \mathrm{E}+00$ \\
$\mathrm{Ps}_{25}$ & $5.655 \mathrm{E}-04$ & $1.240 \mathrm{E}-03$ & $2.719 \mathrm{E}-03$ & $1.219 \mathrm{E}-03$ & $1.340 \mathrm{E}-03$ & $1.473 \mathrm{E}-03$ \\
$\mathrm{~K}_{\mathrm{s}}$ & $6.161 \mathrm{E}-07$ & $1.655 \mathrm{E}-06$ & $4.446 \mathrm{E}-06$ & $2.992 \mathrm{E}-08$ & $8.542 \mathrm{E}-08$ & $2.438 \mathrm{E}-07$ \\
$\mathrm{O}_{43}$ & $5.494 \mathrm{E}-02$ & $7.920 \mathrm{E}-02$ & $1.142 \mathrm{E}-01$ & $1.083 \mathrm{E}-01$ & $1.187 \mathrm{E}-01$ & $1.301 \mathrm{E}-01$ \\
$\mathrm{~K}_{\mathrm{m} 4}$ & $4.961 \mathrm{E}-06$ & $1.260 \mathrm{E}-05$ & $3.200 \mathrm{E}-05$ & $1.086 \mathrm{E}-05$ & $1.115 \mathrm{E}-05$ & $1.145 \mathrm{E}-05$ \\
$\mathrm{~K}_{\mathrm{m} 2}$ & $2.811 \mathrm{E}-05$ & $4.077 \mathrm{E}-05$ & $5.912 \mathrm{E}-05$ & $2.193 \mathrm{E}-05$ & $2.407 \mathrm{E}-05$ & $2.642 \mathrm{E}-05$ \\
$\mathrm{C}_{02 t}$ & $4.693 \mathrm{E}-10$ & $6.750 \mathrm{E}-10$ & $9.708 \mathrm{E}-10$ & $7.245 \mathrm{E}-10$ & $7.707 \mathrm{E}-10$ & $8.199 \mathrm{E}-10$ \\
$\mathrm{H}_{25}$ & $1.692 \mathrm{E}-01$ & $2.610 \mathrm{E}-01$ & $4.025 \mathrm{E}-01$ & $3.704 \mathrm{E}-01$ & $4.439 \mathrm{E}-01$ & $5.320 \mathrm{E}-01$ \\
\hline
\end{tabular}

Note: Definitions of these parameters please refer to supplementary materials, Table S1 and S2.

\section{Conclusion}

The two simulations in this study provided good descriptions of the long-term annually dynamics from 1984 to 2020 (simulation \#1) and the seasonal variation from May 2010 to February 2011 (simulation \#2) of the $\gamma$ $\mathrm{HCH}$ distributions in various environment media in Lake Chaohu. The simulation outputs were consistent with the observations (generally with deviations of less than one order of magnitude) for all environment media except for suspended solids. Higher gaseous $\gamma-\mathrm{HCH}$ concentrations during the summer were mainly attributed to the elevated input from air advection, which could originate from recent illegal application of lindane. Higher concentrations in air particulates and water in the winter were primarily due to low temperature and the latter could also be attributed to the effect resulting from low water level. Atmospheric advection input was the main input source, while the total quantity of $\gamma-\mathrm{HCH}$ in Lake Chaohu decreased by $36 \mathrm{~kg}$ per year. Approximately $31 \mathrm{~kg}$ of $\gamma-\mathrm{HCH}$ was added to water from air and $13 \mathrm{~kg}$ of $\gamma$ - 
$\mathrm{HCH}$ was added to the sediment from water every year. The sensitivity analysis found that Henry's law constant at $25^{\circ} \mathrm{C}$ was the most sensitive static parameter, and temperature was the most sensitive dynamic parameter. The uncertainty analysis by the basic Monte Carlo simulation for simulation \#1 found that high dispersions in fish and sediment were attributed to greater variation of the relevant parameters. The MCMC simulation for simulation \#2 eliminated $77 \%$ of the true model uncertainty in water determined by basic Monte Carlo. It was suggested that rather than calibrating the model, the main function of the MCMC for the fugacity model should be to conduct a proper uncertainty analysis and avoid overestimating the uncertainty in the model prediction.

\section{Acknowledgments}

Funding for this study was provided by the National Science Foundation of China (NSFC) (41030529, 41271462), the National Project for Water Pollution Control (2012ZX07103-002), and the National Foundation for Distinguished Young Scholars (40725004). 
Modeling $\gamma-\mathrm{HCH}$ in a phytoplankton-dominated shallow lake

\section{Supplementary materials}

\section{Details of the MCMC method}

The MCMC simulation method associated with the adapted Metropolis-Hastings algorithm (Saloranta et al. 2008) based on Bayesian inference was conducted in simulation \#2. The 15 parameters determined to be sensitive were chosen in this simulation. A common standard deviation of the concentration of all media (sigma0; in log-scale) was also updated in this simulation with a prior uniform distribution. All of the parameters were spanning a range that was predicted to be wide enough to determine a new local maximum of likelihood. A scheme proposed by Saloranta et al. (2008) was followed for the MCMC simulation.

The statistical characteristics of prior and posterior distributions for the sixteen parameters in the MCMC simulation were listed in Table 1. Except for $\mathrm{K}_{\mathrm{s}}$, most of the parameters centered on their prior distributions with a significantly narrowed dispersion range, such as $\mathrm{h}_{4}$, $\mathrm{L}_{4}$, and Kow. Several other parameters had been slightly displaced compared to their prior distributions, except for $\mathrm{K}_{\mathrm{s}}$, which was considered to be the result of the poor performance of the model in suspended solids. $\mathrm{O}_{43}$ was updated to a higher value, which could be attributed to the underestimation of the concentration in sediment solids in the original simulation. The estimated $\mathrm{K}_{\mathrm{m} 2}$ was on average a factor of 2 lower, the primary reason for which should be the underestimation of the suspended solids. The MCMC simulation was attempting to increase the levels in water so that the estimated concentration in suspended solids would be simultaneously elevated to fit the observations. Posterior estimated $\mathrm{H}_{25}$ was nearly two times higher than the prior values. All of the calculations of the fugacity capacity in the water and sediment phases were related to this parameter. Therefore, this update might have been the combined effect of the model fitting for both compartments in water and sediment.

Although the MCMC simulation could be able to fit the simulation data to the corresponding observations, one must bear in mind that the fugacity model was not established for the purpose of fitting the model results as close as possible to the observations. Calibration in the MCMC simulation was used to avoid improbable parameter combinations, which led to poor fit between the model results and observations and the subsequent overestimation of the model uncertainty. The main function of the MCMC in the fugacity model should decrease the determined uncertainty by obtaining the posterior distribution of the parameters with a narrowed dispersion. 


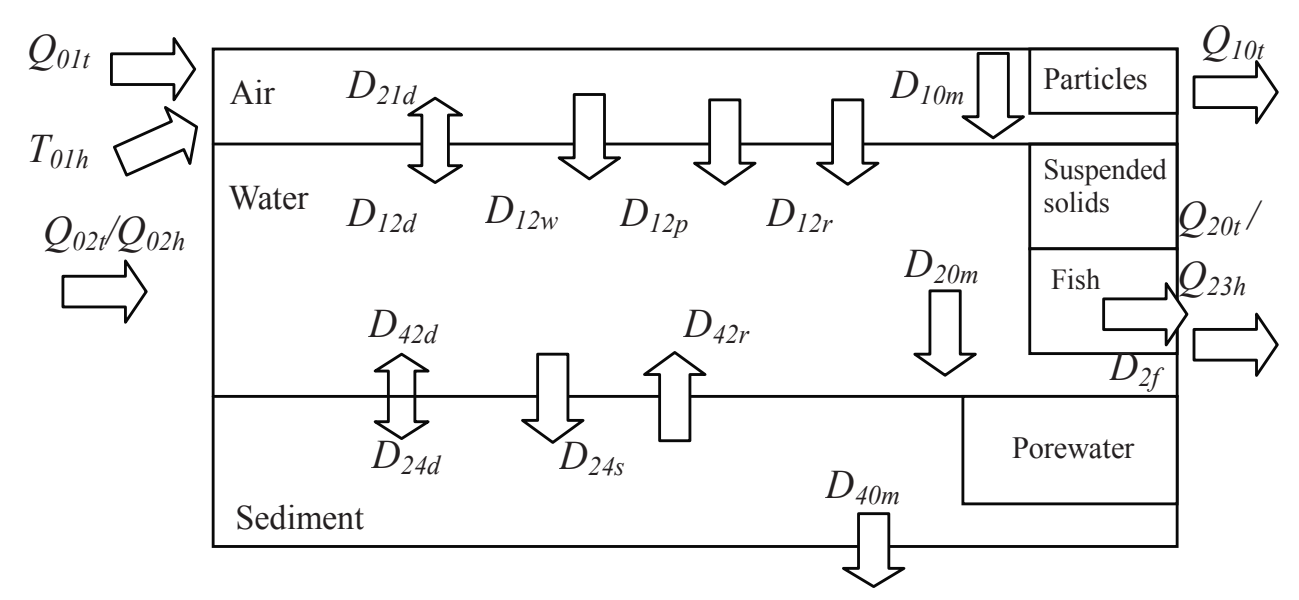

Fig. S1. Transport fluxes of $\gamma-\mathrm{HCH}$ in and out of the Lake Chaohu area and between the adjacent compartments. $D_{12 d,} D_{21 d,} D_{24 d}$ and $D_{42 d}$ represent the diffusion processes between air/water and water/sediment. $D_{12 p}$ and $D_{12 w}$ represent the dry and wet deposition from air to water. $D_{12 r}$ represents scavenging by precipitation. Q Q $01 t, Q_{02 t}$ and $Q_{02 h}$ represent the input of air advection, water inflows and wastewater discharge, respectively. $Q_{10 t}, Q_{20 t}$ and $Q_{23 h}$ represent the output of air advection, water outflows and water reuse by industry and agriculture. $\mathrm{D}_{2 f}$ represents losses from water by fish production. $D_{10 m}, D_{20 m}$ and $D_{40 m}$ represent degradation in air, water and sediment, respectively. 
Modeling $\gamma-\mathrm{HCH}$ in a phytoplankton-dominated shallow lake

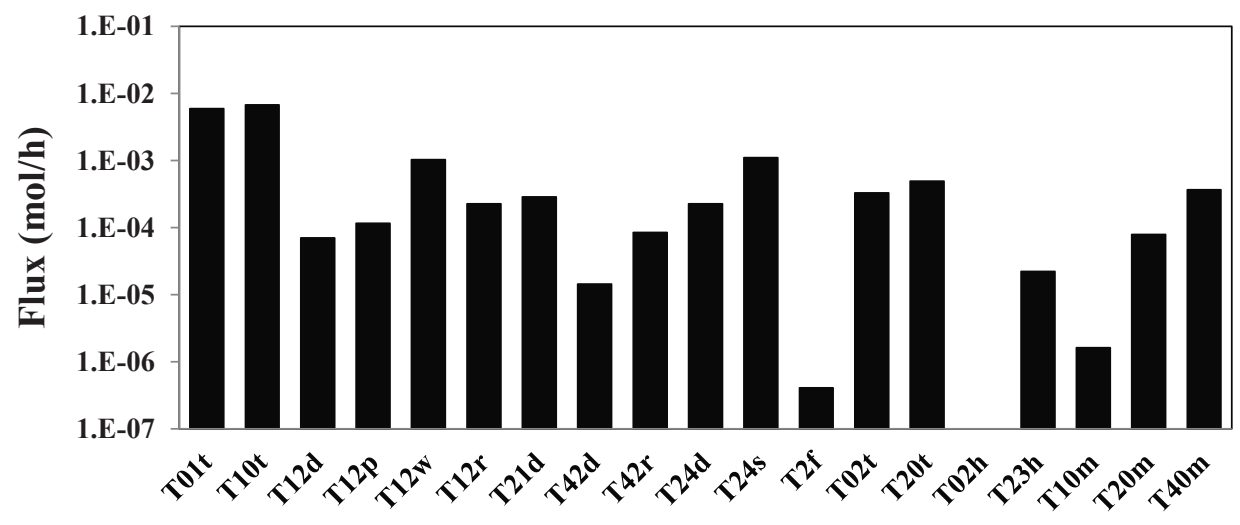

Fig. S2. $\gamma-\mathrm{HCH}$ fluxes in and out of the Lake Chaohu area and between the adjacent compartments. T01t: Air advection flows into the area; T10t: Air advection flows out of the area; T12d: Diffusion from air to water; T12p: Dry deposition from air to water; T12w: Wet deposition from air to water; T12r: Rain scavenging; T21d: Diffusion from water to air; T42d: Diffusion from sediment to water; T42r: Resuspension from sediment to water; T24d: Diffusion from water to sediment; T24s: Sedimentation from water to sediment; T2f: fish production; T02t: Water advection flows into the area; T20t: Water advection flows out of the area; T02h: Locative wastewater discharge (set as zero); T23h: Industry and agriculture water usage; T10m: Degradation in air; T20m: Degradation in water; T40m: Degradation in sediment. 

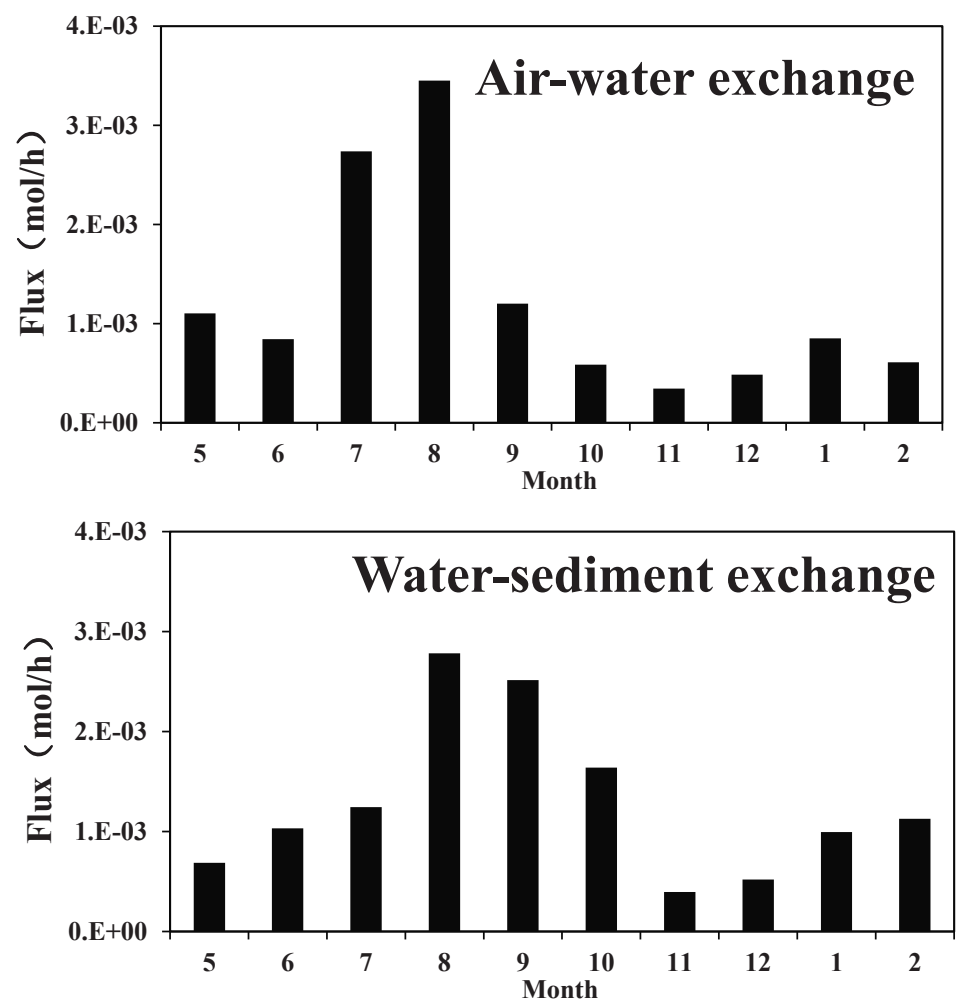

Fig. S3. $\gamma-\mathrm{HCH}$ fluxes between the air-water interface (left) and the watersediment interface (right). The positive values indicate net input from air to water and water to sediment. 
Modeling $\gamma$-HCH in a phytoplankton-dominated shallow lake
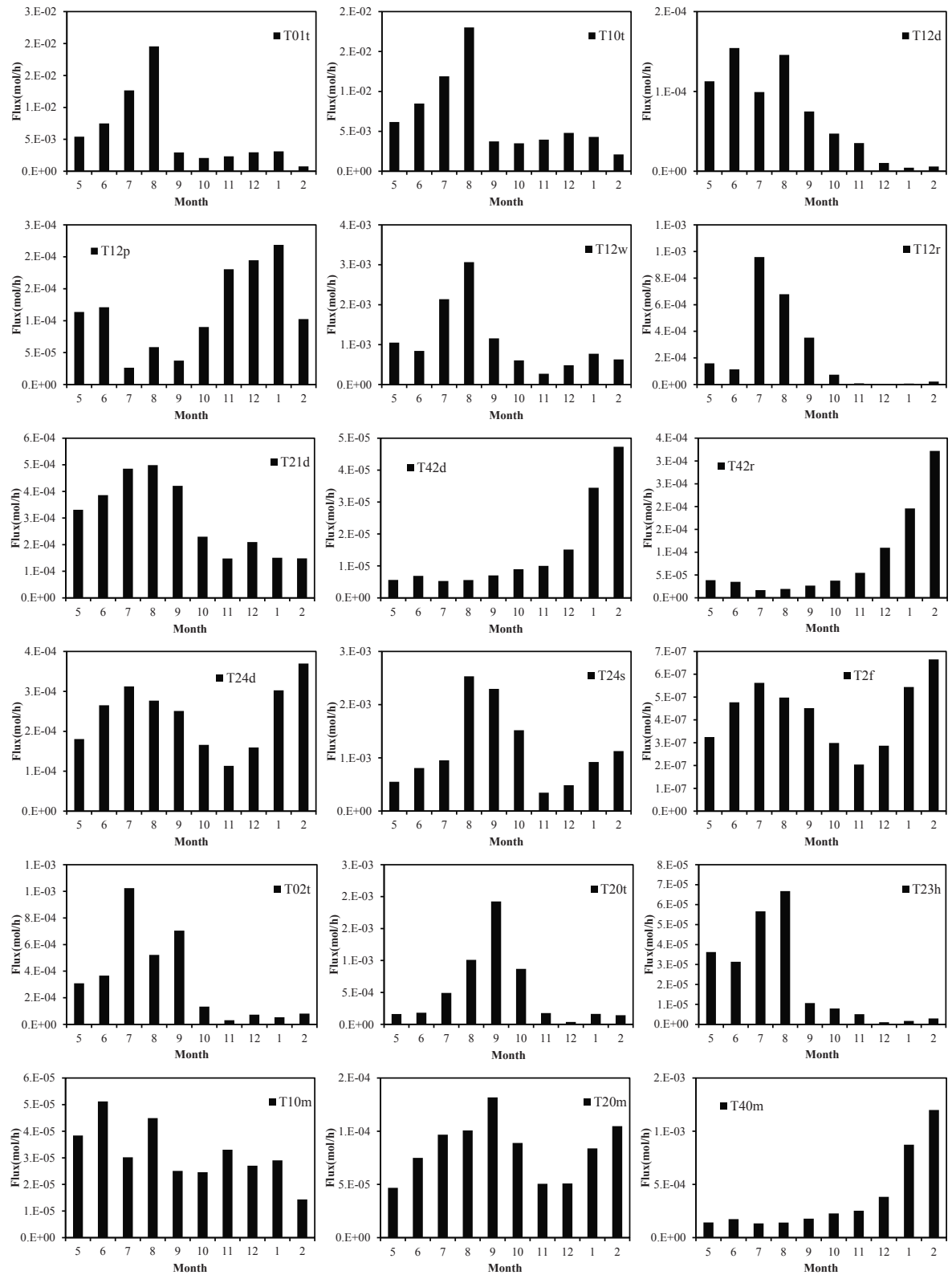

Fig. S4. Seasonal variations of the $\gamma-\mathrm{HCH}$ fluxes in and out of the Lake Chaohu area and between the adjacent compartments. T01t: Air advection flows into the area; T10t: Air advection flows out of the area; T12d: Diffusion from air to water; T12p: Dry deposition from air to water; T12w: Wet deposition from air to water; T12r: Rain scavenging; T21d: Diffusion from water to air; T42d: Diffusion from sediment to water; T42r: Resuspension from sediment to water; T24d: Diffusion from water to sediment; T24s: Sedimentation from water to 
Chapter 4

sediment; T2f: fish production; T02t: Water advection flows into the area; T20t: Water advection flows out of the area; T02h: Locative wastewater discharge (zeros); T23h: Industry and agriculture water usage; T10m: Degradation in air; T20m: Degradation in water; T40m: Degradation in sediment.

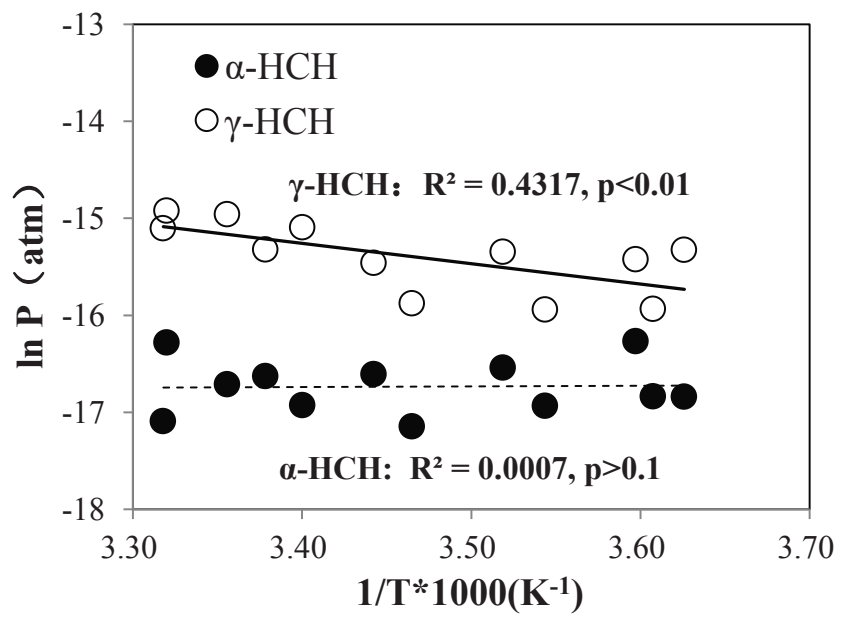

Fig. S5. Logarithm of the partial pressure of $\alpha$-and $\gamma-\mathrm{HCH}$ in air plotted against the reciprocal of the ambient temperature 

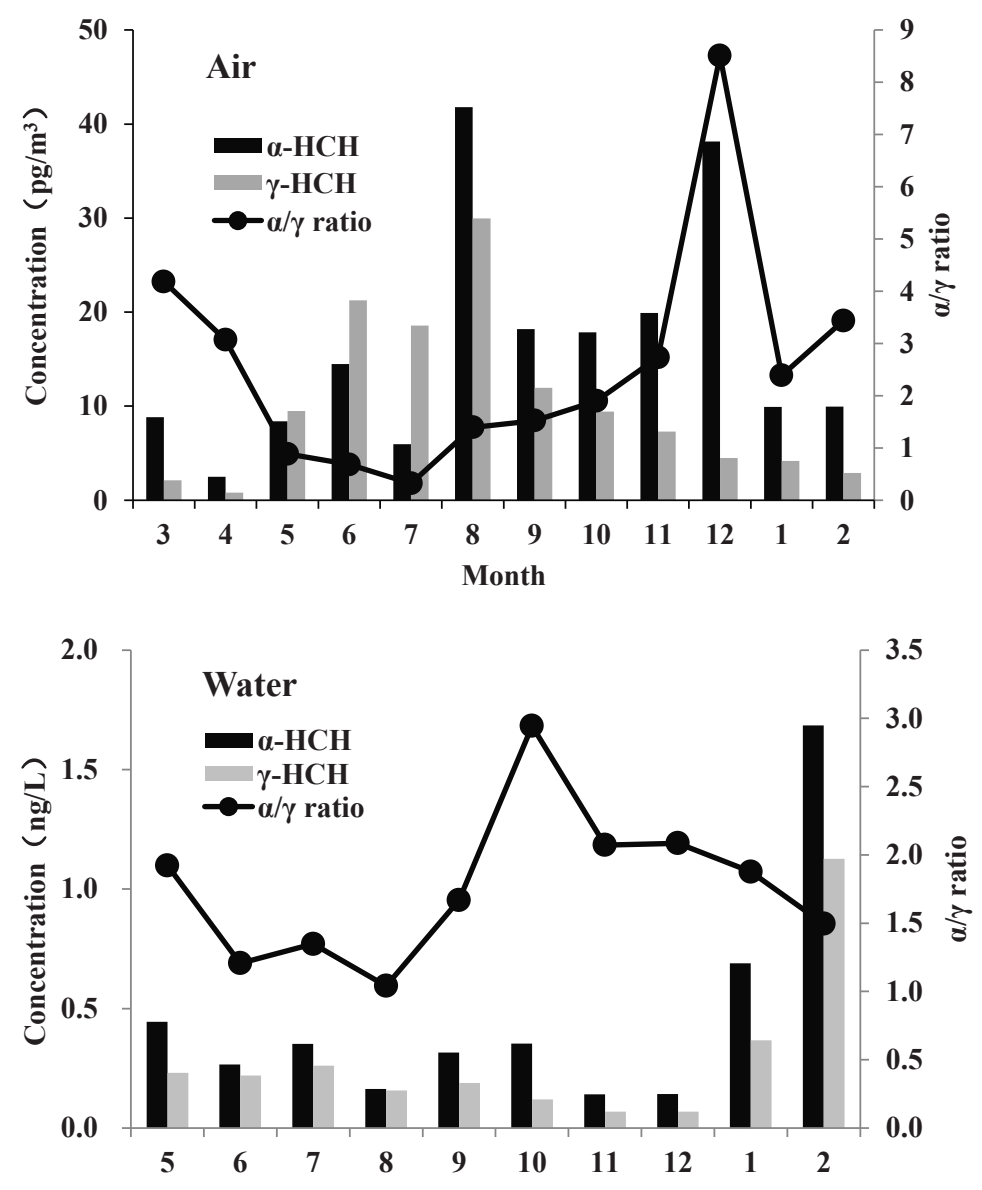

Fig. S6. $\alpha-\mathrm{HCH} / \gamma-\mathrm{HCH}$ concentration ratio in air(left) and water(right) in Lake Chaohu. 
Chapter 4

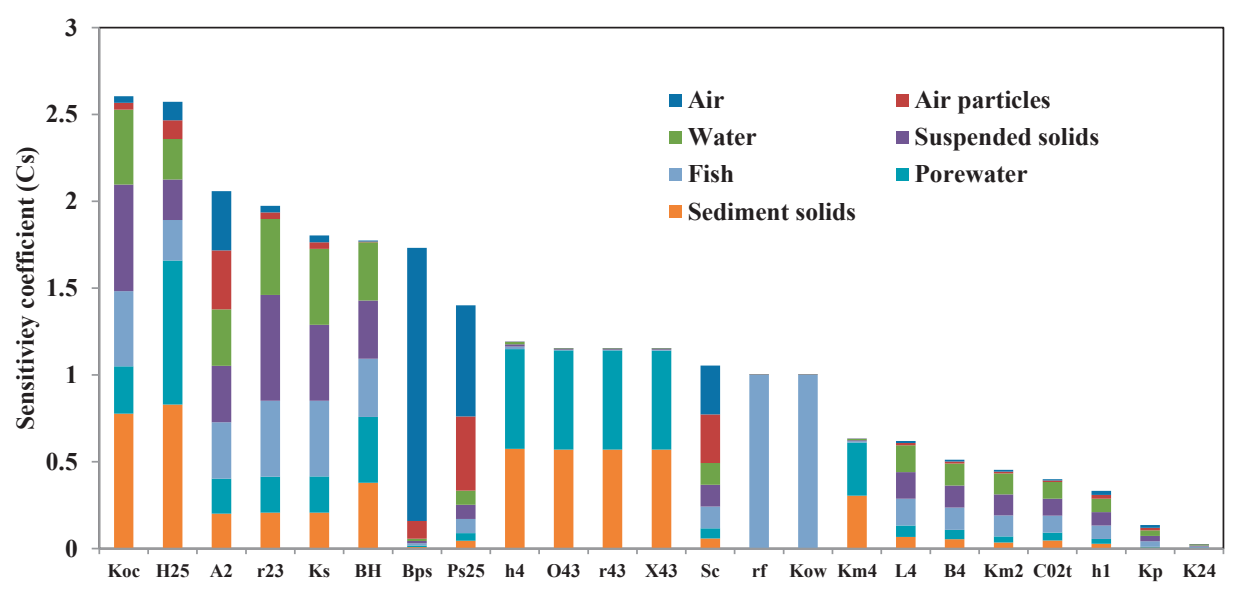

Fig. S7. Sensitivity coefficient for the parameters before CV correction.

r23

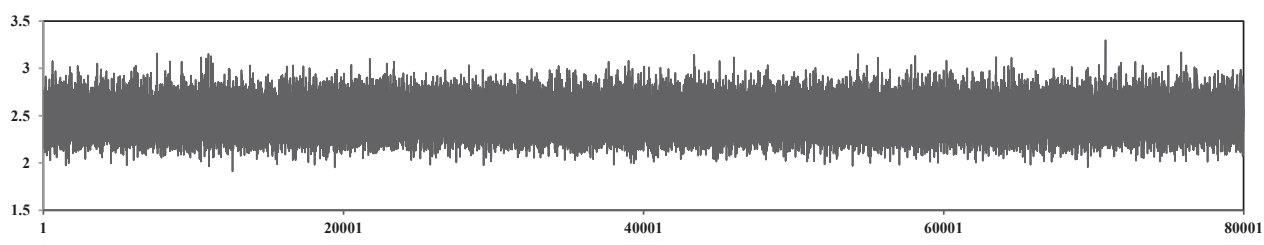

H25

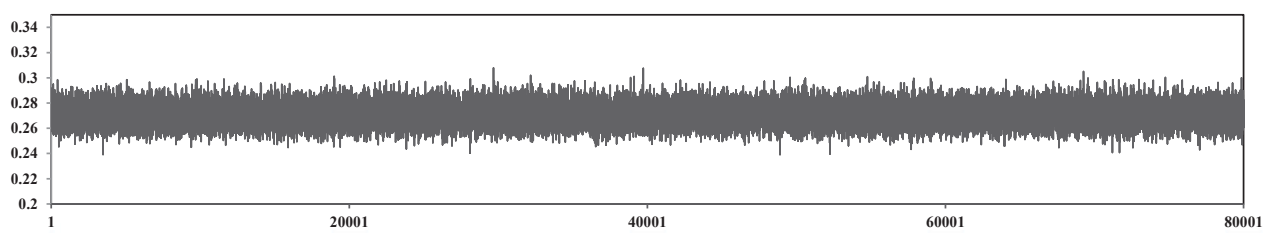

Fig. S8. Examples (H25 and r23) of the corresponding converged chain from MCMC simulation. The last 80000 data from the total 105 runs were taken out for presentation. 

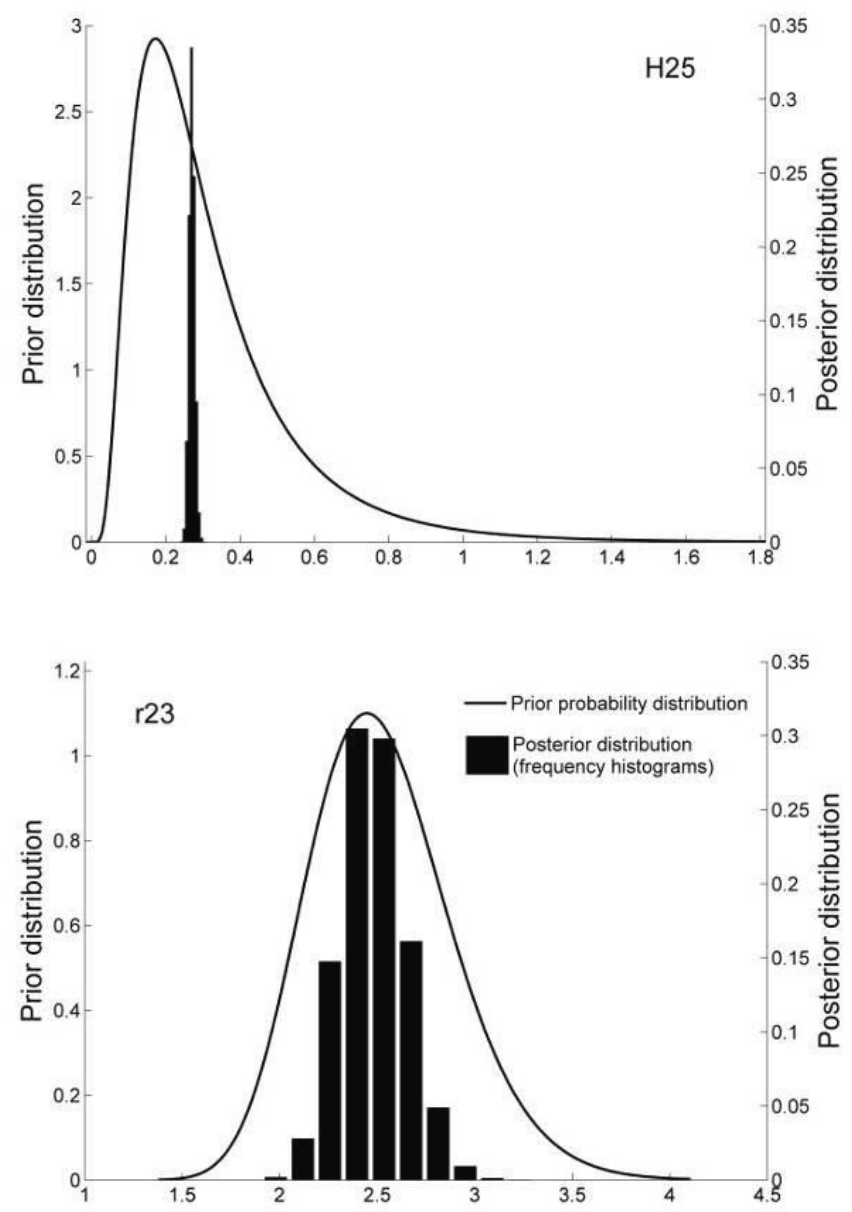

Fig. S9. Examples (H25 and r23) of the prior distributions (shown by the black line) and corresponding posterior distributions derived from the converged parameter chain form MCMC simulation (black histograms). 
Chapter 4

Table S1 Environmental parameters for the model

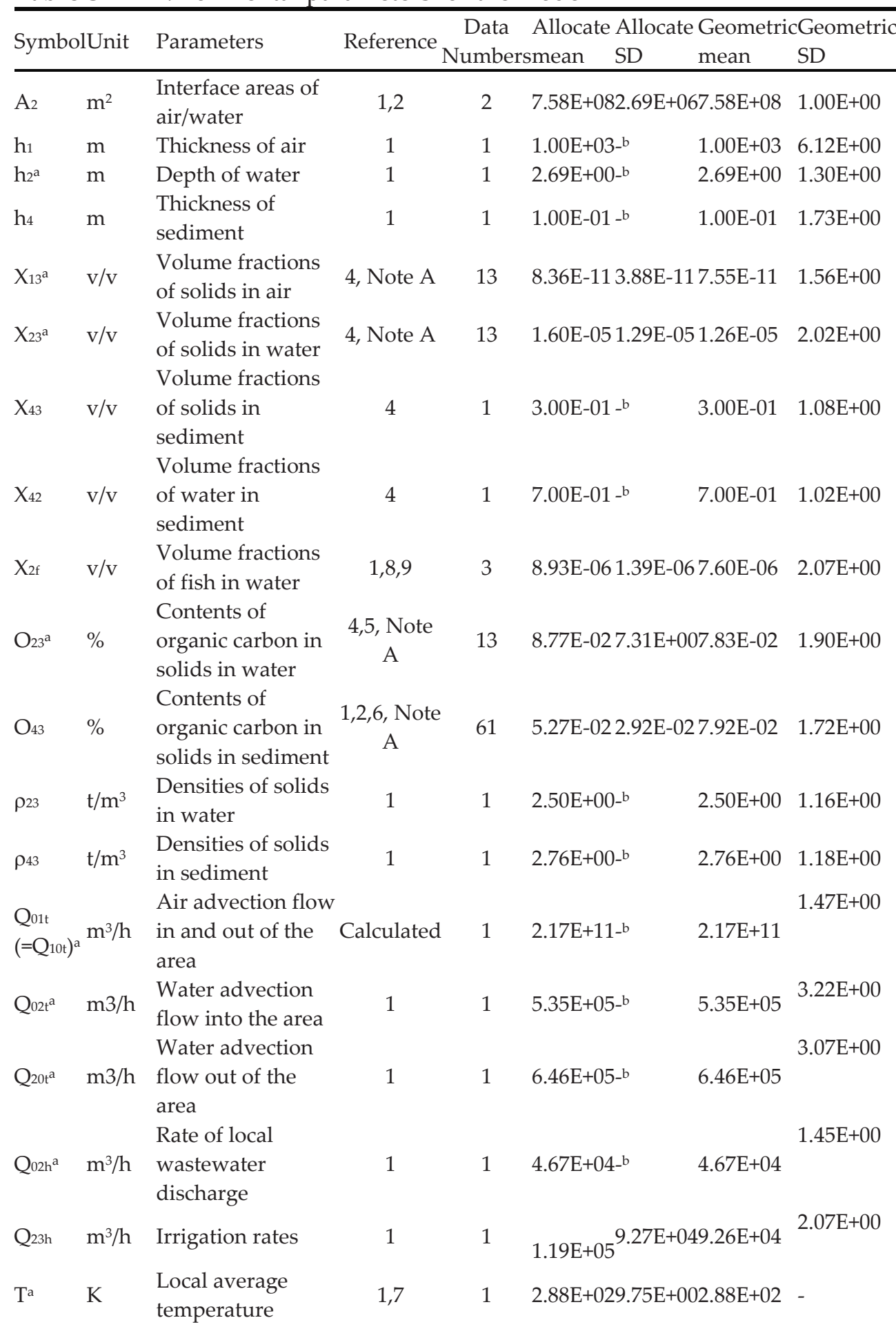


Modeling $\gamma-\mathrm{HCH}$ in a phytoplankton-dominated shallow lake

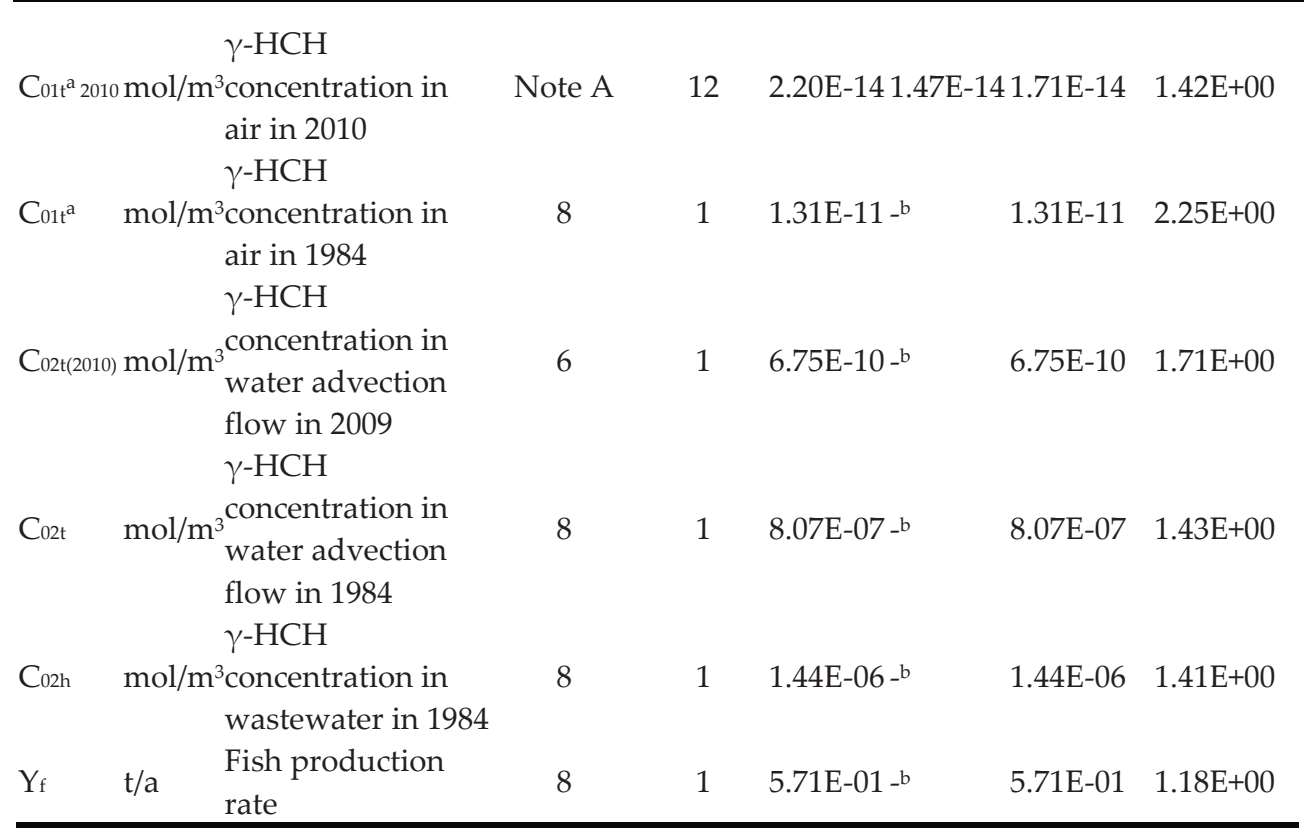

Note A: Measured in Laboratory.

a Dynamic parameters for simulation \#2

b One value only; Geometric SD assigned manually (Log-normal distribution assumed, except for T)

References:

1) Tu, Q.Y., Gu, D.X., Yi, C.Q., Xu, Z.R., Han, G.Z., 1990. The researches on the Lake Chaohu eutrophication. Hefei: Publisher of University of Science and Technology of China.

2) Yin, F.C., 2011. A study on evaluation and control instruments of Chao lake eutrophication. Beijing: China Environmental Science Press.

3) Anhui Hydrological Telemetry Information System (AHTIS), 2010-2011. Hourly water level report. http://61.191.22.154/yc web/yc index frame.aspx

4) Mackay, D., 2001. Multimedia Environmental Models: The Fugacity Approach,second ed. NewYork, USA: Lewis Publishers.

5) Zhou, Z.H., Liu, C.Q., Li, J., Zhu, Z.Z., 2007. Record of ecosystem evolvement processes provided by $\delta 13$ Corg and $\delta 15 \mathrm{~N}$ values in Chaohu Lake sediments. Environmental Science, 28, 1338-1343.

6) Zhang, M., 2009. Distribution characteristic and assessment of typical persistent organic pollutions-Organochlorine pesticides in water of Chaohu Lake watershed [Master dissertation]. Hefei: Anhui Agriculture University.

7) China Meteorological Data Sharing Service System (CMDSSS), 2010-2011. Daily Meteorological Data.

http://www.cma.gov.cn/2011qxfw/2011qsigx/index.htm 
Chapter 4

8) Zhang, T.F., Lu, X.P., 1986. Investigation and evaluation of water environmental quality of Lake Chaohu. In: Lake Chaohu water environment, ecological evaluation and Countermeasures-special report No.11. Hefei, China.

9) Guo, L.G., 2005. Studies on fisheries ecology in a large eutrophic shallow lake, Lake Chaohu [Doctoral dissertation]. Wuhan: Institude of Hydrobiology, Chinese Acadamy of Sciences. 
Modeling $\gamma-\mathrm{HCH}$ in a phytoplankton-dominated shallow lake

Table S2 Mass transfer kinetic and physical-chemical parameters for the model

\begin{tabular}{|c|c|c|c|c|c|c|c|}
\hline Symbol & Unit & Parameters & Reference & $\begin{array}{c}\text { Data } \\
\text { Numbers }\end{array}$ & $\begin{array}{l}\text { Allocate Allocate } \\
\text { mean SD }\end{array}$ & $\begin{array}{l}\text { Geometric } \\
\text { mean }\end{array}$ & $\begin{array}{l}\text { Geometric } \\
\text { SD }\end{array}$ \\
\hline Ps & $\mathrm{Pa}$ & Local vapor pressure & $1-6$ & 7 & 1.13E-02 1.93E-02 & $1.24 \mathrm{E}-03$ & $3.20 \mathrm{E}+00$ \\
\hline $\mathrm{R}$ & $\begin{array}{l}\mathrm{Pa} \cdot \mathrm{m}^{3} / \mathrm{mol} \cdot \\
\mathrm{K}\end{array}$ & The gas constant & 1 & 1 & $8.31 \mathrm{E}+000.00 \mathrm{E}+00$ & $8.31 \mathrm{E}+00$ & $1.00 \mathrm{E}+00$ \\
\hline $\mathrm{F}_{25}$ & - & Fugacity ratio at $25^{\circ} \mathrm{C}$ & 7 & 1 & $8.84 \mathrm{E}-02-\mathrm{b}$ & 8.84E-02 & $1.00 \mathrm{E}+00$ \\
\hline $\mathrm{H}_{25}$ & $\mathrm{~Pa} \cdot \mathrm{m}^{3} / \mathrm{mol}$ & $\begin{array}{l}\text { Henry's constant } \\
\text { Fugacity ratio }\end{array}$ & $1,3,5,6$ & 5 & $2.98 \mathrm{E}-01$ 1.40E-01 & 2.61E-01 & $1.90 \mathrm{E}+00$ \\
\hline $\mathrm{BF}_{\mathrm{F}}$ & - & $\begin{array}{l}\text { temperature } \\
\text { correction factor } \\
\text { Henry's law constant }\end{array}$ & 7 & 1 & $1.24 \mathrm{E}+03-\mathrm{b}$ & $1.24 \mathrm{E}+03$ & $1.00 \mathrm{E}+00$ \\
\hline $\mathrm{BH}_{\mathrm{H}}$ & - & $\begin{array}{l}\text { temperature } \\
\text { correction factor }\end{array}$ & 7 & 1 & $3.09 \mathrm{E}+03-\mathrm{b}$ & $3.09 \mathrm{E}+03$ & $1.00 \mathrm{E}+00$ \\
\hline $\mathrm{BPs}$ & - & $\begin{array}{l}\text { Saturation vapor } \\
\text { pressure temperature } \\
\text { correction factor }\end{array}$ & r & 1 & $5.57 \mathrm{E}+03$ & $5.57 \mathrm{E}+03$ & $1.00 \mathrm{E}+00$ \\
\hline Кос & - & Adsorption coefficient & $1,3,5$ & 4 & $1.64 \mathrm{E}+032.79 \mathrm{E}+02$ & $1.62 \mathrm{E}+03$ & $1.19 \mathrm{E}+00$ \\
\hline Kow & - & $\begin{array}{l}\text { Octanol/water } \\
\text { partition coefficient }\end{array}$ & $1,3,5,13$ & 4 & $4.82 \mathrm{E}+032.30 \mathrm{E}+03$ & $4.60 \mathrm{E}+03$ & $2.32 \mathrm{E}+00$ \\
\hline $\mathrm{BCF}_{\mathrm{f}}$ & - & $\begin{array}{l}\text { Bioconcentration } \\
\text { factors for fish }\end{array}$ & 1 & 1 & $8.77 \mathrm{E}+02-\mathrm{b}$ & $8.77 \mathrm{E}+02$ & $1.66 \mathrm{E}+00$ \\
\hline $\mathrm{K}_{\mathrm{m} 1}$ & - & $\begin{array}{l}\text { Degradation rate of } \gamma- \\
\mathrm{HCH} \text { in air }\end{array}$ & $1,2,5,8,9$ & 5 & $9.69 \mathrm{E}-04$ 6.65E-04 & $6.66 \mathrm{E}-04$ & $1.73 \mathrm{E}+00$ \\
\hline $\mathrm{K}_{\mathrm{m} 2}$ & - & $\begin{array}{l}\text { Degradation rate of } \gamma \text { - } \\
\mathrm{HCH} \text { in water }\end{array}$ & - $1,2,5,10$ & 6 & $1.11 \mathrm{E}-04$ 5.55E-05 & 4.08E-05 & $1.74 \mathrm{E}+00$ \\
\hline $\mathrm{K}_{\mathrm{m} 4}$ & - & $\begin{array}{l}\text { Degradation rate of } \gamma \text { - } \\
\mathrm{HCH} \text { in sediment }\end{array}$ & $1,2,3,5,10$ & 7 & 2.38E-04 2.79E-04 & $1.26 \mathrm{E}-05$ & $3.98 \mathrm{E}+00$ \\
\hline $\mathrm{B}_{1}$ & $\mathrm{~m}^{2} / \mathrm{h}$ & $\begin{array}{l}\text { Molecular } \\
\text { diffusivities in air }\end{array}$ & $2,10,11,12$ & 4 & 2.49E-02 1.03E-02 & $2.36 \mathrm{E}-02$ & $1.44 \mathrm{E}+00$ \\
\hline $\mathrm{B}_{2}$ & $\mathrm{~m}^{2} / \mathrm{h}$ & $\begin{array}{l}\text { Molecular } \\
\text { diffusivities in water } \\
\text { Molecular }\end{array}$ & $2,10,11,12$ & 4 & 2.86E-06 1.17E-06 & $2.68 \mathrm{E}-06$ & $1.54 \mathrm{E}+00$ \\
\hline $\mathrm{B}_{4}$ & $\mathrm{~m}^{2} / \mathrm{h}$ & $\begin{array}{l}\text { diffusivities in } \\
\text { sediment }\end{array}$ & 2,12 & 2 & $1.43 \mathrm{E}-05$ 1.09E-05 & $1.20 \mathrm{E}-05$ & $2.34 \mathrm{E}+00$ \\
\hline $\mathrm{K}_{12^{\mathrm{a}}}$ & $\mathrm{m} / \mathrm{h}$ & $\begin{array}{ll}\text { Air-side } & \text { molecular } \\
\text { transfer } & \text { coefficient } \\
\text { over water } & \end{array}$ & $\begin{array}{l}\mathrm{r}^{13, \text { Calculat }} \\
\text { ed }\end{array}$ & 1 & $7.11 \mathrm{E}+00-\mathrm{b}$ & $6.68 \mathrm{E}+00$ & $1.43 \mathrm{E}+00$ \\
\hline $\mathrm{K}_{21^{\mathrm{a}}}$ & $\mathrm{m} / \mathrm{h}$ & $\begin{array}{l}\text { Water-side molecular } \\
\text { transfer } \\
\text { over air }\end{array}$ & $\begin{array}{c}\text { ed } \\
\text { ed }\end{array}$ & 1 & $2.08 \mathrm{E}-03-\mathrm{b}$ & 2.02E-03 & $1.24 \mathrm{E}+00$ \\
\hline $\mathrm{K}_{24}$ & $\mathrm{~m} / \mathrm{h}$ & $\begin{array}{l}\text { Water-side molecular } \\
\text { transfer coefficient } \\
\text { over sediment }\end{array}$ & t & 1 & $1.00 \mathrm{E}-02-\mathrm{b}$ & $1.00 \mathrm{E}-02$ & $1.59 \mathrm{E}+00$ \\
\hline $\mathrm{K}_{42}$ & $\mathrm{~m} / \mathrm{h}$ & $\begin{array}{l}\text { Sediment-side } \\
\text { molecular transfer } \\
\text { coefficient over water }\end{array}$ & 14 & 1 & $5.39 \mathrm{E}-06-\mathrm{b}$ & 5.39E-06 & $1.52 \mathrm{E}+00$ \\
\hline $\mathrm{K}_{42 \mathrm{r}^{\mathrm{a}}}$ & $\mathrm{m} / \mathrm{h}$ & $\begin{array}{l}\text { Sediment } \\
\text { resuspension rate }\end{array}$ & $\begin{array}{l}\text { 13, Calculat } \\
\text { ed }\end{array}$ & 1 & 2.92E-05 -b & $2.56 \mathrm{E}-05$ & $1.70 \mathrm{E}+00$ \\
\hline $\mathrm{L}_{4}$ & $\mathrm{~m}$ & Diffusion path lengths & 2 & 2 & 3.50E-02 2.12E-02 & $3.16 \mathrm{E}-02$ & $1.91 \mathrm{E}+00$ \\
\hline
\end{tabular}


Chapter 4

\begin{tabular}{|c|c|c|c|c|c|c|c|}
\hline & & in sediment & & & & & \\
\hline $\mathrm{K}_{\mathrm{p}}$ & $\mathrm{m} / \mathrm{h}$ & $\begin{array}{l}\text { Dry deposition } \\
\text { velocity }\end{array}$ & 2,10 & 2 & $1.04 \mathrm{E}+015.66 \mathrm{E}-01$ & $1.04 \mathrm{E}+01$ & $1.06 \mathrm{E}+00$ \\
\hline Ks & $\mathrm{m} / \mathrm{h}$ & $\begin{array}{l}\text { Water sedimentation } \\
\text { rates }\end{array}$ & 14,15 & 5 & 3.62E-06 4.34E-06 & $1.66 \mathrm{E}-06$ & $4.32 \mathrm{E}+00$ \\
\hline $\mathrm{K}_{w^{\mathrm{a}}}$ & $\mathrm{m} / \mathrm{h}$ & $\begin{array}{l}\text { Wet deposition } \\
\text { velocity }\end{array}$ & 14 & 1 & $1.33 \mathrm{E}-04-\mathrm{b}$ & $1.33 \mathrm{E}-04$ & $5.96 \mathrm{E}+00$ \\
\hline $\mathrm{S}_{\mathrm{c}}$ & - & Scavenging Ratio & 2,10 & 2 & $1.34 \mathrm{E}+059.33 \mathrm{E}+04$ & $1.17 \mathrm{E}+05$ & $2.14 \mathrm{E}+00$ \\
\hline
\end{tabular}

a Dynamic parameters for simulation \#2

b One value only; Geometric SD assigned manually (Log-normal distribution assumed, except for T)

References:

1) Cao, H.Y., Liang, T., Tao, S., Zhang, C.S., 2007. Simulating the temporal changes of OCP pollution in Hangzhou, China. Chemosphere, 67, 1335-1345.

2) Mackay, D., 2001. Multimedia Environmental Models: The Fugacity Approach, second ed. NewYork, USA: Lewis Publishers.

3) Cao, H.Y., Cao, J., Xu, F.L., Li, B.G., 2003. Fate and transfer flux of HCHs in Tianjin. Environmental Chemistry, 22, 548-554.

4) Cao, H.Y., Liang, T., Tao, S., 2005. Dynamic simulation and prediction of BHC transfer and residues in Beijing during 50 years. Science in China ser. D Earth Sciences, 35, 980-988.

5) Ao, J.T., Chen, J.W., Tian, F.L., Cai, X.Y., 2009. Application of a level IV fugacity model to simulate the long-term fate of hexachlorocyclohexane isomers in the lower reach of Yellow River basin, China. Chemosphere, 74, 370-376.

6) Dong, J.Y., Gao, H., Wang, S.G., Yao, H.J., Ma, M.Q., 2009. Simulation of the transfer and fate of HCHs since the 1950s in Lanzhou, China. Ecotoxicol Environ Saf, 72, 1950-1956.

7) Paasivirta, J., Sinkkonen, S., Mikkelson, P., Rantio, T., Wania, F., 1999. Estimation of vapor pressures, solubilities and Henry's law constants of selected persistent organic pollutants as functions of temperature. Chemosphere, 39, 811-832.

8) Prinn, R.G., Huang, J., Weiss, R.F., Cunnold, D.M., Fraser, P.J., Simmonds, P.G. et al. 2001. Evidence for substantial variations of atmospheric hydroxyl radicals in the past two decades. Science, 292, 1882-1888.

9) Brubaker, W.W., Hites, R.A., 1998. OH reaction kinetics of gas-phase alphaand gamma-hexachlorocyclohexane and hexachlorobenzene. Environ Sci Technol, 32, 766-769.

10) Breivik, K., Wania, F., 2002. Evaluating a model of the historical behavior of two hexachlorocyclohexanes in the Baltic Sea environment. Environ Sci Technol, 36, 1014-1023. 
Modeling $\gamma-\mathrm{HCH}$ in a phytoplankton-dominated shallow lake

11) Mackay, D., Paterson, S., 1991. Evaluating the multimedia fate of organicchemicals - a level-III fugacity model. Environ Sci Technol, 25, 427-436.

12) Cao, H.Y., Tao, S., Xu, F.L., Coveney, R.M., Cao, J., Li, B.G. et al. 2004. Multimedia fate model for hexachlorocyclohexane in Tianjin, China. Environ Sci Technol, 38, 2126-2132.

13) Tu, Q.Y., Gu, D.X., Yi, C.Q., Xu, Z.R., Han, G.Z., 1990. The researches on the Lake Chaohu eutrophication. Hefei: Publisher of University of Science and Technology of China.

14) Gu, C.J., 2005. Historical Sedimentary Records and Environmental Changes in Chaohu lake. [Master dissertation]. Shanghai: East China Normal University.

15) China Meteorological Data Sharing Service System (CMDSSS), 2010-2011. Daily Meteorological Data.

http://www.cma.gov.cn/2011qxfw/2011qsjgx/index.htm 
Chapter 4 


\section{Multimedia fate modeling of perfluorooctanoic acid (PFOA) and perfluorooctane sulphonate (PFOS) in the shallow lake Chaohu, China}

Xiangzhen Kong", Wenxiu Liu*, Wei He, Fuliu Xu, Albert A.

Koelmans, Wolf M. Mooij

* Authors contributed equally to the manuscript

Published in Environmental Pollution (2018) 237, 339-347 
Chapter 5

\section{Abstract}

Freshwater shallow lake ecosystems provide valuable ecological services to human beings. However, these systems are subject to severe contamination from anthropogenic sources. Per- and polyfluoroalkyl substances (PFASs), including perfluorooctanoic acid (PFOA) and perfluorooctane sulphonate (PFOS), are among the contaminants that have received substantial attention, primarily due to abundant applications, environment persistence, and potential threats to ecological and human health. Understanding the environmental behavior of these contaminants in shallow freshwater lake environments using a modeling approach is therefore critical. Here, we characterized the fate, transport and transformation of both PFOA and PFOS in the fifth largest freshwater lake in China (Chaohu) during a twoyear period (2013-2015) using a fugacity-based multimedia fate model. A reasonable agreement between the measured and modeled concentrations in various compartments confirmed the model's reliability. The model successfully quantified the environmental processes and identified the major sources and input pathways of PFOA and PFOS to the Chaohu water body. Sensitivity analysis revealed the critical role of nonlinear Freundlich sorption, which contributed to a variable fraction of the model true uncertainty in different compartments (8.1\%-93.6\%). Through additional model scenario analyses, we further elucidated the importance of nonlinear Freundlich sorption that is essential for the reliable model performance. We also revealed the distinct composition of emission sources for the two contaminants, as the major sources were indirect soil volatilization and direct release from human activities for PFOA and PFOS, respectively. The present study is expected to provide implications for local management of PFASs pollution in Lake Chaohu and to contribute to developing a general model framework for the evaluation of PFASs in shallow lakes. 
Modeling PFASs in a phytoplankton-dominated shallow lake

\section{Introduction}

Poly - and perfluoroalkyl substances (PFASs) are a group of chemicals that have been produced since the 1950s, and are highly used from the 1970s at a global scale (Lindstrom et al. 2011). After the prohibition of application in 2002 (3M 2003), the countries around the world have still reported the continuous production and application of PFASs, and its production increases annually. Both perfluorooctanoic acid (PFOA) and perfluorooctane sulphonate (PFOS) are the dominant PFASs that have attracted public attention (Loos et al. 2010). It is estimated that about $80 \%$ of perfluorocarboxylates (PFCAs) that have been released to the environment comes from "direct sources" including manufacture and use (Prevedouros et al. 2006). Due to their high water solubility and extreme resistance to thermal or biological degradation, PFOA and PFOS are currently globally distributed in abiotic and biotic media (Giesy and Kannan 2001, Naile et al. 2010). In this context, further investigation has revealed that these compounds are subject to long-range transport (Martin et al. 2004), exert toxic effects on aquatic organisms (Latała et al. 2009), and ultimately pose high health risks for human beings (Fromme et al. 2009, Domingo 2012). In 2009, PFASs were listed in Annex B of the Stockholm Convention (SCPOPs 2009).

Shallow lakes are ecosystems provide essential ecological services for both nature and human society (Millennium Ecosystem Assessment 2005). These systems are, however, receiving severe pressure from anthropogenic activities, including the deterioration of water quality by increasing contamination from substances such as PFASs (Kwadijk et al. 2010, Bao et al. 2012). It was suggested that the majority of PFASs released into soil will be transported to surface or groundwater bodies (Zareitalabad et al. 2013). Therefore, understanding the fate, transport and transformation of PFASs in shallow lake environments, particularly PFOA and PFOS, is a major scientific task and a priority for further development for source indicators, exposure evaluations and environment risk assessments of these substances. To this end, fugacity-based multimedia fate models have been successful in facilitating this investigation (Mackay 2001). To date, modeling approaches of PFASs, however, have generally focused on a regional (Liu et al. 2015a) or on a global scale (Armitage et al. 2009), whereas to the best of our knowledge models for specific lake environments are lacking. Modeling one lake can offer a more detailed description of the environmental behavior of chemicals, including a more specific understanding of the local environment with practical implications for managers. 
Lake Chaohu $\left(31^{\circ} 34^{\prime} \mathrm{N}, 117^{\circ} 34^{\prime} \mathrm{E}\right)$ is the fifth largest freshwater lake in China and is located in the lower reaches of the Yangtze River floodplain. The lake has a surface area of approximately $760 \mathrm{~km}^{2}$ and an average depth of $3 \mathrm{~m}$. The lake is "shallow" as the water column does not have the thermocline and thus is well-mixed without stratification during summer time (Lerman et al. 1995). During the past several decades, this lake has suffered from intensive human disturbance and has become one of the most eutrophic lakes in China (Kong et al. 2017a). Meanwhile, Lake Chaohu has been subject to severe pollution by persistent toxic substances (PTSs) (He et al. 2014) including PFASs (Liu et al. 2015b). A comprehensive evaluation of the distribution and dominant processes of PFASs in this lake using a modeling approach is highly valuable for lake managers. A specific version of a multimedia model for aquatic systems, termed the Quantitative Water Air Sediment Interaction (QWASI) model, has been developed and widely used (Mackay et al. 1983a, Tong et al. 2014). In our previous studies, models modified from the QWASI framework have been developed and applied to multiple PTS groups, including polycyclic aromatic hydrocarbon (PAHs) (Xu et al. 2013, Kong et al. 2017b) and hexachlorocyclohexane (HCHs) (Kong et al. 2014) in Lake Chaohu. The model is readily applicable to the simulation of PFASs on the basis of parameterization and validation against field data. In addition, based on the model analysis, it is relevant to test several hypotheses on PFASs pollution, such as the claimed importance of nonlinear sorption to organic matter (Higgins and Luthy 2006, Kwadijk et al. 2013) and the relative contribution of direct local industry emissions and indirect soil volatilization (Liu et al. 2017), which would provide important scientific basis and implications for PFASs pollution management in aquatic ecosystems.

The objectives of the present study are as follows: 1) to refine a multimedia fate model for PFOA and PFOS that describes their fate, transport and transformation in a lake environment, including air, water, soil and sediment; 2) to investigate parameter sensitivity and their contribution to the model uncertainty; and 3) to unravel the importance of processes such as nonlinear sorption and direct emissions to the model performance.

\section{Materials and methods}

\section{Data collection}

We collected field data for PFOA and PFOS concentrations in various environmental compartments in Lake Chaohu (see Table S1 for a summary of data sources). A two-year monthly dataset was available for atmospheric 
Modeling PFASs in a phytoplankton-dominated shallow lake

(gaseous and particulate, both active air samples) and aquatic (dissolved and suspended solids (SS)) samples between September 2013 and August 2015 at one site at the center of the lake. In addition, data for surface sediment and fish were collected during August 2011. To investigate the PFOA and PFOS inputs to the lake, data on the major rivers flowing into the lake were obtained in both March and September 2013 (unpublished data). The methods for sample collection and measurement are available elsewhere (Liu et al. 2015b). We also collected data from the literature as a supplement to this study. Overall, PFOA and PFOS observations were available for all modeled compartments, which provide adequate support to our model evaluation.

\section{Model development}

Our model is a fugacity-based level IV multimedia fate model for lakes modified from the QWASI model framework (Mackay et al. 1983a). Following our previous study (Kong et al. 2017b), we defined the four main compartments in our model, namely, air, water, soil and sediment (Fig. S1). There are several sub-compartments in each compartment, i.e., 1) gaseous form and aerosol particulates in air; 2) dissolved and SS in water; 3) air, water and solids in soil; and 4) pore-water and solids in sediment. We also defined the major transport and transformation processes of the contaminants (Fig. S1), including emissions from human activities, atmospheric outflow advection, water inflow/outflow advections, air-water/air-soil interface processes including diffusion, wet/dry deposition and rain scavenging, water-sediment interface processes including diffusion, sedimentation and resuspension, fish bioaccumulation and loss from fisheries, and finally, degradation in each of the main compartments. We assumed that emissions from direct sources and the nonlinear Freundlich sorption of carbonaceous materials both play critical roles in the environmental distribution of PFOA and PFOS. Therefore, these two processes were included in the model. Emissions are an input process directly to the air. Nonlinear Freundlich sorption, on the other hand, is applied to the solids in soil, SS and sediment by an additional term $\left(f_{B C} K_{F} C_{W}^{n}\right)$ to the formula for the calculation of the fugacity capacity $\mathrm{Z}$ (Table S2), which determines the sorption intensity (Moermond et al. 2007, Koelmans et al. 2009, Kwadijk et al. 2013). Here, $\mathrm{fBC}_{\mathrm{BC}}(-)$ is the fraction of carbonaceous material, $\mathrm{K}_{\mathrm{F}}\left((\mathrm{ng} / \mathrm{gBC}) /(\mathrm{ng} / \mathrm{L})^{\mathrm{nF}}\right)$ is the Freundlich coefficient for sorption to black carbon, $\mathrm{Cw}_{\mathrm{w}}(\mathrm{ng} / \mathrm{L})$ is the contaminant concentration in water (converted from value in unit of $\mathrm{mol} / \mathrm{m}^{3}$ during simulation), and $\mathrm{nF}(-)$ is the Freundlich exponent. In addition, given that the lake is shallow, we assumed equilibrium within each main compartment, in accordance with earlier modeling studies (Mackay and 
Chapter 5

Paterson 1991). Differential equations of the model are provided in the supporting information, together with the details of all the processes and the calculation equations (Table S2).

\section{Parameter determination}

Definition, statistics and sources for all the parameters in the model are listed in Tables S3-S7. In total, there are 59 parameters, including 42 environmental parameters and 17 chemical-specific parameters (mass transfer and physicochemical parameters). Among the 42 environmental parameters, 11 parameters vary seasonally, while the other 31 parameters remain constant during the model simulation. In addition, 3 out of the 17 chemical-specific parameters are dynamic. The values for these parameters were obtained from either the relevant literature or measured/calculated based on the conditions in Lake Chaohu. In particular, the emission intensity (To1h) was estimated for the region of Lake Chaohu based on the emission inventory for both PFOA and PFOS in China (Xie et al. 2013a, Xie et al. 2013b, Wang et al. 2015, Liu et al. 2017). In addition, temperature corrections were applied to both the subcooled liquid vapor pressure (Ps25; Pa) and Henry's law constant $\left(\mathrm{H}_{25} ; \mathrm{Pa} \cdot \mathrm{m}^{3} / \mathrm{mol}\right)$ at $25^{\circ} \mathrm{C}$ for both substances using the equation in Paasivirta et al. (1999). Furthermore, more than $99 \%$ of the PFOA will occur in its anionic form in water due to a low pKa value (2.8), implying that most of the PFOA does not partition into the gas phase (Goss 2007). We therefore adjusted the vapor pressure (Ps25) of PFOA dividing by the ratio of the anionic form to the neutral form $\left(\sim 10^{6}\right)$, resulting in a much lower Ps25 for PFOA. For the nonlinear sorption of PFOA and PFOS to carbonaceous materials such as black carbon in soil, SS and sediment, we assigned $\mathrm{fBC}_{\mathrm{BC}}$ to 0.002 , which has been shown to be valid in our previous modeling study of PAHs in Lake Chaohu (Kong et al. 2017b). For KF and $\mathrm{nF}$, we collected values from literature for sorption of PFOA and PFOS to different carbonaceous materials (Table S7). Results from Hansen et al. (2010) for both PFOA and PFOS were applied because they determined sorption parameters within environmentally relevant concentration ranges.

\section{Model simulations}

Our simulation duration was from September 2013 until August 2015, for a total of 24 months. Initial values were determined by the observations from September 2013 in different compartments. The model simulation ('Model-0') aimed at evaluating the ability of the model to predict the magnitude and seasonal variations of both the PFOA and PFOS concentrations in Lake Chaohu. In addition, we designed two additional scenarios termed as 
Modeling PFASs in a phytoplankton-dominated shallow lake

'Model-1' and 'Model-2'. In 'Model-1', we removed the nonlinear Freundlich sorption of PFOA and PFOS to carbonaceous materials in soil, SS and sediment solids, while all the other elements remained unchanged. By comparing the outcomes from 'Model- 0 ' and 'Model-1', we deciphered the likely impact of the sorption of carbonaceous materials on the modeling performance of both PFOA and PFOS. Additionally, in 'Model-2', the direct emission process to the atmosphere was eliminated. We aimed to evaluate the relative importance of direct (human release) and indirect (soil volatilization) sources in the local emissions of PFOA and PFOS so that we can provide implications for local environmental management. Note that these scenario analyses would not lead to model unbalance and the model would still comply with the law of conservation of mass. The model was implemented in MATLAB (MathWorks 2002). The differential equations were solved using a fourth-order Runge-Kutta method available in MATLAB (ode45) with a simulation time step of 1 hour.

\section{Model sensitivity and uncertainty analysis}

For the sensitivity analysis, we focused on the static parameters listed in both Tables S3 and S4. We used the "Morris method", which is also known as the "one-step-at-a-time" method (Morris 1991). This means that we varied the parameters one by one by multiplying them with a factor of either 1.1 or 0.9 , while all the other parameters remain constant. This method has shown its feasibility and reliability and has been extensively applied in contaminant fate modeling (Koelmans et al. 2000, Tao et al. 2006, Koelmans et al. 2017). The model usually responded linearly to the small variation applied to the parameters $(10 \%)$, thus does not affect the model but only reveals the importance of these parameters (Saltelli et al. 2000). Similar to previous studies (Cao et al. 2004, Kong et al. 2014), the sensitivity coefficient was calculated using the averaged data over the model simulation (two years), because we were investigating the global averaged rather than the temporally varied parameter sensitivity. Only the parameters contributing up to the $90^{\text {th }}$ percentile of the sensitivity across all the modeled compartments were indicated.

In addition, we determined the uncertainty of the model using Monte Carlo simulations. The uncertainty in model predictions usually can be distinguished into inherent variability and true uncertainty (McKone 1996). We quantitatively evaluated the two parts of model uncertainty by calculating the coefficient of variation (CV) of both measured and modeled contaminant concentrations (after log-transformation) in different compartments. CVs of the measured concentrations were considered as the inherent variability, while 
CVs of the modeled data were the combination of the two parts of uncertainty (Tao et al. 2006). We focused on the most sensitive parameters identified by the sensitivity analysis above, of which the contribution to the uncertainty of model predictions was assumed to be dominant. Distributions of these parameters were determined by the values collected from the literature. The Monte Carlo simulations used 3,000 parameter combinations randomly sampled from the predefined statistical distributions of these parameters. All of the simulated values for each compartment in each model run were collected and analyzed.

\section{Results and discussion}

\section{Model validation}

Our model validation on contaminant concentrations was based on both overall-averaged and monthly-varied data. For the overall-averaged validation, our model showed an acceptable performance for both PFOA and PFOS in various compartments in Lake Chaohu (Fig. 1). The log-transformed deviation between the measured and modeled PFOA concentrations in the gas phase, aerosol solid phase, dissolved state in water, SS, fish, soil and sediment solid phases were $0.31,0.27,0.24,1.11,0.14,0.39$ and $0.19 \log$ units, respectively. For PFOS, these deviations were 1.23, 0.23, 0.21, 1.22, 0.54, 0.57 and $0.46 \log$ units, respectively. Deviations between the measured and modeled concentrations in 11 out of the 14 compartments ( 7 for PFOA and 7 for PFOS) were lower than $0.7 \log$ units, a criterion based on which the contaminant fate model can be considered acceptable (Cowan et al. 1995, Kong et al. 2017b). Exceptions were PFOA in SS (1.11), and PFOS in the gas phase (1.23) and SS (1.22).

We infer that the underestimation of the PFOS concentration in the gas phase (Fig. 1) may result from the underestimated direct emission of PFOS to the atmosphere in the Lake Chaohu area. In fact, the emission flux for PFOS in our model ( $0.35 \mathrm{~mol} / \mathrm{h}$; Table S4) was estimated at the provincial level in China (Xie et al. 2013b), while Lake Chaohu is located in the most developed region in the province. Higher regional emission of PFOS to the Lake Chao area would be expected as the consequences of local or regional industrial production of PFASs (Liu et al. 2015b). We subsequently applied the "inverse modeling" approach (Parajulee and Wania 2014) to estimate the emission flux to air that would be required to explain measured PFOS concentrations in the gas phase. The model will meet the "0.7 log units" criteria for PFOS in the gas phase if the emission flux would be set to $1.25 \mathrm{~mol} / \mathrm{h}$, which was more than three times higher than the reported flux. We, however, retained the original 
Modeling PFASs in a phytoplankton-dominated shallow lake

emission flux $(0.35 \mathrm{~mol} / \mathrm{h})$ in our model because it was evidence-based estimation from literature. Nonetheless, our model revealed a vast underestimation of the PFOS emission inventory in Lake Chaohu area, which thus requires further refinement to increase the spatial resolution.
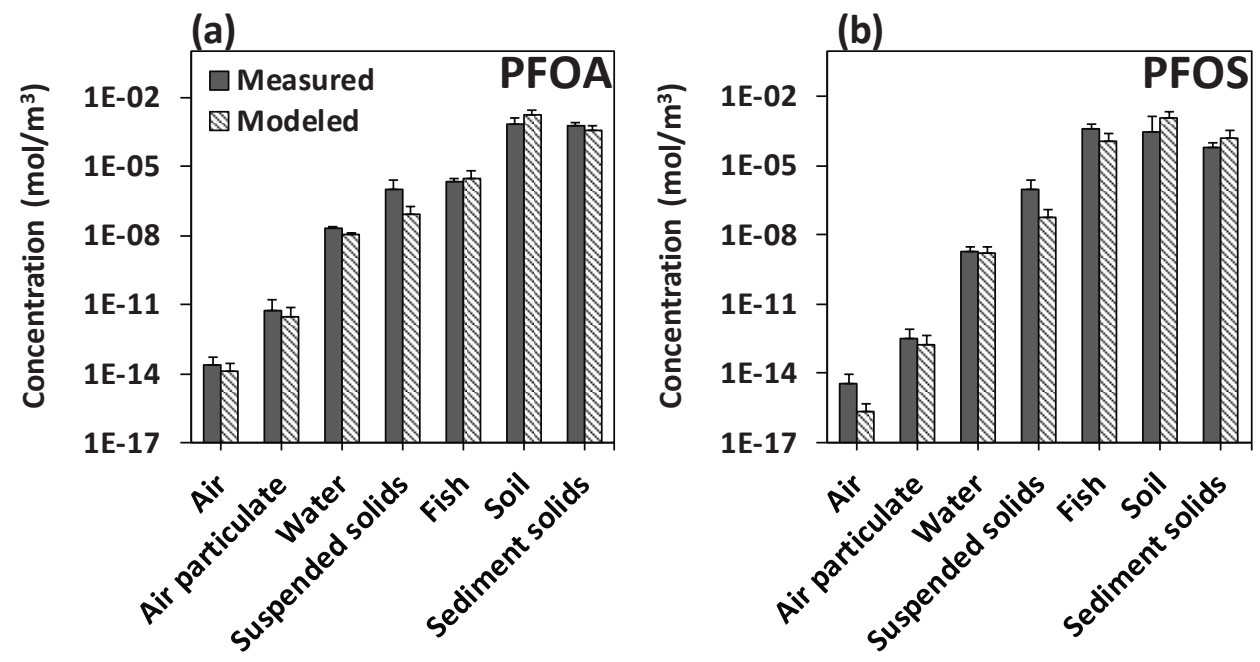

Fig. 1. Comparison of measured and modeled concentrations on a logarithmic scale averaged over the simulation period for PFOA (a) and PFOS (b). Error bars for the measured data of air, air particulates, water and suspended solids relate to the standard deviation (s.d.) of monthly observations. Error bars for the measured data of fish, soil and sediment solids relate to the s.d. of multiple samples. Error bars for the modeled data relate to s.d. of simulation outputs.

It is intriguing that our model underestimated the contaminant concentration in SS for both PFOA and PFOS by approximately an order of magnitude (Fig. 1). Bias in model structure and parameterization can both lead to deficiency of model prediction capacity, which may become a contradiction in modeling approach. We suggest that the leading factor for the underestimation in SS would be the bias in model structure rather than that in parametrization. This is because the values for all the parameters in our model were preassigned and not calibrated during the model simulation, while the model also performed well for the other compartments in the water column simultaneously (dissolved and fish). Oversimplified model may have to compensate the bias in structure by unrealistic parameterization. Increasing the 
model complexity in structure to an intermediate level rather than calibrating parameters would be more beneficial. As a result, we advocate changing the model structure to improve model performance. The incorporation of nonlinear sorption to carbonaceous materials has further reduced the deviations of the model prediction in SS (see below) but this was still insufficient to overcome the lack of fit. Since our SS samples were filtered from the water samples with a $0.45-\mu \mathrm{m}$ glass fiber filter (GFF), plankton was not excluded from the contaminant data in SS (Kong et al. 2014). Hence, the bias may be attributed to this missing component in the model framework for SS, namely zooplankton and phytoplankton. Plankton has been identified as a critical player in driving the fate and transport of POPs in freshwater and marine environments (Dachs et al. 2000). Serving as the 'biological pump', plankton, particularly abundant phytoplankton such as cyanobacteria in eutrophic lakes, can vastly alter the residue levels and seasonal variations of POPs in water and sediment by dictating processes such as air-water exchange, sorption, accumulation and the SS sinking flux (Nizzetto et al. 2012, Tao et al. 2017). PFASs are no exception in this matter (Casal et al. 2017), particularly for lakes such as Chaohu that has been subjected to intensive eutrophication and severe phytoplankton blooms in recent years (Jiang et al. 2014, Yang et al. 2016). In addition, PFOS is commonly recognized as a substance that is subject to biomagnification (Conder et al. 2008, de Vos et al. 2008, Loi et al. 2011). Modeling the food web accumulation and magnification (Kong et al. 2017b) would be a vital step towards a better understanding of the fate of PFASs in lake environments. In our previous model analysis of PAH behavior in Lake Chaohu, we observed a good fit of different PAHs between model predictions and field data in SS (Kong et al. 2017b), for which the inclusion of phytoplankton was crucial. However, in this study, we did not incorporate the plankton or the food web due to the lack of relevant parameters for PFASs sorption/accumulation in plankton and the unavailable PFASs observations in aquatic organisms other than fish. We anticipate that the food web-inclusive multimedia fate modeling for PFASs will lead to better understanding of the fate of PFASs in biota and further improved model performance, which would be a prerequisite for risk assessment and environmental management of PFASs contamination.

We use $\mathrm{R}^{2}$ as a criterion for the evaluation of the model performance in seasonal variations (Fig. S2). For PFOA in gaseous form, aerosol particulates, dissolved state and SS, the $\mathrm{R}^{2}$ values were $0.03,0.01,0.41$ and 0.43 , respectively. For PFOS, these values were $0.01,0.02,0.10$ and 0.45 , respectively. In addition, we observed that the model-predicted concentrations in the gas phase were greater during warm seasons for both PFOA and PFOS, while air particulates 
Modeling PFASs in a phytoplankton-dominated shallow lake

were greater during cold seasons. For water and SS, the modeled data were generally greater during the winter and spring than those in the summer and autumn.

Our model performed better for the aquatic than the atmospheric compartments in terms of the seasonality, whereas the general performance in seasonality modeling remains unsatisfactory with the $\mathrm{R}^{2}$ ranged from 0.01 to 0.45 . This is the case not only in here but also in other previous studies (Lang et al. 2007, Kong et al. 2014). We attribute this to the following two reasons: 1) insufficient sampling size. Using monthly samples from one site could be sufficient for model validation on an average scale, but may lead to increasing uncertainty if these data are used as the representation of the monthly average values due to spatial and temporal heterogeneity. Monitoring data in riverine inflows was also limited. Intensified sampling on both spatial and temporal scales may further reduce the uncertainty. 2) the simplified nature of the fugacity model compared to real conditions. Many influential internal processes for PFASs cycling in lakes, such as organic carbon cycling and phytoplankton growth, are currently not included. Integrating the multimedia fate model to an aquatic ecosystem model (Janssen et al. 2015, Kong et al. 2017a) that accounts for the in-lake abiotic and biotic processes could be a potential solution (Koelmans et al. 2001, Lohmann et al. 2007, Kong et al. 2017b), which, however, would be at the expense of increasing model complexity and propagating uncertainty.

\section{Mass transfer fluxes}

The averaged mass transfer fluxes of PFOA and PFOS over the simulation period provide a systematic view on the environmental behavior of the contaminants (Fig. 2). The primary sources of PFOA and PFOS were the emission flux to the air and erosion of soil to the lake, while the major output pathway was water outflow. For PFOA, degradation was much greater in soil and sediment than that in air and water. On the other hand, degradation for PFOS in various compartments were negligible. This is primarily due to the higher persistence of PFOS than PFOA (Armitage et al. 2009), as the degradation rates of PFOS are one order of magnitude lower in air and water, and 3-4 orders of magnitude lower in soil and sediment than those of PFOA (Table S4). For the interface processes, the major fluxes between air and water were dry/wet deposition and rain scavenging, among which rain scavenging contributed over 90\% (PFOA) and $80 \%$ (PFOS) of the interface processes. In addition, PFOA diffusion from water to air is approximately 4 orders of magnitude greater than it is for PFOS. For the air and soil interface, PFOA and 
PFOS showed distinct features that the PFOA exchange was much more intensive than that for PFOS. The diffusion flux from soil to air was high for PFOA, which suggested an indirect emission source in addition to direct anthropogenic release. For the water-soil interface, the major process was soil erosion for both PFOA and PFOS, which served as the major input to the water. For the water-sediment interface, sedimentation surpassed the other processes, which was another output pathway of PFOA and PFOS from the water in addition to outflow advection. For the water-sediment subsystem in the lake, the model suggested that the annual average net input and output of PFOA were approximately 0.454 and 0.377 tons, respectively, and were approximately 0.243 and 0.142 tons, respectively, for PFOS. The results imply that over the period of 2013-2015 in Lake Chaohu, PFOA and PFOS were accumulating at a rate of 0.077 and 0.101 tons/year, respectively.

Our model evaluation indicated that soil erosion was the dominant source for both PFOA and PFOS in the water body of Lake Chaohu, while water inflow and atmospheric deposition played secondary roles. This pattern is consistent with observations in other lakes, where the transport of PFOA and PFOS from soil to water bodies was significant due to the enhanced sorption capacity of the chemicals in situ (Kim and Kannan 2007, Zareitalabad et al. 2013). The model also revealed that water was not a permanent sink for PFOA and PFOS, since most of the contaminants would be transported to the sediment or removed from the system via riverine outflow. A similar finding was also reported by McMurdo et al. (2008).

\section{Parameter sensitivity and model uncertainty}

The parameters that contribute to the sensitivity of the $90^{\text {th }}$ percentile were identified (Fig. S3). We found that the most sensitive parameters were nF (the parameter defining the nonlinearity of the Freundlich sorption isotherm) and $\mathrm{K}_{\mathrm{F}}$ (Freundlich sorption distribution coefficient) for both PFOA and PFOS, regardless of their distinct values particularly for $\mathrm{nF}$ (Table S7). These two parameters are both related to the nonlinear Freundlich sorption by carbonaceous materials. Hence, the results of the parameter sensitivity analysis, at least in part, support our assumption that nonlinear Freundlich sorption plays critical role in PFOA and PFOS environmental distribution. We further noticed that $\mathrm{n}_{\mathrm{F}}$ and $\mathrm{K}_{\mathrm{F}}$ could influence the PFOA level in both the gas phase and aerosols, which however was not the case for PFOS. The difference might primarily be attributed to the much lower interactions on the interface of air/water and air/soil of PFOS than those of PFOA (Fig. 2). Other sorption related parameters, such as fraction of carbonaceous materials $\left(\mathrm{f}_{\mathrm{BC}}\right)$ and solid 
Modeling PFASs in a phytoplankton-dominated shallow lake

density (r23, $\mathrm{r}_{33}$ and $\mathrm{r}_{43}$ ), were also identified as sensitive but with relatively lower influence. Our results further reflect the need to identify the role of sediment components (e.g., black carbon) in the sorption of PFASs within aquatic systems (Selck et al. 2012).

\section{a) PFOA}

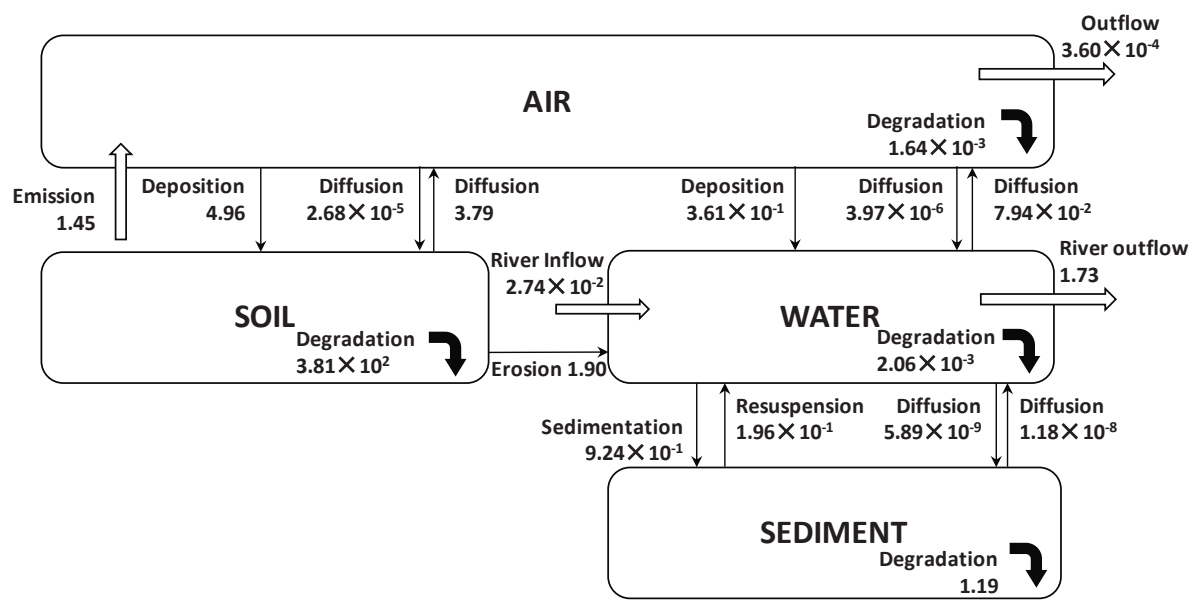

b) PFOS

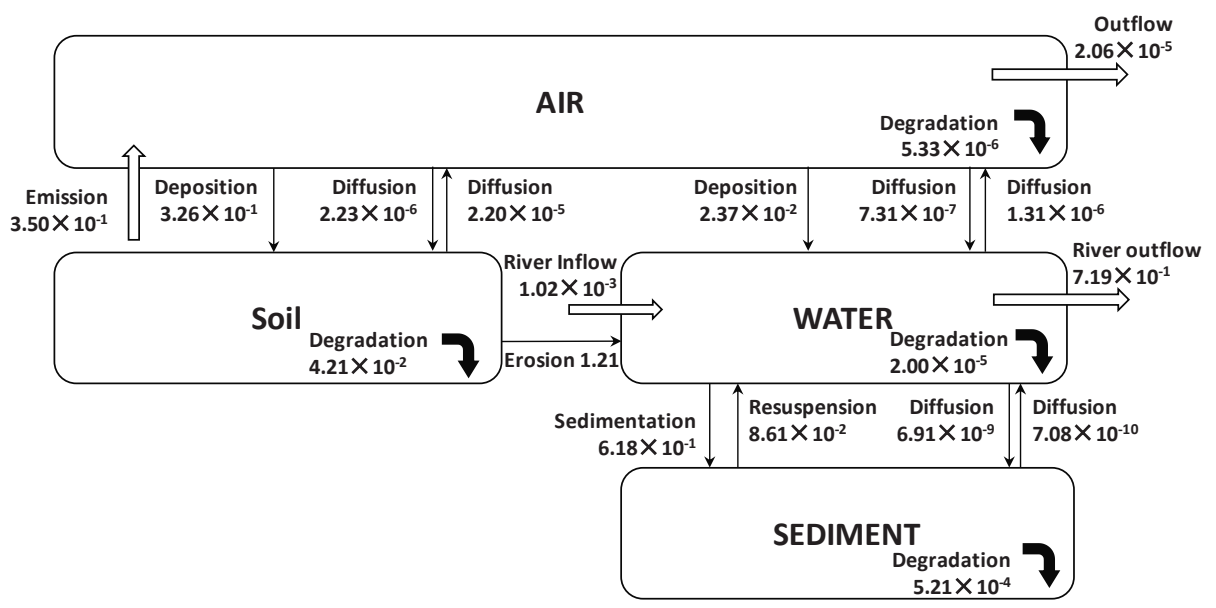

Fig. 2. Modeled transport and transformation fluxes $(\mathrm{mol} / \mathrm{h})$ averaged over the simulation duration for (a) PFOA and (b) PFOS. 
For the other sensitive parameters, many of them are soil-related, indicating the importance of soil acting as the major sink and source of the contaminants. Note that parameters including $\mathrm{K}_{\mathrm{m} 3}, \mathrm{~K}_{13}$ and $\mathrm{L}_{3}$ were only sensitive for PFOA because the air-soil interactions were much stronger for PFOA than for PFOS (Fig. 2). In addition, the vapor pressure (Ps25), Henry's law constant $\left(\mathrm{H}_{25}\right)$ and their temperature adjustment parameters ( $\mathrm{BH}_{\mathrm{H}}$ and $\left.\mathrm{BPs}\right)$ were also found to be critical. Other significant parameters for the model were those that dictated the major mass transfer fluxes, such as $\mathrm{U}_{e}, \mathrm{~K}_{245}, \mathrm{~K}_{\mathrm{p}}$ and Sc, and volume parameters that determined the intensity of the major fluxes (e.g., degradation in soil) such as $\mathrm{A}_{3}$, $\mathrm{h}_{3}$ and $\mathrm{h}_{4}$.

We further evaluated the contributions of the sensitive parameters related to the nonlinear sorption process $\left(\mathrm{nF}_{\mathrm{F}} \mathrm{KF}_{\mathrm{F}} \mathrm{fBC}_{\mathrm{BC}} \mathrm{r}_{23}, \mathrm{r}_{33}\right.$ and $\left.\mathrm{r}_{43}\right)$ to the model uncertainty. The statistic distributions for $\mathrm{n}_{\mathrm{F}}$ and $\mathrm{K}_{\mathrm{F}}$ were determined based on the literature data (Table S7). For fвC, a median value of 0.002 with a CV of 2.5 was assigned based on Hauck et al. (2007). Variations in $\mathrm{r}_{23}$, $\mathrm{r}_{33}$ and $\mathrm{r}_{43}$ were ascertained based on the data from Cao et al. (2004). We found that the dispersions of the modeled concentrations were consistently larger than those of the measured concentrations in all model compartments for both PFOA (Fig. 3) and PFOS (Fig. 4). True uncertainty of the model (due to uncertainty in model parameter) could be represented by the differences of CVs of the model outputs (the total model uncertainty) and the CVs of the measured concentrations (inherent variability due to spatial and/or temporal variations). Our results suggested that the true uncertainty of the model accounted for from $8.1 \%$ (PFOA in SS) to $93.6 \%$ (PFOA in water) of the total model uncertainty. For water, fish and sediment solids, the true model uncertainties were the predominant source of uncertainty in model predictions for both PFOA and PFOS. Note that the true uncertainty determined above was only from the variations of parameters related to nonlinear sorption process. The true uncertainty would be even larger if more parameters would be included in the Monte Carlo simulation. Nonetheless, we highlighted the importance of nonlinear sorption process to model predictions of PFOA and PFOS in lakes by quantitatively showing the high contribution of nonlinear sorption parameters to model uncertainty, particularly for the water, fish and sediment solids compartments. More accurate data for these parameters with much lower variations than those shown in Table S7 would be an effective way to reduce the model uncertainty. 
Modeling PFASs in a phytoplankton-dominated shallow lake
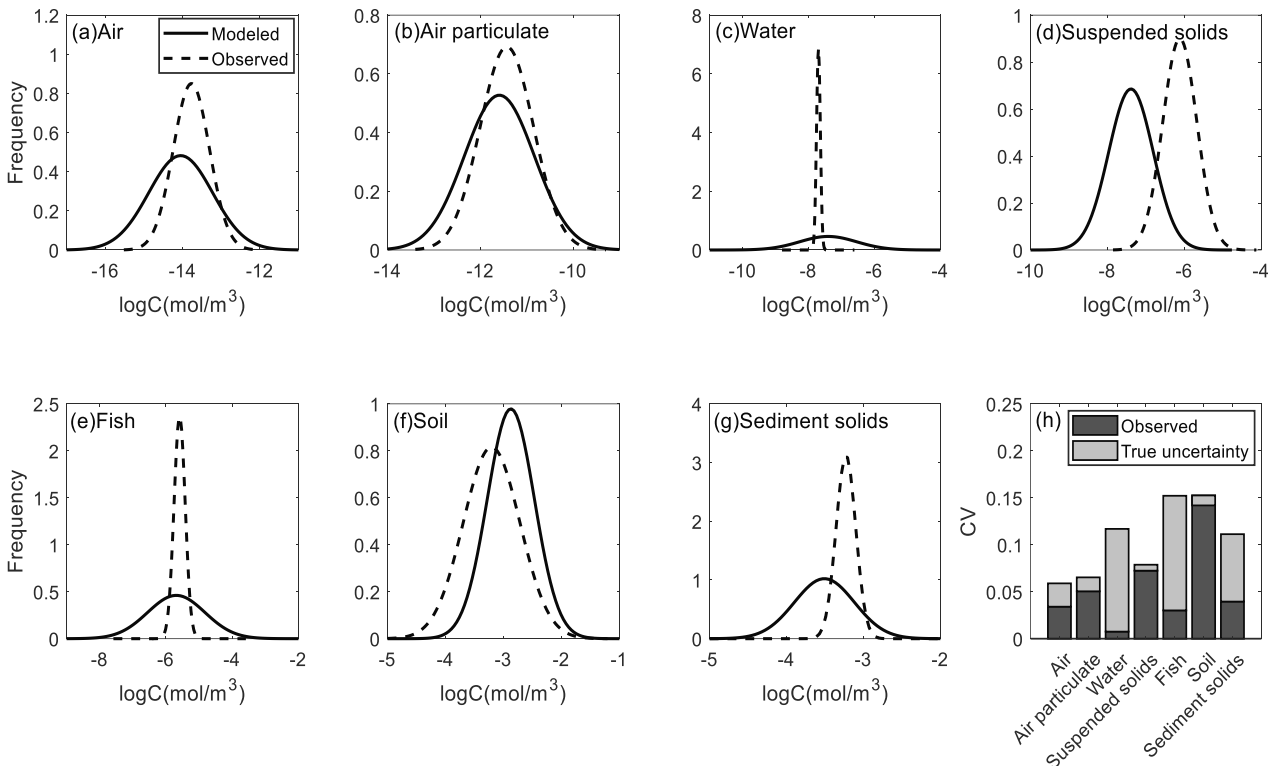

Fig. 3. (a-g) Comparison of the log-transformed distributions of the observed and the modeled PFOA concentrations in the seven compartments. The observed distributions were generated based on geometric means and standard deviations of the measured concentrations, while the modeled distributions were obtained from Monte Carlo simulation. (h) Comparison of the observed variability (reflected by the CVs of the observed concentrations) and the true uncertainty of the model (represented by the differences between the CVs of the concentrations from Monte Carlo simulation and the CVs of the observed concentrations) in the seven compartments.

\section{Model scenarios}

Comparing the model scenario 'Model-1' to 'Model-0', we observed a drastic loss in modeling performance in terms of both magnitude and seasonal variations after the removal of nonlinear Freundlich sorption (Fig. S4). For water and fish, the deviation between the measured and modeled data increased by approximately $3 \log$ units for both PFOA and PFOS (Fig. S4a and b). For air and air particulates, PFOA was more sensitive to the missing nonlinear Freundlich sorption than PFOS, since the deviations of PFOA also increased to over $3 \log$ units. Meanwhile, deviations between the measured and modeled concentrations of PFOA and PFOS in other compartments were generally similar in 'Model- 1 ' and 'Model- 0 '. In addition, the model showed a reduced power in the prediction of seasonal variations for water, as the $\mathrm{R}^{2}$ 
decreased from 0.41 to 0.04 for PFOA, and from 0.11 to 0.01 for PFOS (Fig. S4cf).
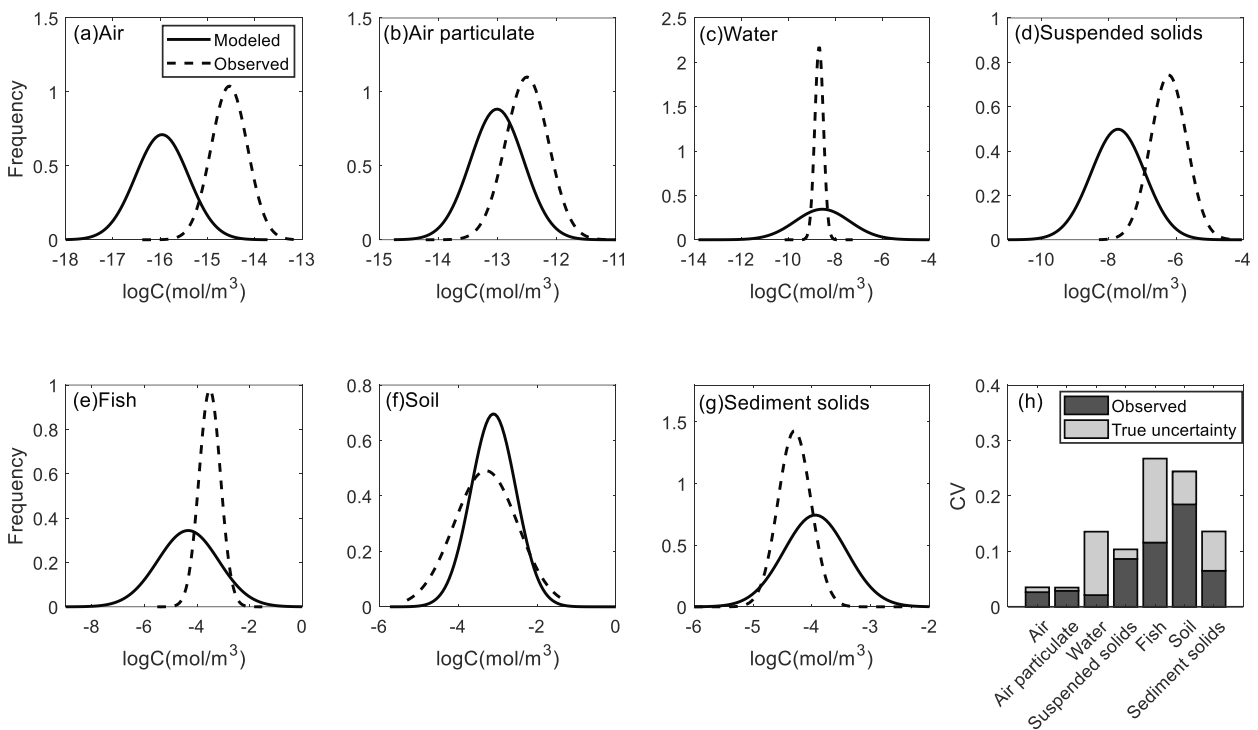

Fig. 4. (a-g) Comparison of the log-transformed distributions of the observed and the modeled PFOS concentrations in the seven compartments. The observed distributions were generated based on geometric means and standard deviations of the measured concentrations, while the modeled distributions were obtained from Monte Carlo simulation. (h) Comparison of the observed variability (reflected by the CVs of the observed concentrations) and the true uncertainty of the model (represented by the differences between the CVs of the concentrations from Monte Carlo simulation and the CVs of the observed concentrations) in the seven compartments.

There is little consensus regarding the sorption characteristics of PFASs to organic matter at present. It remains uncertain, particularly for PFOS with a Freundlich exponent close to unity (0.9) (Higgins and Luthy 2006, Kwadijk et al. 2013), whether the linear partitioning process would be sufficient to describe the sorption of PFASs to soil and sediment or not (Ahrens et al. 2011). Laboratory experiments on PFOA and PFOS based on linear partitioning suggested an average logKoc of approximately 2.06 for PFOA and 2.88 for PFOS (Higgins and Luthy 2006), while in situ data suggested higher logKoc values for both PFOA and PFOS, without which overestimation of PFASs concentrations in water would occur (Zareitalabad et al. 2013). In the 'Model-1' 
Modeling PFASs in a phytoplankton-dominated shallow lake

scenario, applying $\log K o c$ values from in situ data assuming linear partitioning resulted in vastly biased predictions compared to field data. The better performance of the 'Model- 0 ' compared to the 'Model-1' scenario relies on two factors. First, we applied the parameter values for sorption of PFOA from the experimental study within the environmental relevant concentration ranges (Hansen et al. 2010). The nonlinearity in the sorption process was strong for PFOA $(\mathrm{n} F=0.6)$ and therefore inclusion of nonlinear Freundlich sorption became essential. Second, despite a Freundlich exponent close to unity (0.9) for PFOS (Kwadijk et al. 2013), the nonlinear Freundlich sorption process in our model may have compensated for the largely underestimated logKoc values in experimental studies compared to the in situ situation. Overall, in concert with the sensitivity analysis, the 'Model-1' scenario suggested that nonlinear Freundlich sorption of carbonaceous materials was critical in modeling PFOA and PFOS in lake ecosystems, even though the nonlinear process is approaching linear for PFOS.

Partitioning of PFASs between water and particles can be very complicated (Ahrens et al. 2010). In addition to carbonaceous components, other factors, such as sediment density, $\mathrm{Ca}^{2+}, \mathrm{pH}$ and salinity, can also play significant roles (Higgins and Luthy 2006, Ahrens et al. 2009, Chen et al. 2009, Ahrens et al. 2010, Kwadijk et al. 2013, Du et al. 2014), which are not explicitly considered in our model. A more general sorption model describing the effect of electrostatic interactions (Higgins and Luthy 2007) may be an alternative way to more accurately model PFOA and PFOS in future studies, if more data on these environmental conditions are available.

From 'Model-2', we observed a higher sensitivity of PFOS to emissions from "direct" sources than PFOA (Fig. S4). Once the "direct" emission flux was removed, the deviation between the measured and modeled PFOS data in air and air particulates drastically increased to an unreasonable level, while for PFOA, the model performance remained similar between 'Model- 0 ' and 'Model-2'. The insensitivity of PFOA to the removal of the emission flux was attributed to the diffusion from soil to air as another "indirect" source in addition to the 'direct' emission flux from industrial and domestic activities to air (Fig. 2). This is consistent with previous observations that volatilization was one of the most important processes for PFOA (Goss 2007). On the other hand, the "direct" source dominated the emission pathway for PFOS and the diffusion flux from soil to air was much lower than that for PFOA (Fig. 2), because PFOS is less prone to partitioning in air and water than PFOA (Goss 2007) but is subject to sorption on organic matter due to a lower Henry's law constant and a higher $\mathrm{K}_{\mathrm{F}}$ (Tables S4 and S7). 
The 'Model-2' scenario reveals the distinct emission source to air for PFOA and PFOS due to their different chemical properties. Nevertheless, the residual levels of PFOA and PFOS in other compartments including water and sediment were hardly sensitive to the changes in direct emission fluxes to the air (Fig. S4), because the soil erosion was the major source of contamination (Fig. 2). For the local environmental managers, these results may have important implications for management strategies on these two contaminants. For air pollution, the control on the release pathway to soil that subsequently became the "indirect" source should become the priority in management for PFOA, while the "direct" emissions to air from industrial production and manufacture deserve more attention for PFOS. On the other hand, controlling water pollution from PFOA and PFOS would be more effective if we focus more on soil erosion in the catchment.

\section{Conclusion}

In the present study, we managed for the first time to establish a fugacity-based multimedia fate model for PFOA and PFOS in a shallow lake environment. The model provided a quantitative evaluation of the fate, transport and transformation of the two contaminants in shallow Lake Chaohu over a two-year period. A comparison with field data confirms the reliability of the model predictions. Our model revealed the critical role of nonlinear Freundlich sorption, which contribute to a significant part to the uncertainty in modeling predictions on PFOA and PFOS in aquatic systems. Furthermore, model scenarios confirm the importance of nonlinear Freundlich sorption that led to a reliable model performance, and also identified the distinct emission sources of the two contaminants. In future work, it would be valuable to test the model in a second lake to see if the model also works for a similar location, thereby increasing the validity and extending the application domain of the model. We expect that our study will provide implications for the environment assessment on the exposure levels and risks of PFASs in Lake Chaohu, and contribute to developing a general model framework for the evaluation of PFASs in other shallow lakes.

\section{Acknowledgments}

Funding for this study is provided by the National Science Foundation of China (NSFC) (41603088, 41030529, and 41271462), the National Project for Water Pollution Control (2012ZX07103-002) and the National Foundation for 
Modeling PFASs in a phytoplankton-dominated shallow lake

Distinguished Young Scholars (40725004). This work is also supported by the 111 Project (B14001) and project funded by China Postdoctoral Science Foundation. We thank the two anonymous reviewers who provided constructive comments and suggestions to improve the manuscript. This is publication 6491 of the Netherlands Institute of Ecology (NIOO-KNAW). The authors declare no conflicts of interest. 
Chapter 5

\section{Supplementary materials}

\section{SI text: Model equation}

The differential equations for the model are shown as follow:

$$
\begin{aligned}
& \text { Air : } \frac{V_{1} Z_{1} d f_{1}}{d t}=T_{\substack{\text { Emission } \\
\text { Advection }}}-T_{10 t}^{\left(T_{12 d}+T_{12 p}+T_{12 r}+T_{12 w}-T_{21 d}\right)}-\underbrace{\left(T_{13 d}+T_{13 p}+T_{13 r}+T_{13 w}-T_{31 d}\right)}_{\text {Air-water interaction }}-\underbrace{}_{\text {Air-soil interaction }} T_{10 m} \\
& \text { Water: }: \frac{V_{2} Z_{2} d f_{2}}{d t}=\underbrace{T_{02 t}-T_{20 t}}_{\text {Advection }}+\underbrace{\left(T_{12 d}+T_{12}+T_{12 r}+T_{12 w}-T_{21 d}\right)}_{\text {Air-water interaction }}-\underbrace{\left(T_{24 d}+T_{24 s}-T_{42 d}-T_{42 r}\right)}_{\text {Water-sediment interaction }} \\
& +\underbrace{T_{32 e}-T_{20 m}-T_{2 f}}_{\text {Soil erosion Degradation Fishery }} \\
& \text { Soil : } \frac{V_{3} Z_{3} d f_{3}}{d t}=\underbrace{\left(T_{13 d}+T_{13 p}+T_{13 r}+T_{13 w}-T_{31 d}\right)}_{\text {Air-soil interaction }}-\underbrace{T_{32 e}-T_{30 m}}_{\text {Soil erosion }} \\
& \text { Sediment: } \frac{V_{4} Z_{4} d f_{4}}{d t}=\underbrace{\left(T_{24 d}+T_{24}-T_{42 d}-T_{42}\right)}_{\text {Water-sediment interaction }}-\underbrace{T_{40 m}}_{\text {Degradation }}
\end{aligned}
$$

where $f_{i}(i=1,2,3,4)$ denotes the fugacity $(\mathrm{Pa})$ in the different compartments. The model labelling for the main compartments is: " 1 " for air, " 2 " for water, " 3 " for soil and " 4 " for sediment. See Table S2 for a detailed description on the terms in the equations. 


\section{SI figure}

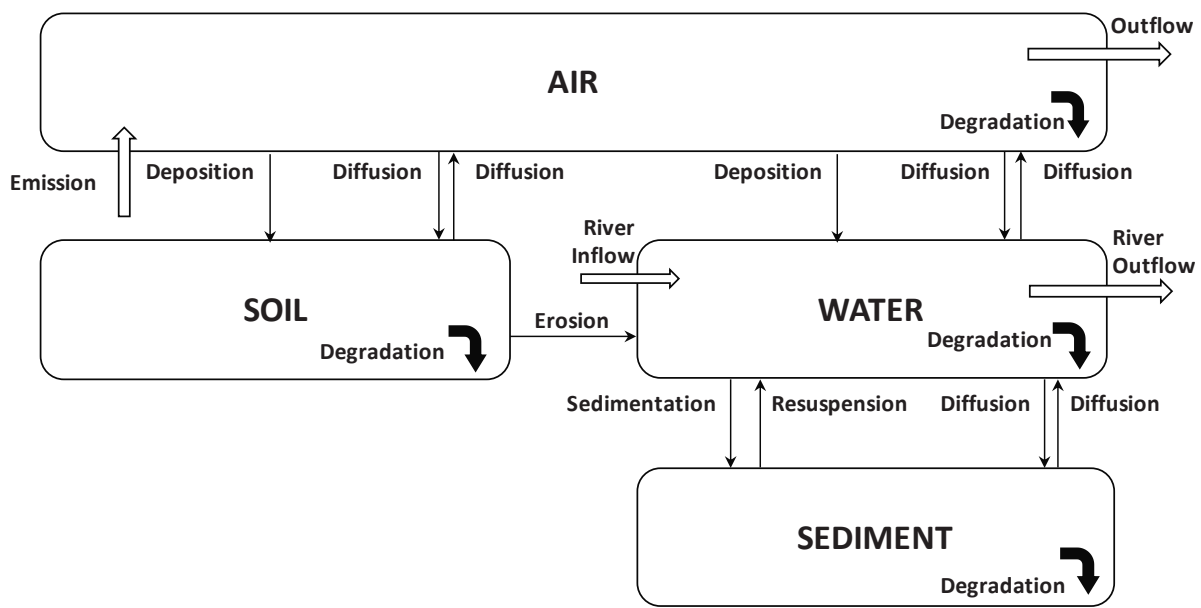

Fig. S1. Conceptual framework of the model. Transport and transformation fluxes in and out of the lake and between the adjacent compartments are presented. See Table S2 in the supporting information for the details of all the defined processes.
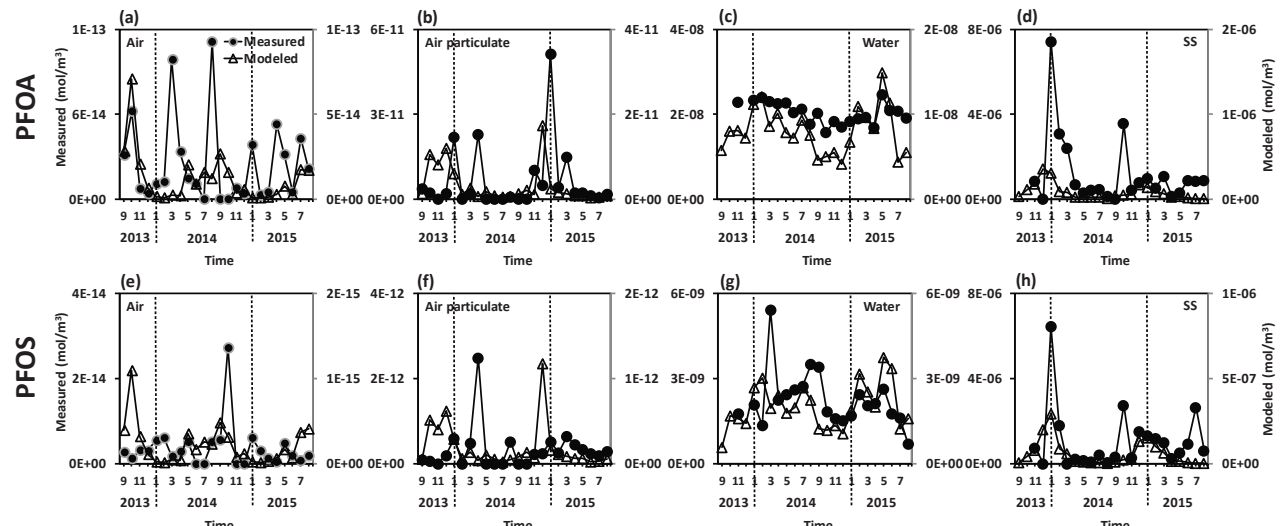

Fig. S2. Comparison of measured and modeled concentrations with seasonal variations. (a-d) Comparison of measured and modeled data with seasonal variations for PFOA in air, air particulates, water and suspended solids. (e-h) Comparison of measured and modeled data with seasonal variations for PFOS in air, air particulates, water and suspended solids. 


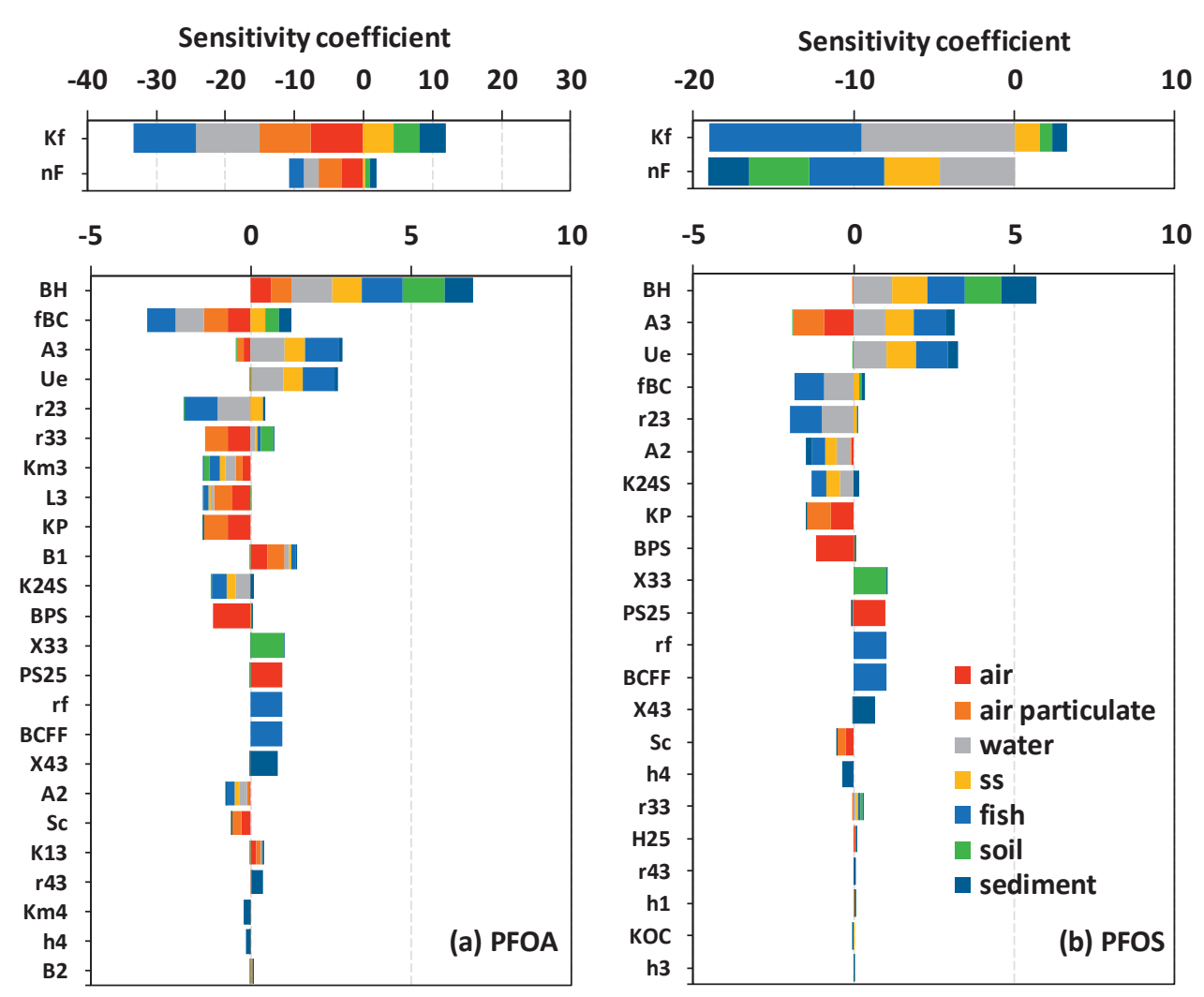

Fig. S3. Sensitivity coefficients of the modeled concentrations in the six compartments to the input parameters for (a) PFOA and (b) PFOS. Only the parameters that contribute to the sensitivity of the $90^{\text {th }}$ percentile are presented. See Tables S3 and S4 in the supporting information for parameter descriptions. 
Modeling PFASs in a phytoplankton-dominated shallow lake
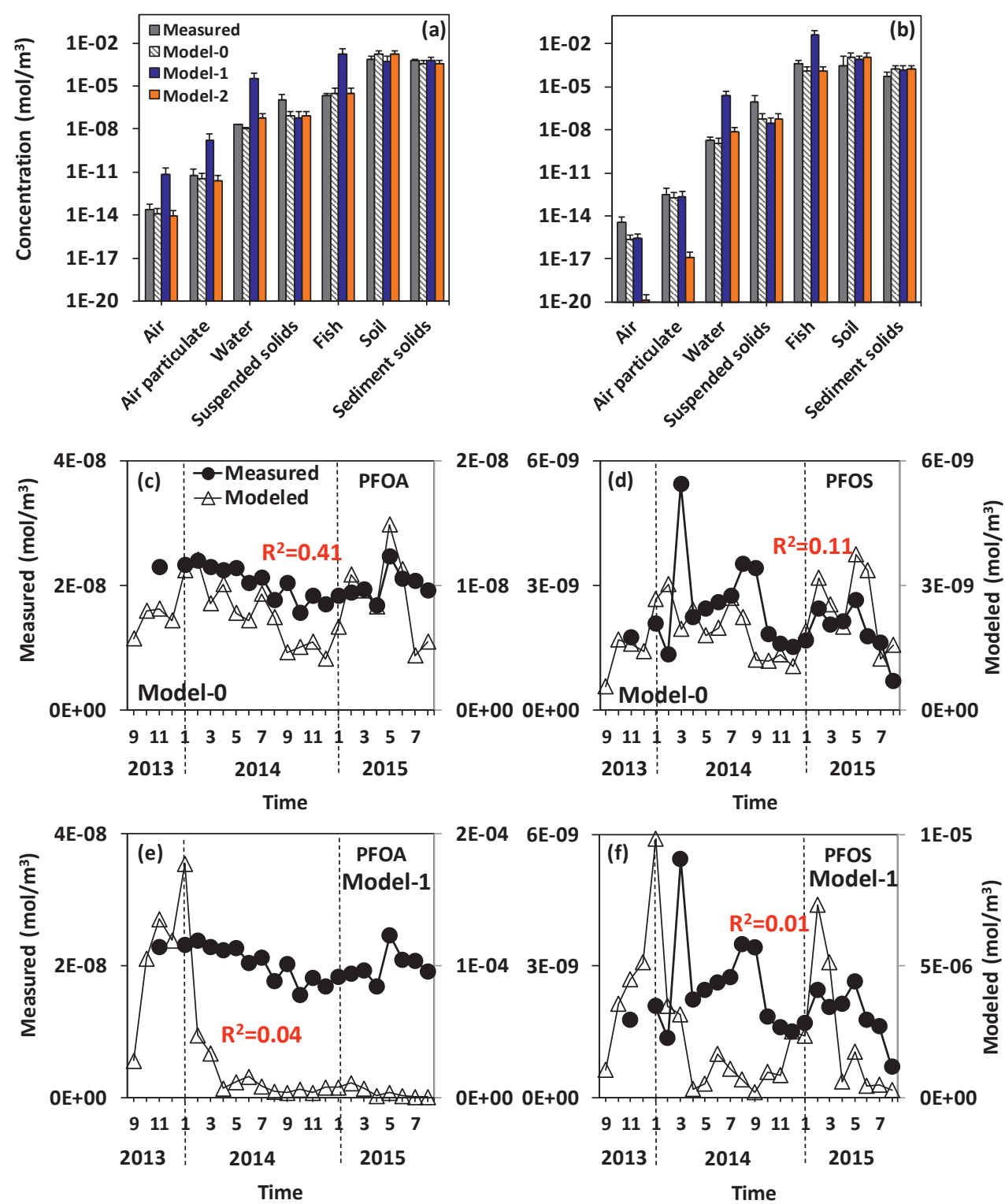

Fig. S4. Comparision of averaged model results to measurements in 'Model-0', 'Model-1' and 'Model-2' for (a) PFOA and (b) PFOS. (c-f) The comparision of seasonal variations in dissolved phase in water between modeled and measured results for PFOA and PFOS in 'Model-0' and 'Model-1'. 


\section{SI Tables}

Table S1 Data source for the present study

\begin{tabular}{|c|c|c|}
\hline Compartment & Reference & Note \\
\hline Air & Liu et al., in preparation(a) & $\begin{array}{l}\text { unpublished data from our } \\
\text { lab }\end{array}$ \\
\hline Water & Liu et al., 2015 & $\begin{array}{l}\text { There are unpublished data } \\
\text { from our lab in addition to } \\
\text { the data in the reference }\end{array}$ \\
\hline Soil & Meng et al., 2013 & $\begin{array}{l}\text { Data for soil samples around } \\
\text { Huaihe river close to Lake } \\
\text { Chaohu }\end{array}$ \\
\hline Sediment & Qi et al., 2015 & $\begin{array}{l}\text { There are unpublished data } \\
\text { from our lab in addition to } \\
\text { the data in the reference }\end{array}$ \\
\hline Fish & Liu et al., in preparation(b) & $\begin{array}{l}\text { unpublished data from our } \\
\text { lab }\end{array}$ \\
\hline
\end{tabular}

Reference

1) Meng, J., Wang, T., Wang, P., Giesy, J.P., Lu, Y., 2013. Perfluorinated compounds and organochlorine pesticides in soils around Huaihe River: a heavily contaminated watershed in Central China. Environ. Sci. Pollut. Res. 20, 3965-3974.

2) Qi, Y., Hu, S., Huo, S., Xi, B., Zhang, J., Wang, X., 2015. Spatial distribution and historical deposition behaviors of perfluoroalkyl substances (PFASs) in sediments of Lake Chaohu, a shallow eutrophic lake in Eastern China. Ecol. Indic. 57, 1-10.

3) Liu, W.X., He, W., Qin, N., Kong, X.Z., He, Q.S., Yang, B., Yang, C., Jorgensen, S.E., $\mathrm{Xu}$, F.L., 2015. Temporal-spatial distributions and ecological risks of perfluoroalkyl acids (PFAAs) in the surface water from the fifth-largest freshwater lake in China (Lake Chaohu). Environ. Pollut. 200, 24-34.

4) Liu, W., He, W., Xu, F., in preparation-a. Distribution, partitioning and inhalation exposure of perfluoroalkyl acids (PFAAs) in urban and rural air nearby Lake Chaohu, China.

5) Liu, W., He, W., Xu, F., in preparation-b. Residues, bioaccumulation and biomagnification of perfluoroalkyl acids (PFAAs) in the aquatic animals from Lake Chaohu, China. 
Modeling PFASs in a phytoplankton-dominated shallow lake

Table S2 Definitions of the transfer and transformation processes

\begin{tabular}{lll}
$\begin{array}{l}\text { Sym } \\
\text { bol }\end{array}$ & Formula & $\begin{array}{l}\text { Calculation of D } \\
(\mathbf{m o l} /(\mathbf{h} \cdot \mathbf{P a}))\end{array}$ \\
\hline System input: & \\
$T_{01 h}$ & - & - \\
$T_{02 t}$ & $Q_{02 t} \times C_{02 t}$ & - \\
System output: & \\
$T_{10 t}$ & $D_{10 t} \times f_{1}$ & $D_{10 t}=Q_{10 t} \times Z_{1}$ \\
& & \\
$T_{20 t}$ & $D_{20 t} \times f_{2}$ & $D_{20 t}=Q_{20 t} \times Z_{2}$ \\
$T_{10 m}$ & $D_{10 m} \times f_{1}$ & $D_{10 m}=K_{m 1} \times A_{1} \times h_{1} \times Z_{1}$ \\
$T_{20 m}$ & $D_{20 m} \times f_{2}$ & $D_{20 m}=K_{m 2} \times A_{2} \times h_{2} \times Z_{2}$ \\
$T_{30 m}$ & $D_{30 m} \times f_{2}$ & $D_{30 m}=K_{m 3} \times A_{3} \times h_{3} \times Z_{3}$ \\
$T_{40 m}$ & $D_{40 m} \times f_{4}$ & $D_{40 m}=K_{m 4} \times A_{4} \times h_{4} \times Z_{4}$
\end{tabular}

Air-water interaction:

$\begin{array}{ll}T_{12 d} \quad D_{12 d} \times f_{1} & D_{12 d}=A_{2} /\left[1 /\left(K_{12} \times Z_{11}\right)\right. \\ & \\ & \left.1 /\left(K_{21} \times Z_{22}\right)\right]\end{array}$

Description

Calculation of $Z$

(fugacity capacity)

Emission to air

Water advection flows into the -

area

Air advection flows out of the area

$Z_{1}=X_{11} \times Z_{11}+X_{13} \times Z_{13}$

Water advection flows out of the area

$Z_{2}=X_{22} \times Z_{22}+X_{23} \times Z_{23}$

Degradation in air

Degradation in water

Degradation in soil

$Z_{3}=X_{32} \times Z_{32}+X_{33} \times Z_{33}$

Degradation in sediment

$Z_{4}=X_{42} \times Z_{42}+X_{43} \times Z_{43}$

Diffusion from air to water

$Z_{11}=Z_{31}=1 / R T$

$Z_{22}=Z_{32}=Z_{42}=1 / H$

$\begin{array}{lll}T_{21 d} & D_{21 d} \times f_{2} & D_{21 d}=D_{12 d} \\ T_{12 p} & D_{12 p} \times f_{1} & D_{12 p}=A_{2} \times K_{p} \times X_{13} \times Z_{13} \\ T_{12 w} & D_{12 w} \times f_{1} & D_{12 w}=A_{2} \times K_{w} \times S_{c} \times X_{13} \times Z_{13} \\ T_{12 r} & D_{12 r} \times f_{1} & D_{12 r}=A_{2} \times K_{w} \times Z_{22}\end{array}$

Diffusion from water to air

Dry deposition from air to water

$Z_{13}=6 \times 10^{6} / P_{s} R T$

Wet deposition from air to water

Air-soil interaction:

$\begin{array}{llll}\text { T13d } & D_{13 d} \times f_{1} & \begin{array}{l}D_{13 d}=A_{3} /\left[1 /\left(K_{13} \times Z_{11}\right)+L_{3} /\right. \\ \left.\left(B_{1} \times Z_{11}+B_{2} \times Z_{22}\right)\right]\end{array} & \text { Diffusion from air to soil } \\ T_{31 d} & D_{31 d} \times f_{2} & D_{31 d}=D_{13 d} & \text { Diffusion from soil to air } \\ T_{13 p} & D_{13 p} \times f_{1} & D_{13 p}=A_{3} \times K_{p} \times X_{13} \times Z_{13} & \text { Dry deposition from air to soil } \\ T_{13 w} & D_{13 w} \times f_{1} & D_{13 w}=A_{3} \times K_{w} \times S_{c} \times X_{13} \times Z_{13} & \text { Wet deposition from air to soil } \\ T_{13 r} & D_{13 r} \times f_{1} & D_{13 r}=A_{3} \times K_{w} \times Z_{22} & \text { Rain scavenging to soil }\end{array}$

Water-soil interaction:
$T_{32 e} \quad D_{32 e} \times f_{3}$
$D_{32 e}=A_{3} \times U_{e} \times Z_{33}$
Erosion from soil to water

$Z_{33}=\left[O_{33} \times K_{o c}+f_{B C} \times K_{F} \times\left(Z_{3}\right.\right.$

$\left.\left.2 \times f_{3}\right)^{n F-1}\right] \times \rho_{33} / H$

Water-sediment interactions:

$\begin{array}{clll}T_{24 d} & D_{24 d} \times f_{2} & \begin{array}{l}D_{24 d}=A_{2} /\left[1 /\left(K_{24} \times Z_{22}\right)+L_{4} /\right. \\ \left.\left(B_{4} \times Z_{22}\right)\right]\end{array} & \begin{array}{l}\text { Diffusion from water to - } \\ \text { sediment }\end{array} \\ T_{42 d} & D_{42 d} \times f_{4} & D_{42 d}=D_{24 d} & \begin{array}{l}\text { Diffusion from sediment to - } \\ \text { water }\end{array}\end{array}$




\section{Chapter 5}

\begin{tabular}{|c|c|c|c|c|}
\hline$T_{24 s}$ & $D_{24 s} \times f_{2}$ & $D_{24 s}=A_{2} \times K_{s} \times Z_{23}$ & $\begin{array}{l}\text { Sedimentation from water to } \\
\text { sediment }\end{array}$ & $\begin{array}{l}Z_{23}=\left[O_{23} \times K_{o c}+f_{B C} \times K_{F} \times\left(Z_{2}\right.\right. \\
\left.\left.2 \times f_{2}\right)^{n F-1}\right] \times \rho_{23} / H\end{array}$ \\
\hline & $D_{42 r} \times f_{4}$ & $D_{42 r}=A_{2} \times K_{42 r} \times Z_{43}$ & $\begin{array}{l}\text { Resuspension from sediment to } \\
\text { water }\end{array}$ & 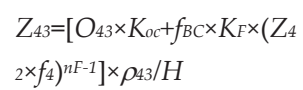 \\
\hline
\end{tabular}

Fishery:

$\begin{array}{cccc}T_{2 f} & D_{2 f} \times f_{2} & D_{24 d}=Y_{f} \times Z_{2 f} & \text { Removal from fishery } \quad Z_{2 f}=B C F_{F} \times \rho_{f} / H\end{array}$

Note: For the definition of the parameters and their values please see Table S3-S6. 
Modeling PFASs in a phytoplankton-dominated shallow lake

Table S3 Environmental and universal mass transfer kinetic parameters for the contaminant fate model

\begin{tabular}{|c|c|c|c|c|c|c|}
\hline Symbol & Unit & Parameters & Reference & $\begin{array}{l}\text { Data } \\
\text { Numbers }\end{array}$ & $\begin{array}{l}\text { Geometric } \\
\text { mean }\end{array}$ & $\begin{array}{l}\text { Geometric } \\
\text { S.D. }\end{array}$ \\
\hline \multicolumn{7}{|c|}{ Static parameters } \\
\hline$A_{2}$ & $\mathrm{~m}^{2}$ & Interface areas of air/water & 1,2 & 2 & $7.581 \mathrm{E}+08$ & $1.004 \mathrm{E}+00$ \\
\hline$A_{3}$ & $\mathrm{~m}^{2}$ & Interface areas of air/soil & 1 & 1 & $1.04 \mathrm{E}+10$ & $1.000 \mathrm{E}+00$ \\
\hline$h_{1}$ & $\mathrm{~m}$ & Thickness of air & 1,10 & 2 & $1.000 \mathrm{E}+02$ & $1.413 \mathrm{E}+00$ \\
\hline$h_{3}$ & $\mathrm{~m}$ & Thickness of soil & 1,10 & 2 & $5.000 \mathrm{E}-01$ & $1.479 \mathrm{E}+00$ \\
\hline$h_{4}$ & $\mathrm{~m}$ & Thickness of sediment & 1,10 & 2 & $1.000 \mathrm{E}-01$ & $1.479 \mathrm{E}+00$ \\
\hline $\mathrm{O}_{33}$ & $\%$ & $\begin{array}{l}\text { Contents of organic carbon } \\
\text { in soil }\end{array}$ & $1,7-11$ & 6 & 6.296E-03 & $1.577 \mathrm{E}+00$ \\
\hline $\mathrm{O}_{43}$ & $\%$ & $\begin{array}{l}\text { Contents of organic carbon } \\
\text { in sediment }\end{array}$ & $1-3$ & 61 & 7.920E-02 & $1.720 \mathrm{E}+00$ \\
\hline$R$ & $\mathrm{~Pa} \cdot \mathrm{m}^{3} / \mathrm{mol} \cdot \mathrm{K}$ & The gas constant & - & 1 & $8.310 \mathrm{E}+00$ & $1.000 \mathrm{E}+00$ \\
\hline$X_{31}$ & $\mathrm{v} / \mathrm{v}$ & $\begin{array}{l}\text { Volume fractions of air in } \\
\text { soil }\end{array}$ & $1,7-11$ & 6 & $2.500 \mathrm{E}-01$ & $5.000 \mathrm{E}-02$ \\
\hline$X_{32}$ & $\mathrm{v} / \mathrm{v}$ & $\begin{array}{l}\text { Volume fractions of water } \\
\text { in soil }\end{array}$ & $1,7-11$ & 6 & 2.500E-01 & $5.000 \mathrm{E}-02$ \\
\hline$X_{33}$ & $\mathrm{v} / \mathrm{v}$ & $\begin{array}{l}\text { Volume fractions of solids } \\
\text { in soil }\end{array}$ & $1,7-11$ & 6 & $5.000 \mathrm{E}-01$ & $1.000 \mathrm{E}-01$ \\
\hline$X_{42}$ & $\mathrm{v} / \mathrm{v}$ & $\begin{array}{l}\text { Volume fractions of water } \\
\text { in sediment }\end{array}$ & 4, 7-11 & 6 & 7.000E-01 & $1.022 \mathrm{E}+00$ \\
\hline$X_{43}$ & $\mathrm{v} / \mathrm{v}$ & $\begin{array}{l}\text { Volume fractions of solids } \\
\text { in sediment }\end{array}$ & $4,7-11$ & 6 & 3.000E-01 & $1.077 \mathrm{E}+00$ \\
\hline$r_{23}$ & $\mathrm{t} / \mathrm{m}^{3}$ & Densities of solids in water & 1,4 & 2 & $1.200 \mathrm{E}+00$ & $1.158 \mathrm{E}+00$ \\
\hline$r_{33}$ & $\mathrm{t} / \mathrm{m}^{3}$ & Densities of solids in soil & $1,8-11$ & 5 & $2.568 \mathrm{E}+00$ & $1.537 \mathrm{E}-01$ \\
\hline$r_{43}$ & $\mathrm{t} / \mathrm{m}^{3}$ & $\begin{array}{l}\text { Densities of solids in } \\
\text { sediment }\end{array}$ & 1,4 & 2 & $2.760 \mathrm{E}+00$ & $1.176 \mathrm{E}+00$ \\
\hline$\rho_{2 f}$ & $\mathrm{t} / \mathrm{m}^{3}$ & Densities of fish & $1,8-11$ & 2 & $1.500 \mathrm{E}+00$ & $1.236 \mathrm{E}-01$ \\
\hline$Y_{f}$ & $\mathrm{~kg} / \mathrm{h}$ & Fish production rate & 1,5 & 2 & 5.710E-01 & $1.183 \mathrm{E}+00$ \\
\hline$K_{13}$ & $\mathrm{~m} / \mathrm{h}$ & $\begin{array}{l}\text { Air-side molecular transfer } \\
\text { coefficient over soil }\end{array}$ & $7-11$ & 6 & $1.000 \mathrm{E}+00$ & $1.324 \mathrm{E}-01$ \\
\hline$K_{24}$ & $\mathrm{~m} / \mathrm{h}$ & $\begin{array}{l}\text { Water-side molecular } \\
\text { transfer coefficient over } \\
\text { sediment }\end{array}$ & $7-11$ & 5 & $1.000 \mathrm{E}-02$ & $1.585 \mathrm{E}+00$ \\
\hline$K_{42}$ & $\mathrm{~m} / \mathrm{h}$ & $\begin{array}{l}\text { Sediment-side molecular } \\
\text { transfer coefficient over } \\
\text { water }\end{array}$ & $1,7-11$ & 6 & 5.390E-06 & $1.520 \mathrm{E}+00$ \\
\hline Ks & $\mathrm{m} / \mathrm{h}$ & Water sedimentation rates & 12 & 3 & $1.655 \mathrm{E}-06$ & $1.254 \mathrm{E}+00$ \\
\hline$L_{3}$ & $\mathrm{~m}$ & $\begin{array}{l}\text { Diffusion path lengths in } \\
\text { soil }\end{array}$ & $7-11$ & 5 & $1.000 \mathrm{E}-01$ & $1.369 \mathrm{E}+00$ \\
\hline$L_{4}$ & $\mathrm{~m}$ & $\begin{array}{l}\text { Diffusion path lengths in } \\
\text { sediment }\end{array}$ & $7-11$ & 5 & $5.000 \mathrm{E}-03$ & $1.912 \mathrm{E}+00$ \\
\hline$K_{P}$ & $\mathrm{~m} / \mathrm{h}$ & Dry deposition velocity & $7-11$ & 5 & $1.039 \mathrm{E}+01$ & $1.056 \mathrm{E}+00$ \\
\hline Ue & $\mathrm{m} / \mathrm{h}$ & Runoff rate of solid phase & 10 & 1 & $1.100 \mathrm{E}-07$ & $1.000 \mathrm{E}+00$ \\
\hline$S_{c}$ & - & Scavenging ratio & 4, 7-11 & 6 & $1.200 \mathrm{E}+05$ & $2.144 \mathrm{E}+00$ \\
\hline$B_{1}$ & $\mathrm{~m}^{2} / \mathrm{h}$ & $\begin{array}{l}\text { Molecular diffusivities in } \\
\text { air }\end{array}$ & $4,7-11$ & 6 & $1.3000 \mathrm{E}-02$ & $1.342 \mathrm{E}+00$ \\
\hline$B_{2}$ & $\mathrm{~m}^{2} / \mathrm{h}$ & $\begin{array}{l}\text { Molecular diffusivities in } \\
\text { water }\end{array}$ & $4,7-11$ & 6 & $1.4000 \mathrm{E}-06$ & $1.621 \mathrm{E}+00$ \\
\hline
\end{tabular}


Chapter 5

\begin{tabular}{|c|c|c|c|c|c|c|}
\hline$B_{4}$ & $\mathrm{~m}^{2} / \mathrm{h}$ & $\begin{array}{l}\text { Molecular diffusivities in } \\
\text { sediment }\end{array}$ & 4, 7-11 & 6 & $6.3000 \mathrm{E}-13$ & $1.483 \mathrm{E}+00$ \\
\hline$f_{B C}$ & - & $\begin{array}{l}\text { Black carbon fraction of } \\
\text { solids in sediment }\end{array}$ & 13 & 1 & $2.000 \mathrm{E}-03$ & $1.000 \mathrm{E}+00$ \\
\hline \multicolumn{7}{|c|}{ Dynamic parameters $^{a}$} \\
\hline$h_{2}$ & $\mathrm{~m}$ & Depth of water & 14 & 24 & $3.390 \mathrm{E}+00$ & $1.296 \mathrm{E}+00$ \\
\hline $\mathrm{O}_{23}$ & $\%$ & $\begin{array}{l}\text { Contents of organic carbon } \\
\text { in solids in water }\end{array}$ & $\begin{array}{l}15, \text { this } \\
\text { study }\end{array}$ & 24 & $7.829 \mathrm{E}-02$ & $1.900 \mathrm{E}+00$ \\
\hline$X_{13}$ & $\mathrm{v} / \mathrm{v}$ & $\begin{array}{l}\text { Volume fractions of solids } \\
\text { in air }\end{array}$ & this study & 24 & $7.628 \mathrm{E}-11$ & $1.562 \mathrm{E}+00$ \\
\hline$X_{23}$ & $\mathrm{v} / \mathrm{v}$ & $\begin{array}{l}\text { Volume fractions of solids } \\
\text { in water }\end{array}$ & this study & 24 & $1.263 \mathrm{E}-05$ & $2.007 \mathrm{E}+00$ \\
\hline$T$ & K & $\begin{array}{l}\text { Local average temperature } \\
\text { in air }\end{array}$ & 16 & 730 & $2.889 \mathrm{E}+02$ & $9.747 \mathrm{E}+00$ \\
\hline$T w^{c}$ & K & $\begin{array}{l}\text { Local average temperature } \\
\text { in water }\end{array}$ & 16,17 & 730 & $1.270 \mathrm{E}+01$ & $2.587 \mathrm{E}+00$ \\
\hline$W$ & $\mathrm{~m} / \mathrm{s}$ & Wind speed & 16 & 730 & $1.083 \mathrm{E}+00$ & $1.521 \mathrm{E}+00$ \\
\hline$Q_{02 t}$ & $\mathrm{~m}^{3} / \mathrm{h}$ & $\begin{array}{l}\text { Water advection flow into } \\
\text { the area }\end{array}$ & 14 & 24 & $3.373 \mathrm{E}+05$ & $3.217 \mathrm{E}+00$ \\
\hline$Q_{20 t}$ & $\mathrm{~m}^{3} / \mathrm{h}$ & $\begin{array}{l}\text { Water advection flow out } \\
\text { of the area }\end{array}$ & 14 & 24 & $4.189 \mathrm{E}+05$ & $3.072 \mathrm{E}+00$ \\
\hline$K_{w}$ & $\mathrm{~m} / \mathrm{h}$ & Wet deposition velocity & 14,16 & 730 & $1.332 \mathrm{E}-04$ & $5.958 \mathrm{E}+00$ \\
\hline$K_{42 r^{d}}$ & $\mathrm{~m} / \mathrm{h}$ & Sediment resuspension rate & 1 & 730 & $2.558 \mathrm{E}-05$ & $1.702 \mathrm{E}+00$ \\
\hline
\end{tabular}

a for values see Table S5

b Normal distribution assumed (instead of lognormal distribution for others)

c Calculate from air temperature according to ref. 17

d Calculated according to ref. 1

References:

1) Tu, Q.Y., Gu, D.X., Yi, C.Q., Xu, Z.R., Han, G.Z., 1990. The researches on the Lake Chaohu eutrophication. Hefei: Publisher of University of Science and Technology of China.

2) Yin, F.C., 2011. A study on evaluation and control instruments of Chao lake eutrophication. Beijing: China Environmental Science Press.

3) Zhang, M., 2009. Distribution characteristic and assessment of typical persistent organic pollutions-Organochlorine pesticides in water of Chaohu Lake watershed [Master dissertation]. Hefei: Anhui Agriculture University.

4) Mackay, D., 2001. Multimedia Environmental Models: The Fugacity Approach,second ed. NewYork, USA: Lewis Publishers.

5) Guo, L.G., 2005. Studies on fisheries ecology in a large eutrophic shallow lake, Lake Chaohu [Doctoral dissertation]. Wuhan: Institude of Hydrobiology, Chinese Acadamy of Sciences (in Chinese).

6) Kong, F.X., Song, L.R., 2011. Study on formation process and its environmental characteristics of cyanobacteria bloom. Beijing: Science Press (in Chinese)

7) Lang, C., Tao, S., Wang, X.J., Zhang, G., Li, J., Fu, J.M., 2007. Seasonal variation of polycyclic aromatic hydrocarbons (PAHs) in Pearl River Delta region, China. Atmos. Environ. 41, 8370-8379. 
8) Lang, C., Tao, S., Wang, X.J., Zhang, G., Fu, J.M., 2008. Modeling polycyclic aromatic hydrocarbon composition profiles of sources and receptors in the Pear River Delta, China. Environ. Toxicol. Chem. 27, 4-9.

9) Wang, R., Cao, H.Y., Li, W., Wang, W., Wang, W.T., Zhang, L.W., Liu, J.M., Ouyang, H., Tao, S., 2011. Spatial and seasonal variations of polycyclic aromatic hydrocarbons in Haihe Plain, China. Environ. Pollut. 159, 1413-1418.

10) Tao, S., Cao, H.Y., Liu, W.X., Li, B.G., Cao, J., Xu, F.L., Wang, X.J., Coveney, R.M., Shen, W.R., Qin, B.P., Sun, R., 2003. Fate modeling of phenanthrene with regional variation in Tianjin, China. Environ. Sci. Technol. 37, 2453-2459.

11) Zhang, X.L., Tao, S., Liu, W.X., Yang, Y., Zuo, Q., Liu, S.Z., 2005. Source diagnostics of polycyclic aromatic hydrocarbons based on species ratios: A multimedia approach. Environ. Sci. Technol. 39, 9109-9114.

12) Gu, C.J., 2005. Historical Sedimentary Records and Environmental Changes in Chaohu lake. [Master dissertation]. Shanghai: East China Normal University (in Chinese).

13) Hauck, M.; Huijbregts, M. A. J.; Koelmans, A. A.; Moermond, C. T. A.; van den Heuvel-Greve, M. J.; Veltman, K.; Hendriks, A. J.; Vethaak, A. D., Including sorption to black carbon in modeling bioaccumulation of polycyclic aromatic hydrocarbons: Uncertainty analysis and comparison to field data. Environ. Sci. Technol. 2007, 41, (8), 2738-2744.

14) Anhui Hydrological Telemetry Information System (AHTIS), 2013-2015. Hourly water level report. http://yc.wswj.net/ahyc/

15) Zhou, Z.H., Liu, C.Q., Li, J., Zhu, Z.Z., 2007. Record of ecosystem evolvement processes provided by $\delta 13$ Corg and $\delta 15 \mathrm{~N}$ values in Chaohu Lake sediments. Environmental Science, 28, 1338-1343.

16) China Meteorological Data Sharing Service System (CMDSSS), 2013-2015. Daily Meteorological Data. http://data.cma.cn/

17) Mooij, W.M., Domis, L., Hulsmann, S., 2008. The impact of climate warming on water temperature, timing of hatching and young-of-the-year growth of fish in shallow lakes in the Netherlands. J. Sea Res. 60, 32-43. 
Chapter 5

Table S4 Chemical specific parameters for the contaminant fate model

\begin{tabular}{|c|c|c|c|c|c|c|}
\hline Parameters & Unit & Definition & PFOA & Ref. & PFOS & Ref. \\
\hline \multicolumn{7}{|l|}{ Static } \\
\hline$P_{S 25}$ & $\mathrm{~Pa}$ & $\begin{array}{l}\text { Subcooled liquid } \\
\text { vapor pressure at } 25^{\circ} \mathrm{C}\end{array}$ & $5.7377 \mathrm{E}-06^{\mathrm{a}}$ & $\begin{array}{l}\text { (Kaiser et al. } \\
\text { 2005, Goss } \\
\text { 2007, Burns } \\
\text { et al. 2008) }\end{array}$ & $1.8400 \mathrm{E}-06$ & (3M 2003) \\
\hline$H_{25}$ & $\mathrm{~Pa} \cdot \mathrm{m}^{3} / \mathrm{mol}$ & $\begin{array}{l}\mathrm{H}_{2{ }^{\circ} \mathrm{C}} \\
25^{\prime} \mathrm{s} \text { constant at }\end{array}$ & $1.4400 \mathrm{E}+01$ & $\begin{array}{l}\text { (Kutsuna } \\
\text { and Hori } \\
\text { 2008) }\end{array}$ & 4.7500E-04 & (3M 2003) \\
\hline$B_{H}$ & - & $\begin{array}{l}\text { Henry's law constant } \\
\text { temperature correction } \\
\text { factor }\end{array}$ & $7.7820 \mathrm{E}+03^{\mathrm{b}}$ & $\begin{array}{l}\text { (Wang and } \\
\text { Shih 2011) }\end{array}$ & $7.7820 \mathrm{E}+03$ & Note c \\
\hline BPS & - & $\begin{array}{l}\text { Subcooled liquid } \\
\text { vapor pressure } \\
\text { temperature correction } \\
\text { factor }\end{array}$ & $3.3879 \mathrm{E}+03$ & $\begin{array}{l}\text { (Kaiser et al. } \\
\text { 2005) }\end{array}$ & $4.9150 \mathrm{E}+03$ & $\begin{array}{l}\text { (Mackay et } \\
\text { al. 1982, } \\
\text { Kaiser et al. } \\
\text { 2005) }\end{array}$ \\
\hline $\log K o C$ & $\mathrm{~m}^{3} / \mathrm{t}$ & Adsorption coefficient & $2.0600 \mathrm{E}+00$ & $\begin{array}{l}\text { (Higgins } \\
\text { and Luthy } \\
\text { 2006) }\end{array}$ & $2.8800 \mathrm{E}+00$ & $\begin{array}{l}\text { (Yang et al. } \\
\text { 2011) }\end{array}$ \\
\hline$K_{m 1}$ & $1 / \mathrm{h}$ & Degradation rate in air & 4.5591E-05 & $\begin{array}{c}\text { (Gomis et al. } \\
\text { 2015) }\end{array}$ & 2.6102E-06 & $\begin{array}{l}\text { (Liu et al. } \\
2015 a)\end{array}$ \\
\hline$K_{m 2}$ & $1 / \mathrm{h}$ & $\begin{array}{l}\text { Degradation rate in } \\
\text { water }\end{array}$ & 5.7190E-06 & $\begin{array}{l}\text { (Gomis et al. } \\
\text { 2015) }\end{array}$ & $1.2600 \mathrm{E}-07$ & $\begin{array}{l}\text { (Liu et al. } \\
2015 a)\end{array}$ \\
\hline$K_{m 3}$ & $1 / \mathrm{h}$ & $\begin{array}{l}\text { Degradation rate in } \\
\text { soil }\end{array}$ & 4.0104E-05 & $\begin{array}{l}\text { (Gomis et al. } \\
\text { 2015) }\end{array}$ & 6.9300E-09 & $\begin{array}{l}\text { (Liu et al. } \\
\text { 2015a) }\end{array}$ \\
\hline$K_{m 4}$ & $1 / \mathrm{h}$ & $\begin{array}{l}\text { Degradation rate in } \\
\text { sediment }\end{array}$ & 4.0104E-05 & $\begin{array}{c}\text { (Gomis et al. } \\
\text { 2015) }\end{array}$ & 4.0765E-08 & $\begin{array}{l}\text { (Liu et al. } \\
\text { 2015a) }\end{array}$ \\
\hline $\log K o w$ & - & $\begin{array}{l}\text { Octanol-water } \\
\text { partition coefficient }\end{array}$ & $4.3000 \mathrm{E}+00$ & $\begin{array}{l}\text { (Arp et al. } \\
\text { 2006, Wang } \\
\text { and Shih } \\
\text { 2011) }\end{array}$ & $4.3500 \mathrm{E}+00$ & $\begin{array}{l}\text { (Arp et al. } \\
\text { 2006, Wang } \\
\text { and Shih } \\
\text { 2011) }\end{array}$ \\
\hline To1h & $\mathrm{mol} / \mathrm{h}$ & Emission rate & $1.4500 \mathrm{E}+00$ & $\begin{array}{l}\text { (Wang et al. } \\
\text { 2015, Liu et } \\
\text { al. 2017) }\end{array}$ & 3.5000E-01 & $\begin{array}{l}\text { (Xie et al. } \\
\text { 2013a, Xie et } \\
\text { al. 2013b) }\end{array}$ \\
\hline$B C F$ & $\mathrm{~L} / \mathrm{g}$ & $\begin{array}{l}\text { Bioconcentration factor } \\
\text { of fish }\end{array}$ & $3.4677 \mathrm{E}+00$ & $\begin{array}{l}\text { (Quinete et } \\
\text { al. 2009) }\end{array}$ & $2.9934 \mathrm{E}+03$ & $\begin{array}{l}\text { (Quinete et } \\
\text { al. 2009) }\end{array}$ \\
\hline \multicolumn{7}{|l|}{ Dynamic } \\
\hline $\mathrm{C}_{02 t}$ & $\mathrm{~mol} / \mathrm{m}^{3}$ & $\begin{array}{l}\text { Concentration in water } \\
\text { advection inflow }\end{array}$ & $4.8067 \mathrm{E}-11$ & This studyd & $1.2904 \mathrm{E}-09$ & This study ${ }^{\mathrm{d}}$ \\
\hline$K_{12}$ & $\mathrm{~m} / \mathrm{h}$ & $\begin{array}{l}\text { Air-side molecular } \\
\text { transfer coefficient } \\
\text { over water }\end{array}$ & $4.6375 \mathrm{E}+00$ & $\begin{array}{l}\text { (Kim and } \\
\text { Kannan } \\
\text { 2007) }\end{array}$ & $5.2850 \mathrm{E}+00$ & $\begin{array}{l}\text { (Liu et al. } \\
\text { 2015a) }\end{array}$ \\
\hline$K_{21}$ & $\mathrm{~m} / \mathrm{h}$ & $\begin{array}{l}\text { Water-side molecular } \\
\text { transfer coefficient } \\
\text { over air }\end{array}$ & $1.9350 \mathrm{E}-03$ & $\begin{array}{l}\text { (Kim and } \\
\text { Kannan } \\
\text { 2007) }\end{array}$ & $2.2050 \mathrm{E}-03$ & $\begin{array}{l}\text { (Liu et al. } \\
\text { 2015a) }\end{array}$ \\
\hline
\end{tabular}

Notes:

a: adjusted based on Burns et al. (2008) and Goss (2008) 
b: Estimated based on the Van 't Hoff equation and the Enthalpy of PFOA $(\Delta \mathrm{H}=64.7$ $\mathrm{kJ} \cdot \mathrm{mol}^{-1}$ ).

c: No data is available in literature. The same value for PFOA is used.

d: Estimated based on the data in the inflow rivers in March and September 2013 and weighted by the inflow volume of these rivers

\section{References:}

1) 3M, 2003. Environmental and health assessment of sulfonic acid and its salts. $3 \mathrm{M}$ Company.

2) Arp, H.P.H., Niederer, C., Goss, K.U., 2006. Predicting the partitioning behavior of various highly fluorinated compounds. Environ. Sci. Technol. 40, 7298-7304.

3) Burns, D.C., Ellis, D.A., Li, H., McMurdo, C.J., Webster, E., 2008. Experimental p K a determination for perfluorooctanoic acid (PFOA) and the potential impact of $\mathrm{p} \mathrm{K} \mathrm{a}$ concentration dependence on laboratory-measured partitioning phenomena and environmental modeling. Environ. Sci. Technol. 42, 9283-9288.

4) Gomis, M.I., Wang, Z., Scheringer, M., Cousins, I.T., 2015. A modeling assessment of the physicochemical properties and environmental fate of emerging and novel per-and polyfluoroalkyl substances. Sci. Total Environ. 505, 981-991.

5) Goss, K.U., 2007. The p K a values of PFOA and other highly fluorinated carboxylic acids. Environ. Sci. Technol. 42, 456-458.

6) Higgins, C.P., Luthy, R.G., 2006. Sorption of perfluorinated surfactants on sediments. Environ. Sci. Technol. 40, 7251-7256.

7) Kaiser, M.A., Larsen, B.S., Kao, C.-P.C., Buck, R.C., 2005. Vapor pressures of perfluorooctanoic,-nonanoic,-decanoic,-undecanoic, and-dodecanoic acids. Journal of Chemical \& Engineering Data 50, 1841-1843.

8) Kim, S.K., Kannan, K., 2007. Perfluorinated acids in air, rain, snow, surface runoff, and lakes: relative importance of pathways to contamination of urban lakes. Environ. Sci. Technol. 41, 8328-8334.

9) Kutsuna, S., Hori, H., 2008. Experimental determination of Henry's law constant of perfluorooctanoic acid (PFOA) at $298 \mathrm{~K}$ by means of an inert-gas stripping method with a helical plate. Atmos. Environ. 42, 8883-8892.

10) Liu, S., Lu, Y., Xie, S., Wang, T., Jones, K.C., Sweetman, A.J., 2015. Exploring the fate, transport and risk of Perfluorooctane Sulfonate (PFOS) in a coastal region of China using a multimedia model. Environ. Inter. 85, 15-26.

11) Liu, Z., Lu, Y., Wang, P., Wang, T., Liu, S., Johnson, A.C., Sweetman, A.J., Baninla, Y., 2017. Pollution pathways and release estimation of perfluorooctane sulfonate (PFOS) and perfluorooctanoic acid (PFOA) in central and eastern China. Sci. Total Environ. 580, 1247-1256.

12) Mackay, D., Bobra, A., Chan, D.W., Shiu, W.Y., 1982. Vapor-pressure correlations for low-volatility environmental chemicals. Environ. Sci. Technol. 16, 645-649.

13) Quinete, N., Wu, Q., Zhang, T., Yun, S.H., Moreira, I., Kannan, K., 2009. Specific profiles of perfluorinated compounds in surface and drinking waters and accumulation in mussels, fish, and dolphins from southeastern Brazil. Chemosphere 77, 863-869. 


\section{Chapter 5}

14) Wang, F., Shih, K., 2011. Adsorption of perfluorooctanesulfonate (PFOS) and perfluorooctanoate (PFOA) on alumina: influence of solution $\mathrm{pH}$ and cations. Water Res. 45, 2925-2930.

15) Wang, T., Wang, P., Meng, J., Liu, S., Lu, Y., Khim, J.S., Giesy, J.P., 2015. A review of sources, multimedia distribution and health risks of perfluoroalkyl acids (PFAAs) in China. Chemosphere 129, 87-99.

16) Xie, S., Lu, Y., Wang, T., Liu, S., Jones, K., Sweetman, A., 2013a. Estimation of PFOS emission from domestic sources in the eastern coastal region of China. Environ. Inter. $59,336-343$.

17) Xie, S., Wang, T., Liu, S., Jones, K.C., Sweetman, A.J., Lu, Y., 2013b. Industrial source identification and emission estimation of perfluorooctane sulfonate in China. Environ. Inter. 52, 1-8.

18) Yang, L., Zhu, L., Liu, Z., 2011. Occurrence and partition of perfluorinated compounds in water and sediment from Liao River and Taihu Lake, China. Chemosphere 83, 806814 . 
Modeling PFASs in a phytoplankton-dominated shallow lake

Table S5 Environmental dynamic parameters for the contaminant fate model

\begin{tabular}{|c|c|c|c|c|c|c|c|c|c|c|c|}
\hline \multirow{2}{*}{ Month } & $h_{2}$ & WS & $X_{13}$ & $X_{23}$ & $Q_{02 t}$ & $Q_{20 t}$ & $T$ & $T_{w}$ & $\mathrm{O}_{23}$ & $K_{w}$ & $K_{42 r}$ \\
\hline & $m$ & $\mathrm{~m} / \mathrm{s}$ & - & - & $m^{3} / h$ & $m^{3} / h$ & K & $K$ & $\%$ & $\mathrm{~mm}$ & $m / h$ \\
\hline 9-2013 & 3.19 & 2.00 & $3.86 \mathrm{E}-11$ & $1.08 \mathrm{E}-04$ & $2.35 \mathrm{E}+07$ & $2.76 \mathrm{E}+07$ & 296.65 & 300.63 & $7.39 \mathrm{E}+00$ & 115.35 & $1.88 \mathrm{E}-07$ \\
\hline $10-2013$ & 3.28 & 1.95 & $5.15 \mathrm{E}-11$ & $1.05 \mathrm{E}-04$ & $2.34 \mathrm{E}+06$ & $7.27 \mathrm{E}+04$ & 289.74 & 294.18 & $5.31 \mathrm{E}+00$ & 11.50 & $1.79 \mathrm{E}-07$ \\
\hline $11-2013$ & 3.22 & 1.85 & 6.97E-11 & $1.24 \mathrm{E}-04$ & $3.25 \mathrm{E}+06$ & $5.48 \mathrm{E}+06$ & 285.03 & 288.23 & $4.14 \mathrm{E}+00$ & 15.95 & $1.72 \mathrm{E}-07$ \\
\hline $12-2013$ & 3.17 & 1.75 & $1.75 \mathrm{E}-10$ & $2.45 \mathrm{E}-04$ & $2.05 E+06$ & $4.02 \mathrm{E}+06$ & 279.77 & 283.81 & $3.19 \mathrm{E}+00$ & 10.05 & $1.66 \mathrm{E}-07$ \\
\hline $1-2014$ & 3.27 & 2.20 & 1.17E-10 & $1.31 \mathrm{E}-04$ & $4.90 \mathrm{E}+06$ & $2.44 \mathrm{E}+06$ & 272.92 & 276.47 & $7.54 \mathrm{E}+00$ & 24.05 & $2.02 \mathrm{E}-07$ \\
\hline 2-2014 & 3.48 & 2.45 & $1.22 \mathrm{E}-10$ & 7.59E-05 & $2.52 \mathrm{E}+07$ & $2.26 \mathrm{E}+07$ & 278.23 & 278.00 & $5.24 \mathrm{E}+00$ & 123.80 & $2.11 \mathrm{E}-07$ \\
\hline $3-2014$ & 3.38 & 2.50 & $1.28 \mathrm{E}-10$ & $8.16 \mathrm{E}-05$ & $1.08 \mathrm{E}+07$ & $1.56 \mathrm{E}+07$ & 282.59 & 282.59 & $4.89 \mathrm{E}+00$ & 52.90 & 2.22E-07 \\
\hline 4-2014 & 3.14 & 2.30 & $1.32 \mathrm{E}-10$ & $6.18 \mathrm{E}-05$ & $3.85 \mathrm{E}+07$ & $5.22 \mathrm{E}+07$ & 290.57 & 289.25 & $4.21 \mathrm{E}+00$ & 188.75 & 2.20E-07 \\
\hline 5-2014 & 2.94 & 2.40 & 7.09E-11 & $5.02 \mathrm{E}-05$ & $1.32 \mathrm{E}+07$ & $2.15 \mathrm{E}+07$ & 295.34 & 296.60 & $7.69 \mathrm{E}+00$ & 64.75 & $2.45 \mathrm{E}-07$ \\
\hline 6-2014 & 3.16 & 2.05 & 9.37E-11 & 5.13E-05 & $2.83 \mathrm{E}+07$ & $2.59 \mathrm{E}+07$ & 297.66 & 298.83 & $2.03 \mathrm{E}+01$ & 139.05 & $1.95 \mathrm{E}-07$ \\
\hline $7-2014$ & 3.91 & 1.95 & 3.99E-11 & 6.77E-05 & $5.48 \mathrm{E}+07$ & $3.91 \mathrm{E}+07$ & 300.95 & 302.04 & $1.23 \mathrm{E}+01$ & 268.60 & $1.49 \mathrm{E}-07$ \\
\hline $8-2014$ & 3.83 & 1.80 & $7.40 \mathrm{E}-11$ & 2.89E-05 & $3.33 \mathrm{E}+07$ & $4.13 \mathrm{E}+07$ & 299.90 & 302.92 & $2.20 \mathrm{E}+01$ & 163.45 & $1.41 \mathrm{E}-07$ \\
\hline 9-2014 & 3.72 & 2.25 & $3.86 \mathrm{E}-11$ & $1.08 \mathrm{E}-04$ & $1.68 \mathrm{E}+07$ & $2.30 \mathrm{E}+07$ & 295.64 & 299.32 & $7.39 \mathrm{E}+00$ & 82.50 & $1.82 \mathrm{E}-07$ \\
\hline $10-2014$ & 3.61 & 2.05 & $5.15 \mathrm{E}-11$ & $1.05 \mathrm{E}-04$ & $1.01 \mathrm{E}+07$ & $1.53 \mathrm{E}+07$ & 290.45 & 294.27 & $5.31 \mathrm{E}+00$ & 49.60 & $1.71 \mathrm{E}-07$ \\
\hline 11-2014 & 3.59 & 2.05 & 6.97E-11 & $1.24 \mathrm{E}-04$ & $2.07 \mathrm{E}+07$ & $2.45 \mathrm{E}+07$ & 286.98 & 290.23 & $4.14 \mathrm{E}+00$ & 101.75 & $1.71 \mathrm{E}-07$ \\
\hline $12-2014$ & 3.26 & 2.15 & $1.75 \mathrm{E}-10$ & $2.45 \mathrm{E}-04$ & $8.26 \mathrm{E}+05$ & $1.16 \mathrm{E}+07$ & 276.88 & 281.74 & $3.19 \mathrm{E}+00$ & 4.05 & $1.98 \mathrm{E}-07$ \\
\hline $1-2015$ & 3.30 & 2.05 & 1.17E-10 & 1.31E-04 & $9.35 \mathrm{E}+06$ & $9.49 \mathrm{E}+06$ & 275.95 & 278.14 & $7.54 \mathrm{E}+00$ & 45.85 & $1.86 \mathrm{E}-07$ \\
\hline 2-2015 & 3.31 & 2.45 & $1.22 \mathrm{E}-10$ & 7.59E-05 & $1.35 \mathrm{E}+07$ & $1.54 \mathrm{E}+07$ & 276.19 & 277.74 & $5.24 \mathrm{E}+00$ & 66.40 & 2.22E-07 \\
\hline $3-2015$ & 3.26 & 2.40 & $1.28 \mathrm{E}-10$ & $8.16 \mathrm{E}-05$ & $1.72 \mathrm{E}+07$ & $2.13 \mathrm{E}+07$ & 282.40 & 281.44 & $4.89 \mathrm{E}+00$ & 84.50 & 2.21E-07 \\
\hline 4-2015 & 2.85 & 2.40 & $1.32 \mathrm{E}-10$ & $6.18 \mathrm{E}-05$ & $2.37 \mathrm{E}+07$ & $4.04 \mathrm{E}+07$ & 291.44 & 290.62 & $4.21 \mathrm{E}+00$ & 116.10 & $2.52 \mathrm{E}-07$ \\
\hline 5-2015 & 3.32 & 2.30 & 7.09E-11 & $5.02 \mathrm{E}-05$ & $2.26 \mathrm{E}+07$ & $1.11 \mathrm{E}+07$ & 294.27 & 293.96 & $7.69 \mathrm{E}+00$ & 110.80 & $2.08 \mathrm{E}-07$ \\
\hline $6-2015$ & 4.47 & 2.20 & 9.37E-11 & $5.13 \mathrm{E}-05$ & $7.56 \mathrm{E}+07$ & $5.09 \mathrm{E}+07$ & 298.12 & 298.46 & $2.03 \mathrm{E}+01$ & 370.75 & $1.48 \mathrm{E}-07$ \\
\hline $7-2015$ & 3.70 & 2.30 & 3.99E-11 & 6.77E-05 & $3.74 \mathrm{E}+07$ & $6.79 \mathrm{E}+07$ & 300.81 & 302.45 & $1.23 \mathrm{E}+01$ & 183.30 & $1.87 \mathrm{E}-07$ \\
\hline 8-2015 & 3.21 & 2.25 & $7.40 \mathrm{E}-11$ & 2.89E-05 & $2.43 \mathrm{E}+07$ & $4.38 \mathrm{E}+07$ & 301.91 & 304.46 & $2.20 \mathrm{E}+01$ & 119.30 & 2.11E-07 \\
\hline
\end{tabular}

Note: for interpretation of the parameters please refer to Table S3. 
Chapter 5

Table S6 Chemical specific dynamic parameters for the contaminant fate model

\begin{tabular}{|c|c|c|c|c|c|c|}
\hline \multirow{2}{*}{ Month } & \multicolumn{2}{|c|}{$C_{02 t}\left(\mathrm{~mol} / \mathrm{m}^{3}\right)$} & \multicolumn{2}{|c|}{$K_{12}(\mathrm{~m} / \mathrm{h})$} & \multicolumn{2}{|c|}{$K_{21}(\mathrm{~m} / \mathrm{h})$} \\
\hline & PFOA & PFOS & PFOA & PFOS & PFOA & PFOS \\
\hline $9-2013$ & $9.85 \mathrm{E}-10$ & 4.10E-11 & $4.89 \mathrm{E}+00$ & $4.29 \mathrm{E}+00$ & $2.06 \mathrm{E}-03$ & $1.81 \mathrm{E}-03$ \\
\hline $10-2013$ & 1.09E-09 & 4.33E-11 & $4.77 \mathrm{E}+00$ & $4.18 \mathrm{E}+00$ & $1.98 \mathrm{E}-03$ & $1.73 \mathrm{E}-03$ \\
\hline $11-2013$ & 1.19E-09 & 4.57E-11 & $4.53 \mathrm{E}+00$ & $3.97 \mathrm{E}+00$ & $1.95 \mathrm{E}-03$ & $1.71 \mathrm{E}-03$ \\
\hline $12-2013$ & $1.29 \mathrm{E}-09$ & $4.81 \mathrm{E}-11$ & $4.29 \mathrm{E}+00$ & $3.77 \mathrm{E}+00$ & $1.97 \mathrm{E}-03$ & $1.73 \mathrm{E}-03$ \\
\hline $1-2014$ & $1.39 \mathrm{E}-09$ & $5.04 \mathrm{E}-11$ & $5.36 \mathrm{E}+00$ & $4.70 \mathrm{E}+00$ & $2.26 \mathrm{E}-03$ & $1.98 \mathrm{E}-03$ \\
\hline $2-2014$ & $1.49 \mathrm{E}-09$ & $5.28 \mathrm{E}-11$ & $5.95 \mathrm{E}+00$ & $5.22 \mathrm{E}+00$ & 2.47E-03 & 2.17E-03 \\
\hline 3-2014 & $1.60 \mathrm{E}-09$ & 5.52E-11 & $6.07 \mathrm{E}+00$ & $5.33 \mathrm{E}+00$ & $2.59 \mathrm{E}-03$ & $2.27 \mathrm{E}-03$ \\
\hline 4-2014 & 1.49E-09 & $5.28 \mathrm{E}-11$ & $5.60 \mathrm{E}+00$ & $4.91 \mathrm{E}+00$ & $2.45 \mathrm{E}-03$ & $2.15 \mathrm{E}-03$ \\
\hline 5-2014 & 1.39E-09 & $5.04 \mathrm{E}-11$ & $5.83 \mathrm{E}+00$ & $5.12 \mathrm{E}+00$ & $2.70 \mathrm{E}-03$ & 2.37E-03 \\
\hline 6-2014 & $1.29 \mathrm{E}-09$ & $4.81 \mathrm{E}-11$ & $5.00 \mathrm{E}+00$ & $4.39 \mathrm{E}+00$ & 2.14E-03 & 1.87E-03 \\
\hline $7-2014$ & 1.19E-09 & 4.57E-11 & $4.77 \mathrm{E}+00$ & $4.18 \mathrm{E}+00$ & $1.75 \mathrm{E}-03$ & $1.54 \mathrm{E}-03$ \\
\hline 8-2014 & $1.09 \mathrm{E}-09$ & 4.33E-11 & $4.41 \mathrm{E}+00$ & $3.87 \mathrm{E}+00$ & $1.73 \mathrm{E}-03$ & $1.52 \mathrm{E}-03$ \\
\hline 9-2014 & $9.85 \mathrm{E}-10$ & 4.10E-11 & $5.48 \mathrm{E}+00$ & $4.81 \mathrm{E}+00$ & 2.13E-03 & $1.87 \mathrm{E}-03$ \\
\hline 10-2014 & $1.09 \mathrm{E}-09$ & 4.33E-11 & $5.00 \mathrm{E}+00$ & $4.39 \mathrm{E}+00$ & $1.95 \mathrm{E}-03$ & $1.71 \mathrm{E}-03$ \\
\hline $11-2014$ & 1.19E-09 & 4.57E-11 & $5.00 \mathrm{E}+00$ & $4.39 \mathrm{E}+00$ & $1.96 \mathrm{E}-03$ & $1.72 \mathrm{E}-03$ \\
\hline $12-2014$ & $1.29 \mathrm{E}-09$ & $4.81 \mathrm{E}-11$ & $5.24 \mathrm{E}+00$ & $4.60 \mathrm{E}+00$ & $2.21 \mathrm{E}-03$ & $1.94 \mathrm{E}-03$ \\
\hline 1-2015 & 1.39E-09 & $5.04 \mathrm{E}-11$ & $5.00 \mathrm{E}+00$ & $4.39 \mathrm{E}+00$ & 2.07E-03 & $1.82 \mathrm{E}-03$ \\
\hline 2-2015 & 1.49E-09 & $5.28 \mathrm{E}-11$ & $5.95 \mathrm{E}+00$ & $5.22 \mathrm{E}+00$ & $2.56 \mathrm{E}-03$ & $2.25 \mathrm{E}-03$ \\
\hline 3-2015 & $1.60 \mathrm{E}-09$ & 5.52E-11 & $5.83 \mathrm{E}+00$ & $5.12 \mathrm{E}+00$ & $2.51 \mathrm{E}-03$ & $2.21 \mathrm{E}-03$ \\
\hline 4-2015 & 1.49E-09 & $5.28 \mathrm{E}-11$ & $5.83 \mathrm{E}+00$ & $5.12 \mathrm{E}+00$ & 2.75E-03 & $2.41 \mathrm{E}-03$ \\
\hline 5-2015 & 1.39E-09 & $5.04 \mathrm{E}-11$ & $5.60 \mathrm{E}+00$ & $4.91 \mathrm{E}+00$ & $2.36 \mathrm{E}-03$ & 2.07E-03 \\
\hline 6-2015 & $1.29 \mathrm{E}-09$ & $4.81 \mathrm{E}-11$ & $5.36 \mathrm{E}+00$ & $4.70 \mathrm{E}+00$ & $1.83 \mathrm{E}-03$ & $1.61 \mathrm{E}-03$ \\
\hline $7-2015$ & 1.19E-09 & 4.57E-11 & $5.60 \mathrm{E}+00$ & $4.91 \mathrm{E}+00$ & 2.19E-03 & $1.92 \mathrm{E}-03$ \\
\hline 8-2015 & $1.09 \mathrm{E}-09$ & 4.33E-11 & $5.48 \mathrm{E}+00$ & $4.81 \mathrm{E}+00$ & 2.35E-03 & $2.06 \mathrm{E}-03$ \\
\hline
\end{tabular}

Note: for interpretation of the parameters please refer to Table S4. 
Modeling PFASs in a phytoplankton-dominated shallow lake

Table S7 Data collection for Freundlich isotherm parameters

\begin{tabular}{|c|c|c|c|c|c|}
\hline \multirow{2}{*}{$\begin{array}{l}\text { Contamina } \\
\text { nt }\end{array}$} & \multirow{2}{*}{ Sorbent } & \multicolumn{2}{|c|}{ Freundlich isotherm } & \multirow{2}{*}{ Conc. range } & \multirow{2}{*}{ References } \\
\hline & & $\log K_{F}$ & $n_{F}$ & & \\
\hline \multirow[t]{6}{*}{ PFOA } & GAC $^{\mathrm{d}}$ & $\begin{array}{l}2.28 \pm 0.11 \\
\mathrm{a}\end{array}$ & $0.29 \pm 0.05$ & $\begin{array}{l}1400 \pm 130 \\
\mathrm{ng} / \mathrm{L}\end{array}$ & Hansen et al. 2010 \\
\hline & $\mathrm{PAC}^{\mathrm{d}}$ & $\begin{array}{l}3.82 \pm 0.14 \\
\text { a }\end{array}$ & $0.6 \pm 0.2$ & $\begin{array}{l}1400 \pm 130 \\
\mathrm{ng} / \mathrm{L}\end{array}$ & Hansen et al. 2010 \\
\hline & $\mathrm{GAC}^{\mathrm{d}}$ & $7.07^{b}$ & 0.28 & $50 \mathrm{mg} / \mathrm{L}$ & Yu et al., 2009 \\
\hline & $\mathrm{PAC}^{\mathrm{d}}$ & $5.79 \mathrm{~b}$ & 0.2 & $50 \mathrm{mg} / \mathrm{L}$ & Yu et al., 2009 \\
\hline & Lake sediment & $2.06^{c}$ & $\begin{array}{l}0.75-1.00 \\
(0.9) \\
\end{array}$ & $0.5-100 \mu \mathrm{g} / \mathrm{L}$ & $\begin{array}{l}\text { Higgins and Luthy, } \\
2006\end{array}$ \\
\hline & $\begin{array}{l}\text { Used in the } \\
\text { model }\end{array}$ & 3.82 & 0.6 & - & For the present study \\
\hline \multirow[t]{7}{*}{ PFOS } & $\mathrm{GAC}^{\mathrm{d}}$ & $\begin{array}{l}2.73 \pm 0.05 \\
\text { a }\end{array}$ & $0.5 \pm 0.03$ & $\begin{array}{l}1400 \pm 200 \\
\mathrm{ng} / \mathrm{L}\end{array}$ & Hansen et al. 2010 \\
\hline & $\mathrm{PAC}^{\mathrm{d}}$ & $4.0 \pm 0.2^{a}$ & $0.9 \pm 0.5$ & $\begin{array}{l}1400 \pm 200 \\
\mathrm{ng} / \mathrm{L}\end{array}$ & Hansen et al. 2010 \\
\hline & Lake sediment & $6.2 \pm 2.1^{\mathrm{e}}$ & $0.92 \pm 0.063$ & $0.05-5 \mathrm{mg} / \mathrm{L}$ & Kwadijk et al., 2013 \\
\hline & $\mathrm{GAC}^{\mathrm{d}}$ & $6.92^{b}$ & 0.18 & $50 \mathrm{mg} / \mathrm{L}$ & Yu et al., 2009 \\
\hline & PAC $^{d}$ & $6.60^{b}$ & 0.18 & $50 \mathrm{mg} / \mathrm{L}$ & Yu et al., 2009 \\
\hline & Lake sediment & $\begin{array}{l}2.57 \pm 0.13 \\
\text { c }\end{array}$ & $\begin{array}{l}0.75-1.00 \\
(0.9)\end{array}$ & $0.5-100 \mu \mathrm{g} / \mathrm{L}$ & $\begin{array}{l}\text { Higgins and Luthy, } \\
2006\end{array}$ \\
\hline & $\begin{array}{l}\text { Used in the } \\
\text { model }\end{array}$ & 4.0 & 0.9 & - & For the present study \\
\hline
\end{tabular}

Notes: $K_{F}$ : Freundlich sorption distribution coefficient; $n_{F}$ : indication of the nonlinearity of the sorption isotherm

a Unit: $(n g / g$ sorbent $)(n g / L)^{-n}$

b Unit: (mmol/g sorbent)( $\mathrm{mmol} / \mathrm{L})^{-n}$

c $\log \mathrm{Koc}(\mathrm{L} / \mathrm{kgOC})$

d PAC: Powdered activated carbon; GAC: Granular activated carbon

e including organic matter fraction $(f \circ)$

\section{References:}

1) Hansen, M.C., Børresen, M.H., Schlabach, M., Cornelissen, G., 2010. Sorption of perfluorinated compounds from contaminated water to activated carbon. Journal of Soils and Sediments 10, 179-185.

2) Yu, Q., Zhang, R., Deng, S., Huang, J., Yu, G., 2009. Sorption of perfluorooctane sulfonate and perfluorooctanoate on activated carbons and resin: kinetic and isotherm study. Water Res. 43, 1150-1158.

3) Higgins, C.; Luthy, R. Sorption of perfluorinated surfactants on sediments Environ. Sci. Technol. 2006, 40, 7251-7256.

4) Kwadijk, C.J.A.F., Velzeboer, I., Koelmans, A.A., 2013. Sorption of perfluorooctane sulfonate to carbon nanotubes in aquatic sediments. Chemosphere 90, 1631-1636. 
Chapter 5 


\section{Chapter 6}

\section{Integrated ecological and chemical food web accumulation modeling explains PAH temporal trends during regime shifts in a shallow lake}

Xiangzhen Kong, Wei He, Ning Qin, Wenxiu Liu, Bin Yang, Chen

Yang, Fuliu Xu, Wolf M. Mooij, Albert A. Koelmans

Published in Water Research (2017) 119, 73-82 
Chapter 6

\section{Abstract}

Shallow lakes can switch suddenly from a turbid situation with high concentrations of phytoplankton and other suspended solids to a vegetated state with clear water, and vice versa. These alternative stable states may have a substantial impact on the fate of hydrophobic organic compounds (HOCs). Models that are fit to simulate impacts from these complex interactions are scarce. We developed a contaminant fate model which is linked to an ecosystem model (PCLake) for shallow lakes. This integrated model was successful in simulating long-term dynamics (1953-2012) of representative polycyclic aromatic hydrocarbons (PAHs) in the main biotic and abiotic components in a large shallow lake (Chaohu in China), which has undergone regime shifts in this period. Historical records from sediment cores were used to evaluate the model. The model revealed that regime shifts in shallow lakes had a strong impact on the fate of less hydrophobic compounds due to the large storage capacity of macrophytes, which accumulated up to $55.6 \%$ of phenanthrene in the clear state. The abrupt disappearance of macrophytes after the regime shift resulted in a sudden change in phenanthrene distribution, as the sediment became the major sink. For more hydrophobic compounds such as benzo(a)pyrene, the modeled impact of the regime shift was negligible for the whole environment, yet large for biotic compartments. This study is the first to provide a full mechanistic analysis of the impact of regime shifts on the fate of PAHs in a real lake ecosystem. 
Impact of regime shift on PAHs in a shallow lake

\section{Introduction}

Freshwater shallow lake ecosystems often suffer from water quality deterioration due to eutrophication (Conley et al. 2009). The response of these systems to eutrophication is non-linear, reinforced by multiple feedback mechanisms (Carpenter et al. 1999) that lead to alternative stable ecosystem states, i.e. a clear, macrophyte-dominated state, and a turbid, phytoplanktondominated state (Scheffer et al. 2001a). Such systems are stable in either of the states (Scheffer et al. 1993) but can shift from one state to another surprisingly, when a threshold of a certain external condition is crossed (e.g. nutrient loading), which is generally referred to as a 'regime shift' (Scheffer and Jeppesen 2007). Over the last decades, many shallow lakes around the globe have undergone such a regime shift from clear to turbid state mainly due to severe pressure from anthropogenic activities (Wang et al. 2012b, Kong et al. 2017a).

Meanwhile, freshwater lake ecosystems in highly populated areas are increasingly contaminated with hazardous chemicals such as hydrophobic organic contaminants (HOCs) (Schwarzenbach et al. 2006). These HOCs are distributed among various compartments in the lake environment and accumulate in the aquatic food web, thereby threatening ecological functions due to toxicity to organisms (Qin et al. 2013b), and potentially undermining human health if contaminated aquatic products are consumed (Wu et al. 2007). The coincidence of eutrophication and contamination in shallow lakes calls for a better understanding of the impacts of regime shifts on the behavior and potential risks of HOCs in such aquatic ecosystems. This is a prerequisite for ecological and human health risk assessment, which in turn may inform environmental management and policy. The ecological structures in the alternative states have been shown to be largely different (Kong et al. 2016), while the fate of HOCs in aquatic ecosystems is largely associated with the biogeochemical cycle of carbon and the dynamics of primary producers (Koelmans et al. 2001, Nizzetto et al. 2012). Consequently, the changes in ecological structure due to the aforementioned regime shifts will drastically alter the fate and bioaccumulation of certain HOCs in lakes. This issue has been addressed by indoor experiments (Roessink et al. 2010) and field studies with several lakes in distinctive ecological states (Moermond et al. 2005), yet illustrative cases of regime shifts within one ecosystem are scarce. This can be explained by lack of long-term observations in lake ecosystems that may have suffered from regime shifts, and by the difficulty in detecting the occurrence of these regime shifts. However, studying regime shifts in one specific system has 
the advantage that confounding factors due to differences among lakes play no role.

The mechanistic understanding of the implications of regime shifts for HOC fate and effects requires the integration of ecosystem and contaminant fate models (Koelmans et al. 2001). Integrated models can be used to test new hypothesis at the interface of the disciplines of aquatic ecology and environmental chemistry. However, such integrated models are poorly available. Furthermore, there is room for improvement with respect to some of the process descriptions, for instance those capturing the dynamics of the food web (Gouin et al. 2013), and those quantifying sorption to condensed carbon phases (Koelmans et al. 2001, Koelmans et al. 2006), which we aim to address in the present study. Finally, whether such models can adequately represent the implications of a regime shift for the cycling of HOCs in a real system remains to be demonstrated.

We applied the model to polycyclic aromatic hydrocarbons (PAHs), which is a class of HOCs that can exert a wide range of different chemical behaviors (Shen et al. 2013). The objectives of the present study are: 1) to develop an integrated ecological and chemical fate model for PAHs that describes their fate in both abiotic and biotic compartments in a lake area at short- and long- term temporal scales, which can include regime shifts, and 2) to investigate the impact of regime shifts on the fate of PAHs in shallow lake ecosystems. To achieve these aims, we coupled a food web accumulation model based on existing approaches for accumulation of PAHs in aquatic organisms (Campfens and Mackay 1997, Arnot and Gobas 2004, Gandhi et al. 2006), to a previously developed contaminant fate model (Kong et al. 2014), which is applicable to multiple groups of HOCs, like for instance PAHs (Xu et al. 2013). The model was further integrated with a well-calibrated ecosystem model (PCLake) (Kong et al. 2017a), which accounted for the ecological processes. To evaluate the model, we used the data from a large shallow lake in China (Lake Chaohu), which had been subject to a regime shift from clear to turbid state over the last several decades (Kong et al. 2017a). Contemporary data of PAHs observations in various biotic and abiotic components in Lake Chaohu were available. To further evaluate the model performance in the longterm, we used the information on historical pollution of PAHs over a time span of 60 years from 1953 to 2012, measured in two sediment cores from the lake. To our knowledge, this is the first study that aims at modeling regime shifts in $\mathrm{PAH}$ cycling, and that combines historical information and modeling results to illustrate the long-term dynamics of PAHs fate in an aquatic environment. 
Impact of regime shift on PAHs in a shallow lake

\section{Materials and methods}

\section{Study area}

Lake Chaohu $\left(31^{\circ} 25^{\prime} 28^{\prime \prime}-31^{\circ} 43^{\prime} 28^{\prime \prime} \mathrm{N}, 117^{\circ} 16^{\prime} 54^{\prime \prime}-117^{\circ} 51^{\prime} 46^{\prime \prime} \mathrm{E}\right)$ is the fifth largest freshwater shallow lake in China with a surface area of $760 \mathrm{~km}^{2}$ and an average depth of $3 \mathrm{~m}$, located in the most developed region among the lower reaches of the Yangtze River floodplain (Fig. 1). The lake used to provide important ecological services to the catchment area, e.g. drinking water supply for large cities Hefei and Chaohu. However, the lake ecosystem has undergone regime shifts between clear and turbid states since the 1950s (Kong et al. 2017a). The heavy flood occurring in 1954 induced a regime shift into a turbid state in this lake, which shifted back to a clear state before 1960 (Kong et al. 2017a). The onset of the sluice in 1963 (Fig. 1), however, tipped the lake into a turbid state again, and increasing nutrient loadings (Kong et al. 2015) triggered the nuisance of phytoplankton blooms since 1980, which has lasted until now. The lake is no longer serving as the drinking water source to adjacent cities. Great effort has been invested into ecological restoration and management of this lake with however limited improvement in lake water quality and ecological status at the current stage (Kong et al. 2017a). Meanwhile, the lake has been subjected to severe PAHs pollution (as well as black carbon) due to increasing energy consumption by biomass fuel combustion for heating in rural areas, vehicle emissions in urban areas and coal combustion at nearby power plants in the catchment (Qin et al. 2014). Reduction in PAHs input to the lake in recent years is not likely to happen due to intensified human activities in the lake catchment (Giesy et al. 2016).

\section{Data collection}

Phenanthrene (Phe), pyrene (Pyr) and benzo(a)pyrene (BaP), were selected to represent low-, moderate- and high-molecular-weight PAHs. Monthly concentrations of these PAHs were available for gaseous, aerosol particles and for suspended solids from May 2010 to April 2011, and aqueous phase from May 2010 to April 2012 (Qin et al. 2013a, Qin et al. 2014), at multiple sampling sites (Fig. 1). Other field data included PAHs in multiple groups of biota for human consumption in 2009 (Qin et al. 2013c) and in phytoplankton in 2012 (provided as Supporting Information). We further collected data from literature, including PAHs in surface sediment in 2011 (Li et al. 2014) and in soil close to the study site in 2007 (Wang et al. 2010). Additionally, we used PAHs concentrations in vegetation for Lake Taihu in 
2014 (Tao et al. 2015) as a proxy for those in Lake Chaohu. This is based on the fact that: 1) both lakes are located in the lower Yangtze River floodplain, where the ecosystems are subjected to very similar (intense) human disruptions and pollutions (Dearing et al. 2012); 2) Both lakes are large shallow lakes with similar eutrophication status since the 1980s (Janssen et al. 2014, Kong et al. 2017a); 3) Both lakes are located in the area with similar intensity of PAHs emission (Zhang et al. 2007). Overall, PAH observations were available for model evaluation in all modeled compartments except for zooplankton. For all organisms, data on lipid fractions were available from our previous measurements (Qin et al. 2013c). In addition, PAH profiles were measured in the first $30 \mathrm{~cm}$ of two sediment cores (Fig. 1), which were collected with a Kajak gravity corer from the centers of the west and the east part of Lake Chaohu on August 23 ${ }^{\text {rd }}, 2011$ (details for PAHs measurement provided as Supporting Information). The time series of historical PAHs records were used for the evaluation of the long-term model simulation. Chronologies were obtained by measuring ${ }^{210} \mathrm{~Pb}$ and ${ }^{137} \mathrm{Cs}$ radionuclide activities in contiguous samples in the cores (details provided as Supporting Information). More details regarding analytical procedures for ${ }^{210} \mathrm{~Pb}$ and ${ }^{137} \mathrm{Cs}$ radionuclide activities in the sediment were reported before (Kong et al. 2017a).

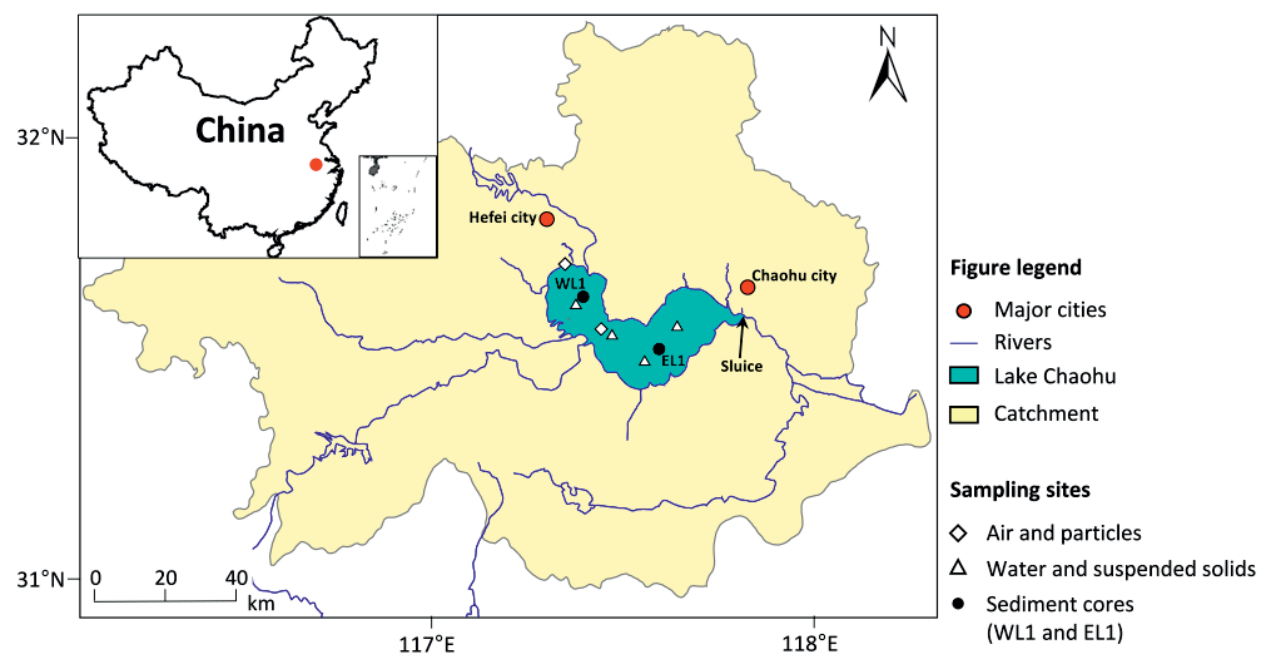

Fig. 1. Lake Chaohu and the catchment area in China, as well as the sampling sites for two gaseous and aerosol particles samples (Qin et al., 2013a), four water and suspended solid samples (Qin et al., 2014) and two sediment core samples (Kong et al., 2017). The locations of major rivers and the sluice built in 1963 are also shown. 
Impact of regime shift on PAHs in a shallow lake

\section{Model development}

The model framework is composed of an ecological module (PCLake model) and a contaminant fate model that includes an abiotic module and a biotic (foodweb) module (Fig. 2). Model equations are provided as Supporting Information. Important environmental processes (e.g. water-sediment interaction) and dynamics of the food web components in Lake Chaohu are simulated using PCLake (Fig. 2). PCLake is a well-developed ecosystem model for shallow lakes in the context of the alternative stable states theory (Janse 2005). This model has been adapted for Lake Chaohu in our previous study and fitted to field observations (including nutrient levels, water quality indicators and biomass of various biota components) in both short-term (20082013) and long-term (1953-2012) simulations (Kong et al. 2017a). PCLake has a food web module that is similar to the biotic module in the contaminant fate model in the present study. Therefore, the biomass for different organism groups as simulated by PCLake (Fig. S1) is used as input for the simulations of the food web PAH bioaccumulation model. This is based on the assumption that PAH toxicity had no influence on the biomass and abundance of species, which is reasonable for the present case study because the PAH concentrations (total and individual $\mathrm{PAH}$ ) in both sediment cores were generally lower than the threshold effect concentration (TEC), and were always below the probable effect concentration (PEC) (MacDonald et al. 2000) (Fig. S2). 


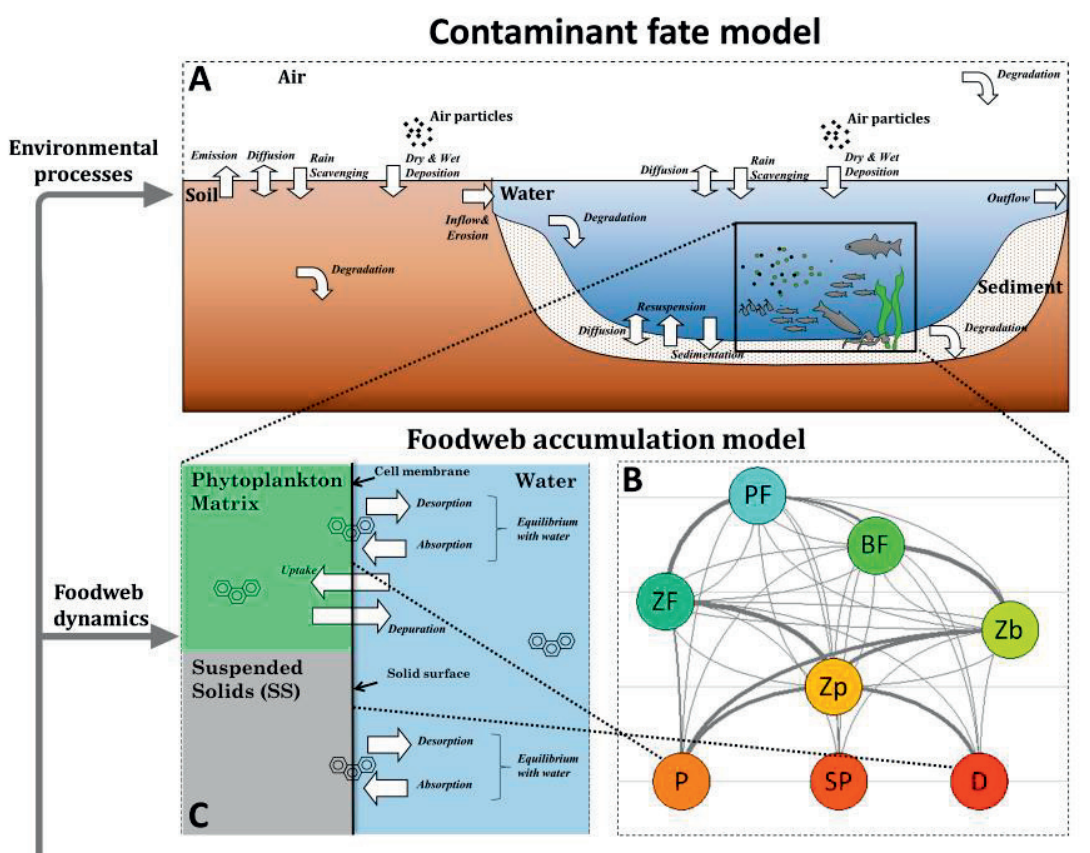

Lake ecosystem \& Food web model

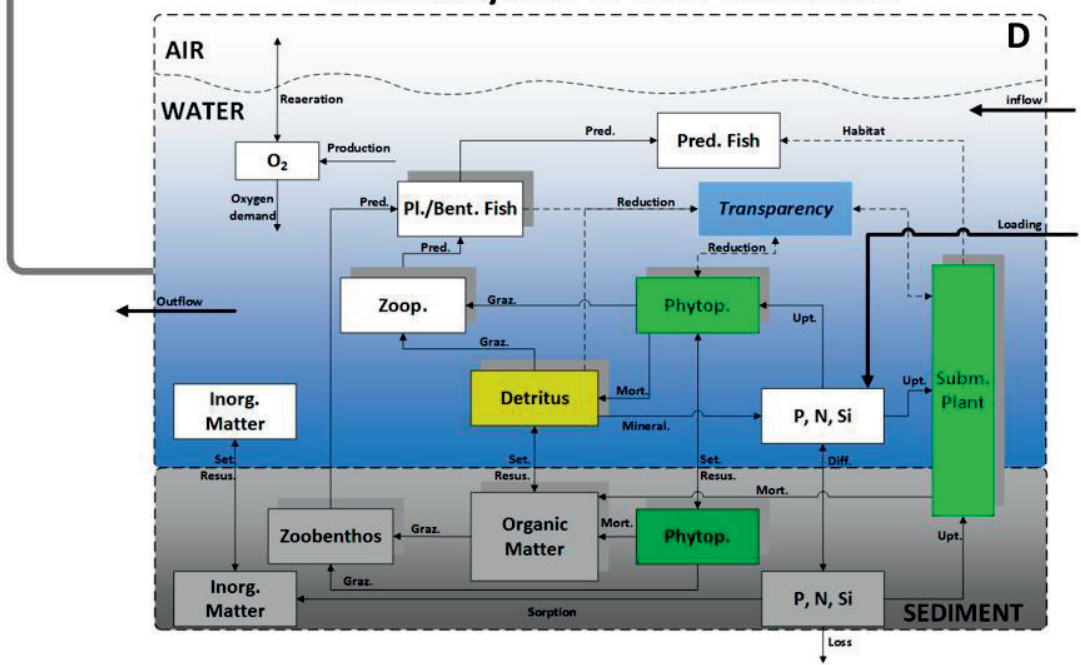

Fig. 2. Overview of the model. (A) Processes between major compartments of the contaminant fate model. (B) Structure of the food web accumulation model, including piscivorous fish $(P F)$, zooplanktivorous fish $(Z F)$, benthivorous fish $(B F)$, zoobenthos $(Z b)$, zooplankton $(Z p)$, phytoplankton $(P)$, submerged macrophytes $(S P)$ and detritus $(D)$. (C) Processes between water and phytoplankton/suspended solids in the model. (D) Schematic framework of shallow lake ecosystem model PCLake (redrawn after Janse, 2005). 
Impact of regime shift on PAHs in a shallow lake

For the contaminant fate model, the abiotic module is a fugacity-based level IV fate model for lakes based on previous studies (Xu et al. 2013, Kong et al. 2014), with an additional soil compartment in the lake basin. The water compartment is assumed well-mixed in this study as the lake is shallow with an average depth of only $3 \mathrm{~m}$. Following earlier modeling (Mackay and Paterson 1991), equilibrium is assumed within each main abiotic compartment. The biotic module is a food web accumulation model (Campfens and Mackay 1997, Gandhi et al. 2006), with an extended description of the PAH exchange between water and phytoplankton (Fig. 2; SI text). Based on our previous study on the food web structure in Lake Chaohu (Kong et al. 2016), we defined a simplified food web structure for the model in the present study that comprises seven functional groups: piscivorous fish, zooplanktivorous fish, benthivorous fish, zoobenthos, zooplankton, phytoplankton, and macrophytes. Suspended solids in the water compartment (i.e. detritus) serve as an additional group in the food web. Modeled processes include exchange through gills from water or pore water in sediment (Dw), uptake from food $\left(D_{A}\right)$, loss by fecal egestion $\left(D_{E}\right)$, loss by growth dilution $\left(D_{G}\right)$, loss by metabolism (DM) and loss by predation (Dp). For the three fish groups, we added the process of production $\left(\mathrm{D}_{2 \mathrm{f}}\right)$ representing the influence of fishery. The exchange with water for fish groups is modeled following Arnot and Gobas (2004), which is also applied for invertebrates (zooplankton and zoobenthos). Growth dilution and metabolism for both fish and invertebrates are modeled as first-order kinetic processes, while the $\mathrm{PAH}$ metabolic transformation rates are approximated following Moermond et al. (2007). Note that metabolism is found to dominate PAH elimination from fish and invertebrates and is thus important for the trophic transfer of PAHs in aquatic ecosystems (Wan et al. 2007). For modeling PAHs in macrophytes and phytoplankton, we used similar principles as those for fish and invertebrates, with modifications based on the uptake model for phytoplankton from Dachs et al. (1999) (SI text). Bioaccumulation is modeled based on the foodweb interactions (Arnot and Gobas 2004) and the dietary composition defined in Table S3. Finally, we modeled elimination by egestion as a constant fraction of the uptake from food, quantified as the limiting biomagnification factor (Q) (Campfens and Mackay 1997).

\section{Parameter determination}

Definition, statistical data and sources for all the parameters in the contaminant fate model are listed in Tables S4-S6. There are 159 parameters in the model, including 46 environmental parameters, 21 chemical-specific 
parameters (mass transfer and physicochemical parameters) and 92 food webrelated parameters. Twenty-one parameters vary seasonally, whereas the other parameters remain constant throughout the simulation. The parameters were obtained from the relevant literature or calculated based on the conditions in Lake Chaohu (Table S4-S6). Temperature corrections were applied to both subcooled liquid vapor pressure $\left(P_{S 25} ; \mathrm{Pa}\right)$ and Henry's law constant $\left(\mathrm{H}_{25}\right.$; $\mathrm{Pa} \cdot \mathrm{m}^{3} / \mathrm{mol}$ ) at $25^{\circ} \mathrm{C}$ (Lun et al. 1998, Paasivirta et al. 1999). Note that vapor pressure for the solid substance of the chemical, which is generally lower than that for the subcooled liquid of the chemical, can lead to an overestimation of the fugacity capacity of aerosol particles and thus to inaccurate predictions (Paasivirta et al. 1999). Sorption of PAH to black carbon (BC) in sediment was taken into account. Following previous approaches (Hauck et al. 2007, Koelmans et al. 2009), a whole-lake median literature value for the fraction of $B C$ in sediment was applied $\left(f_{B C}=0.002\right)$. Other parameters for strong sorption of PAHs to carbonaceous materials and for metabolic transformation were based on Moermond et al. (2007). We used the bioconcentration factors for phytoplankton's matrix and surface $\left(B C F M\right.$ and $B C F s$, respectively; $\mathrm{m}^{3} / \mathrm{kg}$ ) reported by Del Vento and Dachs (2002), adjusted by the factors $k_{d} /\left(k_{d}+k_{G}\right)$ and $k_{d e s} /\left(k_{\text {des }}+k_{G}\right)$, respectively, to account for the dilution effect of growth (Koelmans 2014)\{Koelmans, $1995 \# 2359\}$. The parameters $k_{d}(1 / \mathrm{h}), k_{d e s}(1 / \mathrm{h})$ and $k_{G}(1 / \mathrm{h})$ are the depuration rate, the desorption rate of surface, and the growth rate of phytoplankton, respectively. Uncertainly exists when these parameters are extrapolated to other phytoplankton species (Del Vento and Dachs 2002). However, as the experimentally determined values were not available for species in Lake Chaohu, we used literature data (Del Vento and Dachs 2002). We assumed that species-dependent kinetic factors play a secondary role in determining the fate of POPs in aquatic environments, which has been proved valid for modeling other HOCs (Dachs et al. 1999). For the remainder, the food web accumulation model was parametrized according to previous studies (Campfens and Mackay 1997, Arnot and Gobas 2004, Di Paolo et al. 2010). In the present modeling approach, none of the parameters was optimized by fitting to measured data.

\section{Model simulations}

Two simulations were conducted. The short-term simulation covered the period from May 2010 to April 2012. The long-term simulation covered the period from January 1953 to December 2012, i.e. 60 years in total. The shortterm simulation aimed at evaluating the robustness of the model and the ability of the model to predict the seasonality of PAH concentrations in Lake 
Impact of regime shift on PAHs in a shallow lake

Chaohu. The long-term simulation was designed to investigate the impact of the catastrophic regime shift on the fate and dynamics of PAHs in the catchment of Lake Chaohu. Note that our model is 0-dimensional, which suffices for the present study because the lake is assumed to be well-mixed both horizontally and vertically. The external conditions were derived from our previous study (Kong et al. 2017a), including water inflow and outflow, water depth, wind speed, water temperate and precipitation. Other boundary conditions such as emission inventories are provided as Supporting Information. For the short-term, initial values were the observations from March 2010 for concentrations in air and water, complemented with the available field observations for the other compartments. For the long-term, however, no data were available before the starting date. We assumed initial values to be two orders of magnitude lower than the average values for 20082013 based on the concentrations measured in the deepest (oldest) layers from sediment cores (Fig. S3). The model was implemented in Matlab (MathWorks 2002), The differential equations were solved using a fourth-order Runge-Kutta method as available in Matlab (ode45), with a simulation time step of 1 hour.

\section{Results and discussion}

\section{Model evaluation in the short-term simulation}

In the short-term simulation, our yearly (2-year for dissolved phase in water) average results fit well to the measured data for all modeled compartments (Fig. 3); two-thirds of the outcomes with a deviation smaller than a factor of 3, one-sixths with a deviation between a factor 3 and 5 , and one sixths with a deviation between a factor 5 and 10. An acceptable deviation between measured and modeled values for contaminant fate models is 0.7 logarithm units or lower, i.e. a factor smaller than 5 (Cowan et al. 1995). Thus, five-sixths of the modeling results fall in the acceptable range. We found that model performance for suspended solids, phytoplankton and macrophytes are relatively less robust (with larger deviation), particularly for Phe and BaP. Moreover, previous studies showed that the underestimation of sorption of PAHs to sediment can be due to the neglect of strong nonlinear sorption to condensed carbonaceous materials such as BC in the sediment (Moermond et al. 2007). Here, the inclusion of sorption to BC significantly improves model performance, particularly for the more hydrophobic PAHs, as the deviation between measured and modeled concentrations of Pyr and BaP in the sediment reduces by approximately one order of magnitude (not shown), to only a factor of 2 (Fig. 3). The importance of BC in modeling PAHs sorption in sediment has 
been previously demonstrated (Hauck et al. 2007). The typical value of the fraction (0.002) of BC in aquatic sediments, which is applied in the present study, seems to be a reasonable estimation when field data are not available. In addition, it has been shown that metabolic transformation at higher trophic levels may cause trophic dilution of PAHs in aquatic food webs (Wan et al. 2007). Here, the inclusion of metabolic transformation has a significant positive effect on the outputs of PAHs concentrations in fish and invertebrates (not shown), which is crucial to model the bioaccumulation of PAHs in food web (Moermond et al. 2007). Overall, our model reconfirms the importance of incorporating the processes of $\mathrm{BC}$ sorption and metabolic transformation for PAH modelling (Hauck et al. 2007, Moermond et al. 2007, Di Paolo et al. 2010). On a seasonal scale, the model provides a reasonable match with the observations for the three PAHs in the gaseous phase and aerosol particles in air. However, the model shows a relatively limited ability to predict seasonal variations of $\mathrm{PAH}$ concentrations in the water column (dissolved and suspended solids) (Fig. S4). More details are provided as Supporting Information. The seasonal validation provides more detail on model performance, detail that cannot be clearly demonstrated from annual average results. For example, better model performance for aerosol particles than for the gas phase can be observed from the seasonal simulation data (Fig. S4), but cannot be easily seen on an annual average scale (Fig. 3). Overall, the results imply that within short temporal scales, the developed model, with all the mechanisms above incorporated, is capable of predicting the magnitude in most compartments (less than 0.7 logarithm units deviation between measured and modeled values for five-sixths of outputs) and seasonal patterns in abiotic compartments (air and water) for the three PAH residual concentrations within Lake Chaohu. The model was subsequently evaluated using long-term data. 

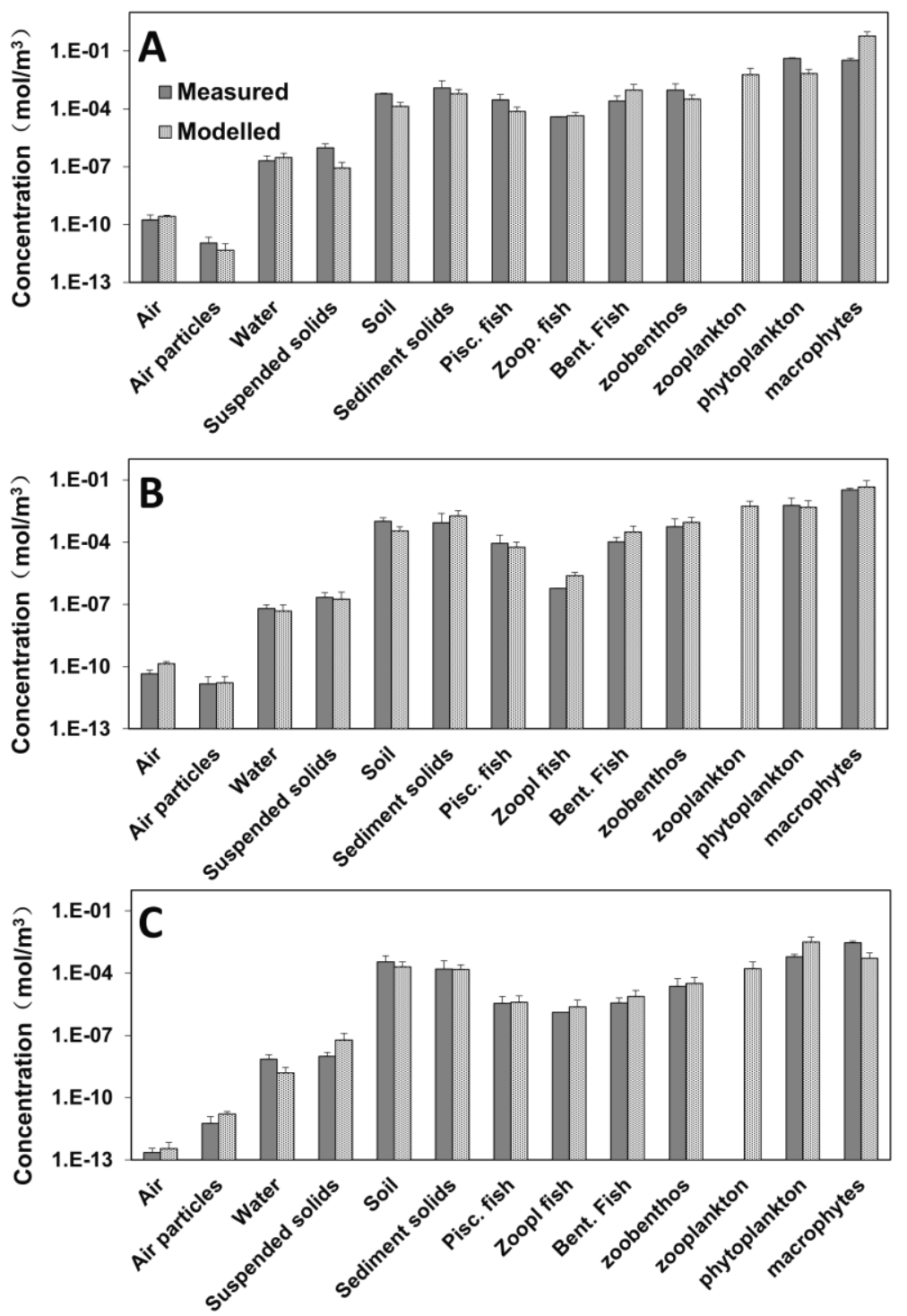

Fig. 3. Comparison of measured and modeled concentrations (on a logarithmic scale) of Phe (A), Pyr (B) and BaP (C) in all the model compartments averaged over the short-term simulation period. Error bars for measured data relate to standard deviation (s.d.) of monthly observations on different sample sites (May 2010 to April 2012 for water phase, and May 2010 to April 2011 for air, aerosol particles and suspended solid), or s.d. obtained from literature (other compartments). Error bars for modeled data relate to s.d. of simulation outputs. Observations in zooplankton are not available. 


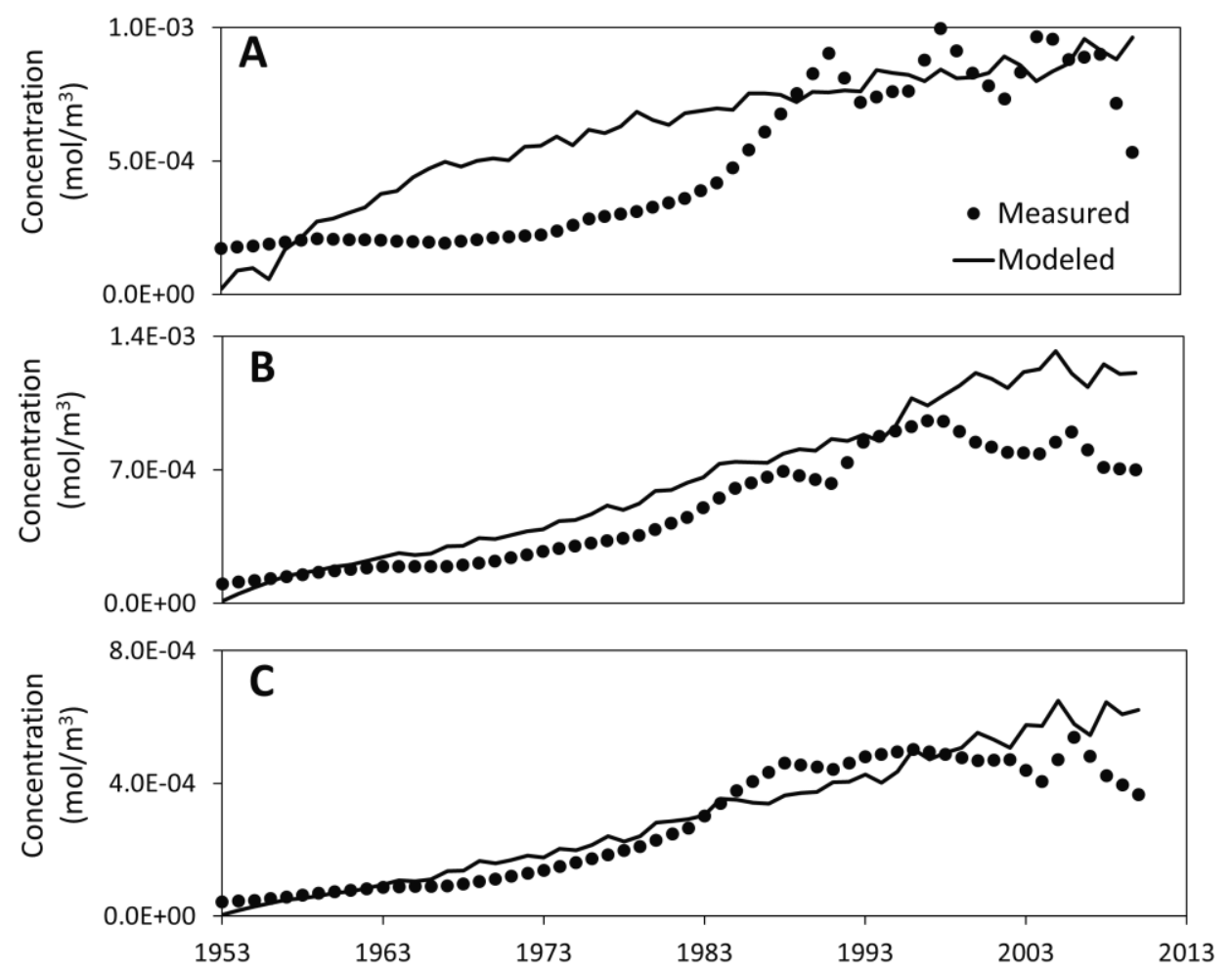

Fig. 4. Comparison of measured and modeled concentrations of Phe (A), Pyr (B) and $\mathrm{BaP}(\mathrm{C})$ in sediment solids for the long term simulation (January 1953 to December 2012). Measured data are the average values from the two sediment cores, and modeled data are plotted as the annual average values of each year.

\section{Model evaluation using long-term simulation}

The 60-year simulation was evaluated against data using the historical records in the sediment cores (Fig. 4). The model predictions for the sediment show a good match to the long-term historical records, whereas the prediction power in other compartments remains untested. Based on the model predictions, emission in the lake catchment (Fig. S3) drives the accumulation of PAHs in the sediment of Lake Chaohu since the 1950s, which is consistent with the positive correlations between $\mathrm{PAH}$ emissions and residue levels in sediments of Lake Chaohu (Ren et al. 2015). However, the model tends to overestimate the concentrations of Phe before 1990 (Fig. 4A). This discrepancy may be attributed to the underestimation of biodegradation of low-molecularweight PAHs, the effect of which may be much stronger in earlier time. The general decreasing trend of PAHs in sediment after the 2000s is in line with the 
Impact of regime shift on PAHs in a shallow lake

emission data (Fig. S3), which was however not fully captured in the model outputs. Multiple factors may contribute to this deviation, such as the absence of long-term data regarding $\mathrm{BC}$ contents in the sediment. A better model prediction may be achieved by using time explicit data of $\mathrm{BC}$ content in sediment cores. This BC content may have decreased after the 2000s due to a higher energy use efficiency (Wang et al. 2014) and enhanced burial. Nonetheless, the general agreement between measured and modeled PAH concentrations in sediment with respect to both magnitude and temporal dynamics implies that long-term model simulation outputs can be used for further evaluation.

\section{Impact of the regime shift on the modeled fate of PAHs}

The regime shift in this lake was characterized by a loss of macrophytes, rapidly developing blooms of phytoplankton, a switch in fish community towards domination of small zooplanktivorous fish, a strong enhancement in sediment resuspension and a substantial increase in suspended solid concentration (Fig. S1). The lake state dynamics are nicely represented by the vegetation coverage from the PCLake model (Fig. 5A), which agrees well with the field data (Kong et al. 2017a).

Long-term dynamics of the mass distribution for the three modeled PAHs among various compartments are simulated for the same period (Fig. 5). In general, our modeling results demonstrate that the mass distribution of less hydrophobic PAH in the lake is more susceptible to changes in ecological structure than that of more hydrophobic PAH (Fig. 5B-D). During the clear state (1958-1962), the model shows that a large fraction of Phe in the lake area is distributed in the food web (55.6\% on average), while the fractions are much lower for Pyr and $\mathrm{BaP}$ (2.6\% and $0.3 \%$ on average, respectively). On the other hand, during the turbid state after the regime shift (1963-2012), the corresponding average values become $0.050 \%, 0.010 \%$ and $0.008 \%$ for Phe, Pyr and $\mathrm{BaP}$, respectively, and the dominant sinks of the three modeled PAHs in the total environment of the lake catchment are soil and sediment. This finding agrees with results from indoor mesocosm experiments (Roessink et al. 2010), which show that the less hydrophobic and more mobile HOCs are more susceptible to ecological changes than the more hydrophobic and less mobile HOCs. 
Chapter 6

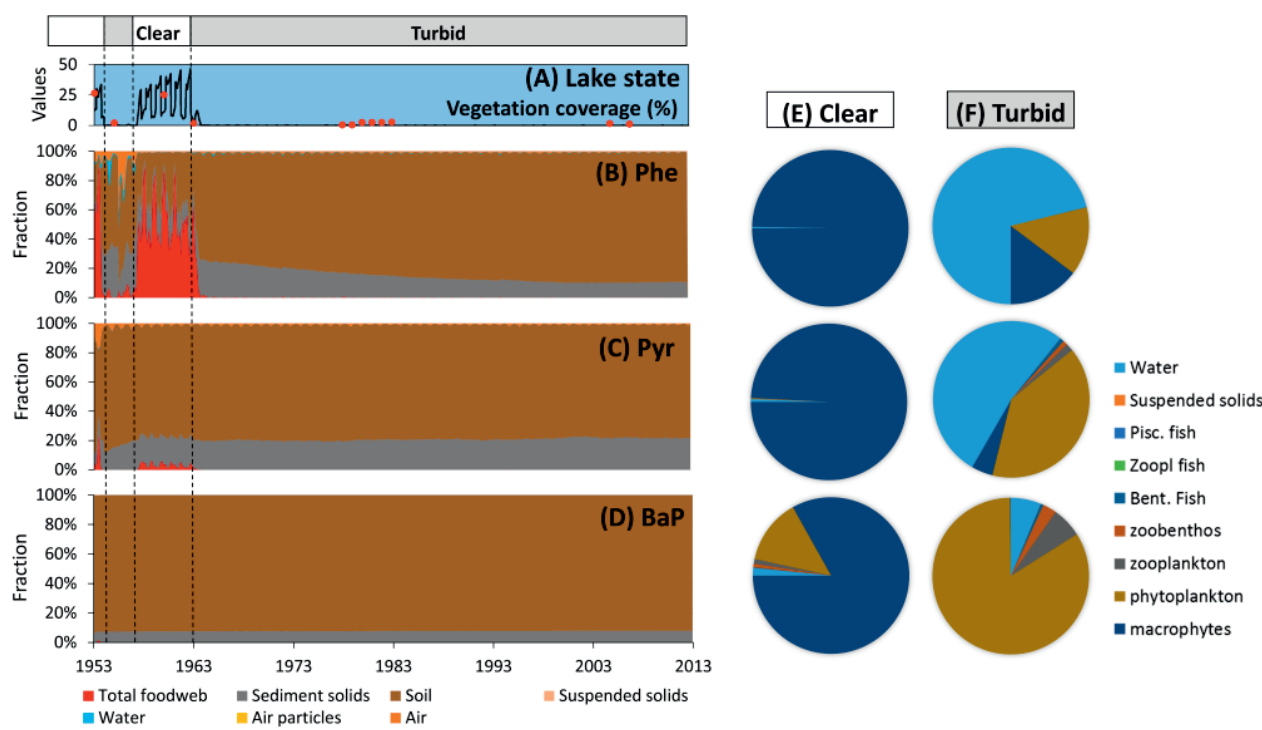

Fig. 5. Long term model simulations from 1953 to 2012. (A) Vegetation coverage from field observations (red dots) and PCLake model simulation (black line) (from Kong et al., 2017), which indicates the lake state (clear or turbid). (B-D) Modeled chemical mass fractions for Phe (B), Pyr (C) and BaP (D) among various compartments in the lake area. (E and F) Modeled average relative mass distributions of Phe, Pyr and $\mathrm{BaP}$ in water, suspended solids and all the biota compartments in the food web during the periods of clear (19581962; E) and turbid (1980-2012; F) states (note that soil and sediment are not included).

The model further indicates that the higher susceptibility to ecological changes for less hydrophobic chemicals is attributable to their higher tendency to get absorbed by macrophytes (Fig. 5B) before they get a chance of being adsorbed to BC. The model confirms that macrophytes are one of the dominant sinks for Phe in addition to soil and sediment in a clear lake basin, which is quantitatively in accordance with earlier results from laboratory mesocosm experiments mimicking conditions of shallow lakes (Roessink et al. 2010). In addition, the fractions of total mass in macrophytes for three modeled PAHs decrease drastically with increasing molecular weight (Fig. 5B-D), resulting in a lower susceptibility to ecological changes for Pyr and BaP. Both Pyr and BaP are primarily bound in soil and sediment rather than in the macrophytes because of their stronger sorption to BC than that of Phe (Koelmans et al. 2006). Therefore, different sorption abilities to $\mathrm{BC}$ of chemicals determine their behaviors during regime shifts. More hydrophobic PAHs may be bound 
Impact of regime shift on PAHs in a shallow lake

primarily to soil and sediment due to stronger BC sorption, thereby being less affected by a regime shift within biotic compartments.

As for modeling PAH bioconcentration by macrophytes, our model may leave some room for improvement. Based on previous modeling work (Janse 2005), the equation for macrophytes (see the Supporting Information) describes the exchange of substances with water and sediment separately, whereas it ignores the transport process between root and shoot, and it considers the chemicals to be evenly distributed in the macrophyte biomass. However, recent work has shown that chemicals were more slowly translocated from root to shoot than the other way around (Diepens et al. 2014). Consequently, including heterogeneity within the macrophytes and accounting for translocation between shoot and root in our model, may further increase ecological realism and provide more accurate simulations, especially when partitioning to macrophytes is important like during the clear state before 1963 (Fig. 5). However, parameters regarding uptake and elimination kinetics of PAH in sediment-rooted macrophytes are still uncertain and scarce (Diepens et al. 2014). More field data, as well as a more comprehensive submodel for macrophytes involving heterogeneity, are expected in future research.

The capacity of macrophytes to store considerable amounts of PAHs, i.e. 'biomass dilution' (Roessink et al. 2010), results in the depletion of PAHs in other environmental compartments, most importantly in biota. The model shows that in a clear lake, macrophytes account for $99.7 \%$ of Phe mass, $99.2 \%$ of Pyr mass and $83.1 \%$ of BaP mass in the water column above the sediment (Fig. 5E). Further indoor experiments have focused on investigating the potential of certain macrophytes to become a major storage reservoir for HOCs (Schneider and Nizzetto 2012). In addition, macrophytes are modeled to stabilize the sediment, thereby reducing resuspension fluxes due to fish bioturbation and wind shear stress in shallow lakes (Janse 2005). Consequently, the concentrations of suspended solids and $\mathrm{PAH}$ in the dissolved phase are lower with macrophytes present, due to lower desorption of PAHs from the suspended solids and to higher accumulation in macrophytes. We can infer that ecological restoration of a turbid lake back to a clear, macrophyte-rich state will not only improve water quality, ecological functioning and services, but also lead to the redistribution of PAHs in the lake ecosystem where higher proportions of PAHs will end up in macrophytes. As a consequence, PAH concentrations in suspended solids and biota compartments, as well as the toxic effects and ecological risks of these contaminants, may be reduced on an annual scale.

After the lake ecosystem tips into a turbid state, the dominant sinks of the three modeled PAHs are primarily soil and sediment, whereas phyto- 
plankton being the primary producer accumulates only a negligible fraction of PAH mass in the whole environment (Fig. 5B-D). The predominant roles of soil and sediment to determine $\mathrm{PAH}$ distribution in an aquatic ecosystem are in agreement to earlier studies (Liu et al. 2007, Roessink et al. 2010). However, within the water column above the sediment (the soil and sediment compartments were both excluded), the model reveals the significant role of phytoplankton in the distribution of PAHs, particularly for more hydrophobic chemicals such as Pyr and BaP, because $39.7 \%$ of Pyr mass and $83.8 \%$ of $\mathrm{BaP}$ mass are associated with the phytoplankton (Fig. 5F). A similar pattern was observed in an earlier laboratory study, in which periphyton dominated the mass distribution of PAHs in indoor model ecosystems when macrophytes were not present (Roessink et al. 2010). This effect also has been recognized for pelagic ecosystems (Nizzetto et al. 2012), in which phytoplankton is referred to as the 'biological pump' (Jurado and Dachs 2008). PCLake shows that biomass of phytoplankton is much higher without macrophytes (Fig. S1), primarily due to the increase of available nutrients from the dead macrophytes and the destabilized sediment. The rapidly increased phytoplankton biomass may bind large amounts of PAHs from the dissolved phase, which may promote the transfer of $\mathrm{PAH}$ from the atmosphere to the water as was suggested before (Dachs et al. 1999). In addition, the mortality of phytoplankton may enhance the vertical flux to sediment, whereas the absence of macrophytes may also result in a higher resuspension intensity. Consequently, the interaction between water and sediment possibly is much stronger in turbid than in clear lakes, which may enlarge the pool of sediment acting as a sink of PAHs. Our study reveals that the capacity of phytoplankton as a storage reservoir of PAHs is much lower than that of macrophytes, but the influence of phytoplankton on the fate of PAHs in the components of the food web and the aqueous phase can be substantial.

\section{Integrated modeling approach: merits and limitations}

The model developed in the present study has several advantages over earlier models. By forcing the contaminant fate model with outputs from the PCLake ecosystem model, our model accounts for processes including organic carbon cycling, transport and accumulation of PAHs in the foodweb, and limnologic processes such as bottom up and top down control, which are essential to evaluate the fate of contaminants in lake ecosystems with changing nutrient loading (Koelmans et al. 2001). In addition, long-term and intensive time series data from field observations in lake ecosystems are usually scarce, particularly those covering a time span where regime shifts occur. Complex 
Impact of regime shift on PAHs in a shallow lake

aquatic ecosystem models describing the main biotic and abiotic components, such as PCLake, can be considered as a 'virtual mesocosm', the output of which can subsequently serve as the supplement of sparse field observations. Our model may provide benefits for lake management, for instance to base a trigger for sediment PAH remediation on anticipated consequences of abatement of eutrophication, which in part have been covered at length in earlier literature (Koelmans et al. 2001).

The toxic effect of PAHs on organisms was assumed to be negligible here, because observed PAH concentrations are below the PEC levels (Fig. S2). Here the thresholds for PAHs (TEC and PEC) are both consensus-based sediment quality guidelines for freshwater ecosystems (MacDonald et al. 2000). This, however, may not be true in other cases. After all, PCLake predictions without accounting for the toxic effects may be biased because toxicity may affect abundances of certain sensitive species (e.g. arthropods), which play key roles in food web interactions (Koelmans et al. 2001). Including the toxic effect of PAHs in the model would permit to investigate if high PAHs concentrations could trigger regime shifts on the ecosystem level. Like all other ecological stressors, toxicity of HOCs is known to cause gradual changes on the level of individuals (e.g. impairment of individuals), populations and communities (e.g. the abundance and diversity of species) (Diepens et al. 2016). Several studies have further indicated adverse effects of chemicals, e.g. tributyltin and organochlorine pesticides, that break down the feedback mechanisms that promote the dominance of macrophytes (Stansfield et al. 1989, Sayer et al. 2006). The possibility of HOCs to cause regime shifts in lakes may largely depend on the systems' stability, i.e., how far the system is from the tipping point, which is generally determined by multiple factors, such as food web interaction, trophic state and chemical pollution.

\section{Conclusion}

We provided an integrated ecological and BC-inclusive chemical transport and food web accumulation model, which predicted concentrations of three different $\mathrm{PAH}$ compounds that are consistent with short-term and long-term measured data. Model simulations revealed a full picture of the impact of demonstrated regime shifts in the shallow lake ecosystem on the fate of the PAHs. Also for the first time, historical records from sediment cores were used for model evaluation, serving as an alternative way to compensate data deficiency. 
Chapter 6

The model revealed that regime shifts in shallow lakes have a stronger impact on the fate of less hydrophobic compounds than on more hydrophobic compounds due to the large storage capacity of macrophytes, which in the studied case accumulated up to $55.6 \%$ of Phe in the clear state. The abrupt disappearance of macrophytes after the regime shift resulted in a sudden change in Phe distribution. For more hydrophobic compounds such as $\mathrm{BaP}$, the impact of the regime shift was negligible for the whole environment, yet large for biotic components. The present study demonstrates how integrated modeling can assist in identifying the central roles of both abiotic components (soil and sediment) and biota at the base of the food web (phytoplankton and macrophytes) in driving the distribution of PAHs in shallow lakes.

The present results may have implications for lake management, as many shallow lakes around the globe are simultaneously polluted by excess nutrient loads and HOCs such as PAHs. A better understanding of their interactions may enhance our prediction power on the fate of HOCs, which in turn may facilitate the development of sound lake management strategies.

\section{Acknowledgments}

Funding for this study was provided by the National Science Foundation of China (NSFC) $(41603088,41030529$, and 41271462), the National Project for Water Pollution Control (2012ZX07103-002) and the National Foundation for Distinguished Young Scholars (40725004). This work is also supported by a grant from the China Scholarship Council and from the 111 Project (B14001). We are grateful to the anonymous reviewers who provided constructive comments and suggestions to improve the manuscript. We also thank Dr. Minghui Fei for valuable discussions. This is publication 6282 of the Netherlands Institute of Ecology (NIOO-KNAW). The authors declare no conflict of interest. 
Impact of regime shift on PAHs in a shallow lake

\section{Supplementary materials}

Additional Information includes: SI Text for model equations, description of modelling water-phytoplankton interactions, methods for PAHs measurement in phytoplankton and sediment cores, methods for chronologies determination in sediment cores, boundary conditions, and model evaluation of seasonal patterns in the short-term simulation. SI Figures include Fig. S1-S5. SI Tables include Table S1-S8.

\section{Model equations}

The equations for the abiotic module in the model are as follows:

$$
\begin{aligned}
& \int \frac{V_{1} Z_{1} d f_{1}}{d t}=T_{01 h}+\underbrace{T_{\text {Alt }}-T_{10 t}}_{\text {Emission }}-\underbrace{\left(T_{12 d}+T_{12 p}+T_{12 r}+T_{12 w}-T_{21 d}\right)}_{\text {Air-water interaction }}-\underbrace{\left(T_{13 d}+T_{13 p}+T_{13 r}+T_{13 w}-T_{31 d}\right)}_{\text {Air-soil interaction }}-\underbrace{T_{10 m}}_{\text {Degradation }} \\
& \frac{V_{2} Z_{2} d f_{2}}{d t}=\underbrace{T_{02 h}+T_{02 t}-T_{20 t}}_{\text {Discharge }}-\underbrace{T_{23 h}+\left(T_{12 d}+T_{12 p}+T_{12 r}+T_{12 w}-T_{21 d}\right)}_{\text {Advection }}-\underbrace{\left(T_{24 d}+T_{24 s}-T_{42 d}-T_{42 r}\right)}_{\text {Air-water interaction }} \\
& +\underbrace{\left(T_{32 e}+T_{32 l}\right)}_{\text {Water-soil interaction }}-\underbrace{T_{20 m}}_{\text {Degradation }} \\
& \frac{V_{3} Z_{3} d f_{3}}{d t}=\underbrace{\left(T_{13 d}+T_{13 p}+T_{13 r}+T_{13 w}-T_{31 d}\right)}_{\text {Air-soil interaction }}-\underbrace{\left(T_{32 e}+T_{32 l}\right)}_{\text {Water-soil interaction }}-\underbrace{T_{30 m}}_{\text {Degradation }} \\
& \frac{V_{4} Z_{4} d f_{4}}{d t}=\underbrace{\left(T_{24 d}+T_{24 s}-T_{42 d}-T_{42 r}\right)}_{\text {Water-sediment interaction }}-\underbrace{T_{40 m}}_{\text {Degradation }}
\end{aligned}
$$

where $f_{i}(i=1,2,3,4)$ denotes the fugacity $(\mathrm{Pa})$ in the different compartments. The model labelling for the main compartments is: "1" for air, " 2 " for water, " 3 " for soil and " 4 " for sediment.

The dynamics of chemicals in various organisms (i) are described by:

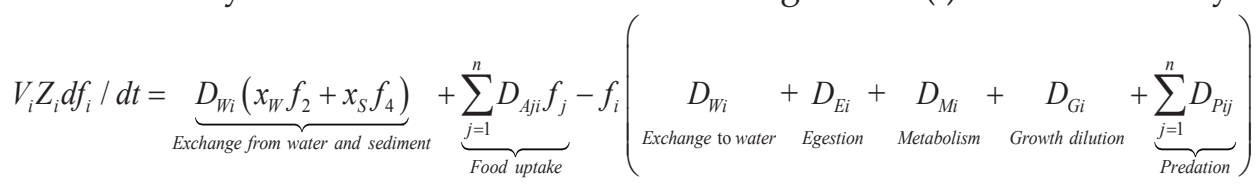

where $f_{i}$ denotes the fugacity $(\mathrm{Pa})$ in different organisms. The food web includes eight components: piscivorous fish, zooplanktivorous fish, benthivorous fish, zoobenthos, zooplankton, phytoplankton, macrophyte, and detritus.

The method for calculation of each process in the equations above is listed in Table S1. Calculation of fugacity capacity $\left(Z ; \mathrm{mol} /\left(\mathrm{m}^{3} \cdot \mathrm{Pa}\right)\right)$ for different compartments is given in Table S2. The equation for fish/organisms is 
$Z_{i}=B C F_{i} \rho_{i} / H$, where $B C F_{i}$ and $\rho_{i}$ are the equilibrium bioconcentration factor and density for group $i$, respectively. $B C F$ for phytoplankton and macrophytes were derived from literature (Del Vento and Dachs 2002). For the other groups, $B C F$ was calculated as the production of lipid fraction $(v L B)$ and Kow. The dietary composition matrix for aquatic organisms is given in Table S3. Symbols, descriptions, values and sources of all the parameters in the model are listed in Table S4-S6.

\section{Modelling the transport of chemicals between water and phytoplankton}

Phytoplankton was assumed to be at equilibrium with water as in the model from Campfens and Mackay (1997), which, however, may not be realistic for hydrophobic compounds for two major reasons: 1) the production of new phytoplankton and changing HOC concentrations in water due to diffusive air-water exchange both make the time to reach equilibrium much longer (Skoglund et al. 1996, Dachs et al. 1999); 2) bioconcentration of HOC in algae is rate limited because desorption rate decreases with increasing exposure time (Koelmans 2014). The dynamics of chemicals in the phytoplankton matrix can be described by equation (1) according to Dachs et al. (2000) :

$\frac{d C_{P, M}}{d t}=k_{u} C_{W}-k_{d} C_{P, M}-k_{G} C_{P, M}$

where $C_{W}\left(\mathrm{~mol} / \mathrm{m}^{3}\right)$ and $C_{P, M}(\mathrm{~mol} / \mathrm{kg})$ are the PAH concentrations in the dissolved phase and the phytoplankton matrix, respectively. $k_{u}\left(\mathrm{~m}^{3} /(\mathrm{kg} \cdot \mathrm{h})\right)$ and $k_{d}(1 / \mathrm{h})$ are the uptake and depuration constants of PAHs in phytoplankton, respectively. $k_{G}(1 / \mathrm{h})$ is the growth rate of the phytoplankton.

The chemical uptake flux between water and phytoplankton $\left(F_{P W} ; \mathrm{mol} / \mathrm{h}\right)$ is calculated by equation (2):

$F_{P W}=-B_{P} A_{2} h_{m i x} \frac{d C_{P, M}}{d t}=-B_{P} A_{2} h_{m i x} k_{u}\left(C_{P, M} \frac{k_{d}+k_{G}}{k_{u}}-C_{W}\right)$

where $B_{P}\left(\mathrm{~kg} / \mathrm{m}^{3}\right)$ is the phytoplankton biomass; $A_{2}\left(\mathrm{~m}^{2}\right)$ is the surface area of the air-water interface; $h_{\text {mix }}(\mathrm{m})$ is the fraction of the water column directly influenced by air-water exchange. The product of $B_{P}, A_{2}$ and $h_{\text {mix }}$ gives the total biomass of phytoplankton in the lake $(\mathrm{kg}) . F_{P W}$ represents the total flux between water and phytoplankton in the lake. 
Impact of regime shift on PAHs in a shallow lake

Here we translated the model from concentration-based model to fugacity-based format. The term $\left(k_{d}+k_{G}\right) / k_{u}$ equates to the reciprocal of the bioconcentration factor of the phytoplankton matrix $\left(B C F_{M} ; \mathrm{m}^{3} / \mathrm{kg}\right)$, where metabolization rate is assumed to be much slower than sorption kinetics $\left(k_{m e t a}<<k_{d}\right)$ (Del Vento and Dachs 2002). As a result, $F_{P W}(\mathrm{~mol} / \mathrm{h})$ is given by equation (3):

$$
F_{P W}=-B_{P} A_{2} h_{m i x} k_{u}\left(\frac{1}{\rho_{P} B C F_{M}} Z_{P, M} f_{P, M}-Z_{W} f_{W}\right)=-D_{W P}\left(f_{P, M}-f_{W}\right)
$$

where $f_{p}(\mathrm{~Pa})$ and $f_{w}(\mathrm{~Pa})$ are the chemical fugacity in the phytoplankton matrix and water, respectively. $\rho_{P}\left(\mathrm{~kg} / \mathrm{m}^{3}\right)$ is density of phytoplankton. $Z w$ $\left(\mathrm{mol} /\left(\mathrm{m}^{3} \cdot \mathrm{Pa}\right)\right)$ and $Z_{P, M}\left(\mathrm{~mol} /\left(\mathrm{m}^{3} \cdot \mathrm{Pa}\right)\right)$ are the fugacity capacity of water and phytoplankton matrix, respectively. Here, $Z_{w}$ equates to the reciprocal of Henry's law constant $\left(1 / \mathrm{H} ; \mathrm{mol} / \mathrm{Pa} \cdot \mathrm{m}^{3}\right)$. DWP $(\mathrm{mol} /(\mathrm{h} \cdot \mathrm{Pa}))$ is the chemical exchange from water to phytoplankton. From equation (3), $D_{W P}$ and $Z_{P, M}$ can be obtained as $D_{W P}=B_{P} A_{2} h_{m i x} k_{u} / H$ and $Z_{P, M}=B C F_{M} \rho_{P} / H$, respectively. See Table S6 for more details.

Note that some earlier studies described phytoplankton uptake with a two-compartment model: uptake from the water to the phytoplankton matrix and uptake from the water to the phytoplankton surface (Koelmans et al. 1993, Koelmans et al. 1995, Skoglund et al. 1996, Dachs et al. 1999, Dachs et al. 2000, Koelmans 2014). However, the sorption to the surface is two orders of magnitude faster than that to the matrix (Dachs et al. 1999, Del Vento and Dachs 2002). Therefore, for simplification, we assumed that PAH in the dissolved phase and at the phytoplankton surface are at equilibrium, and the flux of $F_{P W}$ can be calculated simply by equation (3).

\section{Methods for PAHs measurement in phytoplankton}

Samples of the phytoplankton in Lake Chaohu were collected in May 2012, using a self-developed tool with nylon mesh filter (mesh diameter of 64 $\mu \mathrm{m}$; Patent No. ZL201220617775.X) (Jiang et al. 2014). The filters were wrapped with aluminum foil and immediately transported to laboratory. Filters were frozen $\left(-18^{\circ} \mathrm{C}\right)$ until the extraction process. The processes for PAHs measurements in the phytoplankton samples were similar to those in the sediment samples, which are described in detail below.

\section{Methods for PAHs measurement in sediment cores: sample analysis and quality control}


Chapter 6

The sediment cores were cut into $1 \mathrm{~cm}$ slices, placed in sealed bags and transported back to the laboratory immediately. All samples were freeze-dried and milled to 200 mesh sieve prior to solvent extraction. After the addition of surrogate standards, sediment samples $(10.0 \mathrm{~g})$ were Soxhlet extracted with a $150 \mathrm{ml}$ mixture of dichloromethane/hexane $(1: 1 \mathrm{v}: \mathrm{v})$ for $48 \mathrm{~h}$. The extraction rate was controlled by a cooling water circulating system. Activated copper strips were added to remove elemental sulfur. The extract was concentrated to $\sim 1 \mathrm{ml}$ and solvent- exchanged to hexane, which was further concentrated to 1 $\mathrm{ml}$ using a rotary evaporator. The extract was added to a glass column packed with silica gel $(12 \mathrm{~cm}$ in length and $10 \mathrm{~mm}$ in diameter). The column was washed with $20 \mathrm{ml}$ of hexane, a $70 \mathrm{ml}$ mixture containing hexane and dichloromethane (3:7 v:v) to elute the PAH fraction. The extract was condensed with a rotary evaporator, solvent-exchanged to hexane and concentrated to 1 $\mathrm{ml}$ under a gentle $\mathrm{N}_{2}$ stream. Before instrumental analysis, a known amount of internal standard mixture (Nap-d8, Ace-d10, Ant-d10, Chr-d12 and Perylened12, J\&K Chemical Ltd., USA) was added.

The extracts of the sediment samples were analyzed for the individual concentration of 16 PAH compound by a GC-MS (Agilent 6890GC/5973MSD), including naphthalene (Nap), acenaphthylene (Acy), acenaphthene (Ace), fluorene (Flo), phenanthrene (Phe), anthracene (Ant), fluoranthene (Fla), pyrene $(\mathrm{Pyr})$, benz(a)anthracene $(\mathrm{BaA})$, chrysene $(\mathrm{Chr})$, benzo(b)fluoranthene $(\mathrm{BbF})$, benzo(k)fluoranthene $(\mathrm{BkF})$, benzo(a)pyrene $(\mathrm{BaP})$, dibenz $(\mathrm{a}, \mathrm{h})$ anthracene (Di-ahA), indeno(l,2,3-cd)pyrene (IcdP), and benzo(g,h,i)perylene (BghiP). A $30 \mathrm{~m} \times 0.25 \mathrm{~mm}$ i.d. with a $0.25 \mu \mathrm{m}$ film thickness HP-5MS capillary column (Agilent Technology) was used. The column temperature was programmed to increase from $60{ }^{\circ} \mathrm{C}$ to $280{ }^{\circ} \mathrm{C}$ at $5^{\circ} \mathrm{C} \mathrm{min}-1$ and was then held constant for $20 \mathrm{~min}$. The MSD was operated in the electron impact mode at 70 $\mathrm{eV}$, and the ion source temperature was $230{ }^{\circ} \mathrm{C}$. The mass spectra were recorded using the selected ion monitoring mode.

The quality control process was conducted following our previous study on PAHs in the lake environment (Qin et al. 2013a). Internal standard method was performed using Nap-d8, Ace-d10, Ant-d10, Chr-d12 and Perylene-d12 (J\&K Chemical, Beijing, China). Three replicate samples were collected from each sample of the sediment core. Laboratory blanks were analyzed with the true samples. The values for recoveries and detection limits are shown in Table S7 in the supporting information. The PAH recoveries varied from $45.5 \%$ (Nap) to $96.0 \%$ (Pyr).

\section{Methods for chronologies determination in sediment cores}


Impact of regime shift on PAHs in a shallow lake

Measurements of ${ }^{210} \mathrm{~Pb}$ and ${ }^{137} \mathrm{Cs}$ radionuclide activities for the sediment samples were conducted using Ortec HPGe GWL series of well-type, coaxial, low background, intrinsic germanium detectors (GCW3022 H-P Ge) at the State Key Laboratory of Lake Science and Environment of Chinese Academy of Sciences (CAS), Nanjing, China. Sediment age determined by unsupported ${ }^{210} \mathrm{~Pb}$ was based on the composite model for both cores (Appleby 2001), and the results were in accordance with the ${ }^{137} \mathrm{Cs}$ age (1963 AD). For more details see Kong et al. (2017a).

\section{Boundary conditions for model simulation}

\section{Emission inventory}

The annual emission of three modeled PAHs in the Lake Chaohu catchment from 1953 to 2012 was calculated (Fig. S3) following the methods below. Zhang et al. (2008) provided an annual total PAH ( $\left.\sum \mathrm{PAH}\right)$ emission inventory in China from 1953 to 2005. Shen et al. (2013) estimated that $\sum \mathrm{PAH}$ emission in China in 2007 was 106,000 tons, whereas the emission from 2008 to 2030 will decrease by $48 \%$, i.e., approximately $2 \%$ per year. We estimated the $\Sigma \mathrm{PAH}$ emissions from 2008 to 2012 accordingly. The value for 2006 was calculated as the average value of $\Sigma \mathrm{PAH}$ emission in 2005 and 2007. The annual emissions to the Anhui province (where the lake is located) were subsequently calculated using the fact that the Anhui province ranked the $7^{\text {th }}$ position in the emission rate (1,200 out of 25,300 tons) (Xu et al. 2006). The emissions were further adjusted to the Lake Chaohu catchment according to the surface area fraction $\left(1.3 \times 10^{4} \mathrm{~km}^{2}\right.$ of the catchment, about one-tenth of that for Anhui province $\left.\left(1.39 \times 10^{5} \mathrm{~km}^{2}\right)\right)$. In order to apportion $\sum \mathrm{PAH}$ to Phe, Pyr and $\mathrm{BaP}$ emission, data on chemical profiles of the emitted PAHs were used $(\mathrm{Xu}$ et al. 2006). The annual emission was further downscaled to monthly values in proportion to the seasonal pattern for China (Zhang et al. 2008).

\section{Other major inputs}

Besides emission to the catchment area, other major inputs include air and water advection inflows. For the air advection, we used observations from a third sample site at the shore of Lake Chaohu as the concentration in the inflow (unpublished data). For the water advection, we used observation from sample sites at the entrances of major rivers to the lake as the concentrations in the inflows (unpublished data). The method details for sampling and measurement were the same as those in our previous studies (Qin et al. 2014, Liu et al. 2015b). The total advection inflows for both air and water were 
Chapter 6

calculated monthly following the method in our previous study (Kong et al. 2014). The values are given in Table S8, together with the estimated monthly emission rates for the three modeled PAHs (Phe, Pyr and BaP). For the longterm simulation, emission data are available (Fig. S3); however, no observations were available to calculate the air and water advection inflows. We applied a strategy as follows: we used the monthly data for 2011 as the reference (Table S8), and estimated the monthly data for the other years (19532010 and 2012; data not shown) based on the ratio of emission rates shown in Fig. S3.

\section{Model evaluation of seasonal patterns in the short-term simulation}

On a seasonal scale, deviation ranges over time between measured and modeled values (in logarithm units) are 0.10-1.02 (Phe), 0.19-0.95 (Pyr), 0.06$1.46(\mathrm{BaP})$ in gaseous phase; 0.08-0.90 (Phe), 0.01-0.71 (Pyr), 0.08-1.32 (BaP) in aerosol particles; 0.09-1.08 (Phe), 0.04-0.42 (Pyr), 0.49-0.69 (BaP) in dissolved phase; and 0.03-1.33 (Phe), 0.02-0.95 (Pyr), 0.10-1.25 (BaP) in suspended solids in water. The PAH concentrations in the gaseous phase and aerosol particles in the air are strongly driven by sources, which are primarily emission from coal and biomass combustion. Long-range transport of gaseous and particulate PAHs to Lake Chaohu can be considered as another source (Kong et al. 2013), but plays a secondary role because atmospheric degradation is significant during PAH transport (Hafner and Hites 2003). Moreover, our previous modeling study has identified temperature as the most sensitive parameter that drives the seasonal variations of hexachlorocyclohexanes (HCHs) in the same area (Kong et al. 2014). Here, the temperature dependence of aerosolparticle partitioning may also contribute to the high concentration of particulate PAHs in winter, due to cold trapping of gases at lower temperatures (Gustafson and Dickhut 1997). On the other hand, the model shows a relatively limited ability to predict seasonal variations of PAH concentrations in the water column (dissolved and suspended solids) compared to PAH concentrations in the atmospheric phase (Fig. S4). This lower prediction power may be explained in two ways. First, our approach assumed that the water column is well-mixed, which is often a presupposition in 0-dimensional contaminant fate modeling (Mackay and Paterson 1991). Nonetheless, some non-uniformity may have contributed to the lack of fit. It would be interesting to couple our model to a spatially explicit hydrodynamic model in order to address spatial heterogeneity, which contributes to the uncertainty of the contaminant fate models (Tao et al. 2003). Second, the seasonal dynamics of PAHs cycling in the water column can be driven by both 
Impact of regime shift on PAHs in a shallow lake

variations in inputs and processes inside the lake. On one hand, major inputs to the fraction of $\mathrm{PAH}$ in the dissolved phase include river inflows and atmospheric input (by diffusion and deposition) (Fig. S5), which has been nicely captured. Higher concentrations during summer (Fig. S4) are primarily driven by the higher input of PAHs from river inflows (Table S8), which was similar to what has been found elsewhere (Lang et al. 2007). A lower dilution potential is unlikely to occur in Lake Chaohu during summer because water inflows and water levels are both higher (Kong et al. 2017a). On the other hand, the variations of PAHs in the water column are also due to many other factors. Our samples included the fraction of PAHs adsorbed to dissolved organic matter in water column, whereas this process was not incorporated in our model at the current stage. In addition, the ageing of organic matter in suspended solids may also cause increased fixation of PAHs onto organic particles (Koelmans et al. 1997) and further affect the seasonal variations of PAHs in water column. The missing mechanisms above may therefore lead to limitations of the model in predicting the seasonal variations of PAHs in the water column. Nonetheless, the seasonal validation provides more detail on model performance, detail that cannot be clearly demonstrated from annual average results. For example, better model performance for aerosol particles than for the gas phase can be observed from the seasonal simulation data (Fig. S4), but cannot be easily seen on an annual average scale (Fig. 3 in the main text). 
Chapter 6
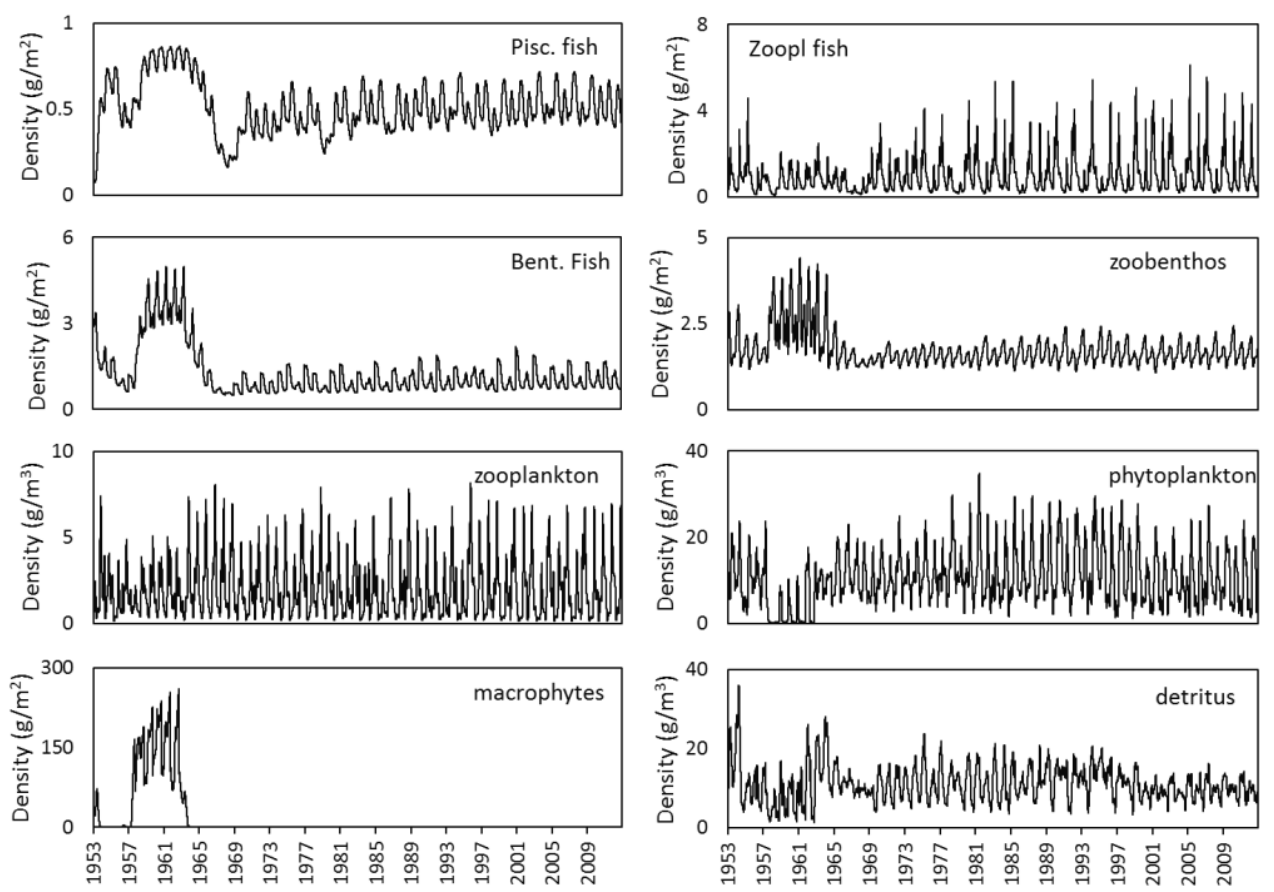

Fig. S1. Density of the eight food web components over time during 1953 to 2012 (daily) obtained from PCLake simulation (Kong et al., 2017).

Reference:

Kong, X., He, Q., Yang, B., He, W., Xu, F., Janssen, A.B.G., Kuiper, J.J., van Gerven, L.P.A., Qin, N., Jiang, Y., Liu, W., Yang, C., Bai, Z., Zhang, M., Kong, F., Janse, J.H. and Mooij, W.M. (2017) Hydrological regulation drives regime shifts: evidence from paleolimnology and ecosystem modelling of a large shallow Chinese lake. Global Change Biology 23(2), 737-754. 

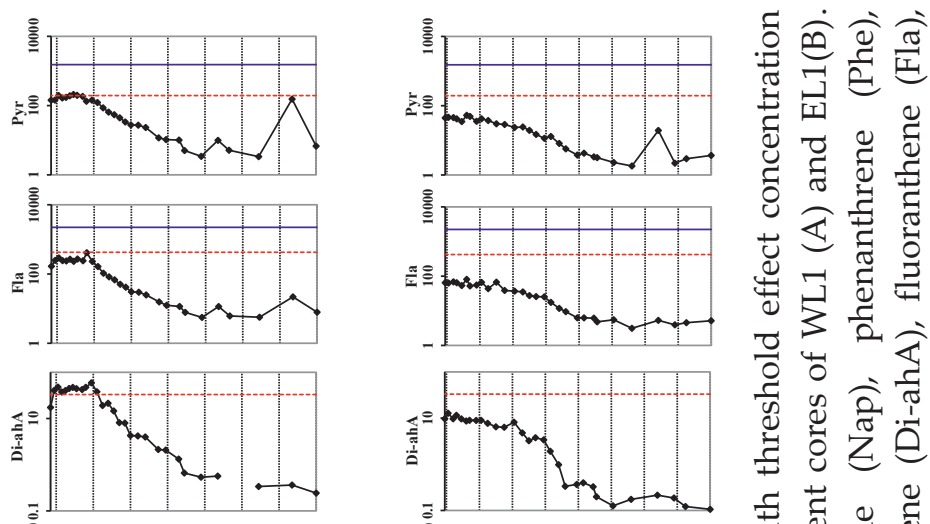

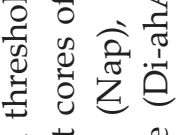
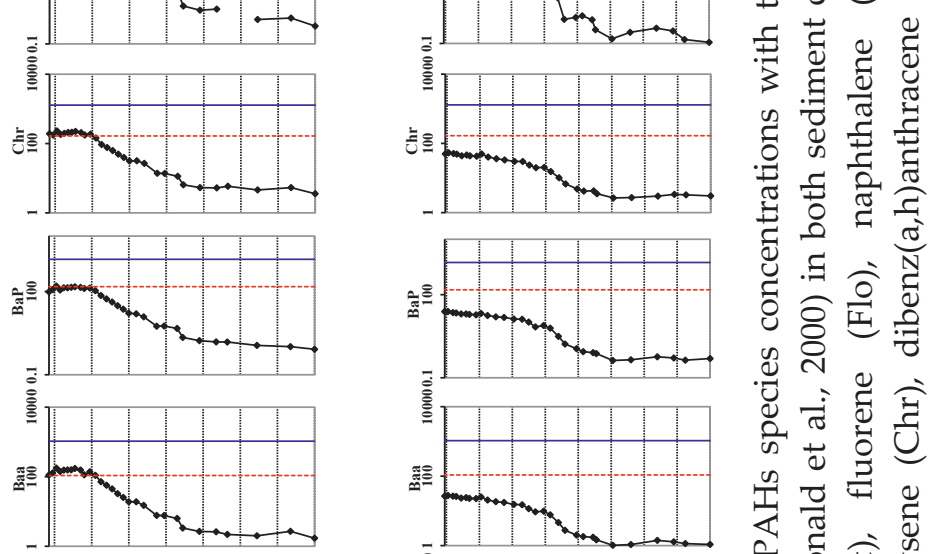

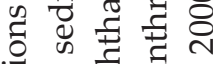
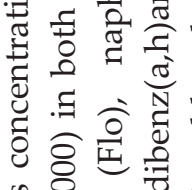

过

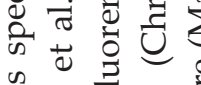

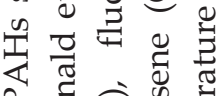

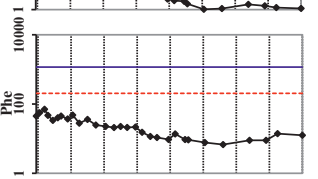

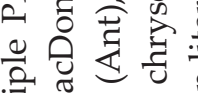
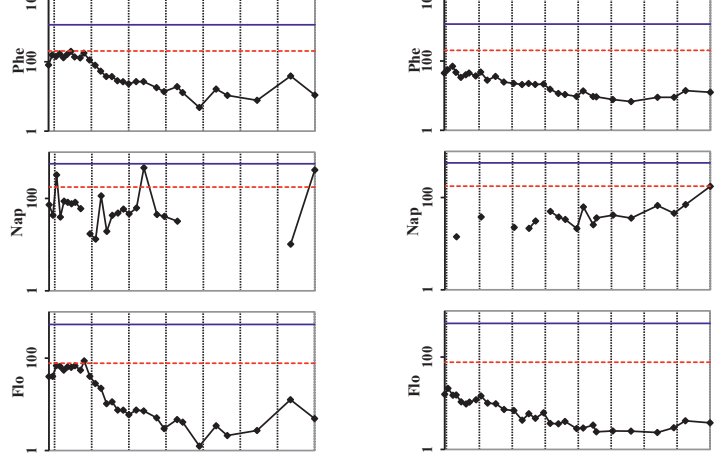

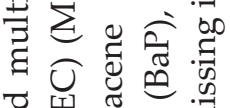

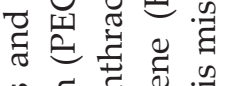

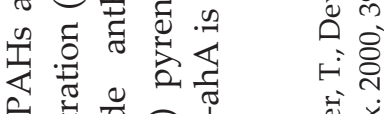

表芯

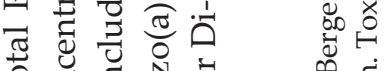

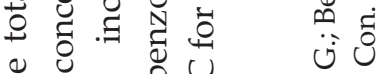

¿

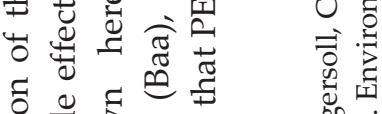
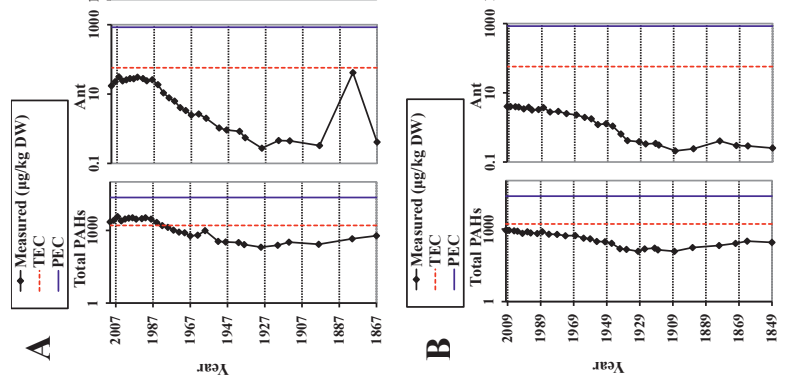

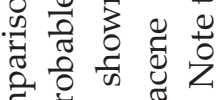

क्षे क $z$ वे

द्वे कै 全

तं वृष्त ह

के ชิ త్ర

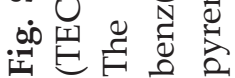




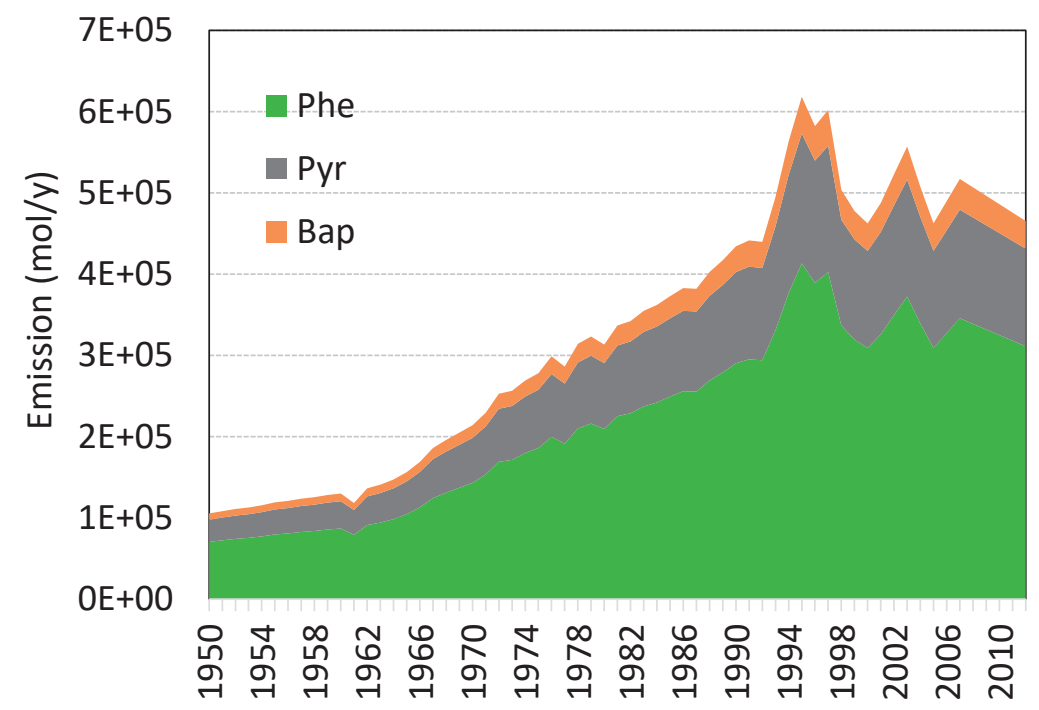

Fig. S3. Estimated emission inventory from 1950 to 2012 for the three modeled PAHs in the Lake Chaohu catchment. 
Impact of regime shift on PAHs in a shallow lake

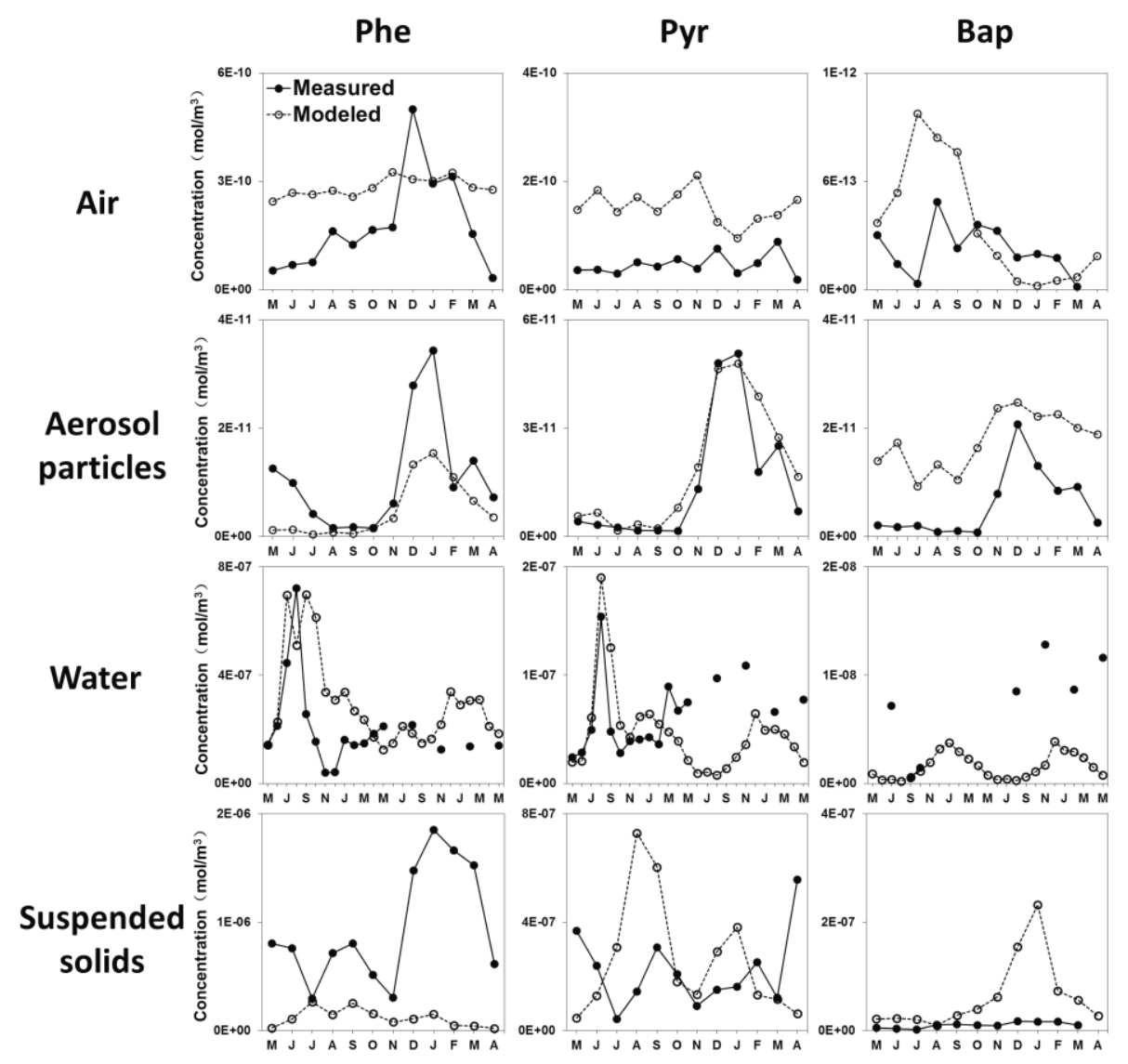

Fig. S4. Comparison of measured and modeled monthly concentrations of Phe, Pyr and $\mathrm{BaP}$ in air, aerosol particles, water and suspended solids for the short term simulation. Measured data correspond to the average of observations for each month in different sample sites ( 2 for gaseous and aerosol particles, and 4 for water and suspended solids). Note the different time scales for water (May 2010 to April 2012) and others (May 2010 to April 2011). 
A

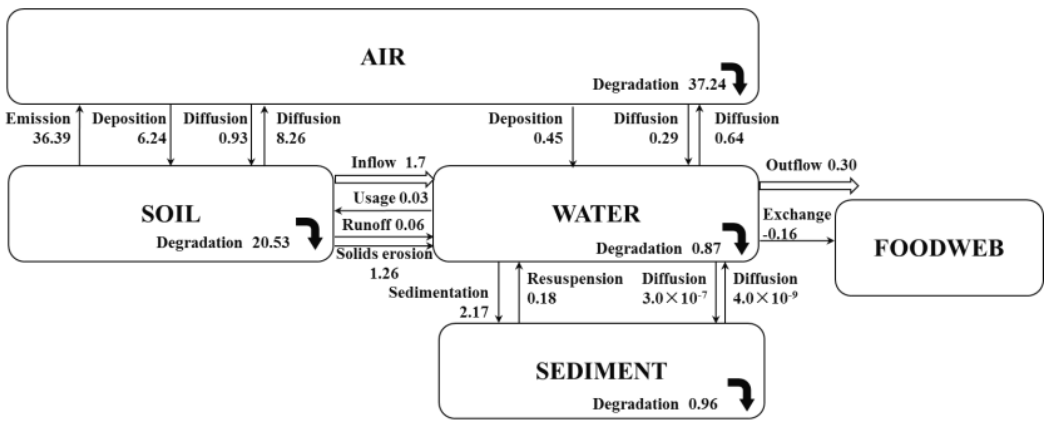

B

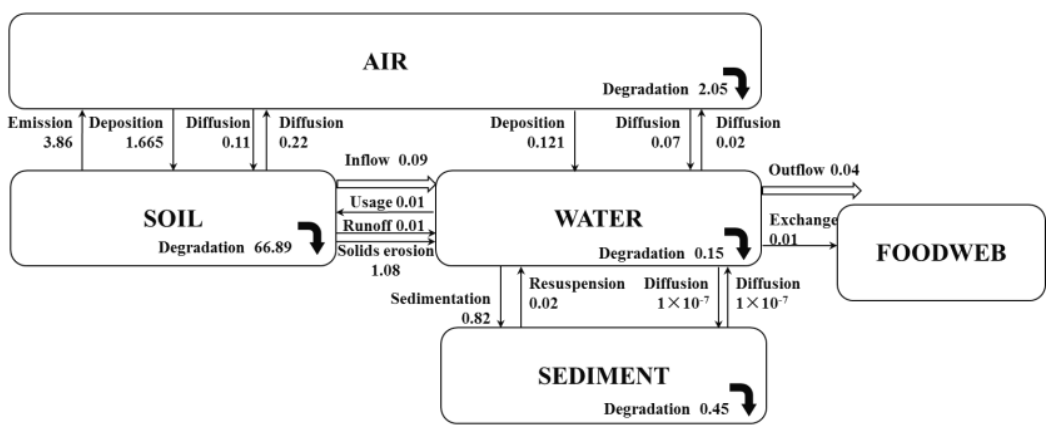

C

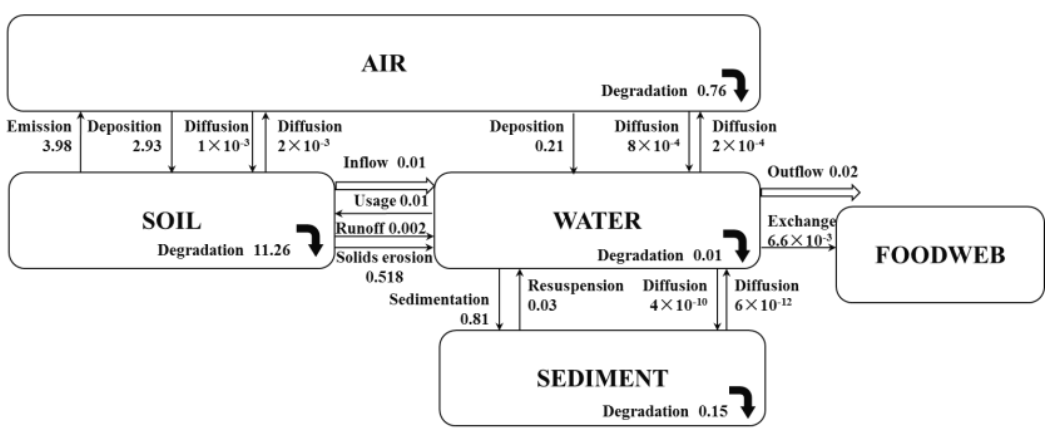

Fig. S5. Annual average simulated fluxes $(\mathrm{mol} / \mathrm{h})$ between compartments for Phe (A), Pyr (B) and Bap (C) in the Lake Chaohu catchment from May 2010 to April 2012. 
Impact of regime shift on PAHs in a shallow lake

Table S1 Definitions of the transfer and transformation processes

\begin{tabular}{|c|c|c|c|}
\hline Symbol & Formula & $\begin{array}{l}\text { Calculation of D } \\
(\mathrm{mol} /(\mathrm{h} \cdot \mathrm{Pa}))\end{array}$ & Description \\
\hline \multicolumn{4}{|l|}{$\begin{array}{l}\text { System } \\
\text { input: }\end{array}$} \\
\hline To1t & $Q_{01 t} \times C_{01 t}$ & - & Air advection flows into the area \\
\hline To1h & - & - & Emission to air \\
\hline$T_{02 t}$ & $Q_{02 t} \times C_{02 t}$ & - & Water advection flows into the area \\
\hline To2h & $Q_{02 h} \times C_{02 h}$ & - & Locative wastewater discharge \\
\hline \multicolumn{4}{|c|}{ System output: } \\
\hline$T_{10 t}$ & $D_{10 t} \times f_{1}$ & $D_{10 t}=Q_{10 t} \times Z_{1}$ & Air advection flows out of the area \\
\hline$T_{20 t}$ & $D_{20 t} \times f_{2}$ & $D_{20 t}=Q_{20 t} \times Z_{2}$ & Water advection flows out of the area \\
\hline$T_{10 m}$ & $D_{10 m} \times f_{1}$ & $D_{10 m}=K_{m 1} \times A_{1} \times h_{1} \times Z_{1}$ & Degradation in air \\
\hline$T_{20 m}$ & $D_{20 m} \times f_{2}$ & $D_{20 m}=K_{m 2} \times A_{2} \times h_{2} \times Z_{2}$ & Degradation in water \\
\hline$T_{30 m}$ & $D_{30 m} \times f_{2}$ & $D_{30 m}=K_{m 3} \times A_{3} \times h_{3} \times Z_{3}$ & Degradation in soil \\
\hline$T_{40 m}$ & $D_{40 m} \times f_{4}$ & $D_{40 m}=K_{m 4} \times A_{4} \times h_{4} \times Z_{4}$ & Degradation in sediment \\
\hline$T_{23 h}$ & $D_{23 h} \times f_{2}$ & $D_{23 h}=Q_{23 h} \times Z_{2}$ & Agriculture irrigation \\
\hline
\end{tabular}

Air-water interaction:

$\begin{array}{llll}T_{12 d} & D_{12 d} \times f_{1} & \begin{array}{l}D_{12 d}=A_{2} /\left[1 /\left(K_{12} \times Z_{11}\right)+\right. \\ \left.1 /\left(K_{21} \times Z_{22}\right)\right]\end{array} & \text { Diffusion from air to water } \\ T_{21 d} & D_{21 d} \times f_{2} & D_{21 d}=D_{12 d} & \text { Diffusion from water to air } \\ T_{12 p} & D_{12 p} \times f_{1} & D_{12 p}=A_{2} \times K_{p} \times X_{13} \times Z_{13} & \text { Dry deposition from air to water } \\ T_{12 w} & D_{12 w} \times f_{1} & D_{12 w}=A_{2} \times K_{w} \times S_{c} \times X_{13} \times Z_{13} & \text { Wet deposition from air to water } \\ T_{12 r} & D_{12 r} \times f_{1} & D_{12 r}=A_{2} \times K_{w} \times Z_{22} & \text { Rain scavenging to soil }\end{array}$

Air-soil interaction:

$\begin{array}{llll}T_{13 d} & D_{13 d} \times f_{1} & \begin{array}{l}D_{13 d}=A_{3} /\left[1 /\left(K_{13} \times Z_{11}\right)+\right. \\ \left.1 /\left(K_{31} \times Z_{32}\right)\right]\end{array} & \text { Diffusion from air to soil } \\ T_{31 d} & D_{31 d} \times f_{2} & D_{31 d}=D_{13 d} & \text { Diffusion from soil to air } \\ T_{13 p} & D_{13 p} \times f_{1} & D_{13 p}=A_{3} \times K_{p} \times X_{13} \times Z_{13} & \text { Dry deposition from air to soil } \\ T_{13 w} & D_{13 w} \times f_{1} & D_{13 w}=A_{3} \times K_{w} \times S_{c} \times X_{13} \times Z_{13} & \text { Wet deposition from air to soil } \\ T_{13 r} & D_{13 r} \times f_{1} & D_{13 r}=A_{3} \times K_{w} \times Z_{22} & \text { Rain scavenging to soil }\end{array}$

Water-soil interaction:

$T_{32 e} \quad D_{32 e} \times f$

$T_{32 l} \quad D_{32 l} \times f_{3}$

Erosion from soil to water in solids

Erosion from soil to water in liquid

Water-sediment interactions:
$T_{24 d}$
$D_{24 d} \times f_{2}$
$D_{24 d}=A_{2} /\left[1 /\left(K_{24} \times Z_{22}\right)+L_{4} /\left(B_{4}\right.\right.$ $\left.\times Z_{22}\right)$ ]
$T_{42 d} \quad D_{42 d} \times f_{4}$
$D_{42 d}=D_{24 d}$
Diffusion from water to sediment
Diffusion from sediment to water 
Chapter 6

$\begin{array}{llll} & D_{24 s}=A_{2} \times K_{s} \times\left(Z_{23} \times X_{23}+Z_{2 p} \times\right. & \text { Sedimentation from water to } \\ T_{24 s} & D_{24 s} \times f_{2} & \left.X_{2 p}\right) /\left(X_{23}+X_{2 p}\right) & \text { sediment } \\ & D_{42 r}=A_{2} \times K_{42} \times Z_{4} & \text { Resuspension from sediment to water }\end{array}$

Food web interaction:

\begin{tabular}{|c|c|c|c|}
\hline \multirow[t]{2}{*}{$T w$} & $D w \times\left(x w f_{2}+x s f_{4}-f_{i}\right)$ & $D_{W_{i}}=k_{u} \times h_{2} \times B_{p} \times A_{2} \times Z_{22}$ & $\begin{array}{l}\text { Exchange with water or porewater in } \\
\text { sediment } \\
\text { (phytoplankton and macrophytes) }\end{array}$ \\
\hline & & $D_{W i}=G_{w} \times E_{w} \times Z_{22}$ & (Other biota) \\
\hline$T_{E}$ & $D_{E} \times f_{i}$ & $D_{E i}=D_{W i} / Q_{i}$ & Loss by egestion \\
\hline$T_{M}$ & $D_{M} \times f_{i}$ & $D_{M i}=k_{M i} \times V_{i} \times Z_{i}$ & Loss by metabolism \\
\hline$T_{G}$ & $D_{G} \times f_{i}$ & $D_{G i}=Z_{i} \times\left(d V_{i} / d t\right)=k_{G i} \times V_{i} \times Z_{i}$ & Loss by growth dilution \\
\hline$T_{f}$ & $D_{f} \times f_{i}$ & $D_{f i}=B C F_{f i} \times Y_{f} / H$ & Loss by harvest (only for fish) \\
\hline$T_{A}$ & $\sum_{j=1}^{n} D_{A i j} f_{j}$ & $D_{A i j}=G_{A i} \times E_{A i} \times Z_{j j} \times D T_{i j}$ & Uptake from food \\
\hline$T_{P}$ & $f_{i} \sum_{j=1}^{n} D_{P j i}$ & $D_{P j i}=D_{A i j}$ & Loss by predation or grazing \\
\hline
\end{tabular}

Note: For the calculation of $Z$ please see Table S2. For the definition of the parameters and their values please see Table S4-S6. 
Impact of regime shift on PAHs in a shallow lake

Table S2 Calculation of $Z$ values

\begin{tabular}{|c|c|c|}
\hline Phase & Equations for $\mathrm{Z}(\mathrm{mol} / \mathrm{m3} \cdot \mathrm{Pa})$ & \\
\hline Air & $\mathrm{Z11}=\mathrm{Z31}=1 / \mathrm{RT}$ & $Z 1=X 11 \times Z 11+X 13 \times Z 13$ \\
\hline Water & $\begin{array}{l}\mathrm{Z} 22=\mathrm{Z} 32=\mathrm{Z} 42=1 / \mathrm{H} \\
\mathrm{Z} 13=6 \times 106 / P_{S} R T\end{array}$ & $Z 2=X 22 \times Z 22+X 23 \times Z 23$ \\
\hline Solid sorbent & $\begin{array}{l}\mathrm{Z} 23=\mathrm{O} 23 \times \rho 23 \times \mathrm{Koc} / \mathrm{H} \\
\mathrm{Z} 43=\mathrm{O} 43 \times \rho 43 \times \mathrm{Koc} / \mathrm{H}\end{array}$ & - \\
\hline Soil & - & $\begin{array}{l}Z 3=\quad X 31 \times Z 31+\quad X 32 \times Z 32+ \\
X 33 \times Z 33\end{array}$ \\
\hline Sediment & - & $\mathrm{Z} 4=\mathrm{X} 42 \times \mathrm{Z} 42+\mathrm{X} 43 \times \mathrm{Z} 43$ \\
\hline Lipid and octanol & $\mathrm{ZO}=\mathrm{Kow} / \mathrm{H}$ & - \\
\hline Fish/Organism & $\mathrm{Zi}=\mathrm{BCF} i \times \rho i / H=v L B \times \rho i \times \mathrm{ZO}$ & - \\
\hline
\end{tabular}

Table S3 Dietary composition matrix for aquatic organisms (based on Kong et al., 2016)

\begin{tabular}{ccccccc}
\hline No. & Group & Pisc. fish & Zoopl. fish & Bent. fish & zoobenthos & zooplankton \\
\hline 1 & Pisc. fish & 0 & 0 & 0 & 0 & 0 \\
2 & Zoopl. fish & 0.8 & 0 & 0 & 0 & 0 \\
3 & Bent. fish & 0.2 & 0 & 0 & 0 & 0 \\
4 & zoobenthos & 0 & 0 & 0.9 & 0 & 0 \\
5 & zooplankton & 0 & 0.9 & 0.05 & 0.6 & 0 \\
6 & phytoplankton & 0 & 0.1 & 0 & 0.4 & 0.4 \\
7 & macrophytes & 0 & 0 & 0.05 & 0 & 0 \\
8 & detritus & 0 & 0 & 0 & 0 & 0.6 \\
& sum & 1 & 1 & 1 & 1 & 1 \\
\hline
\end{tabular}

Reference:

Kong, X.; He, W.; Liu, W.; Yang, B.; Xu, F.; Jørgensen, S. E.; Mooij, W. M., Changes in food web structure and ecosystem functioning of a large shallow Chinese lake during 1950s, 1980s and 2000s. Ecol. Model. 2016, 319, 31-41. 
Chapter 6

Table S4 Environmental and universal mass transfer kinetic parameters for the contaminant fate model

\begin{tabular}{|c|c|c|c|c|c|c|}
\hline \multicolumn{2}{|c|}{ SymbolUnit } & Parameters & Reference & $\begin{array}{l}\text { Data } \\
\text { Numbers }\end{array}$ & $\begin{array}{l}\text { Geometric } \\
\text { mean }\end{array}$ & $\begin{array}{l}\text { Geometric } \\
\text { S.D. }\end{array}$ \\
\hline \multicolumn{7}{|c|}{ Static parameters } \\
\hline$A_{2}$ & $\mathrm{~m}^{2}$ & Interface areas of air/water & 1,2 & 2 & $7.581 \mathrm{E}+08$ & $1.004 \mathrm{E}+00$ \\
\hline$A_{3}$ & $\mathrm{~m}^{2}$ & Interface areas of air/soil & 1 & 1 & $1.04 \mathrm{E}+10$ & $1.000 \mathrm{E}+00$ \\
\hline$h_{1}$ & $\mathrm{~m}$ & Thickness of air & 1,10 & 2 & $1.000 \mathrm{E}+02$ & $1.413 \mathrm{E}+00$ \\
\hline$h_{3}$ & $\mathrm{~m}$ & Thickness of soil & 1,10 & 2 & $5.000 \mathrm{E}-01$ & $1.479 \mathrm{E}+00$ \\
\hline$h_{4}$ & $\mathrm{~m}$ & Thickness of sediment & 1,10 & 2 & $1.000 \mathrm{E}-01$ & $1.479 \mathrm{E}+00$ \\
\hline $\mathrm{O}_{33}$ & $\%$ & $\begin{array}{l}\text { Contents of organic carbon in } \\
\text { soil }\end{array}$ & $n_{1,7-11}$ & 6 & $6.296 \mathrm{E}-03$ & $1.577 \mathrm{E}+00$ \\
\hline $\mathrm{O}_{43}$ & $\%$ & $\begin{array}{l}\text { Contents of organic carbon in } \\
\text { sediment }\end{array}$ & \multicolumn{2}{|c|}{$n_{1-3}$, Note A 61} & 7.920E-02 & $1.720 \mathrm{E}+00$ \\
\hline$R$ & \multicolumn{2}{|c|}{$\mathrm{Pa} \cdot \mathrm{m}^{3} / \mathrm{mol} \cdot \mathrm{KT}$ he gas constant } & - & 1 & $8.310 \mathrm{E}+00$ & $1.000 \mathrm{E}+00$ \\
\hline$X_{31}$ & $\mathrm{v} / \mathrm{v}$ & Volume fractions of air in soil & $1,7-11$ & 6 & $2.500 \mathrm{E}-01$ & $5.000 \mathrm{E}-02$ \\
\hline$X_{32}$ & $\mathrm{v} / \mathrm{v}$ & $\begin{array}{l}\text { Volume fractions of water in } \\
\text { soil }\end{array}$ & $n_{1,7-11}$ & 6 & $2.500 \mathrm{E}-01$ & $5.000 \mathrm{E}-02$ \\
\hline$X_{33}$ & $\mathrm{v} / \mathrm{v}$ & $\begin{array}{l}\text { Volume fractions of solids in } \\
\text { soil }\end{array}$ & $n_{1,7-11}$ & 6 & $5.000 \mathrm{E}-01$ & $1.000 \mathrm{E}-01$ \\
\hline$X_{42}$ & $\mathrm{v} / \mathrm{v}$ & $\begin{array}{l}\text { Volume fractions of water in } \\
\text { sediment }\end{array}$ & $n_{4,7-11}$ & 6 & 7.000E-01 & $1.022 \mathrm{E}+00$ \\
\hline$X_{43}$ & $\mathrm{v} / \mathrm{v}$ & $\begin{array}{l}\text { Volume fractions of solids it } \\
\text { sediment }\end{array}$ & $n_{4,7-11}$ & 6 & $3.000 \mathrm{E}-01$ & $1.077 \mathrm{E}+00$ \\
\hline$\rho_{23}$ & $\mathrm{t} / \mathrm{m}^{3}$ & Densities of solids in water & 1,4 & 2 & $1.200 \mathrm{E}+00$ & $1.158 \mathrm{E}+00$ \\
\hline$\rho_{33}$ & $t / m^{3}$ & Densities of solids in soil & $1,8-11$ & 5 & $2.568 \mathrm{E}+00$ & $1.537 \mathrm{E}-01$ \\
\hline$\rho_{43}$ & $t / m^{3}$ & Densities of solids in sediment & 1,4 & 2 & $2.760 \mathrm{E}+00$ & $1.176 \mathrm{E}+00$ \\
\hline$Y_{f}$ & $\mathrm{~kg} / \mathrm{h}$ & Fish production rate & 1,5 & 2 & $5.710 \mathrm{E}-01$ & $1.183 \mathrm{E}+00$ \\
\hline$r_{d}$ & $\mu \mathrm{m}$ & Diameter of phytoplankton & Note A,6 & 13 & $8.717 \mathrm{E}+00$ & $2.048 \mathrm{E}+00$ \\
\hline$K_{24}$ & $\mathrm{~m} / \mathrm{h}$ & $\begin{array}{l}\text { Water-side molecular transfe } \\
\text { coefficient over sediment }\end{array}$ & rer $7-11$ & 5 & $1.000 \mathrm{E}-02$ & $1.585 \mathrm{E}+00$ \\
\hline$K_{42}$ & $\mathrm{~m} / \mathrm{h}$ & $\begin{array}{l}\text { Sediment-side molecula } \\
\text { transfer coefficient over water }\end{array}$ & $\mathrm{ar}_{1,7-11}$ & 6 & $5.390 \mathrm{E}-06$ & $1.520 \mathrm{E}+00$ \\
\hline Ks & $\mathrm{m} / \mathrm{h}$ & Water sedimentation rates & 12 & 3 & $1.655 \mathrm{E}-06$ & $1.254 \mathrm{E}+00$ \\
\hline$L_{4}$ & $\mathrm{~m}$ & $\begin{array}{l}\text { Diffusion path lengths } \\
\text { sediment }\end{array}$ & $n_{7-11}$ & 5 & $5.000 \mathrm{E}-03$ & $1.912 \mathrm{E}+00$ \\
\hline$K_{p}$ & $\mathrm{~m} / \mathrm{h}$ & Dry deposition velocity & 7-11 & 5 & $1.039 \mathrm{E}+01$ & $1.056 \mathrm{E}+00$ \\
\hline$S_{c}$ & - & Scavenging Ratio & $4,7-11$ & 6 & $1.200 \mathrm{E}+05$ & $2.144 \mathrm{E}+00$ \\
\hline$U l$ & $\mathrm{~m} / \mathrm{h}$ & Runoff rate of dissolved phase & 10 & 1 & $1.240 \mathrm{E}-05$ & $1.000 \mathrm{E}+00$ \\
\hline Ue & $\mathrm{m} / \mathrm{h}$ & Runoff rate of solid phase & 10 & 1 & $1.100 \mathrm{E}-07$ & $1.000 \mathrm{E}+00$ \\
\hline$S$ & $\%$ & $\begin{array}{l}\text { Degree of oxygen saturation o } \\
\text { water }\end{array}$ & & 1 & $1.00 \mathrm{E}+02$ & $1.000 \mathrm{E}+00$ \\
\hline$n_{F}$ & - & $\begin{array}{l}\text { Freundlich coefficient fo } \\
\text { sorption to black carbon }\end{array}$ & & 1 & 7.000E-01 & $1.000 \mathrm{E}+00$ \\
\hline$f_{B C}$ & - & $\begin{array}{l}\text { Black carbon fraction of solid } \\
\text { in sediment }\end{array}$ & $\mathrm{ss}_{13}$ & 1 & 2.000E-03 & $1.000 \mathrm{E}+00$ \\
\hline
\end{tabular}


Impact of regime shift on PAHs in a shallow lake

\begin{tabular}{|c|c|c|c|c|c|}
\hline \\
\hline \multicolumn{6}{|c|}{$\begin{array}{l}\text { Dynamic parameters }^{b} \\
h_{2} \mathrm{~m} \quad \text { Depth of water }\end{array}$} \\
\hline $\mathrm{O}_{23}$ & $\%$ & $\begin{array}{l}\text { Contents of organic carbon in } 4,15 \text {, Note } \\
\text { solids in water }\end{array}$ & 24 & $7.829 \mathrm{E}-02$ & $1.900 \mathrm{E}+00$ \\
\hline$X_{13}$ & $\mathrm{v} / \mathrm{v}$ & Volume fractions of solids in air Note A & 24 & $7.628 \mathrm{E}-11$ & $1.562 \mathrm{E}+00$ \\
\hline$X_{23}$ & $\mathrm{v} / \mathrm{v}$ & $\begin{array}{l}\text { Volume fractions of solids in } \\
\text { water }\end{array}$ & 24 & $1.263 \mathrm{E}-05$ & $2.007 \mathrm{E}+00$ \\
\hline$T^{c}$ & K & $\begin{array}{l}\text { Local average temperature in } 16 \\
\text { air }\end{array}$ & 730 & $2.889 \mathrm{E}+02^{c}$ & $9.747 \mathrm{E}+00^{c}$ \\
\hline$T w^{a, c}$ & K & $\begin{array}{l}\text { Local average temperature in } 16 \\
\text { water }\end{array}$ & 730 & $1.270 \mathrm{E}+01$ & $2.587 \mathrm{E}+00$ \\
\hline$W$ & $\mathrm{~m} / \mathrm{s}$ & Wind speed 16 & 730 & $1.083 \mathrm{E}+00$ & $1.521 \mathrm{E}+00$ \\
\hline DO & $\mathrm{mg} / \mathrm{m}^{3}$ & $\begin{array}{l}\text { Concentration of dissolved } \\
\text { oxygen in water }\end{array}$ & 730 & $1.127 \mathrm{E}+01$ & $1.285 \mathrm{E}+00$ \\
\hline $\begin{array}{l}Q_{01 t} \\
\left(=Q_{10 t}\right)^{a}\end{array}$ & $\mathrm{~m}^{3} / \mathrm{h}$ & $\begin{array}{l}\text { Air advection flow in and out of } \\
\text { the area }\end{array}$ & 24 & $1.878 \mathrm{E}+11$ & $1.471 \mathrm{E}+00$ \\
\hline$Q_{02 t^{a}}$ & $\mathrm{~m}^{3} / \mathrm{h}$ & $\begin{array}{l}\text { Water advection flow into the } \\
\text { area }\end{array}$ & 24 & $3.373 \mathrm{E}+05$ & $3.217 \mathrm{E}+00$ \\
\hline$Q_{20 t^{a}}$ & $\mathrm{~m}^{3} / \mathrm{h}$ & $\begin{array}{l}\text { Water advection flow out of the } \\
\text { area }\end{array}$ & 24 & $4.189 \mathrm{E}+05$ & $3.072 \mathrm{E}+00$ \\
\hline$Q_{02 h^{a}}$ & $\mathrm{~m}^{3} / \mathrm{h}$ & $\begin{array}{l}\text { Rate of local wastewater } \\
\text { discharge }\end{array}$ & 24 & $4.656 \mathrm{E}+04$ & $1.447 \mathrm{E}+00$ \\
\hline$Q_{23 h}$ & $\mathrm{~m}^{3} / \mathrm{h}$ & Irrigation rates & 24 & $9.264 \mathrm{E}+04$ & $2.066 \mathrm{E}+00$ \\
\hline$K_{w^{a}}$ & $\mathrm{~m} / \mathrm{h}$ & Wet deposition velocity & 730 & $1.332 \mathrm{E}-04$ & $5.958 \mathrm{E}+00$ \\
\hline$K_{42 r^{a}}$ & $\mathrm{~m} / \mathrm{h}$ & Sediment resuspension rate & 730 & $2.558 \mathrm{E}-05$ & $1.702 \mathrm{E}+00$ \\
\hline
\end{tabular}

a Calculate from air temperature according to Ref. 20

b Values for both short-(2010.5-2012.4) and long-(1953.1-2012.12) term simulation were collected, only short term values are given here.

c Normal distribution assumed

Note A: Measured

Note B: Calculated according to air thickness and wind speed.

Note C: Calculated according to method in the reference.

References:

1) Tu, Q.Y., Gu, D.X., Yi, C.Q., Xu, Z.R., Han, G.Z., The Researches on the Lake Chaohu Eutrophication. Hefei: Publisher of University of Science and Technology of China; 1990 (in Chinese).

2) Yin, F.C., A study on evaluation and control instruments of Chao lake eutrophication. Beijing: China Environmental Science Press; 2011 (in Chinese).

3) Zhang, M., Distribution characteristic and assessment of typical persistent organic pollutions-Organochlorine pesticides in water of Chaohu Lake watershed [Master dissertation]. Hefei: Anhui Agriculture University; 2009 (in Chinese).

4) Mackay, D., Multimedia Environmental Models: The Fugacity Approach,second ed. NewYork, USA: Lewis Publishers; 2001. 


\section{Chapter 6}

5) Guo, L.G. Studies on fisheries ecology in a large eutrophic shallow lake, Lake Chaohu [Doctoral dissertation]. Wuhan: Institude of Hydrobiology, Chinese Acadamy of Sciences; 2005 (in Chinese).

6) Kong, F.X., Song, L.R., Study on formation process and its environmental characteristics of cyanobacteria bloom. Beijing: Science Press; 2011 (in Chinese)

7) Lang, C., Tao, S., Wang, X.J., Zhang, G., Li, J., Fu, J.M., 2007. Seasonal variation of polycyclic aromatic hydrocarbons (PAHs) in Pearl River Delta region, China. Atmos. Environ. 41, 8370-8379.

8) Lang, C., Tao, S., Wang, X.J., Zhang, G., Fu, J.M., 2008. Modeling polycyclic aromatic hydrocarbon composition profiles of sources and receptors in the Pearl River Delta, China. Environ. Toxicol. Chem. 27, 4-9.

9) Wang, R., Cao, H.Y., Li, W., Wang, W., Wang, W.T., Zhang, L.W., Liu, J.M., Ouyang, H., Tao, S., 2011. Spatial and seasonal variations of polycyclic aromatic hydrocarbons in Haihe Plain, China. Environ. Pollut. 159, 1413-1418.

10) Tao, S., Cao, H.Y., Liu, W.X., Li, B.G., Cao, J., Xu, F.L., Wang, X.J., Coveney, R.M., Shen, W.R., Qin, B.P., Sun, R., 2003. Fate modeling of phenanthrene with regional variation in Tianjin, China. Environ. Sci. Technol. 37, 2453-2459.

11) Zhang, X.L., Tao, S., Liu, W.X., Yang, Y., Zuo, Q., Liu, S.Z., 2005. Source diagnostics of polycyclic aromatic hydrocarbons based on species ratios: A multimedia approach. Environ. Sci. Technol. 39, 9109-9114.

12) Gu CJ. Historical Sedimentary Records and Environmental Changes in Chaohu lake. [Master dissertation]. Shanghai: East China Normal University; 2005 (in Chinese).

13) Hauck, M.; Huijbregts, M. A. J.; Koelmans, A. A.; Moermond, C. T. A.; van den Heuvel-Greve, M. J.; Veltman, K.; Hendriks, A. J.; Vethaak, A. D., Including sorption to black carbon in modeling bioaccumulation of polycyclic aromatic hydrocarbons: Uncertainty analysis and comparison to field data. Environ. Sci. Technol. 2007, 41, (8), 2738-2744.

14) Anhui Hydrological Telemetry Information System (AHTIS), 2010-2011. Hourly water level report. http://61.191.22.154/yc_web/yc_index_frame.aspx

15) Zhou, Z.H., Liu, C.Q., Li, J., Zhu, Z.Z., Record of ecosystem evolvement processes provided by $\delta 13$ Corg and $\delta 15 \mathrm{~N}$ values in Chaohu Lake sediments. Environmental Science 2007;28; 1338-1343 (in Chinese).

16) China Meteorological Data Sharing Service System (CMDSSS), 2010-2011. Daily Meteorological Data. http://www.cma.gov.cn/2011qxfw/2011qsjgx/index.htm

17) Cai, Y.F., 2012.Comparative study of composition and dynamics of cyanobacteria and their driving factors in Lake Taihu and Lake Chaohu [Doctoral dissertation]. Nanjing. Nanjing Institute of Geography and Limnology, Chinese Academy of Sciences.

18) He, W., Qin, N., Kong, X., Liu, W., He, Q., Ouyang, H., Yang, C., Jiang, Y., Wang, Q., Yang, B., Xu, F.L., 2013. Spatio-temporal distributions and the ecological and health risks of phthalate esters (PAEs) in the surface water of a large, shallow Chinese lake. Sci Total Environ 461-462: 672-680.

19) Anhui Water Regime and Drought Monitoring Network (AWRDMN) website. 20102011. http://shangqing.wswj.net

20) Mooij, W.M., Domis, L., Hulsmann, S., 2008. The impact of climate warming on water temperature, timing of hatching and young-of-the-year growth of fish in shallow lakes in the Netherlands. J. Sea Res. 60, 32-43 
Impact of regime shift on PAHs in a shallow lake

Table S5 Chemical specific parameters for the contaminant fate model

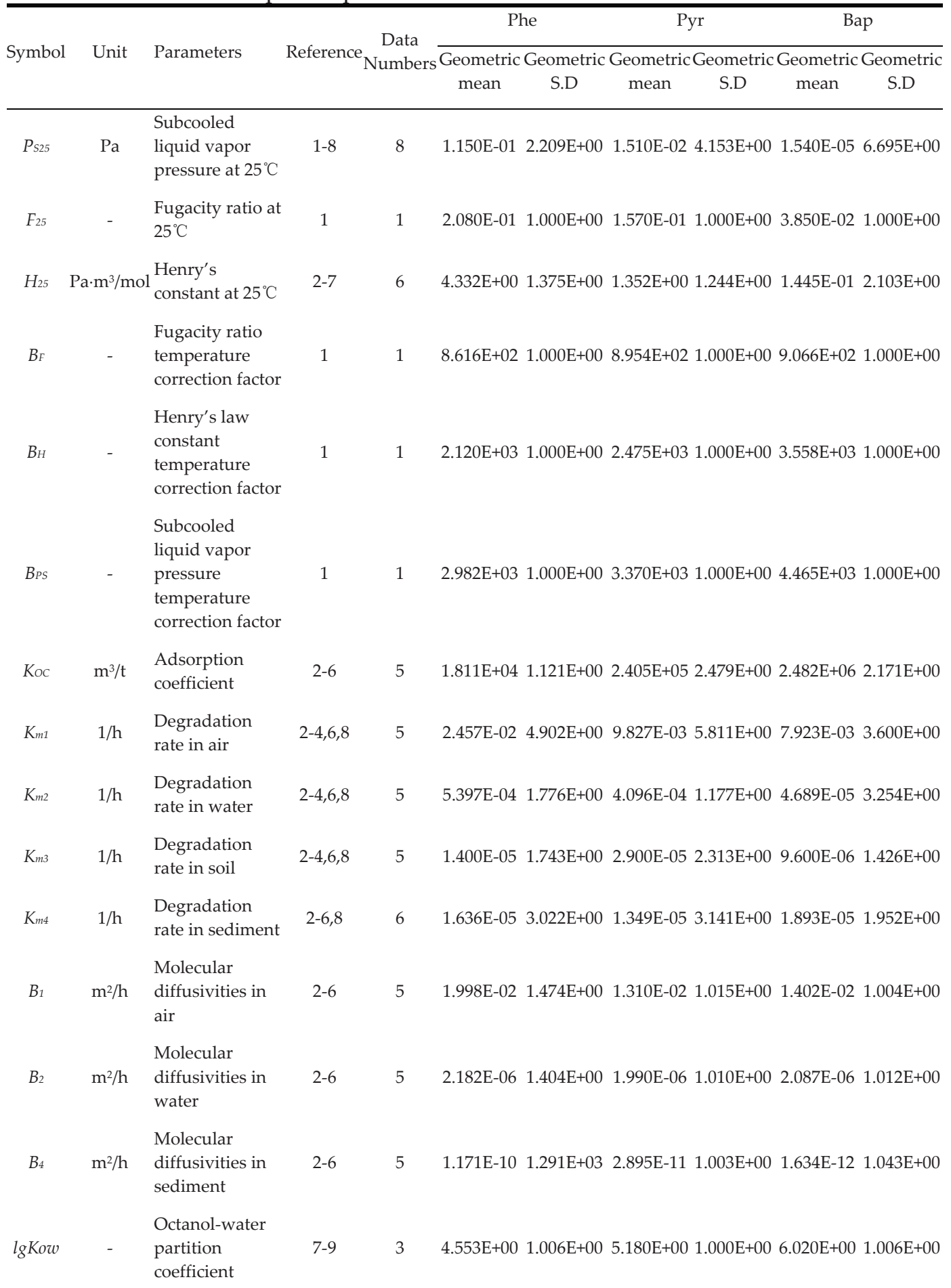




\section{Chapter 6}

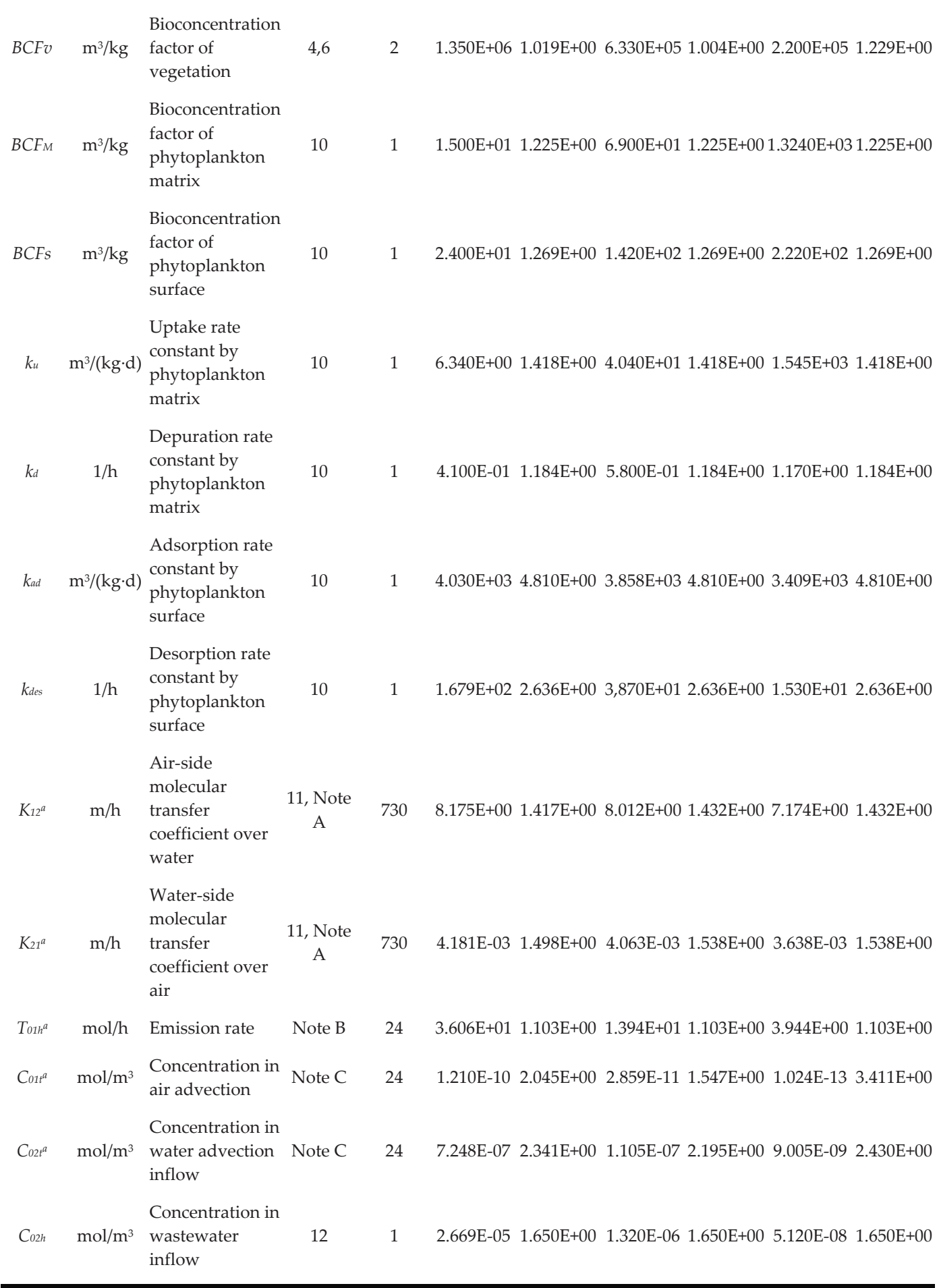

Note A: Calculated according to method in the reference. 
Note B: Estimated

Note C: Measured.

a Dynamic parameters for simulation

References:

1) Paasivirta J, Sinkkonen S, Mikkelson P, Rantio T, Wania F. 1999. Estimation of vapor pressures, solubilities and Henry's law constants of selected persistent organic pollutants as functions of temperature. Chemosphere 39; 811-832.

2) Lang, C., Tao, S., Wang, X.J., Zhang, G., Li, J., Fu, J.M., 2007. Seasonal variation of polycyclic aromatic hydrocarbons (PAHs) in Pearl River Delta region, China. Atmos. Environ. 41, 8370-8379.

3) Lang, C., Tao, S., Wang, X.J., Zhang, G., Fu, J.M., 2008. Modeling polycyclic aromatic hydrocarbon composition profiles of sources and receptors in the Pearl River Delta, China. Environ. Toxicol. Chem. 27, 4-9.

4) Wang, R., Cao, H.Y., Li, W., Wang, W., Wang, W.T., Zhang, L.W., Liu, J.M., Ouyang, H., Tao, S., 2011. Spatial and seasonal variations of polycyclic aromatic hydrocarbons in Haihe Plain, China. Environ. Pollut. 159, 1413-1418.

5) Tao, S., Cao, H.Y., Liu, W.X., Li, B.G., Cao, J., Xu, F.L., Wang, X.J., Coveney, R.M., Shen, W.R., Qin, B.P., Sun, R., 2003. Fate modeling of phenanthrene with regional variation in Tianjin, China. Environ. Sci. Technol. 37, 2453-2459.

6) Zhang, X.L., Tao, S., Liu, W.X., Yang, Y., Zuo, Q., Liu, S.Z., 2005. Source diagnostics of polycyclic aromatic hydrocarbons based on species ratios: A multimedia approach. Environ. Sci. Technol. 39, 9109-9114.

7) Mackay, D., Hickie, B., 2000. Mass balance model of source apportionment, transport and fate of PAHs in Lac Saint Louis, Quebec. Chemosphere 41, 681-692.

8) Mackay D. Multimedia Environmental Models: The Fugacity Approach, second ed. NewYork, USA: Lewis Publishers; 2001.

9) Wu SP. 2005. Atmospheric particulate polycyclic aromatic hydrocarbons and its dry deposition flux in Tianjin city, China. [Doctoral dissertation]. Beijing. Peking University (in Chinese).

10) Del Vento, S., Dachs, J., 2002. Prediction of uptake dynamics of persistent organic pollutants by bacteria and phytoplankton. Environ. Toxicol. Chem. 21, 2099-2107.

11) Southworth GR. Role of volatilization in removing Polycyclic Aromatic Hydrocarbons from aquatic environments. Bull Environ Contam Toxicol 1979;21:507-514.

12) Zhang $\mathrm{TF}$, Lu XP. Investigation and evaluation of water environmental quality of Lake Chaohu. In: Lake Chaohu water environment, ecological evaluation and Countermeasures-special report No.11. Hefei; 1986 (in Chinese). 


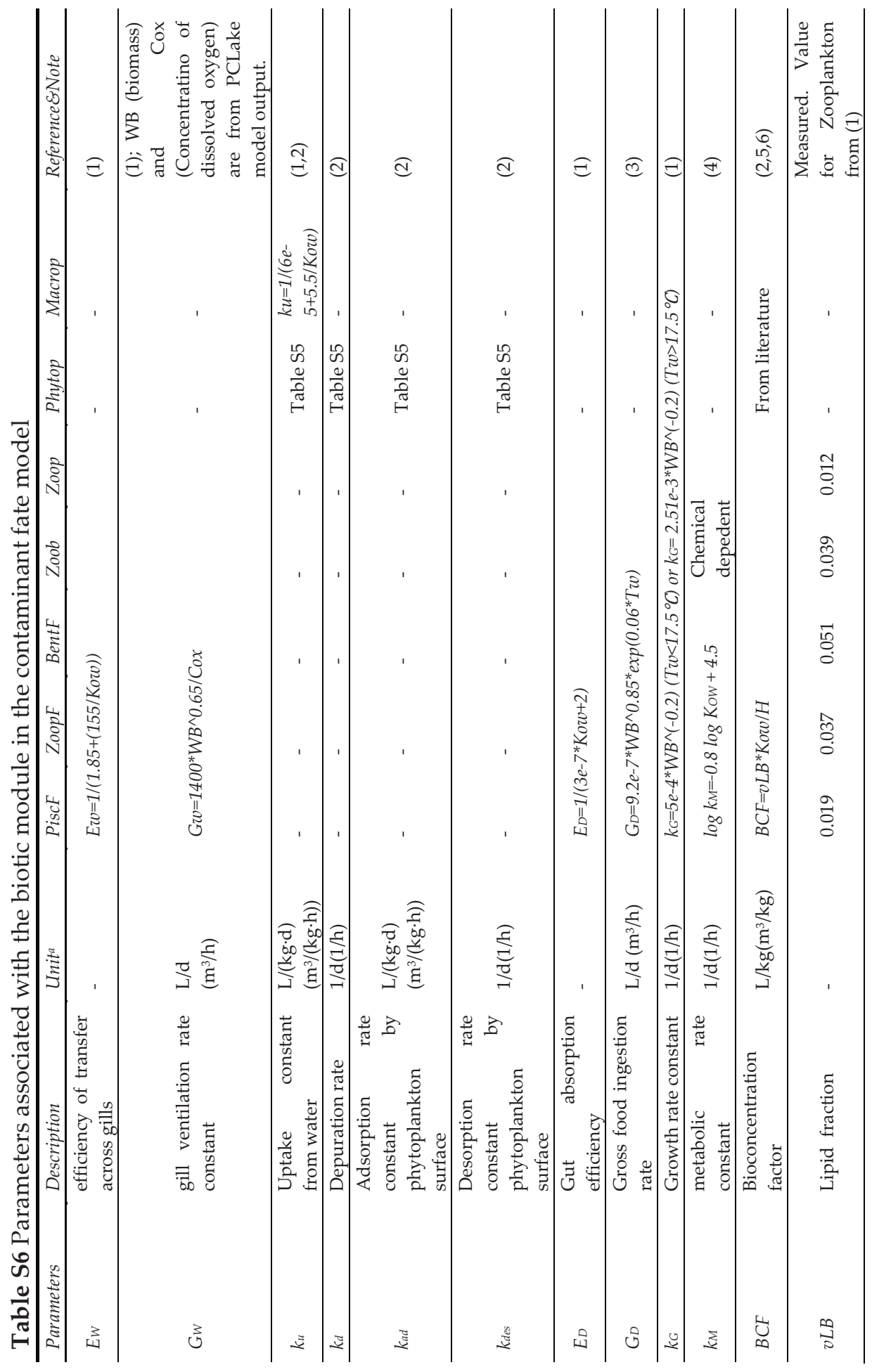




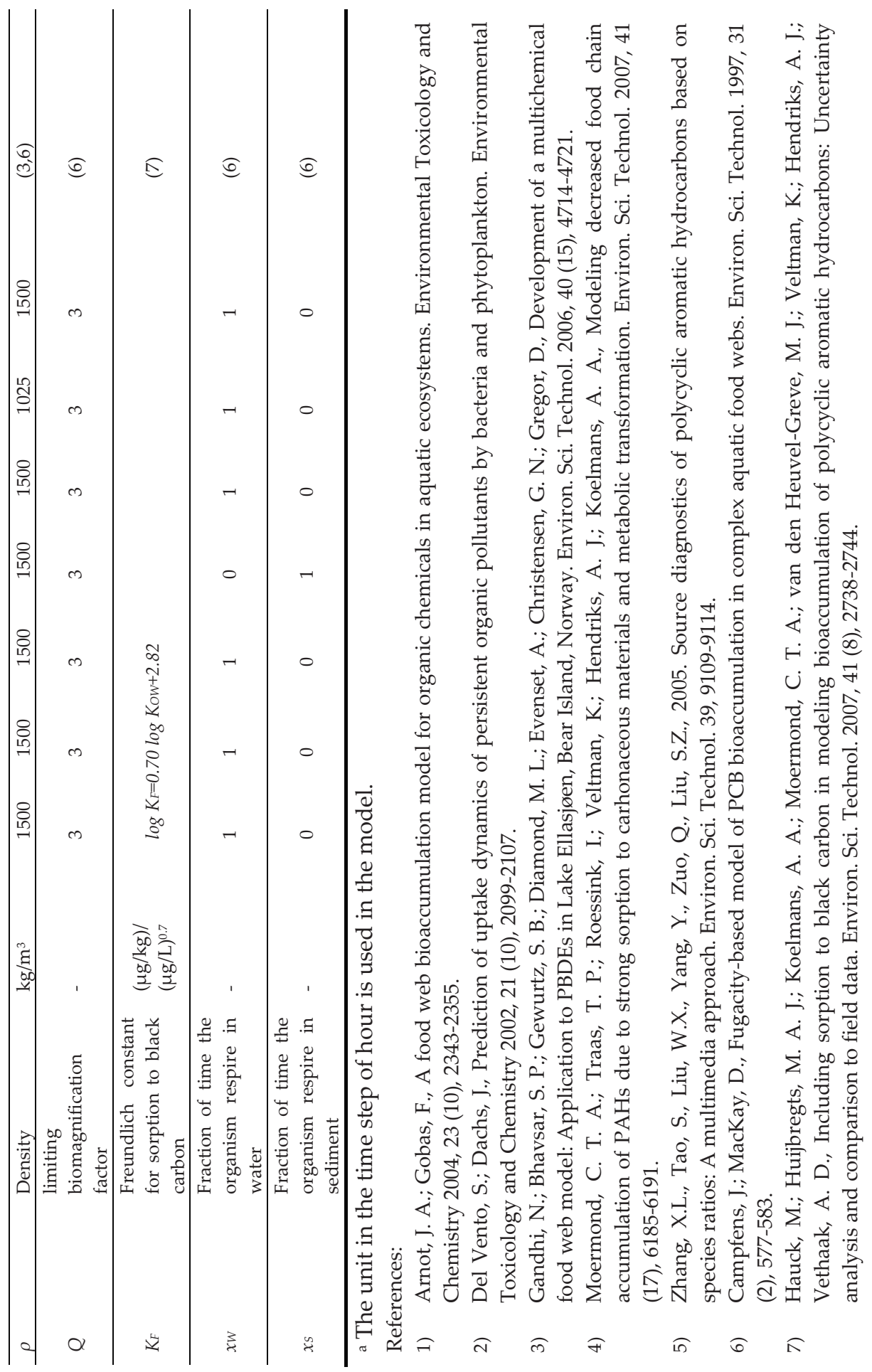


Chapter 6

Table S7 Recoveries and detection limits for PAHs in sediment cores

\begin{tabular}{llll}
\hline Abbr. & PAHs & Recoveries $(\%)$ & Detection limits $\left(\mu \mathrm{g} \cdot \mathrm{L}^{-1}\right)$ \\
\hline Nap & Naphthalene & 45.5 & 0.5 \\
Ace & Acenaphthene; & 79.7 & 0.5 \\
Acy & Acenaphthylene & 73.8 & 1.0 \\
Flo & Fluorene & 76.7 & 0.5 \\
Phe & Phenanthrene & 95.1 & 0.5 \\
Ant & Anthracene & 85.1 & 0.5 \\
Fla & Fluoranthene & 95.3 & 0.5 \\
Pyr & Pyrene & 96.0 & 0.5 \\
Baa & Benzo[a]anthracene & 93.9 & 1.0 \\
Chr & Chrysene & 95.0 & 1.0 \\
Bbf & Benzo[b]fluoranthene & 95.3 & 1.0 \\
Bkf & Benzo[k]fluorant hene & 95.1 & 1.0 \\
Bap & Benzo[a]pyrene; & 88.8 & 1.0 \\
DahA & Dibenz[a,h]anthracene & 89.0 & 1.0 \\
IcdP & Indeno[1,2,3-cd]pyrene & 85.5 & 1.0 \\
BghiP & Benzo[ghi]perylene & 91.2 & 1.0 \\
\hline
\end{tabular}


Impact of regime shift on PAHs in a shallow lake

Table S8 Boundary conditions for the short-term model simulation

\begin{tabular}{|c|c|c|c|c|c|c|c|c|c|c|}
\hline \multirow[b]{2}{*}{ Year } & \multirow[b]{2}{*}{ Month } & \multicolumn{3}{|c|}{ Phe } & \multicolumn{3}{|c|}{ Pyr } & \multicolumn{3}{|c|}{$\mathrm{BaP}$} \\
\hline & & $\begin{array}{c}\mathrm{T}_{01 \mathrm{t}^{\mathrm{a}}} \\
(\mathrm{mol} / \mathrm{h})\end{array}$ & $\begin{array}{c}\mathrm{T}_{01 \mathrm{~h}^{\mathrm{a}}} \\
(\mathrm{mol} / \mathrm{h})\end{array}$ & $\begin{array}{c}\mathrm{T}_{02 \mathrm{t}^{\mathrm{a}}} \\
(\mathrm{mol} / \mathrm{h})\end{array}$ & $\begin{array}{c}\text { To1t } \\
(\mathrm{mol} / \mathrm{h})\end{array}$ & $\begin{array}{c}\mathrm{T}_{01 \mathrm{~h}} \\
(\mathrm{~mol} / \mathrm{h})\end{array}$ & $\begin{array}{c}\mathrm{T}_{02 \mathrm{t}} \\
(\mathrm{mol} / \mathrm{h})\end{array}$ & $\begin{array}{c}\text { To1t } \\
(\mathrm{mol} / \mathrm{h})\end{array}$ & $\begin{array}{c}\text { To1h } \\
(\mathrm{mol} / \mathrm{h})\end{array}$ & $\begin{array}{c}\mathrm{T}_{02 \mathrm{t}} \\
(\mathrm{mol} / \mathrm{h})\end{array}$ \\
\hline \multirow{8}{*}{2010} & 5 & $9.09 \mathrm{E}-03$ & $3.26 \mathrm{E}+01$ & $6.91 \mathrm{E}-01$ & 3.47E-03 & $3.00 \mathrm{E}+00$ & $2.14 \mathrm{E}-02$ & $8.54 \mathrm{E}-05$ & $3.56 \mathrm{E}+00$ & 2.73E-03 \\
\hline & 6 & 1.17E-02 & $1.16 \mathrm{E}+01$ & $3.90 \mathrm{E}-01$ & 2.69E-03 & $2.46 \mathrm{E}+00$ & 2.51E-01 & 3.82E-05 & $3.68 \mathrm{E}+00$ & $3.20 \mathrm{E}-03$ \\
\hline & 7 & $1.03 \mathrm{E}-02$ & $1.20 \mathrm{E}+01$ & 3.71E-01 & 3.59E-03 & $3.67 \mathrm{E}+00$ & 6.67E-01 & 4.03E-06 & $3.92 \mathrm{E}+00$ & $8.50 \mathrm{E}-03$ \\
\hline & 8 & $1.76 \mathrm{E}-02$ & $1.03 \mathrm{E}+01$ & $1.52 \mathrm{E}+00$ & $5.46 \mathrm{E}-03$ & $5.11 \mathrm{E}+00$ & 3.49E-01 & $4.74 \mathrm{E}-05$ & $3.86 \mathrm{E}+00$ & $4.45 \mathrm{E}-03$ \\
\hline & 9 & $2.43 \mathrm{E}-02$ & $9.26 \mathrm{E}+00$ & $9.66 \mathrm{E}-01$ & $1.91 \mathrm{E}-03$ & $1.91 \mathrm{E}+00$ & 4.65E-01 & $1.16 \mathrm{E}-05$ & $3.71 E+00$ & $5.93 \mathrm{E}-03$ \\
\hline & 10 & $1.60 \mathrm{E}-02$ & $8.71 \mathrm{E}+00$ & $1.25 \mathrm{E}+00$ & $2.45 \mathrm{E}-03$ & $2.83 \mathrm{E}+00$ & $1.03 \mathrm{E}-02$ & 1.47E-05 & $3.71 E+00$ & $1.31 \mathrm{E}-03$ \\
\hline & 11 & $1.84 \mathrm{E}-02$ & $9.01 E+00$ & $2.11 \mathrm{E}+00$ & $3.72 \mathrm{E}-03$ & $4.40 \mathrm{E}+00$ & $3.89 \mathrm{E}-03$ & 4.06E-05 & $4.19 \mathrm{E}+00$ & $4.96 \mathrm{E}-04$ \\
\hline & 12 & $4.48 \mathrm{E}-02$ & $9.58 \mathrm{E}+00$ & $2.67 E+00$ & $1.16 \mathrm{E}-02$ & $9.64 \mathrm{E}+00$ & $6.46 \mathrm{E}-03$ & $6.70 \mathrm{E}-06$ & $4.48 \mathrm{E}+00$ & $8.23 \mathrm{E}-04$ \\
\hline \multirow{12}{*}{2011} & 1 & $1.02 \mathrm{E}-01$ & $9.45 \mathrm{E}+00$ & $9.82 \mathrm{E}-01$ & $3.64 \mathrm{E}-03$ & $3.80 \mathrm{E}+00$ & $5.24 \mathrm{E}-03$ & $2.10 \mathrm{E}-05$ & $4.62 \mathrm{E}+00$ & 6.67E-04 \\
\hline & 2 & 3.23E-02 & $9.06 \mathrm{E}+00$ & $1.06 \mathrm{E}+00$ & $4.58 \mathrm{E}-03$ & $4.28 \mathrm{E}+00$ & 7.16E-03 & 4.85E-06 & $4.80 \mathrm{E}+00$ & $9.13 \mathrm{E}-04$ \\
\hline & 3 & 3.39E-02 & $9.06 \mathrm{E}+00$ & 3.84E-01 & 3.13E-03 & $3.06 \mathrm{E}+00$ & 1.33E-02 & $3.88 \mathrm{E}-06$ & $4.12 \mathrm{E}+00$ & $1.69 \mathrm{E}-03$ \\
\hline & 4 & 1.13E-02 & $1.02 \mathrm{E}+01$ & 9.23E-01 & 2.63E-03 & $2.15 \mathrm{E}+00$ & 4.57E-03 & $1.98 \mathrm{E}-06$ & $3.71 E+00$ & $5.82 \mathrm{E}-04$ \\
\hline & 5 & 8.41E-03 & $1.10 \mathrm{E}+01$ & $1.21 \mathrm{E}-01$ & 3.67E-03 & $3.00 \mathrm{E}+00$ & $1.35 \mathrm{E}-02$ & 9.03E-05 & $3.49 \mathrm{E}+00$ & $1.72 \mathrm{E}-03$ \\
\hline & 6 & $1.05 \mathrm{E}-02$ & $1.05 \mathrm{E}+01$ & 4.34E-01 & $2.58 \mathrm{E}-03$ & $2.46 \mathrm{E}+00$ & $6.10 \mathrm{E}-02$ & $3.66 \mathrm{E}-05$ & $3.61 E+00$ & $7.78 \mathrm{E}-02$ \\
\hline & 7 & 1.19E-02 & $1.09 \mathrm{E}+01$ & 2.57E-01 & $3.76 \mathrm{E}-03$ & $3.67 \mathrm{E}+00$ & $7.46 \mathrm{E}-02$ & $4.21 \mathrm{E}-06$ & $3.84 \mathrm{E}+00$ & $9.50 \mathrm{E}-02$ \\
\hline & 8 & 1.47E-02 & $9.37 \mathrm{E}+00$ & 9.52E-01 & $5.23 \mathrm{E}-03$ & $5.11 \mathrm{E}+00$ & $6.16 \mathrm{E}-02$ & 4.54E-05 & $3.78 \mathrm{E}+00$ & $7.85 \mathrm{E}-02$ \\
\hline & 9 & $3.06 \mathrm{E}-02$ & $8.43 \mathrm{E}+00$ & 5.54E-01 & 2.04E-03 & $1.91 \mathrm{E}+00$ & $9.75 \mathrm{E}-03$ & $1.24 \mathrm{E}-05$ & $3.63 \mathrm{E}+00$ & $1.24 \mathrm{E}-03$ \\
\hline & 10 & $1.83 \mathrm{E}-02$ & $7.92 \mathrm{E}+00$ & $7.60 \mathrm{E}-01$ & $2.71 \mathrm{E}-03$ & $2.83 \mathrm{E}+00$ & $1.30 \mathrm{E}-02$ & 1.62E-05 & $3.63 \mathrm{E}+00$ & $1.66 \mathrm{E}-03$ \\
\hline & 11 & 2.07E-02 & $8.20 \mathrm{E}+00$ & $1.45 \mathrm{E}+00$ & $4.21 \mathrm{E}-03$ & $4.40 \mathrm{E}+00$ & $1.38 \mathrm{E}-02$ & $4.60 \mathrm{E}-05$ & $4.10 \mathrm{E}+00$ & $1.76 \mathrm{E}-03$ \\
\hline & 12 & $4.00 \mathrm{E}-02$ & $8.72 \mathrm{E}+00$ & $1.64 \mathrm{E}+00$ & 8.37E-03 & $9.64 \mathrm{E}+00$ & 5.27E-03 & 4.84E-06 & $4.39 \mathrm{E}+00$ & $6.72 \mathrm{E}-04$ \\
\hline \multirow{4}{*}{2012} & 1 & 7.81E-02 & $8.60 \mathrm{E}+00$ & $1.08 \mathrm{E}+00$ & 3.30E-03 & $3.80 \mathrm{E}+00$ & $6.48 \mathrm{E}-03$ & $1.91 \mathrm{E}-05$ & $4.52 \mathrm{E}+00$ & $8.26 \mathrm{E}-04$ \\
\hline & 2 & $4.71 \mathrm{E}-02$ & $8.24 \mathrm{E}+00$ & $1.60 \mathrm{E}+00$ & $4.10 \mathrm{E}-03$ & $4.28 \mathrm{E}+00$ & $1.92 \mathrm{E}-02$ & 4.35E-06 & $4.69 \mathrm{E}+00$ & $2.45 \mathrm{E}-03$ \\
\hline & 3 & $3.50 \mathrm{E}-02$ & $8.24 \mathrm{E}+00$ & $6.58 \mathrm{E}-01$ & $3.40 \mathrm{E}-03$ & $3.06 \mathrm{E}+00$ & 2.33E-02 & $4.22 \mathrm{E}-06$ & $4.03 E+00$ & $2.96 \mathrm{E}-03$ \\
\hline & 4 & $1.01 \mathrm{E}-02$ & $9.32 \mathrm{E}+00$ & 8.72E-01 & 2.29E-03 & $2.15 \mathrm{E}+00$ & $1.56 \mathrm{E}-02$ & $1.73 \mathrm{E}-06$ & $3.63 E+00$ & $1.99 \mathrm{E}-03$ \\
\hline
\end{tabular}

Note (a): T01h: Emission rate; T01t: Air advection inflow rate; T02t: Water advection inflow rate. 
Chapter 6 
Chapter 7

\section{General discussion}


General discussion

\section{Introduction}

In this chapter, I first synthesize the data from this thesis obtained from two shallow lake ecosystems with distinct states (clear state, Lake Small Baiyangdian, and turbid state, Lake Chaohu) and present field evidence on how eutrophication interacts with contamination. Then, I go through the chapters in this thesis, summarize the efforts in modeling development towards an integrated ecological and chemical fate model (i.e. EUTOX framework (Koelmans et al. 2001)), discuss in detail the advantages of our model over other existing models with similar objectives, indicate the limitations of our modeling tool, and finally propose future directions for investigating interactions between eutrophication and contamination in shallow lake ecosystems. In particular, I emphasize the importance to incorporate the ecological model PCLake into our model framework and to appropriately apply advanced uncertainty analysis tools (Bayesian Markov Chain Monte Carlo) for contaminant fate models. Furthermore, I point out the missing components for simulating toxic effects and spatial heterogeneity in the current modeling configuration, and propose a more comprehensive modeling framework (EUTOX-S) that includes EUTOX components and also hydrodynamic models for lakes, which serves as the potential direction for future modeling development. In addition, I propose a novel 'golden triangle' conceptual framework for limnologic research in the future, which combines contemporary observations, paleo-observations and models. This strategy has facilitated our research in investigating how critical transitions in shallow lake ecosystems affect fate and transport of contaminants, which also may be promising in other multidisciplinary approaches to lake research.

\section{Fate of contaminants in lakes with distinct ecological states}

Understanding the mass distribution of contaminants in lakes with distinct ecological structure is crucial for the management of contaminants in floodplain lakes in either clear or turbid states. In this thesis, my colleagues and I have collected data for 16 PAHs with priority attention in various compartments of two shallow lakes in China, i.e. Lake Small Baiyangdian, a vegetation-dominated lake and Lake Chaohu, a phytoplankton-dominated lake. Note that many factors are different between these two lakes, including climate, intensity of PAHs discharge and social-environmental conditions. Therefore, direct comparison of PAHs residual levels in both lakes is inappropriate. 
However, it would be interesting to compare the PAHs mass distributions over different compartments, thereby facilitating the quantitative assessment of the impact of ecological states and processes on PAHs behavior in shallow lakes.

PAHs data, as well as the basic catchment/lake characteristics, were synthesized from Chapters 2 and 6. Additional PAHs data in macrophytes from Lake Small Baiyangdian were obtained elsewhere from our group (Zhu et al. 2009, Qin et al. 2012). Data was available for the water column, suspended solids, fish, macrophytes and sediment in both lakes. Considering that sediment was the major sink for PAHs, it was excluded from the following analysis to obtain a clear picture of PAHs distribution in water column.
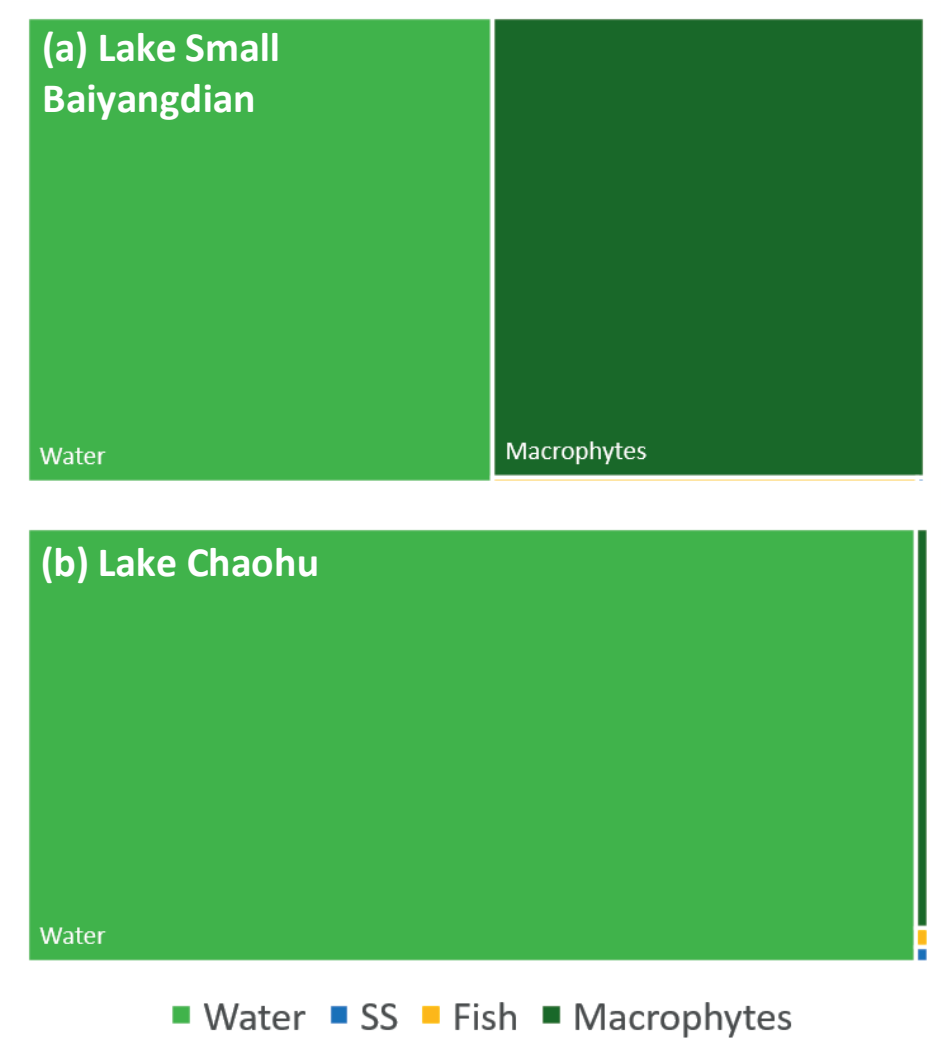

Fig. 1. Distribution of total PAHs ( $\left.\sum 16 \mathrm{PAHs}\right)$ in the water-suspended solidsfish-macrophytes system in (a) Lake Small Baiyangdian (clear state), and (b) Lake Chaohu (turbid state) during contemporary sampling. 
General discussion

I observed distinct features in the mass distribution of total PAHs ( $\Sigma$ 16PAHs) in Lake Small Baiyangdian and Lake Chaohu (Fig. 1). In Lake Small Baiyangdian, $\Sigma 16 \mathrm{PAHs}$ distributed equally between the water column and the macrophytes, while Lake Chaohu exhibited the dominating role of the water column as a sink for PAHs in the pelagic compartments above the sediment. In both lakes, the total mass of $\Sigma 16 \mathrm{PAH}$ in suspended solids and fish was negligible, despite their equal or relatively higher $\sum 16 \mathrm{PAHs}$ concentrations compared to those in water (Chapter 2 and 6). The PAHs data for phytoplankton was not available for Lake Small Baiyangdian, but the Chl-a concentration was relatively lower than that in Lake Chaohu, primarily due to the competition and suppression of macrophytes ( $\mathrm{Xu}$ et al. 2011a). As a result, the contribution of phytoplankton to the profile of PAHs in Lake Small Baiyangdian was low. This finding was consistent with the modeling results in Chapter 6, where distinct features of PAHs distribution in the water column of the lake were predicted before and after the regime shifts in lake ecosystems. The data synthesis from both lakes for multimedia distribution of PAHs provided evidence for the substantial impact of ecological processes on contaminant behavior in shallow lake ecosystems.

The results from this thesis further support the hypothesis that complex interactions occur between eutrophication and contamination in shallow lakes, which can be described by two frameworks, i.e. the interactions between nutrients and organic contaminants (Skei et al. 2000, Roessink et al. 2008, Roessink et al. 2010) and community ecology (Rohr et al. 2006, Halstead et al. 2014). In the present study, scavenging of contaminants by macrophytes, as the 'Type II mechanism' among the four mechanisms for interaction (Roessink et al. 2008), plays a critical role. The interaction framework by Roessink et al. (2008) mainly focused on the cycling of contaminants, but contained less detail on toxic effects on the lake at a system level. On the other hand, the community ecology framework by Rohr et al. (2006) may explicitly illustrate the direct and indirect toxic effects, but remains incapable to address the interaction between contamination and eutrophication. I therefore propose to take the advantages of the two frameworks by combining them into a comprehensive modeling approach (EUTOX; see below), which may shed new light on understanding of the interaction between eutrophication and contamination in shallow lakes.

\section{A step towards an integrated ecological and chemical fate model (EUTOX)}

\section{What is an EUTOX model?}


The concept of EUTOX (EUtrophication and TOXicant) model was proposed by Koelmans et al. (2001). EUTOX models are expected to simulate the fate and food chain accumulation of different contaminants of prior attention at varying trophic states in aquatic environments (Koelmans et al. 2001). To achieve this goal, an EUTOX model needs to integrate four single issue models, namely, an eutrophication model, a food web model, a contaminant fate model and a food chain accumulation model. These single issue models should be linked by the following processes (Koelmans et al. 2001):

1) Cycling of organic carbon and interaction between contaminants and organic matter.

2) Acute and chronic toxicity of contaminants and the impact on food web structure and ecosystem functioning.

3) Food web accumulation of the contaminants.

4) Impact of nutrient cycling on food web structure and functioning, particularly phytoplankton as the primary producers.

\section{A step towards an EUTOX model}

The model developed in this thesis is expected to make a step towards the development of a full EUTOX model. In brief, my colleagues and I have developed a model consisting of the four single issue modules as described above, which is per se a typical fugacity-based contaminant fate model linked to a food web accumulation model and an aquatic ecosystem model for shallow lakes (PCLake) (Fig. 2).

At the beginning, my coauthors and I started from building a contaminant fate model at steady state, i.e., a level III fugacity-based multimedia model (Chapter 2). This model was developed based on the QWASI framework (Mackay et al. 1983a) with several modifications in our study (see Chapter 2 for details), serving as the basis for the modeling approach throughout this thesis. This model focused on the abiotic processes of contaminants in the lake environment including the cycling of organic carbon and its interaction with contaminants, while the bioaccumulation by several biological components (water plants and fish) were also incorporated. However, food chain accumulation was not considered. Besides, the model was at steady state so that neither inter- nor intra- year dynamics was simulated. This model fulfilled the first requirement for an EUTOX model. 
General discussion

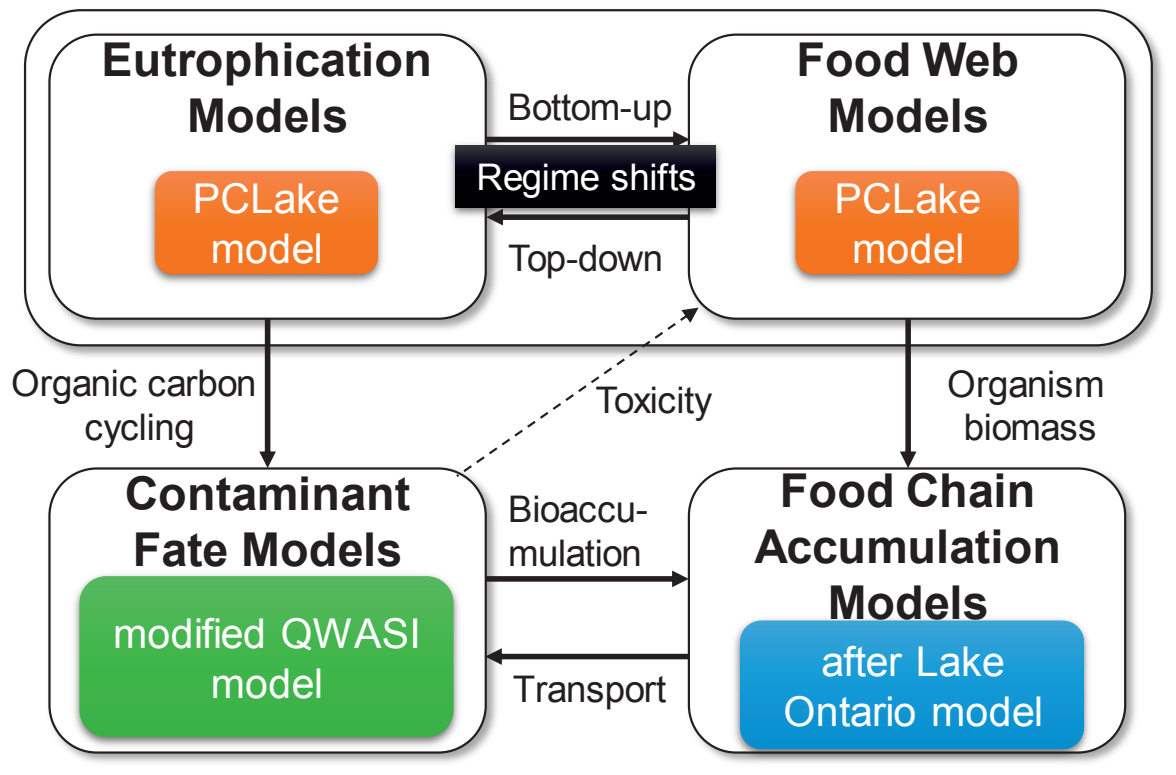

Fig. 2. Conceptual framework of the model developed in this thesis (after Koelmans et al., 2001). The four single issue models are shown in the boxes and their links are given by the arrows in between. All the required links of EUTOX models have been accomplished, except for toxicity (dashed arrow), which is currently not considered, yet expected to be accomplished in the near future.

My coauthors and I then applied the model above to several other contaminants of prior concern $(\alpha-\mathrm{HCH}, \gamma-\mathrm{HCH}, \mathrm{PFOA}$ and PFOS; Chapter 3-5), while we also made great efforts in understanding, investigating and upgrading the model. We extended the model from steady state (Level III) to dynamic (Level IV), which enabled the model to simulate seasonal variations (Chapter 3-5) and long-term dynamics on a decadal scale (Chapter 3 and 4) of contaminants in shallow lakes. In addition, we performed a sensitivity analysis on the model for each of these contaminants in order to understand the model behavior and the most influential components.

I consistently found that for studies in the eutrophic Lake Chaohu with abundant algae biomass, our model usually underestimated the contaminant level in the suspended solids (Chapter 3-5). I hypothesized that our field samples of suspended solids included the pelagic plankton, which was not considered in the modeling framework. The model simulated the sorption of the contaminant to the organic matter in the suspended solids, while the impact of plankton remained unclear. 
My coauthors and I therefore incorporated the processes of nutrient cycling, ecosystem dynamics and food web accumulation into our model (Chapter 6). This was achieved by coupling the aquatic ecosystem model (PCLake) and a food web accumulation model (Arnot and Gobas 2004) into the contaminant fate model. The integrated model not only resolved the unsatisfactory performance of our model with respect to suspended solids, but also served as a bridge between ecological and chemical modeling that embraced the complex interaction between ecological processes and chemical transport in shallow lakes. Requirements three and four for EUTOX models were therefore accomplished.

\section{Advantages of our model}

I compare our model to some other integrated models with similar objectives and application domain (GBMB, AQUATOX, and CATS-5), following the features of the model proposed for EUTOX (Koelmans et al. 2001) (Table 1). Surprisingly, development of these integrated models for simulation of both ecological and chemical processes is relatively slow, and continuous efforts are only performed for a few models such as AQUATOX (Park et al. 2008).

Table 1. Comparison of integrated models ${ }^{a}$

\begin{tabular}{|c|c|c|c|c|}
\hline Name of the models & This study & GBMB & AQUATOX & CATS-5 \\
\hline \multicolumn{5}{|l|}{ General characteristics } \\
\hline $\begin{array}{l}\text { Number of trophic levels in food } \\
\text { chain/number of components in food } \\
\text { chain }\end{array}$ & $4 / 14^{\mathrm{b}}$ & $4 / 7$ & $\begin{array}{l}\text { Flexible, user- } \\
\text { defined }^{1}\end{array}$ & $3 / 7$ \\
\hline $\begin{array}{l}\text { Focus on food web or specific target } \\
\text { organism }\end{array}$ & Food web & Food web & Food web & Food web \\
\hline Type of toxicants & $\mathrm{HOC}$ & $\mathrm{HOC}$ & $\begin{array}{l}\text { Organic } \\
\text { chemicals }^{1}\end{array}$ & $\mathrm{HOC}$ \\
\hline Steady state (SS) or dynamic model & Dynamic & Dynamic & Dynamic & Dynamic \\
\hline Generic or specific & Generic & Generic & Generic & Generic \\
\hline Type of environment & Shallow lakes & Lakes & $\begin{array}{l}\text { Streams, } \\
\text { ponds, lakes, } \\
\text { reservoirs, } \\
\text { estuary }\end{array}$ & Shallow lakes \\
\hline Dimensions & 0 & $\begin{array}{l}, \\
+ \text { stratification } \\
\end{array}$ & $\begin{array}{l}\text { 0, } \\
+ \text { stratification }\end{array}$ & 0 \\
\hline $\begin{array}{l}\text { Level of special aggregation } \\
\text { (fine/rough) }\end{array}$ & Rough & Rough & Rough & Rough \\
\hline Time step & Daily & $\mathrm{NC}$ & $\begin{array}{l}\text { Average daily } \\
\text { conditions }\end{array}$ & $\begin{array}{l}<1 \text { day } \\
\text { (variable) }\end{array}$ \\
\hline
\end{tabular}


General discussion

\begin{tabular}{|c|c|c|c|c|}
\hline $\begin{array}{l}\text { Validation. } \\
\text { Tested against real data (which } \\
\text { system) }\end{array}$ & $\begin{array}{l}\text { +Lake Chaohu, } \\
\text { Lake Small } \\
\text { Baiyangdian }\end{array}$ & $\begin{array}{l}\text { +Green Bay, } \\
\text { Lake Michigan, } \\
\text { Fox river }\end{array}$ & $\begin{array}{l}\text { +Lake } \\
\text { Onondaga, } \\
\text { Coralville } \\
\text { reservoir, Lake } \\
\text { Ontario, etc. }\end{array}$ & $\begin{array}{l}+ \text { microcosm } \\
\text { data }\end{array}$ \\
\hline Useful tool for long-term predictions & + & + & +1 & $-c$ \\
\hline $\begin{array}{l}\text { Useful for management scenario } \\
\text { studies }\end{array}$ & + & + & + & + \\
\hline $\begin{array}{l}\text { (possible) connection with } \\
\text { hydrodynamic model }\end{array}$ & $++^{\mathrm{d}}$ & + (included) & + & - \\
\hline $\begin{array}{l}\text { (possible) connection with loading } \\
\text { model (especially for non-point } \\
\text { sources) }\end{array}$ & $+\mathrm{e}$ & NC & $\begin{array}{l}+^{+1}(\text { link to } \\
\text { SWAT) }\end{array}$ & $\begin{array}{l}+ \text { (but not used } \\
\text { for cosm data) }\end{array}$ \\
\hline \multicolumn{5}{|l|}{ Biotic and physical compartments } \\
\hline \multicolumn{5}{|l|}{ Ecosystem components } \\
\hline \multicolumn{5}{|l|}{ Primary producers } \\
\hline Macrophytes & +6 types $^{\mathrm{f}}$ & - & +2 types & + \\
\hline Phytoplankton & +3 types & + & +3 types & +2 types \\
\hline $\begin{array}{r}\begin{array}{r}\text { Periphyton (algae on sediment or } \\
\text { plants) }\end{array} \\
\end{array}$ & - & - & + & + \\
\hline
\end{tabular}

\begin{tabular}{|c|c|c|c|c|}
\hline \multicolumn{5}{|l|}{ Herbivores } \\
\hline Zooplankton & + & + & + & + \\
\hline Molluscs & $+g$ & $-\mathrm{h}$ & +1 & + \\
\hline Herbivorous fish & $+g$ & + & + & - \\
\hline Detrivores (shredders) & - & - & + & + \\
\hline${ }^{* *}$ Omnivores (fish) & $+g$ & - & +1 & - \\
\hline **Benthivores (fish) & + & - & +1 & - \\
\hline \multicolumn{5}{|l|}{ Carnivores } \\
\hline Carnivorous macrofauna & $+g$ & - & + & + \\
\hline Carnivorous fish & + & + & + & - \\
\hline Decomposers (m.o., bacteria) & - & - & - & + \\
\hline Benthic organisms & + & - & + & + \\
\hline Particulate organic carbon/detritus & + & + & Detritus $^{i}$ & + \\
\hline Dissolved organic carbon & +8 & + & Detritusj & + \\
\hline \multicolumn{5}{|l|}{ Physical compartments } \\
\hline $\begin{array}{l}\text { Sediment compartments } \\
\text { surface layer? } \\
\text { fluxes) }\end{array}$ & $\begin{array}{l}\text { Active surface } \\
\text { layer, } \\
\text { burial layer, } \\
\text { Dynamic fluxes. }\end{array}$ & $\begin{array}{l}\text { Active } 0-4 \mathrm{~cm} \\
\text { layer, } 4-12 \\
\text { mixed layer, } \\
\text { Dynamic } \\
\text { fluxes. }\end{array}$ & $\begin{array}{l}\text { Active surface } \\
\text { layer, } \\
\text { burial layer, } \\
\text { refractory } \\
\text { and labile, } \\
\text { Dynamic } \\
\text { fluxes. }\end{array}$ & $\begin{array}{l}0-10 \mathrm{~cm} \\
\text { mixed, } \\
\text { Dynamic } \\
\text { fluxes. }\end{array}$ \\
\hline
\end{tabular}


Chapter 7

\begin{tabular}{|c|c|c|c|c|}
\hline $\begin{array}{l}\text { **Soil (terrestrial area in the } \\
\text { catchment) }\end{array}$ & + & - & - & - \\
\hline Water & + & + & + & + \\
\hline Air & + & + & + & - \\
\hline \multicolumn{5}{|l|}{$\begin{array}{l}\text { Fate of nutrients, carbon and } \\
\text { contaminants }\end{array}$} \\
\hline \multicolumn{5}{|l|}{ Fate of nutrients/organic matter } \\
\hline $\mathrm{N}$ balance & + & + & + & $+\mathrm{tk}$ \\
\hline P balance & + & + & +1 & + \\
\hline Organic matter balance & + & + & +1 & + \\
\hline Sedimentation & + & + & +1 & + \\
\hline Resuspension & + & + & +1 & + \\
\hline Advection & + & + & +1 & NC \\
\hline Dispersion & + & + & Only vertical & $\mathrm{NC}$ \\
\hline \multicolumn{5}{|l|}{ Fate of toxic compound } \\
\hline \multicolumn{5}{|l|}{ Transport } \\
\hline Advection & + & + & +1 & Homog mixed \\
\hline Dispersion & + & + & Only vertical & Homog mixed \\
\hline \multicolumn{5}{|l|}{ Transformation of toxic compounds } \\
\hline Hydrolysis & $+\mathrm{m}$ & $+^{n}$ & + & + \\
\hline Photolysis & $+\mathrm{m}$ & $+^{n}$ & + & + \\
\hline Biodegradation & $+\mathrm{m}$ & $+n$ & + & + \\
\hline \multicolumn{5}{|l|}{ Sorption } \\
\hline Sorption to phytoplankton & + & + & + & + \\
\hline $\begin{array}{r}{ }^{* *} \text { Absorption by phyto-/zoo- } \\
\text { plankton }\end{array}$ & + & - & - & - \\
\hline Sorption to macrophytes & + & - & + & + \\
\hline Sorption to sediment & + & + & + & + \\
\hline Sorption to suspended solids/POC & + & + & + & + \\
\hline Sorption to DOC & - & + & + & - \\
\hline Sorption to exudates/faeces & - & - & +1 & - \\
\hline Sorption to animals (fish etc.) & $\begin{array}{l}+(\text { fish as a } \\
\text { whole })\end{array}$ & - & + (gills\&guts) & - \\
\hline \multicolumn{5}{|l|}{ Sediment-water exchange } \\
\hline Diffusion of toxic compounds & + & + & +1 & + \\
\hline Air - water exchance/volatilisation & + & + & + & + \\
\hline Bioconcentration & + & + & + & $-\mathrm{o}$ \\
\hline $\begin{array}{l}\text { Elimination of toxic compounds } \\
\text { from biota }\end{array}$ & + & + & + & $-\mathrm{o}$ \\
\hline
\end{tabular}


General discussion

\begin{tabular}{|c|c|c|c|c|}
\hline Bioaccumulation/biomagnification & + & + & + & - \\
\hline \multicolumn{5}{|l|}{$\begin{array}{l}\text { Comparison of models: biology and } \\
\text { effects }\end{array}$} \\
\hline \multicolumn{5}{|l|}{ Biology } \\
\hline Mineralisation & + & + & + & $+($ first order $)$ \\
\hline $\begin{array}{l}\text { Algal growth (light/nutrient/temp } \\
\text { dependent) }\end{array}$ & $+(1 / \mathrm{n} / \mathrm{t})$ & $+(1 / \mathrm{n} / \mathrm{t})$ & + & $+(\text { monod })^{p}$ \\
\hline $\begin{array}{l}\text { Algal losses } \\
\text { (respiration/decay/sedimentation/ } \\
\text { grazing/wash-out) }\end{array}$ & + & $+\mathrm{r} / \mathrm{d} / \mathrm{s} / \mathrm{w}$ & $+\mathrm{r} / \mathrm{d} / \mathrm{s} / \mathrm{g} / \mathrm{w}^{j}$ & + \\
\hline $\begin{array}{l}\text { Growth terms for ecosystem } \\
\text { components }\end{array}$ & + & - & + & $\begin{array}{l}\text { Macrophyte } \\
\text { (droop) }\end{array}$ \\
\hline \multicolumn{5}{|l|}{ Effects } \\
\hline Acute toxicity & - & - & + & + \\
\hline Chronic toxicity & - & - & + & + \\
\hline $\begin{array}{l}\text { Occurrence of changes in chemical } \\
\text { environment }(\mathrm{pH} / \mathrm{T} / \text { redox })\end{array}$ & $+\mathrm{T}$, redox & - & $+\mathrm{Tq},(\mathrm{pH})$ & $\mathrm{NC}$ \\
\hline
\end{tabular}

Note: this table is designed and updated after Koelmans et al. (2001).

a (+): present; (-) not present; NC: not clear; ${ }^{* *}$ : new items in this study compared to Koelmans et al. (2001).

b The food web is typically consisted of 4 trophic levels (TL) and 14 components: $(\mathrm{TL}=4)$ carnivorous fish; $(\mathrm{TL}=3)$ zooplanktovorous, benthovorous fish; $(\mathrm{TL}=2)$ zooplankton, zoobenthos; $(\mathrm{TL}=1)$ cyanobacteria, green algae, diatom, detritus (both pelagic and sediment), macrophytes.

c Applicable to study short term ecological responses to environmental perturbations, such as changes in loading or the effects of pesticides.

d PCLake model has been connected to Delft3D (Janssen et al. 2017) and two other hydrodynamic models, GOTM and GETM (Hu et al. 2016).

e PCLake model has been connected to SWAT model as the catchment loading models (Nielsen et al. 2017).

${ }^{f}$ PCLake model can include six types of macrophytes via connecting to PCDitch (Van Gerven et al. 2017).

g This component is added to PCLake model when it was applied in the subtropical shallow lake (Lake Chaohu) (Kong et al. 2017a).

$\mathrm{h}$ A herbivorous invertebrate is modelled, for instance a mollusk.

i Detritus is defined including all non-living organic matter (dissolved and particulate) and the associated decomposers bacteria and fungi.

j Also excretion is modelled and this changes algal biomass.

k Descriptions of primary productivity and nutrient cycles are from PCLake (Janse et al. 1992).

${ }^{1}$ Updated for AQUATOX after Koelmans et al. (2001).

$\mathrm{m}$ The three transformation processes are modelled as a lumped decay rate. 
${ }^{\mathrm{n}}$ Degradation of the toxic compound in air, water and soil is modelled probably as a lumped decay rate.

o included in precursor model CATS-2 (Traas et al., 1994).

$\mathrm{p}$ Temperature responses included. $\mathrm{pH}$ will be included in the next version.

q Temperature is incorporated in the PCLake modules for macrophytes and algae, but not functional in the microcosm implementation (constant temperature).

From the comparison I found that, first, our model showed several advantages over the other models, mainly because PCLake was utilized as the ecological module in our model framework. By incorporating PCLake, my coauthors and I utilized the modeling strength associated with the development of PCLake itself and incorporation of PCLake with other modeling tools. PCLake model in this modeling approach served as the combined eutrophication and food web model described in the EUTOX framework (Koelmans et al. 2001). PCLake is capable of simulating the nutrient cycling, primary production dynamics and the trophic interactions in shallow lake ecosystems at both short- and long-term temporal scales. The strength of PCLake model has been illustrated by the determination of critical nutrient loading (Janse 2005, Janse et al. 2008), prediction of cyanobacterial blooms in the context of climate change (Nielsen et al. 2014, Trolle et al. 2014), and also by investigating the food web stability in shallow lakes via coupling to a classic Lokta-Volterra type food web model (Kuiper et al. 2015). Therefore, in this thesis, PCLake was applied to provide food web structure information for the bioaccumulation model, and to offer critical parameters for environmental processes in the contaminant fate model, which has proven its feasibility (Chapter 6). In addition, food web structure of PCLake can be modified so that our model may overcome the issue of most integrated models that the food web structure is fixed rather than flexible, as pointed out by Koelmans et al. (2001). Moreover, our integrated model is capable of long term simulations for contaminant exposure and food web bioaccumulation (Chapter 6), which is proposed as one of the challenges for integrated modeling (Koelmans et al. 2001). This advantage is mainly attributed to the food web module in PCLake.

PCLake is under continuously development to broaden its application domain. The model has been adapted to ditch systems and to sub-tropical shallow lake ecosystems by adding more essential abiotic and biotic components (Fragoso et al. 2011, Kong et al. 2017a, Van Gerven et al. 2017). In addition, it has been connected to hydrodynamic models including Delft3D, GOTM and GETM (Fragoso et al. 2011, Hu et al. 2016, Janssen et al. 2017), which also paves the way for the contaminant fate model to be linked to 
General discussion

hydrodynamic modeling. A recent study combined PCLake to the lake catchment model (SWAT) so that effect of land use changes on nutrient loading and ecological processes in lakes can be tested (Nielsen et al. 2017). The contaminant fate and food web accumulation modeling may therefore benefit from these fruitful developments in aquatic ecosystem modeling.

Another strength of using PCLake is that I can test the impact of critical transitions on contaminant fate and transport in shallow lakes. It is hypothesized that a regime shift in a shallow lake may exert large impacts on the chemical cycling of HOCs, due to the significant reconfiguration of food web structure and ecosystem functioning. However, the corresponding model simulations cannot be realized unless an ecosystem model, such as PCLake that is capable of mimicking the nonlinear patterns along the eutrophication of shallow lakes, is incorporated. As a result, my coauthors and I have simulated how regime shifts in shallow lakes alter the fate and transport of contaminants (Chapter 6). The integrated model may also identify the major players and underlying mechanisms in driving these changes, thereby focusing on the question: how ecological processes may interact with the biogeochemical cycling of contaminants in shallow lakes (Skei et al. 2000). These outcomes may have profound implications on the decision making and management policy with respect to shallow lakes, which are subject to both severe eutrophication and HOC contaminations (e.g. Lake Chaohu).

I consider PCLake as a 'virtual mesocosm' of shallow lake ecosystems, which enables researchers to investigate lakes in silicon. By providing essential and reliable information for the other approaches such as food web modeling and contaminant food web accumulation modeling, which rely on the external input of biomass data, PCLake may have a much broader application domain beyond the current research field in shallow lake ecosystems.

Our model also contains more components than the other models, such as the soil compartment in shallow lake catchments, more types of macrophytes and fish (Table 1). Besides, our model accounts for more processes, such as absorption of contaminants by plankton, which would be critical in understanding the partitioning of HOC between water and phytoplankton (Table 1). This is particularly essential for eutrophic lakes with abundant algae blooms (Dachs et al. 2000, Nizzetto et al. 2012). Last but not the least, my coauthors and I have also developed our model for specific lake systems. This would provide concrete case studies for specific lake ecosystems, so that the model can provide a detailed description on the chemical behavior in specific systems. 


\section{Uncertainty analysis of contaminant fate models}

It is critical to quantify the uncertainty in model simulations and predictions. The robustness and reliability of models relies on the total model uncertainty, including inherent variability (due to spatial and/or temporal variations) and true uncertainty (due to uncertainty in model structure and parameters) (McKone 1996). It is the true uncertainty that is usually addressed in uncertainty analysis, which could be reduced by incorporating more components into the fugacity models, such as vegetation (Diepens et al. 2014) and dissolved organic matter ( $\mathrm{Li}$ et al. 2015). For the true uncertainty of model parameters, the Monte Carlo method has been commonly used as the standard tool (see Chapter 2, 3 \& 5). I found that the ascertained uncertainty of the contaminant fate model could span 1-2 orders of magnitude (Chapter 5), with a coefficient of variation (CV) up to $60 \%$ (Chapter 2). This phenomenon exists not only in our study but also in other fate modeling studies with similar model configuration (Tao et al. 2003, Cao et al. 2004, Tao et al. 2006, Lang et al. 2007). I consider this a key challenge that should be resolved before the contaminant fate model can be employed in scenario predictions.

My coauthors and I therefore sought to improve our uncertainty analysis by using more advanced algorithms, i.e. Bayesian Markov Chain Monte Carlo (MCMC) simulations. We observed that the MCMC method eliminated $77 \%$ of the true uncertainty in the model predictions for the water column estimated by the traditional Monte Carlo method (Chapter 4). This indicates that a major part of the uncertainty ascertained by the traditional MC algorithm may be redundant, so that uncertainty for the contaminant fate model in the earlier studies may be largely overestimated. This is mainly attributed to the manually-defined probability distributions for the model input parameters, particularly those with a high impact on the model (i.e. high sensitivity coefficients). This issue is, however, difficult to resolve because the data for the proper determination of many parameters are usually limited, thereby reducing confidence in and reliability of fate modeling (Saloranta et al. 2008).

I consider Bayesian MCMC an adequate tool for estimating uncertainty of contaminant fate models for two reasons. First, for contaminant fate modeling, I could obtain or assume prior distributions of most parameters from literature and/or laboratory experiments, which may or may not comply with their theoretical ranges. Bayesian MCMC is, however, capable of continuously updating the parameter priors towards a better fit between the simulated and observed data, thereby refining the model parametric space and 
General discussion

reducing the redundant uncertainty of the model predictions in a proper manner. Second, during the simulations of Bayesian MCMC, the contaminant fate model has been actually calibrated, which was not possible before due to large deviations between modeled and observed data (up to one order of magnitude) (Cao et al. 2004). Overall, Bayesian MCMC may reconcile the dilemma of 'cannot be calibrated' for fate modeling, which has raised doubts to many environmental and ecological modelers. I propose that the Bayesian MCMC may become a standard tool for not only contaminant fate modeling, but also other modeling approaches subject to manual calibration, such as the lake ecosystem modeling using PCLake.

\section{Limitations and future perspectives}

\section{The other way around?}

The present model focuses on the impact of ecological processes on the fate, transport and transformation of contaminants in shallow lakes. However, on the other way around, the model has not incorporated the potential toxic effects of contaminants on lake ecosystems (Fig. 2 and Table 1). As a result, requirement two for EUTOX framework has not been fulfilled yet, which remains a critical step towards a fully-functional EUTOX model. The current model configuration is reasonable only if the toxic effects from the residual level of the contaminants are insignificant and can be neglected (such as the PAHs in Lake Chaohu; see Chapter 6), which would be, however, violated when the contaminant levels increase beyond the thresholds for toxic impact.

Intensive evidence from the literature has shown that contaminants, especially HOCs, may cause gradual changes on the level of individuals (e.g. impairment of individuals), populations, and communities (e.g. the abundance and diversity of species), and may also trigger nonlinear critical transition due to their toxic effects on keystone species, which dampen the feedback mechanisms that maintain the stability and resilience of the ecosystems (Stansfield et al. 1989, Sayer et al. 2006, De Laender et al. 2016). The negative impacts of chemical pollution on the human well-being has been addressed within the framework of a 'safe operating space' for humanity, whereas the planetary boundary for chemical pollution remains unquantified (Rockström et al. 2009). The boundary or the 'threshold' for chemical pollution may be convenient to determine for individual species or populations using statistical tools such as species sensitivity distributions (SSD) based on experimental data (Xu et al. 2015), but may remain challenging to be quantified on the ecosystem or regional level. 
It has been proposed that community ecology may serve as a tool to investigate the toxic impact of the emerging contaminants on the ecosystems (Rohr et al. 2006). The analogy, e.g., 'pesticide-as-predator' or 'pesticide-ascompetitor', may facilitate the investigation of the toxic effects of chemical pollution, particularly the 'indirect effects' on one species caused by other species or factors directly affected by contaminants, thereby better predicting the indirect effects of contaminants on the ecosystem (Rohr et al. 2006, Halstead et al. 2014). One limitation of this method is that bottom-up effects in food webs are difficult to evaluate because abiotic components such as nutrient are usually not directly considered in the community ecology framework. Although this framework may remain difficult to apply practically by environmental scientists, it sheds light on how to unify environmental and ecological research, and to utilize the fruitful discoveries from community and system ecology researches.

\section{Spatial heterogeneity and "EUTOX-S"}

Another limitation of the model in this thesis is that spatial variation has not been considered. This may be negligible for small lakes such as Lake Small Baiyangdian, but may become problematic for large lakes such as Lake Chaohu. Though I observe fair agreement between modeled and observed data in most of the studies for Lake Chaohu, incorporation of spatial explicitly modeling remains a critical step towards a more comprehensive framework (EUTOX-S) (Fig. 3). Spatially explicit multimedia fate models have unraveled critical factors that drive the spatial patterns of contaminants at regional and global scales for terrestrial systems (Wania and Mackay 1995, Zhu et al. 2015). It is found that spatial distributions of contaminants in air are generally determined by emission inventory, whereas distributions in soil are controlled by the spatial distributions of soil organic carbon (Tao et al. 2003, Wang et al. 2011a, Liu et al. 2014). Several modeling studies focus on the spatial patterns of contaminants in river systems (Ao et al. 2009, Wang et al. 2012a, Quik et al. 2015), while those on lakes are rare. When modeling contaminants in lakes, the water column is usually assumed to be well mixed. Horizontal and vertical fluxes of contaminants could be stronger in the water column than in soil. This feature may, on one hand, alleviate the spatial heterogeneity of contaminants in lakes, but on the other hand may transport the contaminant to a large scale and create a more complicated spatial pattern of contamination, particularly in case of point sources in lakes. Therefore, hydrodynamic models will play a vital role in EUTOX-S models with spatial recognition, which may simulate water and contaminant fluxes between spatial compartments and predict 
General discussion

spatial patterns of water contamination (Fig. 3). Fortunately, the recent advancements in hydrodynamic models for aquatic systems (Hu et al. 2016, Janssen et al. 2017) shed light on the spatial approach outlined above.

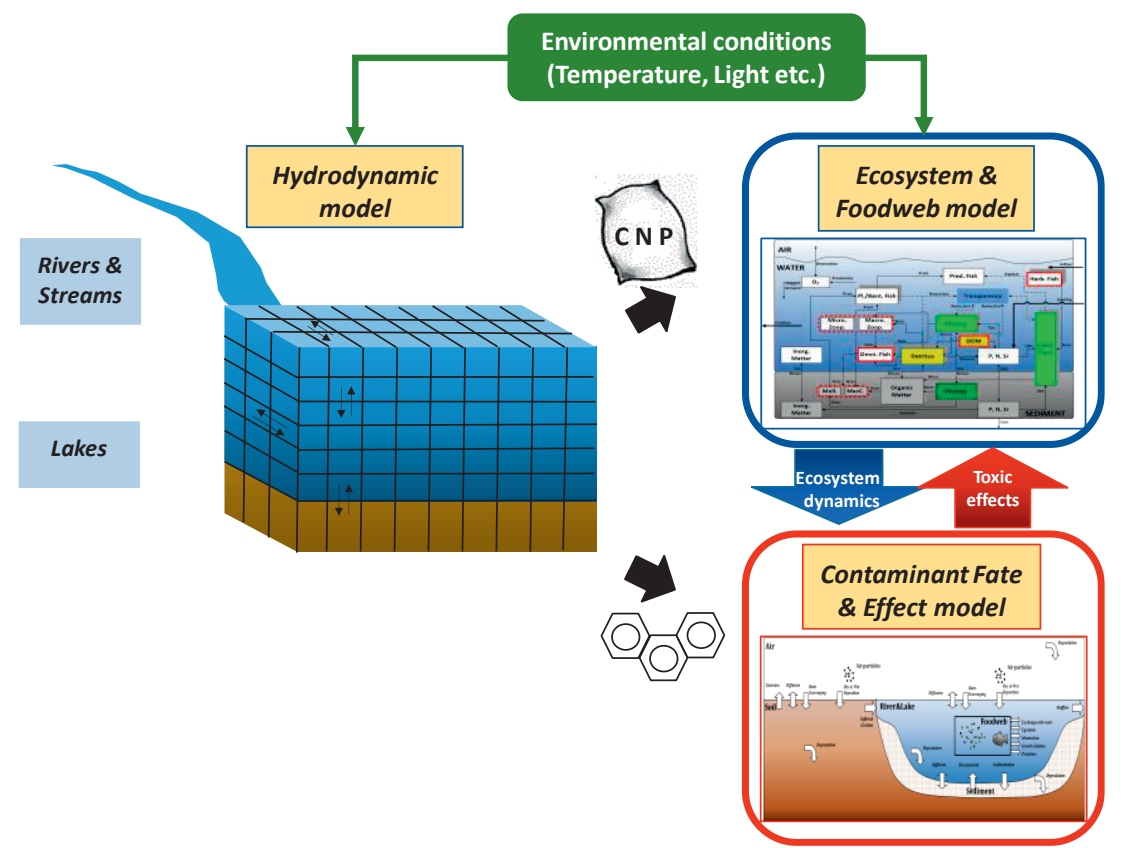

Fig. 3. Conceptual diagram of the 'EUTOX-S' modeling framework to be used in future studies.

\section{Model accuracy}

In model development, it is important to strive at a deviation between simulated and observed data as low as possible. For aquatic ecosystem modeling, criteria for model performance evaluation have been proposed and tested (Arhonditsis and Brett 2004). However, such criteria for quantifying ecological model performance are not applicable, for contaminant fate modeling. Instead, my coauthors and I used a threshold of 0.7 logarithm units, i.e. a factor smaller than 5 , as the acceptable deviation between measured and modeled values for contaminant fate models. This criterion was proposed elsewhere (Cowan et al. 1995) and has been applied in several earlier fate modeling studies (Cao et al. 2004, Tao et al. 2006, Wang et al. 2011a), where deviations below a factor of 3-4 are considered to represent a good consistency between modeled and measured concentrations. This may sound unreasonable 
for environmental modelers, who may raise the question how for a contaminant at the concentration of $1.0 \mu \mathrm{g} / \mathrm{m}^{3}$, a model that predicts a range from 0.2 to $5.0 \mu \mathrm{g} / \mathrm{m}^{3}$ can be acceptable? I argue that, this is, in fact, acceptable. Due to the relatively larger dispersion of contamination concentrations in the various compartments in the environment than limnologic indicators (such as nutrient levels, dissolved oxygen and algae biomass), I argue that it is not possible to request the fate models to fit to the field observations as good as those in aquatic ecosystem modeling. The inherent variability of data for contamination is so large that the acceptable magnitude of deviation in contaminant fate models may be higher. Besides, for prediction of the fate of contaminants in ecosystems, an order of magnitude is usually sufficient for managers in decision making, while accurate predictions are usually unnecessary. This is similar to identification of disease from human pathogens in medical caring, in which the power of the bacteria abundance value is all the doctors need for diagnosis. Nevertheless, ecological and health risk assessment would benefit more from fate models with higher prediction accuracy. Overall, it is still relevant to set up a standardized evaluation system for contaminant fate models. I recommend to develop different criteria for different model types depending on the objectives and requirements.

\section{Seasonal variations}

Seasonal variations of contaminants in aquatic systems have been extensively addressed in field studies (Ridal et al. 1996, Carlson et al. 2004, Zheng et al. 2010), whereas modeling approaches remain scarce. I find that the performance of our model in capturing the seasonality of contaminants in various compartments in the lake environment remains uncertain. For some contaminants (HCHs) the model performed relatively well (Chapter 3 and 4), but not for others (PAHs and PFSAs) (Chapter 5 and 6).

At the very beginning of fugacity models development, the motivation for Level IV models was to predict the residual levels of contaminants in the environment in response to significant changes in the source (Mackay 1979). Simulating seasonality of contaminant behavior has rarely been the main objective of fugacity modeling, which is in fact also difficult. This is because too many factors, alone or together, could become the dominant driver(s) of the seasonality of the contaminants in the environment. These factors include the seasonal variations in the source, climate and biological components, etc., the importance of which varies for different contaminants with distinct chemical properties, as well as for sites with different characteristics. For example, uncertainties in the emission inventories and limited knowledge of 
General discussion

fate and behavior of PAHs are proposed to be the major reason for the unpredicted seasonality of PAHs (Prevedouros et al. 2004). On the other hand, modeling based on detailed seasonal emission inventories showed much higher performance in predicting seasonality of PAHs (Lang et al. 2007). Also, seasonal variations in $\mathrm{HCHs}$ were well predicted using models with dynamic temperature and precipitation data as external conditions (Breivik and Wania 2002), which is also the case in our studies (Chapter 3 and 4). For arctic lakes, the seasonality of contaminants largely depends on the variations of longrange atmospheric transport driven by the global climate system (Wang et al. 2009, Hallanger et al. 2011). In addition, for eutrophic lakes with abundant algae blooms, the seasonality of contaminants may be largely influenced by the life cycles of cyanobacteria, which may play a major role in driving the fate of contaminants in both freshwater and marine systems (Dachs et al. 2000, Meijer et al. 2009, Nizzetto et al. 2012). Therefore, to predict seasonal variations of contaminants in lakes, I suggest to first identify the major factor(s) in driving the seasonality of the contaminants in lakes, and then to incorporate these factors into the modeling approach. On the other hand, I propose to be cautious when using fugacity-based models for seasonality predictions of contaminants, because the relatively large uncertainty in model predictions as discussed above may mask the true variations in seasonal variations.

\section{Future perspectives}

I propose that coupled ecosystem and contaminant fate \& effect models may provide more reliable tools to address the direct and indirect effects of contaminants on aquatic organisms. Our approach not only incorporates the trophic interactions in the food web, but also involves the biogeochemical processes in the ecosystems, particularly $\mathrm{C}, \mathrm{N}$ and $\mathrm{P}$ cycling, which links the abiotic and biotic components (Fig. 3). These two types of models are mutual beneficial, as ecosystem dynamics in highly polluted systems are strongly driven by the toxic effects of contaminants, while the fate of contaminants is also determined by the carbon cycles in the lakes. This advantage over the classic community ecology approaches enables us to further predict the implications of toxic contaminants on the ecosystem level involving the biotic components and their interactions.

I further propose to fulfil the need for managing contaminants under the EUTOX-S framework (Fig. 3), which makes it fit to the urgent requirements of end users including water boards, consultancy agencies and scientific researchers. We need to focus on those contaminants which are highly toxic to aquatic organisms, and with the potential of triggering drastic changes in 
aquatic ecosystems. EUTOX-S models will cover various aquatic ecosystems, including lakes, ditches and streams, thereby helping water managers to: 1) quantitatively understand the causality between the external conditions (such as contaminant discharge, nutrient loading and hydrological cycles) and the response quality variables (such as contaminant levels in water and various organisms) in the water body on both spatial and temporary scales; 2) identify the contaminant thresholds for ecosystem stability and resilience under various external conditions, below which the ecosystem will operate within the "safe operating space" and health risks for human beings will remain at an acceptable level; and 3) make prognosis for the effects of different management options, thereby providing hints for policy making. Based on these results, it is possible to evaluate the impacts of contaminants and the combined effects with other external stressors (such as nutrients, hydrology, climate) on aquatic ecosystems, understand how far away we are from a tipping point towards a repulsive ecosystem state (e.g., turbid, algae-dominant state in lakes), and set up targets for contaminant discharge. Overall, based on EUTOX-S, we can develop a new model for ecological risk assessment of contaminants, which will serve as a new option for water quality evaluation and direct the future aquatic ecosystems management from both environmental and ecological aspects.

\section{A 'golden triangle' framework of contemporary observations, paleo-observations and models}

Based on the methodology in this study, I further propose a 'golden triangle' framework for the evaluation of fate, transport and transformation of contaminants in lakes, which consists of contemporary pelagic observations, paleo-observations and environmental modeling using a EUTOX-S framework (Fig. 4). 


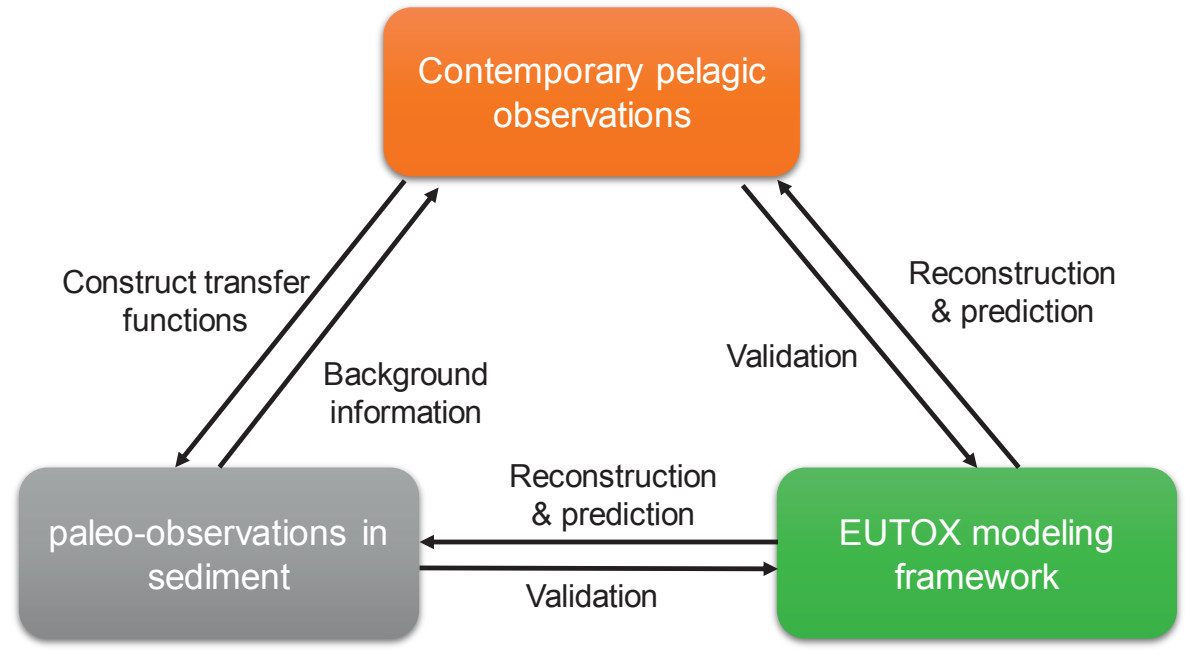

Fig. 4. A 'golden triangle' framework of for contaminant research in lakes

The strength in combining contemporary ecology and paleolimnology to investigate lake ecosystem dynamics on multiple timescales has been emphasized (Sayer et al. 2010). Contemporary limnology provides critical insights into the structure and functions of lake ecosystems such as interactions between organisms on a short-term timescale $(<1-15$ years), whereas seasonality, inter-annual variation and noisy multiple structuring forces may obscure underlying patterns (Sayer et al. 2010). On the other hand, paleolimnology records unravel the ecological dynamics of lakes on a much longer time scale (centuries to millennia) than the reach of contemporary monitoring data (Sayer et al. 2010, Randsalu-Wendrup et al. 2014), which however, largely rely on the assistance of contemporary limnology to reconstruct transfer functions from proxies (such as diatom assembly) to single environmental variables (such as TP) (Chen et al. 2011). The key opportunities of this transdisciplinary approach are to yield long-term records of lake histories, thereby facilitating the investigation of the response of the lakes to external stressors such as nutrient loads and climate change on a much broader temporary scale. Therefore, it has been strongly advocated to link paleolimnology to current aquatic ecology, which provide a valuable long-term dimension to our understanding of shallow lake responses to human activities (Smol 1990, Battarbee et al. 2005).

In addition, a recent study from my colleagues and I combines contemporary limnology, paleolimnology and ecosystem modeling, which provided deeper insights into a shallow lake system dynamics over a decadal 
scale (Kong et al. 2017a). The ecosystem modeling approach serves as a new dimension to the field records from the lake water column and sediment cores, on which we can reconstruct and predict lake ecosystem dynamics under distinct scenarios. This new dimension therefore provides us with a better understanding of the major drivers and underlying mechanisms. I therefore advocate this 'golden triangle' to be applied in future limnology studies, which particularly focus on long-term ecosystem dynamics.

The advancement in limnological research may inspire environmental scientists on toxicant research, as a similar 'golden triangle' strategy may also apply (Fig. 4). Despite the intensive literature on sediment records of historical contaminants (Sayer et al. 2006, Kang et al. 2015, Ren et al. 2015), contemporary evaluation (Tao et al. 2017) and the fate modeling discussed extensively above, studies that combine the strengths from these three research domains are scarce. Residual levels of contaminants in sediment cores show the trends on the longer-term and provide background information for the current pollution status. It is essential to assess the current status and ascertain the pollution level while acknowledging the data from pristine state of the lake, which may also provide insights in how system-level ecological changes affect the fate and transport of contaminants. In addition, contemporary evaluation reveals the patterns of contaminant distributions in the lake environment, with which environmental scientists can understand the processes related to the cycling of these substances in lakes. Furthermore, the strengths of the integration of pelagic monitoring, sediment data and modeling are reflected in the here presented study on PAHs in Lake Chaohu (Chapter 6), in which my coauthors and I unravel how abrupt changes in shallow lake ecosystems alter the fate and transport of PAHs. The model is validated by field data from both contemporary and paleo records, and is subsequently used to reconstruct the fate and transport of PAHs in different components of the lake on a decadal scale. This cannot be achieved by analysis of the field data itself. If contemporary monitoring in lakes is like taking a photo of a train during its journey without a full temporary records (Smol 1990), I propose that the 'golden triangle' can serve as a video recording part of the train's journey that are of particular interested. Overall, it will enhance our power to understand the past of lake ecosystems and to foresee how they will change in the future.

\section{Conclusion remarks}

Freshwater ecosystems generate a wide range of supporting services that sustain human well-beings. However, the last several decades bears 
General discussion

witness to increasing anthropogenic pressures that globally led to a substantial degradation of aquatic ecosystems. The pressures of an increasing population and growing food demand have resulted in a rapid expansion of agricultural land use and an excessive application of fertilizers, leading to intensified eutrophication and water quality deterioration in adjacent lakes. Meanwhile, freshwater ecosystems in highly populated areas suffer from the increasing contamination with hazardous chemicals due to intensive industrial and agricultural activities. These contaminants can accumulate in the aquatic food web, thereby threatening ecological functions due to toxicity to organisms, or human health due to direct consumption. This is for example the case for many large shallow lakes in China. The environmental effects of both eutrophication and contaminants in shallow lakes cannot be predicted from each process alone. Therefore, understanding the interactions between them using data from both contemporary pelagic and paleolimnolgic samples, and further implementation of modeling approaches on the basis of a systematic framework (e.g. EUTOX-S) for simulation and prediction, is a prerequisite for ecological and human health risk assessment. In turn, this may inform environmental management and policy profoundly. 
Chapter 7 


\section{References}

3M. 2003. Environmental and health assessment of sulfonic acid and its salts. 3M Company.

Ahrens, L., S. Taniyasu, L. W. Yeung, N. Yamashita, P. K. Lam, and R. Ebinghaus. 2010. Distribution of polyfluoroalkyl compounds in water, suspended particulate matter and sediment from Tokyo Bay, Japan. Chemosphere 79:266-272.

Ahrens, L., N. Yamashita, L. W. Yeung, S. Taniyasu, Y. Horii, P. K. Lam, and R. Ebinghaus. 2009. Partitioning behavior of per-and polyfluoroalkyl compounds between pore water and sediment in two sediment cores from Tokyo Bay, Japan. Environmental Science \& Technology 43:6969-6975.

Ahrens, L., L. W. Yeung, S. Taniyasu, P. K. Lam, and N. Yamashita. 2011. Partitioning of perfluorooctanoate (PFOA), perfluorooctane sulfonate (PFOS) and perfluorooctane sulfonamide (PFOSA) between water and sediment. Chemosphere 85:731-737.

Aldenberg, T., J. H. Janse, and P. R. G. Kramer. 1995. Fitting the dynamic-model PCLAKE to a multilake survey through Bayesian statistics. Ecological Modelling 78:83-99.

Ao, J. T., J. W. Chen, F. L. Tian, and X. Y. Cai. 2009. Application of a level IV fugacity model to simulate the long-term fate of hexachlorocyclohexane isomers in the lower reach of Yellow River basin, China. Chemosphere 74:370-376.

Appleby, P. 2001. Chronostratigraphic techniques in recent sediments. Pages 171-203 Tracking environmental change using lake sediments. Springer.

Arhonditsis, G. B., and M. T. Brett. 2004. Evaluation of the current state of mechanistic aquatic biogeochemical modeling. Marine ecology progress series 271:13-26.

Armitage, J. M., U. Schenker, M. Scheringer, J. W. Martin, M. MacLeod, and I. T. Cousins. 2009. Modeling the global fate and transport of perfluorooctane sulfonate (PFOS) and precursor compounds in relation to temporal trends in wildlife exposure. Environmental Science \& Technology 43:9274-9280.

Arnot, J. A., and F. Gobas. 2004. A food web bioaccumulation model for organic chemicals in aquatic ecosystems. Environmental Toxicology and Chemistry 23:2343-2355.

Arp, H. P. H., C. Niederer, and K. U. Goss. 2006. Predicting the partitioning behavior of various highly fluorinated compounds. Environmental Science \& Technology 40:7298-7304.

Baek, J. M., and S. J. Park. 2000. Tracking the distribution of organic compounds using fugacity model. Korean Journal of Chemical Engineering 17:12-16.

Ballschmiter, K. 1992. Transport and fate of organic-compounds in the global environment. Angewandte Chemie-International Edition in English 31:487-515.

Bao, L., K. A. Maruya, S. A. Snyder, and E. Y. Zeng. 2012. China's water pollution by persistent organic pollutants. Environmental Pollution 163:100-108.

Battarbee, R. W., N. John Anderson, E. Jeppesen, and P. R. Leavitt. 2005. Combining palaeolimnological and limnological approaches in assessing lake ecosystem response to nutrient reduction. Freshwater Biology 50:1772-1780.

Berglund, O., P. Larsson, G. Ewald, and L. Okla. 2001. The effect of lake trophy on lipid content and PCB concentrations in planktonic food webs. Ecology 82:1078-1088.

Berrojalbiz, N., J. Dachs, S. Del Vento, M. J. Ojeda, M. C. Valle, J. Castro-Jimenez, G. Mariani, J. Wollgast, and G. Hanke. 2011. Persistent Organic Pollutants in Mediterranean Seawater and Processes Affecting Their Accumulation in Plankton. Environmental Science \& Technology 45:4315-4322.

Berrojalbiz, N., S. Lacorte, A. Calbet, E. Saiz, C. Barata, and J. Dachs. 2009. Accumulation and Cycling of Polycyclic Aromatic Hydrocarbons in Zooplankton. Environmental Science \& Technology 43:2295-2301.

Binelli, A., and A. Provini. 2003. The PCB pollution of Lake Iseo (N. Italy) and the role of biomagnification in the pelagic food web. Chemosphere 53:143-151. 


\section{References}

Breivik, K., and F. Wania. 2002. Evaluating a model of the historical behavior of two hexachlorocyclohexanes in the Baltic sea environment. Environmental Science \& Technology 36:1014-1023.

Burns, D. C., D. A. Ellis, H. Li, C. J. McMurdo, and E. Webster. 2008. Experimental p K a determination for perfluorooctanoic acid (PFOA) and the potential impact of $\mathrm{p} \mathrm{K}$ a concentration dependence on laboratory-measured partitioning phenomena and environmental modeling. Environmental Science \& Technology 42:9283-9288.

Cai, R. 2010. Agri-chemicals inputs and its impact on Environment. CHINA POPULATION, RESOURCES AND ENVIRONMENT 20:107-110 (in Chinese).

Calamari, D., M. Vighi, and E. Bacci. 1987. The use of terrestrial plant biomass as a parameter in the fugacity model. Chemosphere 16:2359-2364.

Campfens, J., and D. Mackay. 1997. Fugacity-based model of PCB bioaccumulation in complex aquatic food webs. Environmental Science \& Technology 31:577-583.

Cao, H., S. Tao, F. Xu, R. Coveney, J. Cao, B. Li, W. Liu, X. Wang, J. Hu, W. Shen, B. Qin, and R. Sun. 2004. Multimedia fate model for hexachlorocyclohexane in Tianjin, China. Environmental Science \& Technology 38:2126-2132.

Cao, H. Y., T. Liang, S. Tao, and C. S. Zhang. 2007. Simulating the temporal changes of OCP pollution in Hangzhou, China. Chemosphere 67:1335-1345.

Carlson, D. L., I. Basu, and R. A. Hites. 2004. Annual variations of pesticide concentrations in great lakes precipitation. Environmental Science \& Technology 38:5290-5296.

Carpenter, S. R., D. Ludwig, and W. A. Brock. 1999. Management of eutrophication for lakes subject to potentially irreversible change. Ecological Applications 9:751-771.

Carson, R. 2002. Silent spring. Houghton Mifflin Harcourt, New York, USA.

Casal, P., B. n. González-Gaya, Y. Zhang, A. J. Reardon, J. W. Martin, B. a. Jiménez, and J. Dachs. 2017. Accumulation of Perfluoroalkylated Substances in Oceanic Plankton. Environmental Science \& Technology 51:2766-2775.

Chen, H., S. Chen, X. Quan, Y. Zhao, and H. Zhao. 2009. Sorption of perfluorooctane sulfonate (PFOS) on oil and oil-derived black carbon: influence of solution $\mathrm{pH}$ and $\left[\mathrm{Ca}^{2+}\right]$. Chemosphere 77:1406-1411.

Chen, X., X. Yang, X. Dong, and Q. Liu. 2011. Nutrient dynamics linked to hydrological condition and anthropogenic nutrient loading in Chaohu Lake (southeast China). Hydrobiologia 661:223234.

Conder, J. M., R. A. Hoke, W. d. Wolf, M. H. Russell, and R. C. Buck. 2008. Are PFCAs bioaccumulative? A critical review and comparison with regulatory criteria and persistent lipophilic compounds. Environmental Science \& Technology 42:995-1003.

Conley, D. J., H. W. Paerl, R. W. Howarth, D. F. Boesch, S. P. Seitzinger, K. E. Havens, C. Lancelot, and G. E. Likens. 2009. Controlling eutrophication: nitrogen and phosphorus. Science 323:10141015.

Connolly, J. P., and C. J. Pedersen. 1988. A thermodynamic-based evaluation of organic-chemical accumulation in aquatic organisms. Environmental Science \& Technology 22:99-103.

Cowan, C. E., D. Mackay, T. C. J. Feijtel, D. van de Meent, A. Di Guardo, J. Davies, and N. Mackay. 1995. The multi-media fate model: a vital tool for predicting the fate of chemicals. SETAC Press, Pensacola, FL, USA.

Crosley, R. W., D. B. Donald, and H. O. Block. 1998. Trends and seasonality in alpha- and gammahexachlorocyclohexane in western Canadian surface waters (1975-94). Environmental Pollution 103:277-285.

Dachs, J., S. J. Eisenreich, J. E. Baker, F. C. Ko, and J. D. Jeremiason. 1999. Coupling of phytoplankton uptake and air-water exchange of persistent organic pollutants. Environmental Science \& Technology 33:3653-3660.

Dachs, J., S. J. Eisenreich, and R. M. Hoff. 2000. Influence of eutrophication on air-water exchange, vertical fluxes, and phytoplankton concentrations of persistent organic pollutants. Environmental Science \& Technology 34:1095-1102. 
De Laender, F., J. R. Rohr, R. Ashauer, D. J. Baird, U. Berger, N. Eisenhauer, V. Grimm, U. Hommen, L. Maltby, and C. J. Meliàn. 2016. Reintroducing environmental change drivers in biodiversityecosystem functioning research. Trends in Ecology \& Evolution 31:905-915.

de Vos, M. G., M. A. Huijbregts, M. J. van den Heuvel-Greve, A. D. Vethaak, K. I. Van de Vijver, P. E. Leonards, S. Van Leeuwen, P. De Voogt, and A. J. Hendriks. 2008. Accumulation of perfluorooctane sulfonate (PFOS) in the food chain of the Western Scheldt estuary: Comparing field measurements with kinetic modeling. Chemosphere 70:1766-1773.

Dearing, J. A., R. Wang, K. Zhang, J. G. Dyke, H. Haberl, M. S. Hossain, P. G. Langdon, T. M. Lenton, K. Raworth, and S. Brown. 2014. Safe and just operating spaces for regional social-ecological systems. Global Environmental Change 28:227-238.

Dearing, J. A., X. D. Yang, X. H. Dong, E. L. Zhang, X. Chen, P. G. Langdon, K. Zhang, W. G. Zhang, and T. P. Dawson. 2012. Extending the timescale and range of ecosystem services through paleoenvironmental analyses, exemplified in the lower Yangtze basin. Proceedings of the National Academy of Sciences, USA 109:E1111-E1120.

Del Vento, S., and J. Dachs. 2002. Prediction of uptake dynamics of persistent organic pollutants by bacteria and phytoplankton. Environmental Toxicology and Chemistry 21:2099-2107.

Di Paolo, C., N. Gandhi, S. P. Bhavsar, M. Van den Heuvel-Greve, and A. A. Koelmans. 2010. Black carbon inclusive multichemical modeling of PBDE and PCB biomagnification and transformation in estuarine food webs. Environmental Science \& Technology 44:7548-7554.

Diamond, M., M. Ganapathy, S. Peterson, and C. Mach. 2000. Mercury dynamics in the Lahontan Reservoir, Nevada: Application of the QWASI fugacity/aquivalence multispecies model. Water, Air, and Soil Pollution 117:133-156.

Diamond, M. L., S. P. Bhavsar, P. A. Helm, G. A. Stern, and M. Alaee. 2005. Fate of organochlorine contaminants in arctic and subarctic lakes estimated by mass balance modelling. Science of the Total Environment 342:245-259.

Diamond, M. L., D. MacKay, D. J. Poulton, and F. A. Stride. 1996. Assessing chemical behavior and developing remedial actions using a mass balance model of chemical fate in the Bay of Quinte. Water Research 30:405-421.

Dich, J., S. H. Zahm, A. Hanberg, and H. O. Adami. 1997. Pesticides and cancer. Cancer Causes \& Control 8:420-443.

Diepens, N. J., G. H. P. Arts, A. Focks, and A. A. Koelmans. 2014. Uptake, translocation, and elimination in sediment-rooted macrophytes: A model-supported analysis of whole sediment test data. Environmental Science \& Technology 48:12344-12353.

Diepens, N. J., W. H. Beltman, A. A. Koelmans, P. J. Van den Brink, and J. M. Baveco. 2016. Dynamics and recovery of a sediment-exposed Chironomus riparius population: A modelling approach. Environmental Pollution 213:741-750.

Domingo, J. L. 2012. Health risks of dietary exposure to perfluorinated compounds. Environment International 40:187-195.

Dong, J. Y., H. Gao, S. G. Wang, H. J. Yao, and M. Q. Ma. 2009. Simulation of the transfer and fate of HCHs since the 1950s in Lanzhou, China. Ecotoxicology and Environmental Safety 72:19501956.

Downing, A. S., E. H. van Nes, J. H. Janse, F. Witte, I. J. M. Cornelissen, M. Scheffer, and W. M. Mooij. 2012. Collapse and reorganization of a food web of Mwanza Gulf, Lake Victoria. Ecological Applications 22:229-239.

Du, Z., S. Deng, Y. Bei, Q. Huang, B. Wang, J. Huang, and G. Yu. 2014. Adsorption behavior and mechanism of perfluorinated compounds on various adsorbents: a review. Journal of hazardous materials 274:443-454.

Edwards, F. G., E. Egemen, R. Brennan, and N. Nirmalakhandan. 1999. Ranking of toxics release inventory chemicals using a Level III fugacity model and toxicity. Water Science and Technology 39:83-90. 


\section{References}

Fragoso, C. R., D. Marques, T. F. Ferreira, J. H. Janse, and E. H. van Nes. 2011. Potential effects of climate change and eutrophication on a large subtropical shallow lake. Environmental Modelling \& Software 26:1337-1348.

Fragoso, C. R., E. H. van Nes, J. H. Janse, and D. D. Marques. 2009. IPH-TRIM3D-PCLake: A threedimensional complex dynamic model for subtropical aquatic ecosystems. Environmental Modelling \& Software 24:1347-1348.

Fromme, H., S. A. Tittlemier, W. Völkel, M. Wilhelm, and D. Twardella. 2009. Perfluorinated compounds-exposure assessment for the general population in Western countries. International journal of hygiene and environmental health 212:239-270.

Gandhi, N., S. P. Bhavsar, S. B. Gewurtz, M. L. Diamond, A. Evenset, G. N. Christensen, and D. Gregor. 2006. Development of a multichemical food web model: Application to PBDEs in Lake Ellasjøen, Bear Island, Norway. Environmental Science \& Technology 40:4714-4721.

Gao, J. J., and H. Q. Zhao. 2012. Residues of organic chlorine pesticide and their distribution characteristics in arable land soil of Chaohu Lake region. Journal of Anhui Agricultural University 39:613-618.

Giesy, J. P., and K. Kannan. 2001. Global distribution of perfluorooctane sulfonate in wildlife. Environmental Science \& Technology 35:1339-1342.

Giesy, J. P., Z. Tang, and X. Zhao. 2016. Historical record of effects of human activities on absolute and relative concentrations of Polycyclic aromatic hydrocarbons (PAHs) in Lake Chao, China. Journal of Environmental Sciences 46:1-4.

Gilbertson, M. 1996. Organochlorine contaminants in the Great Lakes. Ecological Applications 6:966-971.

Gobas, F., and J. A. Arnot. 2010. Food web bioaccumulation model for polychlorinated biphenyls in San francisco bay, California, USA. Environmental Toxicology and Chemistry 29:1385-1395.

Gobas, F., J. B. Wilcockson, R. W. Russell, and G. D. Haffner. 1999. Mechanism of biomagnification in fish under laboratory and field conditions. Environmental Science \& Technology 33:133-141.

Gobas, F., X. Zhang, and R. Wells. 1993. Gastrointestinal magnification - the mechanism of biomagnification and food-chain accumulation of organic-chemicals. Environmental Science \& Technology 27:2855-2863.

Gomis, M. I., Z. Wang, M. Scheringer, and I. T. Cousins. 2015. A modeling assessment of the physicochemical properties and environmental fate of emerging and novel per-and polyfluoroalkyl substances. Science of the Total Environment 505:981-991.

Goss, K. U. 2007. The p K a values of PFOA and other highly fluorinated carboxylic acids. Environmental Science \& Technology 42:456-458.

Gouin, T., J. M. Armitage, I. T. Cousins, D. C. Muir, C. A. Ng, L. Reid, and S. Tao. 2013. Influence of global climate change on chemical fate and bioaccumulation: The role of multimedia models. Environmental Toxicology and Chemistry 32:20-31.

Gustafson, K. E., and R. M. Dickhut. 1997. Particle/gas concentrations and distributions of PAHs in the atmosphere of southern Chesapeake Bay. Environmental Science \& Technology 31:140-147.

Hafner, W. D., and R. A. Hites. 2003. Potential sources pesticides, PCBs, and PAHs to the atmosphere of the Great Lakes. Environmental Science \& Technology 37:3764-3773.

Hallanger, I. G., A. Ruus, D. Herzke, N. A. Warner, A. Evenset, E. S. Heimstad, G. W. Gabrielsen, and K. Borgå. 2011. Influence of season, location, and feeding strategy on bioaccumulation of halogenated organic contaminants in Arctic marine zooplankton. Environmental Toxicology and Chemistry 30:77-87.

Halstead, N. T., T. A. McMahon, S. A. Johnson, T. R. Raffel, J. M. Romansic, P. W. Crumrine, and J. R. Rohr. 2014. Community ecology theory predicts the effects of agrochemical mixtures on aquatic biodiversity and ecosystem properties. Ecology Letters 17:932-941.

Hansen, M. C., M. H. Børresen, M. Schlabach, and G. Cornelissen. 2010. Sorption of perfluorinated compounds from contaminated water to activated carbon. Journal of Soils and Sediments 10:179-185. 
Hargrave, B. T., G. A. Phillips, W. P. Vass, P. Bruecker, H. E. Welch, and T. D. Siferd. 2000. Seasonality in bioaccumulation of organochlorines in lower trophic level arctic marine biota. Environmental Science \& Technology 34:980-987.

Harvey, R. G. 1991. Polycyclic aromatic hydrocarbons: chemistry and carcinogenicity. CUP Archive.

Hauck, M., H. W. M. Hendriks, M. A. J. Huijbregts, A. M. J. Ragas, D. van de Meent, and A. J. Hendriks. 2011. Parameter uncertainty in modeling bioaccumulation factors of fish. Environmental Toxicology and Chemistry 30:403-412.

Hauck, M., M. A. J. Huijbregts, A. A. Koelmans, C. T. A. Moermond, M. J. van den Heuvel-Greve, K. Veltman, A. J. Hendriks, and A. D. Vethaak. 2007. Including sorption to black carbon in modeling bioaccumulation of polycyclic aromatic hydrocarbons: Uncertainty analysis and comparison to field data. Environmental Science \& Technology 41:2738-2744.

Haugen, J. E., F. Wania, N. Ritter, and M. Schlabach. 1998. Hexachlorocyclohexanes in air in southern Norway. Temporal variation, source allocation, and temperature dependence. Environmental Science \& Technology 32:217-224.

He, W., N. Qin, Q. S. He, Y. Wang, X. Z. Kong, and F. L. Xu. 2012. Characterization, ecological and health risks of DDTs and HCHs in water from a large shallow Chinese lake. Ecological Informatics 12:77-84.

He, W., N. Qin, X. Kong, W. Liu, Q. He, Q. Wang, C. Yang, Y. Jiang, B. Yang, and W. Wu. 2014. Water quality benchmarking (WQB) and priority control screening (PCS) of persistent toxic substances (PTSs) in China: necessity, method and a case study. Science of the Total Environment 472:1108-1120.

Helm, P. A., M. L. Diamond, R. Semkin, W. M. J. Strachan, C. Teixeira, and D. Gregor. 2002. A mass balance model describing multiyear fate of organochlorine compounds in a high Arctic lake. Environmental Science \& Technology 36:996-1003.

Higgins, C. P., and R. G. Luthy. 2006. Sorption of perfluorinated surfactants on sediments. Environmental Science \& Technology 40:7251-7256.

Higgins, C. P., and R. G. Luthy. 2007. Modeling sorption of anionic surfactants onto sediment materials: an a priori approach for perfluoroalkyl surfactants and linear alkylbenzene sulfonates. Environmental Science \& Technology 41:3254-3261.

Holysh, M., S. Paterson, D. Mackay, and M. M. Bandurraga. 1986. Assessment of the environmental fate of linear alkylbenzenesulphonates. Chemosphere 15:3-20.

Hu, F., K. Bolding, J. Bruggeman, E. Jeppesen, M. Flindt, L. P. A. van Gerven, J. H. Janse, A. B. G. Janssen, J. J. Kuiper, and W. M. Mooij. 2016. FABM-1 PCLake-linking aquatic ecology with 2 hydro-dynamics. Geoscientific Model Development 9.

Hung, H., and D. Mackay. 1997. A novel and simple model of the uptake of organic chemicals by vegetation from air and soil. Chemosphere 35:959-977.

Jørgensen, S. E., Fath, B. D. 2011. Fundamentals of Ecological Modelling, 4th ed. Elsevier, Amsterdam.

Janse, J. H. 1997. A model of nutrient dynamics in shallow lakes in relation to multiple stable states. Hydrobiologia 342:1-8.

Janse, J. H. 2005. Model studies on the eutrophication of shallow lakes and ditches [Doctoral dissertation]. Wageningen University, Wageningen, The Netherlands.

Janse, J. H., T. Aldenberg, and P. R. G. Kramer. 1992. A MATHEMATICAL-MODEL OF THE PHOSPHORUS CYCLE IN LAKE LOOSDRECHT AND SIMULATION OF ADDITIONAL MEASURES. Hydrobiologia 233:119-136.

Janse, J. H., L. Domis, M. Scheffer, L. Lijklema, L. Van Liere, M. Klinge, and W. M. Mooij. 2008. Critical phosphorus loading of different types of shallow lakes and the consequences for management estimated with the ecosystem model PCLake. Limnologica 38:203-219.

Janse, J. H., M. Scheffer, L. Lijklema, L. Van Liere, J. S. Sloot, and W. M. Mooij. 2010. Estimating the critical phosphorus loading of shallow lakes with the ecosystem model PCLake: Sensitivity, calibration and uncertainty. Ecological Modelling 221:654-665.

Janse, J. H., E. Van Donk, and T. Aldenberg. 1998. A model study on the stability of the macrophytedominated state as affected by biological factors. Water Research 32:2696-2706. 


\section{References}

Janse, J. H., and L. van Liere. 1995. PCLake: A modelling tool for the evaluation of lake restoration scenarios. Water Science and Technology 31:371-374.

Janssen, A. B. G., V. C. de Jager, J. H. Janse, X. Kong, S. Liu, Q. Ye, and W. M. Mooij. 2017. Spatial identification of critical nutrient loads of large shallow lakes: Implications for Lake Taihu (China). Water Research 119:276-287.

Janssen, A. B. G., S. Teurlincx, S. An, J. H. Janse, H. W. Paerl, and W. M. Mooij. 2014. Alternative stable states in large shallow lakes? Journal of Great Lakes Research 40:813-826.

Janssen, A. B. G., G. Arhonditsis, A. Beusen, K. Bolding, L. Bruce, J. Bruggeman, R. M. Couture, A. Downing, J. Alex Elliott, M. Frassl, G. Gal, D. Gerla, M. Hipsey, F. Hu, S. Ives, J. H. Janse, E. Jeppesen, K. Jöhnk, D. Kneis, X. Kong, J. J. Kuiper, M. Lehmann, C. Lemmen, D. Özkundakci, T. Petzoldt, K. Rinke, B. Robson, R. Sachse, S. Schep, M. Schmid, H. Scholten, S. Teurlincx, D. Trolle, T. Troost, A. Van Dam, L. P. A. Van Gerven, M. Weijerman, S. Wells, and W. M. Mooij. 2015. Exploring, exploiting and evolving diversity of aquatic ecosystem models: a community perspective. Aquatic Ecology 49:513-548.

Jeppesen, E., B. Kronvang, J. E. Olesen, J. Audet, M. Søndergaard, C. C. Hoffmann, H. E. Andersen, T. L. Lauridsen, L. Liboriussen, and S. E. Larsen. 2011. Climate change effects on nitrogen loading from cultivated catchments in Europe: implications for nitrogen retention, ecological state of lakes and adaptation. Hydrobiologia 663:1-21.

Jepson, P. D., and R. J. Law. 2016. Persistent pollutants, persistent threats. Science 352:1388-1389.

Jiang, Y., W. He, W. Liu, N. Qin, H. Ouyang, Q. Wang, X. Kong, Q. He, C. Yang, and B. Yang. 2014. The seasonal and spatial variations of phytoplankton community and their correlation with environmental factors in a large eutrophic Chinese lake (Lake Chaohu). Ecological Indicators 40:58-67.

Jones, K. C., and P. De Voogt. 1999. Persistent organic pollutants (POPs): state of the science. Environmental Pollution 100:209-221.

Jurado, E., and J. Dachs. 2008. Seasonality in the "grasshopping" and atmospheric residence times of persistent organic pollutants over the oceans. Geophysical Research Letters 35:DOI: 10.1029/2008g1034698.

Kaiser, M. A., B. S. Larsen, C.-P. C. Kao, and R. C. Buck. 2005. Vapor pressures of perfluorooctanoic,nonanoic,-decanoic,-undecanoic, and-dodecanoic acids. Journal of Chemical \& Engineering Data 50:1841-1843.

Kalantzi, O. I., R. Hewitt, K. J. Ford, L. Cooper, R. E. Alcock, G. O. Thomas, J. A. Morris, T. J. McMillan, K. C. Jones, and F. L. Martin. 2004a. Low dose induction of micronuclei by lindane. Carcinogenesis 25:613-622.

Kalantzi, O. I., F. L. Martin, G. O. Thomas, R. E. Alcock, H. R. Tang, S. C. Drury, P. L. Carmichael, J. K. Nicholson, and K. C. Jones. 2004b. Different levels of polybrominated diphenyl ethers (PBDEs) and chlorinated compounds in breast milk from two UK regions. Environmental Health Perspectives 112:1085-1091.

Kang, L., Q. Wang, Q. He, W. He, W. Liu, X. Kong, B. Yang, C. Yang, Y. Jiang, and F. Xu. 2015. Current status and historical variations of phthalate ester (PAE) contamination in the sediments from a large Chinese lake (Lake Chaohu). Environmental Science and Pollution Research 23:1039310405.

Kim, S. K., and K. Kannan. 2007. Perfluorinated acids in air, rain, snow, surface runoff, and lakes: relative importance of pathways to contamination of urban lakes. Environmental Science \& Technology 41:8328-8334.

Koelmans, A. A. 2014. Limited reversibility of bioconcentration of hydrophobic organic chemicals in phytoplankton. Environmental Science \& Technology 48:7341-7348.

Koelmans, A. A., S. F. Anzion, and L. Lijklema. 1995. Dynamics of organic micropollutant biosorption to cyanobacteria and detritus. Environmental Science \& Technology 29:933-940.

Koelmans, A. A., F. Gillissen, W. Makatita, and M. VandenBerg. 1997. Organic carbon normalisation of PCB, PAH and pesticide concentrations in suspended solids. Water Research 31:461-470. 
References

Koelmans, A. A., E. Hubert, H. W. Koopman, R. Portielje, and S. J. H. Crum. 2000. Modeling the vertical distribution of carbendazim in sediments. Environmental Toxicology and Chemistry 19:793800 .

Koelmans, A. A., C. S. Jimenez, and L. Lijklema. 1993. Sorption of Chlorobenzenes to Mineralizing Phytoplankton. Environmental Toxicology and Chemistry 12:1425-1439.

Koelmans, A. A., M. T. O. Jonker, G. Cornelissen, T. D. Bucheli, P. C. M. Van Noort, and O. Gustafsson. 2006. Black carbon: The reverse of its dark side. Chemosphere 63:365-377.

Koelmans, A. A., K. Kaag, A. Sneekes, and E. T. H. M. Peeters. 2009. Triple domain in situ sorption modeling of organochlorine pesticides, polychlorobiphenyls, polyaromatic hydrocarbons, polychlorinated dibenzo-p-dioxins, and polychlorinated dibenzofurans in aquatic sediments. Environmental Science \& Technology 43:8847-8853.

Koelmans, A. A., M. Kooi, K. L. Law, and E. van Sebille. 2017. All is not lost: deriving a top-down mass budget of plastic at sea. Environmental Research Letters 12:114028.

Koelmans, A. A., A. Van der Heijde, L. M. Knijff, and R. H. Aalderink. 2001. Integrated modelling of eutrophication and organic contaminant fate \& effects in aquatic ecosystems. A review. Water Research 35:3517-3536.

Kong, X., L. Dong, W. He, Q. Wang, W. M. Mooij, and F. Xu. 2015. Estimation of the long-term nutrient budget and thresholds of regime shift for a large shallow lake in China. Ecological Indicators 52:231-244.

Kong, X., Q. He, B. Yang, W. He, F. Xu, A. B. G. Janssen, J. J. Kuiper, L. P. A. van Gerven, N. Qin, Y. Jiang, W. Liu, C. Yang, Z. Bai, M. Zhang, F. Kong, J. H. Janse, and W. M. Mooij. 2017a. Hydrological regulation drives regime shifts: evidence from paleolimnology and ecosystem modelling of a large shallow Chinese lake. Global Change Biology 23:737-754.

Kong, X., W. He, W. Liu, B. Yang, F. Xu, S. E. Jørgensen, and W. M. Mooij. 2016. Changes in food web structure and ecosystem functioning of a large shallow Chinese lake during 1950s, 1980s and 2000s. Ecological Modelling 319:31-41.

Kong, X., W. He, N. Qin, Q. He, B. Yang, H. Ouyang, Q. Wang, and F. Xu. 2013. Comparison of transport pathways and potential sources of PM10 in two cities around a large Chinese lake using the modified trajectory analysis. Atmospheric Research 122:284-297.

Kong, X., W. He, N. Qin, Q. He, B. Yang, H. Ouyang, Q. Wang, C. Yang, Y. Jiang, and F. Xu. 2014. Modeling the multimedia fate dynamics of $\gamma$-hexachlorocyclohexane in a large Chinese lake. Ecological Indicators 41:65-74.

Kong, X., W. He, N. Qin, W. Liu, B. Yang, C. Yang, F. Xu, W. M. Mooij, and A. A. Koelmans. 2017b. Integrated ecological and chemical food web accumulation modeling explains PAH temporal trends during regime shifts in a shallow lake. Water Research 119:73-82.

Kong, X., W. He, N. Qin, Q. S. He, B. Yang, H. L. Ouyang, Q. M. Wang, C. Yang, Y. J. Jiang, and F. L. Xu. 2012. Simulation of the fate and seasonal variations of alpha-hexachlorocyclohexane in lake Chaohu using a dynamic fugacity model. Scientific World Journal, DOI: 10.1100/2012/691539.

Kuiper, J. J., C. van Altena, P. C. de Ruiter, L. P. A. van Gerven, J. H. Janse, and W. M. Mooij. 2015. Food-web stability signals critical transitions in temperate shallow lakes. Nature Communications:doi 10.1038/ncomms8727.

Kutsuna, S., and H. Hori. 2008. Experimental determination of Henry's law constant of perfluorooctanoic acid (PFOA) at $298 \mathrm{~K}$ by means of an inert-gas stripping method with a helical plate. Atmospheric Environment 42:8883-8892.

Kwadijk, C. J. A. F., P. Korytar, and A. A. Koelmans. 2010. Distribution of Perfluorinated Compounds in Aquatic Systems in The Netherlands. Environmental Science \& Technology 44:3746-3751.

Kwadijk, C. J. A. F., I. Velzeboer, and A. A. Koelmans. 2013. Sorption of perfluorooctane sulfonate to carbon nanotubes in aquatic sediments. Chemosphere 90:1631-1636.

Lang, C., S. Tao, X. Wang, G. Zhang, J. Li, and J. Fu. 2007. Seasonal variation of polycyclic aromatic hydrocarbons (PAHs) in Pearl River Delta region, China. Atmospheric Environment 41:83708379 . 


\section{References}

Lang, C., S. Tao, X. J. Wangj, G. Zhang, and J. M. Fu. 2008. Modeling polycyclic aromatic hydrocarbon composition profiles of sources and receptors in the Pear River Delta, China. Environmental Toxicology and Chemistry 27:4-9.

Larsson, P., A. Andersson, D. Broman, J. Nordbäck, and E. Lundberg. 2000. Persistent organic pollutants (POPs) in pelagic systems. AMBIO: A Journal of the Human Environment 29:202209.

Latała, A., M. Nędzi, and P. Stepnowski. 2009. Acute toxicity assessment of perfluorinated carboxylic acids towards the Baltic microalgae. Environmental Toxicology and Pharmacology 28:167-171.

Lerman, A., D. Imboden, and J. Gat. 1995. Physics and chemistry of lakes. Springer, New York, USA.

Lewis, G. N., and M. Randall. 1961. Thermodynamics/Thermodynamics and the free energy of chemical substances. McGraw-Hill, New York.

Li, C., S. Huo, Z. Yu, B. Xi, X. Zeng, and F. Wu. 2014. Spatial distribution, potential risk assessment, and source apportionment of polycyclic aromatic hydrocarbons (PAHs) in sediments of Lake Chaohu, China. Environmental Science and Pollution Research 21:12028-12039.

Li, W., Y. Shi, L. Gao, J. Liu, and Y. Cai. 2012. Occurrence of antibiotics in water, sediments, aquatic plants, and animals from Baiyangdian Lake in North China. Chemosphere 89:1307-1315.

Li, Y., W. He, W. Liu, X. Kong, B. Yang, C. Yang, and F. Xu. 2015. Influences of binding to dissolved organic matter on hydrophobic organic compounds in a multi-contaminant system: Coefficients, mechanisms and ecological risks. Environmental Pollution 206:461-468.

Li, Y. F., D. J. Cai, Z. J. Shan, and Z. L. Zhu. 2001. Gridded usage inventories of technical hexachlorocyclohexane and lindane for china with $1 / 6$ degrees latitude by $1 / 4$ degrees longitude resolution. Archives of Environmental Contamination and Toxicology 41:261-266.

Li, Y. F., R. W. Macdonald, L. M. M. Jantunen, T. Harner, T. F. Bidleman, and W. M. J. Strachan. 2002. The transport of beta-hexachlorocyclohexane to the western Arctic Ocean: a contrast to alphaHCH. Science of the Total Environment 291:229-246.

Lindstrom, A. B., M. J. Strynar, and E. L. Libelo. 2011. Polyfluorinated compounds: past, present, and future. Environmental Science \& Technology 45:7954-7961.

Ling, H., M. Diamond, and D. Mackay. 1993. Application of the QWASI fugacity/aquivalence model to assessing sources and fate of contaminants in Hamilton Harbour. Journal of Great Lakes Research 19:582-602.

Lischke, B., S. Hilt, J. H. Janse, J. J. Kuiper, T. Mehner, W. M. Mooij, and U. Gaedke. 2014. Enhanced input of terrestrial particulate organic matter reduces the resilience of the clear-water state of shallow lakes: A model study. Ecosystems 17:616-626.

Liu, S., Y. Lu, T. Wang, S. Xie, K. C. Jones, and A. J. Sweetman. 2014. Using gridded multimedia model to simulate spatial fate of Benzo $[\alpha]$ pyrene on regional scale. Environment International 63:53-63.

Liu, S., Y. Lu, S. Xie, T. Wang, K. C. Jones, and A. J. Sweetman. 2015a. Exploring the fate, transport and risk of Perfluorooctane Sulfonate (PFOS) in a coastal region of China using a multimedia model. Environment International 85:15-26.

Liu, W., W. He, N. Qin, X. Kong, Q. He, B. Yang, C. Yang, S. E. Jorgensen, and F. Xu. 2015b. Temporalspatial distributions and ecological risks of perfluoroalkyl acids (PFAAs) in the surface water from the fifth-largest freshwater lake in China (Lake Chaohu). Environmental Pollution 200:24-34.

Liu, W. X., W. He, N. Qin, X. Z. Kong, Q. S. He, H. L. Ouyang, B. Yang, Q. M. Wang, C. Yang, Y. J. Jiang, W. J. Wu, and F. L. Xu. 2012. Residues, distributions, sources, and ecological risks of ocps in the water from Lake Chaohu, China. The Scientific World Journal dx.doi.org/10.1100/2012/897697.

Liu, Z., Y. Lu, P. Wang, T. Wang, S. Liu, A. C. Johnson, A. J. Sweetman, and Y. Baninla. 2017. Pollution pathways and release estimation of perfluorooctane sulfonate (PFOS) and perfluorooctanoic acid (PFOA) in central and eastern China. Science of the Total Environment 580:1247-1256.

Liu, Z., X. Quan, and F. Yang. 2007. Long-term fate of three hexachlorocyclohexanes in the lower reach of Liao River basin: Dynamic mass budgets and pathways. Chemosphere 69:1159-1165. 
Lohmann, R., K. Breivik, J. Dachs, and D. Muir. 2007. Global fate of POPs: current and future research directions. Environmental Pollution 150:150-165.

Lohmann, R., M. Dapsis, E. J. Morgan, V. Dekany, and P. J. Luey. 2011. Determining air- water exchange, spatial and temporal trends of freely dissolved PAHs in an urban estuary using passive polyethylene samplers. Environmental Science \& Technology 45:2655-2662.

Loi, E. I., L. W. Yeung, S. Taniyasu, P. K. Lam, K. Kannan, and N. Yamashita. 2011. Trophic magnification of poly-and perfluorinated compounds in a subtropical food web. Environmental Science \& Technology 45:5506-5513.

Loos, R., G. Locoro, S. Comero, S. Contini, D. Schwesig, F. Werres, P. Balsaa, O. Gans, S. Weiss, and L. Blaha. 2010. Pan-European survey on the occurrence of selected polar organic persistent pollutants in ground water. Water Research 44:4115-4126.

Loverde-Oliveira, S. M., V. L. M. Huszar, N. Mazzeo, and M. Scheffer. 2009. Hydrology-driven regime shifts in a shallow tropical lake. Ecosystems 12:807-819.

Lun, R., K. Lee, L. De Marco, C. Nalewajko, and D. Mackay. 1998. A model of the fate of polycyclic aromatic hydrocarbons in the Saguenay Fjord, Canada. Environmental Toxicology and Chemistry 17:333-341.

MacDonald, D. D., C. G. Ingersoll, and T. Berger. 2000. Development and evaluation of consensus-based sediment quality guidelines for freshwater ecosystems. Archives of Environmental Contamination and Toxicology 39:20-31.

Mackay, D. 1979. Finding fugacity feasible. Environmental Science \& Technology 13:1218-1223.

Mackay, D. 1982. Correlation of bioconcentration factors. Environmental Science \& Technology 16:274278.

Mackay, D. 2001. Multimedia Environmental Models: The Fugacity Approach, second ed. . Lewis Publishers, New York, USA.

Mackay, D., A. Bobra, D. W. Chan, and W. Y. Shiu. 1982. Vapor-pressure correlations for low-volatility environmental chemicals. Environmental Science \& Technology 16:645-649.

Mackay, D., and M. Diamond. 1989. Application of the QWASI (quantitative water air sediment interaction) fugacity model to the dynamics of organic and inorganic chemicals in lakes. Chemosphere 18:1343-1365.

Mackay, D., and A. Fraser. 2000. Bioaccumulation of persistent organic chemicals: mechanisms and models. Environmental Pollution 110:375-391.

Mackay, D., and A. I. Hughes. 1984. 3-parameter equation describing the uptake of organic-compounds by fish. Environmental Science \& Technology 18:439-444.

Mackay, D., M. Joy, and S. Paterson. 1983a. A quantitative water, air, sediment interaction (QWASI) fugacity model for describing the fate of chemicals in lakes. Chemosphere 12:981-997.

Mackay, D., and S. Paterson. 1981. Calculating fugacity. Environmental Science \& Technology 15:10061014.

Mackay, D., and S. Paterson. 1982. Fugacity revisited - the fugacity approach to environmental transport. Environmental Science \& Technology 16:A654-A660.

Mackay, D., and S. Paterson. 1991. Evaluating the multimedia fate of organic-chemicals - a Level-III fugacity model. Environmental Science \& Technology 25:427-436.

Mackay, D., S. Paterson, and M. Joy. 1983b. A quantitative water, air, sediment interaction (QWASI) fugacity model for describing the fate of chemicals in rivers. Chemosphere 12:1193-1208.

Mackay, D., S. Paterson, and W. H. Schroeder. 1986. Model describing the rates of transfer processes of organic-chemicals between atmosphere and water. Environmental Science \& Technology 20:810-816.

Mackay, D., S. Paterson, and W. Y. Shiu. 1992. Generic models for evaluating the regional fate of chemicals. Chemosphere 24:695-717.

Martin, J. W., M. M. Smithwick, B. M. Braune, P. F. Hoekstra, D. C. Muir, and S. A. Mabury. 2004. Identification of long-chain perfluorinated acids in biota from the Canadian Arctic. Environmental Science \& Technology 38:373-380.

MathWorks. 2002. Using MATLAB version 6; The MathWorks, Inc.: Natick, MA, US. 


\section{References}

Matozzo, V., A. Binelli, M. Parolini, M. Previato, L. Masiero, L. Finos, M. Bressan, and M. G. Marin. 2012. Biomarker responses in the clam Ruditapes philippinarum and contamination levels in sediments from seaward and landward sites in the Lagoon of Venice. Ecological Indicators 19:191-205.

McKone, T. E. 1996. Alternative modeling approaches for contaminant fate in soils: uncertainty, variability, and reliability. Reliability Engineering \& System Safety 54:165-181.

McKone, T. E., and R. L. Maddalena. 2007. Plant uptake of organic pollutants from soil: Bioconcentration estimates based on models and experiments. Environmental Toxicology and Chemistry 26:2494-2504.

McMurdo, C. J., D. A. Ellis, E. Webster, J. Butler, R. D. Christensen, and L. K. Reid. 2008. Aerosol enrichment of the surfactant PFO and mediation of the water-air transport of gaseous PFOA. Environmental Science \& Technology 42:3969-3974.

Meijer, S. N., J. O. Grimalt, P. Fernandez, and J. Dachs. 2009. Seasonal fluxes and temperaturedependent accumulation of persistent organic pollutants in lakes: The role of internal biogeochemical cycling. Environmental Pollution 157:1815-1822.

Millennium Ecosystem Assessment. 2005. Synthesis Report. Island, Washington, DC.

Moermond, C. T. A., T. P. Traas, I. Roessink, K. Veltman, A. J. Hendriks, and A. A. Koelmans. 2007. Modeling decreased food chain accumulation of PAHs due to strong sorption to carhonaceous materials and metabolic transformation. Environmental Science \& Technology 41:6185-6191.

Moermond, C. T. A., J. J. G. Zwolsman, and A. A. Koelmans. 2005. Black carbon and ecological factors affect in situ biota to sediment accumulation factors for hydrophobic organic compounds in flood plain lakes. Environmental Science \& Technology 39:3101-3109.

Mooij, W. M., L. N. D. Domis, and J. H. Janse. 2009. Linking species- and ecosystem-level impacts of climate change in lakes with a complex and a minimal model. Ecological Modelling 220:30113020.

Mooij, W. M., J. H. Janse, L. Domis, S. Hulsmann, and B. W. Ibelings. 2007. Predicting the effect of climate change on temperate shallow lakes with the ecosystem model PCLake. Hydrobiologia 584:443-454.

Mooij, W. M., D. Trolle, E. Jeppesen, G. Arhonditsis, P. V. Belolipetsky, D. B. R. Chitamwebwa, A. G. Degermendzhy, D. L. DeAngelis, L. N. D. Domis, A. S. Downing, J. A. Elliott, C. R. Fragoso, U. Gaedke, S. N. Genova, R. D. Gulati, L. Hakanson, D. P. Hamilton, M. R. Hipsey, J. t Hoen, S. Hulsmann, F. H. Los, V. Makler-Pick, T. Petzoldt, I. G. Prokopkin, K. Rinke, S. A. Schep, K. Tominaga, A. A. Van Dam, E. H. Van Nes, S. A. Wells, and J. H. Janse. 2010. Challenges and opportunities for integrating lake ecosystem modelling approaches. Aquatic Ecology 44:633667.

Morris, M. D. 1991. Factorial sampling plans for preliminary computational experiments. Technometrics 33:161-174.

Naile, J. E., J. S. Khim, T. Wang, C. Chen, W. Luo, B.-O. Kwon, J. Park, C.-H. Koh, P. D. Jones, and Y. Lu. 2010. Perfluorinated compounds in water, sediment, soil and biota from estuarine and coastal areas of Korea. Environmental Pollution 158:1237-1244.

Nielsen, A., K. Bolding, F. Hu, and D. Trolle. 2017. An open source QGIS-based workflow for model application and experimentation with aquatic ecosystems. Environmental Modelling \& Software 95:358-364.

Nielsen, A., D. Trolle, R. Bjerring, M. Søndergaard, J. E. Olesen, J. H. Janse, W. M. Mooij, and E. Jeppesen. 2014. Effects of climate and nutrient load on the water quality of shallow lakes assessed through ensemble runs by PCLake. Ecological Applications 24:1926-1944.

Nizzetto, L., R. Gioia, J. Li, K. Borga, F. Pomati, R. Bettinetti, J. Dachs, and K. C. Jones. 2012. Biological pump control of the fate and distribution of hydrophobic organic pollutants in water and plankton. Environmental Science \& Technology 46:3204-3211. 
Odabasi, M., B. Cetin, E. Demircioglu, and A. Sofuoglu. 2008. Air-water exchange of polychlorinated biphenyls (PCBs) and organochlorine pesticides (OCPs) at a coastal site in Izmir Bay, Turkey. Marine Chemistry 109:115-129.

Ouyang, H. L., W. He, N. Qin, X.-Z. Kong, W.-X. Liu, Q.-S. He, Y.-J. Jiang, Q.-M. Wang, C. Yang, B. Yang, and F.-L. Xu. 2012. Levels, temporal-spatial variations and sources of organochlorine pesticides in ambient air of Lake Chaohu, China. The Scientific World Journal dx.doi.org/10.1100/2012/504576.

Paasivirta, J., S. Sinkkonen, P. Mikkelson, T. Rantio, and F. Wania. 1999. Estimation of vapor pressures, solubilities and Henry's law constants of selected persistent organic pollutants as functions of temperature. Chemosphere 39:811-832.

Parajulee, A., and F. Wania. 2014. Evaluating officially reported polycyclic aromatic hydrocarbon emissions in the Athabasca oil sands region with a multimedia fate model. Proceedings of the National Academy of Sciences of the United States of America 111:3344-3349.

Park, R. A., J. S. Clough, and M. C. Wellman. 2008. AQUATOX: Modeling environmental fate and ecological effects in aquatic ecosystems. Ecological Modelling 213:1-15.

Paterson, S., D. Mackay, and A. Gladman. 1991. A fugacity model of chemical uptake by plants from soil and air. Chemosphere 23:539-565.

Paterson, S., D. Mackay, and C. McFarlane. 1994. A model of organic-chemical uptake by plants from soil and the atmosphere. Environmental Science \& Technology 28:2259-2266.

Paterson, S., D. Mackay, D. Tam, and W. Shiu. 1990. Uptake of organic chemicals by plants: A review of processes, correlations and models. Chemosphere 21:297-331.

Prevedouros, K., E. Brorström-Lundén, C. J. Halsall, K. C. Jones, R. G. Lee, and A. J. Sweetman. 2004. Seasonal and long-term trends in atmospheric PAH concentrations: evidence and implications. Environmental Pollution 128:17-27.

Prevedouros, K., I. T. Cousins, R. C. Buck, and S. H. Korzeniowski. 2006. Sources, fate and transport of perfluorocarboxylates. Environmental Science \& Technology 40:32-44.

Prokopkin, I. G., W. M. Mooij, J. H. Janse, and A. G. Degermendzhy. 2010. A general one-dimensional vertical ecosystem model of Lake Shira (Russia, Khakasia): description, parametrization and analysis. Aquatic Ecology 44:585-618.

Qin, N., W. He, X. Kong, W. Liu, Q. He, B. Yang, H. Ouyang, Q. Wang, and F. Xu. 2013a. Atmospheric partitioning and the air-water exchange of polycyclic aromatic hydrocarbons in a large shallow Chinese lake (Lake Chaohu). Chemosphere 93:1685-1693.

Qin, N., W. He, X. Kong, W. Liu, Q. He, B. Yang, H. Ouyang, Q. Wang, and F. Xu. 2013b. Ecological risk assessment of polycyclic aromatic hydrocarbons (PAHs) in the water from a large Chinese lake based on multiple indicators. Ecological Indicators 24:599-608.

Qin, N., W. He, X. Kong, W. Liu, Q. He, B. Yang, Q. Wang, C. Yang, Y. Jiang, and S. E. Jorgensen. 2014. Distribution, partitioning and sources of polycyclic aromatic hydrocarbons in the waterSPM-sediment system of Lake Chaohu, China. Science of the Total Environment 496:414-423.

Qin, N., W. He, Y. Wang, Q. He, X. Kong, H. Ouyang, and F. Xu. 2013c. Residues and health risk of polycyclic aromatic hydrocarbons in the water and aquatic products from Lake Chaohu. Acta Scientiae Circumstantiae 33:230-239 (in Chinese).

Qin, N., X. Kong, Y. Zhu, W. He, Q. He, B. Yang, H. Ouyang, W. Liu, Q. Wang, and F. Xu. 2012. Distributions, sources, and backward trajectories of atmospheric polycyclic aromatic hydrocarbons at Lake Small Baiyangdian, Northern China. The Scientific World Journal dx.doi.org/10.1100/2012/416321.

Qiu, X. H., T. Zhu, F. Wang, and J. X. Hu. 2008. Air-water gas exchange of organochlorine pesticides in Taihu Lake, China. Environmental Science \& Technology 42:1928-1932.

Qu, C. S., W. Chen, J. Bi, L. Huang, and F. Y. Li. 2011. Ecological risk assessment of pesticide residues in Taihu Lake wetland, China. Ecological Modelling 222:287-292.

Quik, J. T., J. J. de Klein, and A. A. Koelmans. 2015. Spatially explicit fate modelling of nanomaterials in natural waters. Water Research 80:200-208. 


\section{References}

Quinete, N., Q. Wu, T. Zhang, S. H. Yun, I. Moreira, and K. Kannan. 2009. Specific profiles of perfluorinated compounds in surface and drinking waters and accumulation in mussels, fish, and dolphins from southeastern Brazil. Chemosphere 77:863-869.

Randsalu-Wendrup, L., D. J. Conley, J. Carstensen, L.-A. Hansson, C. Brönmark, S. C. Fritz, P. Choudhary, J. Routh, and D. Hammarlund. 2014. Combining limnology and palaeolimnology to investigate recent regime shifts in a shallow, eutrophic lake. Journal of Paleolimnology 51:437-448.

Ren, C., Y. Wu, S. Zhang, L. Wu, X. Liang, T. Chen, C. Zhu, S. O. Sojinu, and J. Wang. 2015. PAHs in sediment cores at main river estuaries of Chaohu Lake: implication for the change of local anthropogenic activities. Environmental Science and Pollution Research 22:1687-1696.

Ridal, J. J., B. Kerman, L. Durham, and M. E. Fox. 1996. Seasonality of air-water fluxes of hexachlorocyclohexanes in Lake Ontario. Environmental Science \& Technology 30:852-858.

Rockström, J., W. Steffen, K. Noone, Å. Persson, F. S. Chapin, E. F. Lambin, T. M. Lenton, M. Scheffer, C. Folke, and H. J. Schellnhuber. 2009. A safe operating space for humanity. Nature 461:472-475.

Roessink, I., A. A. Koelmans, and T. C. M. Brock. 2008. Interactions between nutrients and organic micro-pollutants in shallow freshwater model ecosystems. Science of the Total Environment 406:436-442.

Roessink, I., C. T. A. Moermond, F. Gillissen, and A. A. Koelmans. 2010. Impacts of manipulated regime shifts in shallow lake model ecosystems on the fate of hydrophobic organic compounds. Water Research 44:6153-6163.

Rohr, J. R., J. L. Kerby, and A. Sih. 2006. Community ecology as a framework for predicting contaminant effects. Trends in Ecology \& Evolution 21:606-613.

Saloranta, T. M., J. M. Armitage, H. Haario, K. Naes, I. T. Cousins, and D. N. Barton. 2008. Modeling the effects and uncertainties of contaminated sediment remediation scenarios in a Norwegian Fjord by Markov chain Monte Carlo simulation. Environmental Science \& Technology 42:200206.

Saltelli, A., S. Tarantola, and F. Campolongo. 2000. Sensitivity analysis as an ingredient of modeling. Statistical Science:377-395.

Sayer, C. D., T. A. Davidson, J. I. Jones, and P. G. Langdon. 2010. Combining contemporary ecology and palaeolimnology to understand shallow lake ecosystem change. Freshwater Biology 55:487499.

Sayer, C. D., D. J. Hoare, G. L. Simpson, A. C. Henderson, E. R. Liptrot, M. J. Jackson, P. G. Appleby, J. F. Boyle, J. I. Jones, and M. J. Waldock. 2006. TBT causes regime shift in shallow lakes. Environmental Science \& Technology 40:5269-5275.

Scheffer, M. 2004. Ecology of shallow lakes. Kluwer Academic Publisher, London, UK.

Scheffer, M., S. Barrett, S. Carpenter, C. Folke, A. J. Green, M. Holmgren, T. Hughes, S. Kosten, I. van de Leemput, and D. Nepstad. 2015. Creating a safe operating space for iconic ecosystems. Science 347:1317-1319.

Scheffer, M., S. Carpenter, J. A. Foley, C. Folke, and B. Walker. 2001a. Catastrophic shifts in ecosystems. Nature 413:591-596.

Scheffer, M., and S. R. Carpenter. 2003. Catastrophic regime shifts in ecosystems: linking theory to observation. Trends in Ecology \& Evolution 18:648-656.

Scheffer, M., S. H. Hosper, M. L. Meijer, B. Moss, and E. Jeppesen. 1993. Alternative equilibria in shallow lakes. Trends in Ecology \& Evolution 8:275-279.

Scheffer, M., and E. Jeppesen. 2007. Regime shifts in shallow lakes. Ecosystems 10:1-3.

Scheffer, M., D. Straile, E. H. van Nes, and H. Hosper. 2001b. Climatic warming causes regime shifts in lake food webs. Limnology and Oceanography 46:1780-1783.

Scheffer, M., and E. H. van Nes. 2007. Shallow lakes theory revisited: various alternative regimes driven by climate, nutrients, depth and lake size. Hydrobiologia 584:455-466.

Schenker, U., M. Scheringer, M. D. Sohn, R. L. Maddalena, T. E. McKone, and K. Hungerbuhler. 2009. Using information on uncertainty to improve environmental fate modeling: A case study on DDT. Environmental Science \& Technology 43:128-134. 
Schneider, S. C., and L. Nizzetto. 2012. Bioconcentration and intracellular storage of hexachlorobenzene in charophytes and their potential role in monitoring and remediation actions. Environmental Science \& Technology 46:12427-12434.

Schooler, S. S., B. Salau, M. H. Julien, and A. R. Ives. 2011. Alternative stable states explain unpredictable biological control of Salvinia molesta in Kakadu. Nature 470:86-89.

Schwarzenbach, R. P., B. I. Escher, K. Fenner, T. B. Hofstetter, C. A. Johnson, U. Von Gunten, and B. Wehrli. 2006. The challenge of micropollutants in aquatic systems. Science 313:1072-1077.

SCPOPs. 2009. Stockholm Convention on Persistent Organic Pollutants C.N.524.2009.TREATIES-4 (Depositary Notification). http://chm.pops.int/Portals/0/download.aspx?d=UNEP-POPS-COPCONVTEXT-2009.En.pdf.

Selck, H., K. Drouillard, K. Eisenreich, A. A. Koelmans, A. Palmqvist, A. Ruus, D. Salvito, I. Schultz, R. Stewart, A. Weisbrod, N. W. van den Brink, and M. van den Heuvel-Greve. 2012. Explaining differences between bioaccumulation measurements in laboratory and field data through use of a probabilistic modeling approach. Integrated Environmental Assessment and Management 8:42-63.

Sharpe, S., and D. Mackay. 2000. A framework for evaluating bioaccumulation in food webs. Environmental Science \& Technology 34:2373-2379.

Shen, H., Y. Huang, R. Wang, D. Zhu, W. Li, G. Shen, B. Wang, Y. Zhang, Y. Chen, and Y. Lu. 2013. Global atmospheric emissions of polycyclic aromatic hydrocarbons from 1960 to 2008 and future predictions. Environmental Science \& Technology 47:6415-6424.

Skei, J., P. Larsson, R. Rosenberg, P. Jonsson, M. Olsson, and D. Broman. 2000. Eutrophication and contaminants in aquatic ecosystems. AMBIO: A Journal of the Human Environment 29:184194.

Skoglund, R. S., K. Stange, and D. L. Swackhamer. 1996. A kinetics model for predicting the accumulation of PCBs in phytoplankton. Environmental Science \& Technology 30:2113-2120.

Smol, J. P. 1990. Are we building enough bridges between paleolimnology and aquatic ecology? Pages 201-206 Environmental History and Palaeolimnology. Springer.

Smol, J. P., A. P. Wolfe, H. J. B. Birks, M. S. Douglas, V. J. Jones, A. Korhola, R. Pienitz, K. Rühland, S. Sorvari, and D. Antoniades. 2005. Climate-driven regime shifts in the biological communities of arctic lakes. Proceedings of the National Academy of Sciences of the United States of America 102:4397-4402.

Southworth, G. R. 1979. Role of volatilization in removing polycyclic aromatic hydrocarbons from aquatic environments. Bulletin of Environmental Contamination and Toxicology 21:507-514.

Stansfield, J., B. Moss, and K. Irvine. 1989. The loss of submerged plants with eutrophication III. Potential role of organochlorine pesticides: a palaeoecological study. Freshwater Biology 22:109-132.

Steffen, W., K. Richardson, J. Rockström, S. E. Cornell, I. Fetzer, E. M. Bennett, R. Biggs, S. R. Carpenter, W. de Vries, and C. A. de Wit. 2015. Planetary boundaries: Guiding human development on a changing planet. Science 347:1259855.

Tao, S., H. Cao, W. Liu, B. Li, J. Cao, F. Xu, X. Wang, R. M. Coveney, W. Shen, B. Qin, and R. Sun. 2003. Fate modeling of phenanthrene with regional variation in Tianjin, China. Environmental Science \& Technology 37:2453-2459.

Tao, S., J. Cao, W. Wang, J. Zhao, W. Wang, Z. Wang, H. Cao, and B. Xing. 2009. A passive sampler with improved performance for collecting gaseous and particulate phase polycyclic aromatic hydrocarbons in air. Environmental Science \& Technology 43:4124-4129.

Tao, S., W. X. Liu, Y. Li, Y. Yang, Q. Zuo, B. G. Li, and J. Cao. 2008. Organochlorine Pesticides Contaminated Surface Soil As Reemission Source in the Haihe Plain, China. Environmental Science \& Technology 42:8395-8400.

Tao, S., Y. Yang, H. Y. Cao, W. X. Liu, R. M. Coveney, F. L. Xu, J. Cao, B. G. Li, X. J. Wang, J. Y. Hua, and J. Y. Fang. 2006. Modeling the dynamic changes in concentrations of $\gamma$-hexachlorocyclohexane $(\gamma-$ $\mathrm{HCH}$ ) in Tianjin region from 1953 to 2020 . Environmental Pollution 139:183-193. 


\section{References}

Tao, Y., B. Xue, and S. Yao. 2015. Using linoleic Acid embedded cellulose acetate membranes to in situ monitor polycyclic aromatic hydrocarbons in lakes and predict their bioavailability to submerged macrophytes. Environmental Science \& Technology 49:6077-6084.

Tao, Y., J. Yu, G. Lei, B. Xue, F. Zhang, and S. Yao. 2017. Indirect influence of eutrophication on airwater exchange fluxes, sinking fluxes, and occurrence of polycyclic aromatic hydrocarbons. Water Research 122:512-525.

Thomas, G., A. J. Sweetman, W. A. Ockenden, D. Mackay, and K. C. Jones. 1998. Air-pasture transfer of PCBs. Environmental Science \& Technology 32:936-942.

Tong, Y., W. Zhang, C. Chen, L. Chen, W. Wang, X. Hu, H. Wang, D. Hu, L. Ou, and X. Wang. 2014. Fate modeling of mercury species and fluxes estimation in an urban river. Environmental Pollution 184:54-61.

Trolle, D., J. A. Elliott, W. M. Mooij, J. H. Janse, K. Bolding, D. P. Hamilton, and E. Jeppesen. 2014. Advancing projections of phytoplankton responses to climate change through ensemble modelling. Environmental Modelling \& Software 61:371-379.

Tu, Q. Y., D. X. Gu, C. Q. Yi, Z. R. Xu, and G. Z. Han. 1990. The Researches on the Lake Chaohu Eutrophication. . Publisher of University of Science and Technology of China, Hefei (in Chinese).

van Geest, G. J., H. Coops, M. Scheffer, and E. H. van Nes. 2007. Long transients near the ghost of a stable state in eutrophic shallow lakes with fluctuating water levels. Ecosystems 10:36-46.

Van Gerven, L. P. A., J. J. Kuiper, J. H. Janse, A. B. G. Janssen, M. Jeuken, W. M. Mooij, and J. J. De Klein. 2017. How Regime Shifts in Connected Aquatic Ecosystems Are Affected by the Typical Downstream Increase of Water Flow. Ecosystems 20:733-744.

van Puijenbroek, P., J. H. Janse, and J. M. Knoop. 2004. Integrated modelling for nutrient loading and ecology of lakes in The Netherlands. Ecological Modelling 174:127-141.

Vijgen, J., P. C. Abhilash, Y. F. Li, R. Lal, M. Forter, J. Torres, N. Singh, M. Yunus, C. G. Tian, A. Schaffer, and R. Weber. 2011. Hexachlorocyclohexane $(\mathrm{HCH})$ as new Stockholm Convention POPs-a global perspective on the management of Lindane and its waste isomers. Environmental Science and Pollution Research 18:152-162.

Waliszewski, S. M. 1993. RESIDUES OF LINDANE, HCH ISOMERS AND HCB IN THE SOIL AFTER LINDANE APPLICATION. Environmental Pollution 82:289-293.

Walker, K., D. A. Vallero, and R. G. Lewis. 1999. Factors influencing the distribution of lindane and other hexachlorocyclohexanes in the environment. Environmental Science \& Technology 33:4373-4378.

Wan, Y., X. Jin, J. Hu, and F. Jin. 2007. Trophic dilution of polycyclic aromatic hydrocarbons (PAHs) in a marine food web from Bohai Bay, North China. Environmental Science \& Technology 41:3109-3114.

Wang, C., Y. Feng, Q. Sun, S. Zhao, P. Gao, and B.-L. Li. 2012a. A multimedia fate model to evaluate the fate of PAHs in Songhua River, China. Environmental Pollution 164:81-88.

Wang, F., and K. Shih. 2011. Adsorption of perfluorooctanesulfonate (PFOS) and perfluorooctanoate (PFOA) on alumina: influence of solution $\mathrm{pH}$ and cations. Water Research 45:2925-2930.

Wang, R., H. Y. Cao, W. Li, W. Wang, W. T. Wang, L. W. Zhang, J. M. Liu, H. Ouyang, and S. Tao. 2011a. Spatial and seasonal variations of polycyclic aromatic hydrocarbons in Haihe Plain, China. Environmental Pollution 159:1413-1418.

Wang, R., J. A. Dearing, P. G. Langdon, E. Zhang, X. Yang, V. Dakos, and M. Scheffer. 2012b. Flickering gives early warning signals of a critical transition to a eutrophic lake state. Nature 492:419-422.

Wang, R., G. Liu, C. Chou, J. Liu, and J. Zhang. 2010. Environmental assessment of PAHs in soils around the Anhui Coal District, China. Archives of Environmental Contamination and Toxicology 59:62-70.

Wang, R., S. Tao, H. Shen, Y. Huang, H. Chen, Y. Balkanski, O. Boucher, P. Ciais, G. Shen, and W. Li. 2014. Time trend of global black carbon emissions from 1960 to 2007. Environmental Science \& Technology 48:6780-6787. 
References

Wang, R., S. Tao, B. Wang, Y. Yang, C. Lang, Y. Zhang, J. Hu, J. Ma, and H. Hung. 2009. Sources and pathways of polycyclic aromatic hydrocarbons transported to Alert, the Canadian High Arctic. Environmental Science \& Technology 44:1017-1022.

Wang, T., P. Wang, J. Meng, S. Liu, Y. Lu, J. S. Khim, and J. P. Giesy. 2015. A review of sources, multimedia distribution and health risks of perfluoroalkyl acids (PFAAs) in China. Chemosphere 129:87-99.

Wang, X., R. Hua, J. Pan, Q. Gao, X. Li, H. Cao, X. Wu, and J. Tang. 2011b. Distribution and composition of organochlorine pesticides in farmland top soils of Anhui Province. Chinese Journal of Applied Ecology 22:3285-3292.

Wang, X. L., S. Tao, F. L. Xu, R. W. Dawson, J. Cao, B. G. Li, and J. Y. Fang. 2002. Modeling the fate of benzo a pyrene in the wastewater-irrigated areas of Tianjin with a fugacity model. Journal of Environmental Quality 31:896-903.

Wang, Y., W. He, N. Qin, and Q. S. He. 2012c. Residual levels and ecological risks of organochlorine pesticides in surface sediments from Lake Chaohu. Acta Scientiae Circumstantiae 32:308-316 (in Chinese).

Wang, Y., W. Wu, W. He, N. Qin, Q. He, and F. Xu. 2013. Residues and ecological risks of organochlorine pesticides in Lake Small Baiyangdian, North China. Environmental Monitoring and Assessment 185:917-929.

Wania, F., K. Breivik, N. J. Persson, and M. S. McLachlan. 2006. CoZMo-POP 2 - A fugacity-based dynamic multi-compartmental mass balance model of the fate of persistent organic pollutants. Environmental Modelling \& Software 21:868-884.

Wania, F., and D. Mackay. 1995. A global distribution model for persistent organic-chemicals. Science of the Total Environment 160-61:211-232.

Woodfine, D. G., R. Seth, D. Mackay, and M. Havas. 2000. Simulating the response of metal contaminated lakes to reductions in atmospheric loading using a modified QWASI model. Chemosphere 41:1377-1388.

Wu, N., T. Herrmann, O. Paepke, J. Tickner, R. Hale, E. Harvey, M. La Guardia, M. D. McClean, and T. F. Webster. 2007. Human exposure to PBDEs: associations of PBDE body burdens with food consumption and house dust concentrations. Environmental Science \& Technology 41:15841589.

Xia, H. S., Y. D. Yue, and X. Y. Du. 1987. Residues of HCHs in soil of Anhui tea plant regions. Journal of Tea Business 3:30-33.

Xia, X., P. K. Hopke, T. M. Holsen, and B. S. Crimmins. 2011. Modeling toxaphene behavior in the Great Lakes. Science of the Total Environment 409:792-799.

Xie, P. 2009. Reading about the histories of cyanobacteria, eutrophication and geological evolution in Lake Chaohu. Science Press, Beijing (in Chinese).

Xie, S., Y. Lu, T. Wang, S. Liu, K. Jones, and A. Sweetman. 2013a. Estimation of PFOS emission from domestic sources in the eastern coastal region of China. Environment International 59:336-343.

Xie, S., T. Wang, S. Liu, K. C. Jones, A. J. Sweetman, and Y. Lu. 2013b. Industrial source identification and emission estimation of perfluorooctane sulfonate in China. Environment International 52:1-8.

Xu, F., Y. Li, Y. Wang, W. He, X. Kong, N. Qin, W. Liu, W. Wu, and S. E. Jorgensen. 2015. Key issues for the development and application of the species sensitivity distribution (SSD) model for ecological risk assessment. Ecological Indicators 54:227-237.

Xu, F., N. Qin, Y. Zhu, W. He, X. Kong, M. T. Barbour, Q. He, Y. Wang, H. Ouyang, and S. Tao. 2013. Multimedia fate modeling of polycyclic aromatic hydrocarbons (PAHs) in Lake Small Baiyangdian, Northern China. Ecological Modelling 252:246-257.

Xu, F., Z. Yang, B. Chen, and Y. Zhao. 2011a. Ecosystem health assessment of the plant-dominated Baiyangdian Lake based on eco-exergy. Ecological Modelling 222:201-209.

Xu, F. L., S. E. Jorgensen, S. Tao, and B. G. Li. 1999a. Modeling the effects of ecological engineering on ecosystem health of a shallow eutrophic Chinese lake (Lake Chao). Ecological Modelling 117:239-260. 


\section{References}

Xu, F. L., N. Qin, Y. Zhu, W. He, X. Z. Kong, M. T. Barbour, Q. S. He, Y. Wang, H. L. OUyang, and S. Tao. 2012. Multimedia fate modeling of polycyclic aromatic hydrocarbons (PAHs) in Lake Small Baiyangdian, Northern China. Ecological Modelling 252:246-257.

Xu, F. L., S. Tao, and Z. R. Xu. 1999b. The restoration of riparian wetlands and macrophytes in Lake Chao, an eutrophic Chinese lake: possibilities and effects. Hydrobiologia 405:169-178.

Xu, F. L., W. J. Wu, J. J. Wang, N. Qin, Y. Wang, Q. S. He, W. He, and S. Tao. 2011b. Residual levels and health risk of polycyclic aromatic hydrocarbons in freshwater fishes from Lake Small BaiYang-Dian, Northern China. Ecological Modelling 222:275-286.

Xu, S., W. Liu, and S. Tao. 2006. Emission of polycyclic aromatic hydrocarbons in China. Environmental Science \& Technology 40:702-708.

Yang, B., Y.-J. Jiang, W. He, W.-X. Liu, X.-Z. Kong, S. E. Jørgensen, and F.-L. Xu. 2016. The tempo-spatial variations of phytoplankton diversities and their correlation with trophic state levels in a large eutrophic Chinese lake. Ecological Indicators 66:153-162.

Yang, L., L. Zhu, and Z. Liu. 2011. Occurrence and partition of perfluorinated compounds in water and sediment from Liao River and Taihu Lake, China. Chemosphere 83:806-814.

Yue, Y. D., R. M. Hua, L. Z. Zhu, S. W. Zhu, and D. D. Chen. 1990. Residual form and level of BHC and DDT in argoenvironment of Anhui. Journal of Anhui Agricultural College 17:194-197.

Zareitalabad, P., J. Siemens, M. Hamer, and W. Amelung. 2013. Perfluorooctanoic acid (PFOA) and perfluorooctanesulfonic acid (PFOS) in surface waters, sediments, soils and wastewater-a review on concentrations and distribution coefficients. Chemosphere 91:725-732.

Zhang, K., J. A. Dearing, T. P. Dawson, X. Dong, X. Yang, and W. Zhang. 2015a. Poverty alleviation strategies in eastern China lead to critical ecological dynamics. Science of the Total Environment 506:164-181.

Zhang, M., C. Xie, L. A. Hansson, W. Hu, and J. Che. 2012. Trophic level changes of fishery catches in Lake Chaohu, Anhui Province, China: Trends and causes. Fisheries research 131:15-20.

Zhang, T. F., and X. P. Lu. 1986. Investigation and evaluation of water environmental quality of Lake Chaohu. Hefei.

Zhang, Y., H. Dou, B. Chang, Z. Wei, W. Qiu, S. Liu, W. Liu, and S. Tao. 2008. Emission of polycyclic aromatic hydrocarbons from indoor straw burning and emission inventory updating in China. Annals of the New York Academy of Sciences 1140:218-227.

Zhang, Y., R. Ma, M. Zhang, H. Duan, S. Loiselle, and J. Xu. 2015b. Fourteen-year record (2000-2013) of the spatial and temporal dynamics of floating algae blooms in lake chaohu, observed from time series of modis images. Remote Sensing 7:10523-10542.

Zhang, Y., and S. Tao. 2009. Global atmospheric emission inventory of polycyclic aromatic hydrocarbons (PAHs) for 2004. Atmospheric Environment 43:812-819.

Zhang, Y., S. Tao, J. Cao, and R. M. Coveney, Jr. 2007. Emission of polycyclic aromatic hydrocarbons in China by county. Environmental Science \& Technology 41:683-687.

Zhang, Y., S. Tao, H. Shen, and J. Ma. 2009. Inhalation exposure to ambient polycyclic aromatic hydrocarbons and lung cancer risk of Chinese population. Proceedings of the National Academy of Sciences of the United States of America 106:21063-21067.

Zheng, X. Y., D. Z. Chen, X. D. Liu, Q. F. Zhou, Y. Liu, W. Yang, and G. B. Jiang. 2010. Spatial and seasonal variations of organochlorine compounds in air on an urban-rural transect across Tianjin, China. Chemosphere 78:92-98.

Zhu, Y., S. Tao, O. R. Price, H. Shen, K. C. Jones, and A. J. Sweetman. 2015. Environmental distributions of benzo [a] pyrene $(\mathrm{BaP})$ in China: Current and future emission reduction scenarios explored using a spatially explicit multi-media fate model. Environmental Science \& Technology.

Zhu, Y., W. Wu, J. Wang, N. Qin, Y. Wang, Y. Wang, Q. He, and F. Xu. 2009. Distribution, sources and ecological risks of polycyclic aromatic hydrocarbons in water-sediment system in Lake Small Baiyangdian. Journal of Lake Science 21:44-53. 
Summary

\section{Summary}

Freshwater ecosystems in highly populated areas suffer from graduate or abrupt ecological changes during eutrophication and increasing contamination of toxic hydrophobic organic compounds (HOCs), which are among the key issues for scientific research and aquatic ecosystem management. This is particularly the case for many shallow lakes in China. The behavior of HOCs in aquatic ecosystems is largely associated with the biogeochemical cycle of carbon and the dynamics of primary producers. Consequently, the changes in ecological structure due to the eutrophication will alter the fate, transport and transformation of HOCs in the lake environment. Understanding the behavior of HOCs in aquatic ecosystems under distinct nutrient loading and in specific ecological states is therefore a prerequisite for ecological and human health risk assessment, which in turn may inform management and policy.

For the issue above, integrating ecosystem and contaminant fate models are required to obtain accurate prognoses. However, such integrated modeling tools are still limited in both model availability and completeness of process description. To this end, an integrated contaminant and ecological model has been developed in this thesis. The model is composed of one contaminant fate module (CF), one food web accumulation module (FW) and one ecological module (EM). To test our model, abundant field observations have been collected for three groups of HOCs with prior attention, i.e. hexachlorocyclohexanes $(\mathrm{HCHs})$, polycyclic aromatic hydrocarbons (PAHs) and Per- and polyfluoroalkyl substances (PFASs), in multiple media (gaseous, aerosol particles, dissolved phase in water, suspended solids, sediment pore water, sediment solids) from two Chinese shallow lakes that are currently in distinct ecological states, i.e., Lake Small Baiyangdian (clear state) and Lake Chaohu (turbid state). Fate, transport and bioaccumulation of the HOCs in the two lakes, as well as the impact of regime shifts in Lake Chaohu on PAHs distributions over the last several decades, have been explicitly investigated using the modeling tool.

In Chapter 2, a basic version of the model including the CF module and a simplified FW module has been developed. The model was applied to characterize the fate of fifteen priority PAHs in Lake Small Baiyangdian, a typical macrophyte-dominated shallow lake. The PAH concentrations in the air (air, particulates), water (water, suspended solids, plants and fishes) and sediment (water and solids) as well as the transfer fluxes between adjacent compartments were derived under the steady-state (Level III). For most PAHs, 
the model simulation showed good agreement to the measured data, with differences within one order of magnitude. Sensitivity analysis revealed that temperature was the most influential parameter for the model, and that the model sensitivity increase from low- to middle- and high-molecular-weight PAHs, which were considered as the source contributing to the model uncertainty. The model further unraveled that the net transfer directions of PAHs were from air to water and subsequently to sediment, indicating the sediment as the major sink for the contaminants. In addition, we observed that the average bioaccumulation flux of PAHs by aquatic plants was four times higher than that by other biological components such as fish, which implies the predominant role of the macrophytes in driving the cycling of HOCs in shallow lake ecosystems. This motivated us to further investigate the PAHs in the other lake (Lake Chaohu) in which the macrophytes are absent due to eutrophication (Chapter 6).

In Chapter 3, seasonal variations of $\alpha$-hexachlorocyclohexane $(\alpha-\mathrm{HCH})$, one of the HCHs isomer, in a typical phytoplankton-dominated shallow lake (Lake Chaohu) were simulated using a level-IV fugacity model developed based on the model in Chapter 2. We collected monthly data over one year, and we observed good agreement in seasonal dynamics between calculated and measured values except for suspended solids (SS) in the water column, which might be due to the missing sorption process of plankton components that were in fact included in SS samples. In addition, sensitivity analysis was conducted for both stable and dynamic parameters. We found a higher sensitivity of parameters related to input and degradation processes, because the major source of $\alpha-\mathrm{HCH}$ was input from atmospheric advection, while the major environmental outputs were atmospheric advection and sediment degradation. We further concluded that temperature variation was the predominant factor in driving the dynamics of the $\alpha-\mathrm{HCH}$ in different compartments of the lake. Uncertainty of the dynamic model simulations was evaluated using basic Monte Carlo simulations, where we found relatively large model uncertainty as simulations in some compartments may span up to one order of magnitude.

In Chapter 4, we applied the level IV contaminant fate model above (with slight modification in structure) to simulate both long-term inter-year dynamics (1984-2020) and intra-year seasonal variation of $\gamma$-Hexachlorocyclohexane $(\gamma-\mathrm{HCH}$, another $\mathrm{HCH}$ isomer) in various environmental media in Lake Chaohu. Data for $\gamma-\mathrm{HCH}$ were available from a one-year sampling, while limited records for water and fish were also collected back to the 1980s. Modelled data were generally consistent with the observations in both longand short- simulations. For uncertainty analysis, both basic Monte Carlo and a 
Summary

more advanced algorithm, the Bayesian Markov Chain Monte Carlo (MCMC) method, were undertaken and the results were compared. Results from the basic Monte Carlo method showed that the dispersion for each media were less than two orders of magnitude, but remain unacceptable for accurate predictions due to redundant uncertainty from overestimated variation in the relevant parameters. The MCMC method, on the other hand, eliminated $77 \%$ of the model true uncertainty (for water phase) ascertained by basic Monte Carlo method, and significant elimination in other phases can be speculated. We concluded that the MCMC method can not only allow "calibration" of contaminant fate model, but also remove the overestimated uncertainty in model predictions which is critical for the positive evaluation on the reliability of the model.

In Chapter 5, we further applied the level IV contaminant fate model described above to characterize the fate, transport and transformation of PFOA and PFOS, both of which are among the per- and polyfluoroalkyl substances (PFASs) that have received substantial attention due to abundant applications, environment persistence, and potential threats to ecological and human health. To validate our model, we collected data in Lake Chaohu over two years (20132015). We found reasonable agreement between the measured and modeled concentrations in various compartments. This result confirmed the reliability of our model to predict the fate of emerging HOCs such as PFOA and PFOS in shallow lake ecosystems, in addition to traditional HOCs such as OCPs and PAHs. Furthermore, we conducted both sensitivity and uncertainty analysis, not only on parameters but also on processes dictating fate of PFOA and PFOS in lakes. The model revealed the critical role of nonlinear Freundlich sorption, which contributed to a variable fraction of the model true uncertainty in different compartments (8.1\%-93.6\%). Additional scenario analyses further elucidated the importance of nonlinear Freundlich sorption for reliable model performance. This finding provided new insights for the research on PFASs, for which the sorption mechanism to organic matter is still unclear. In addition, our model identified the major sources and input pathways of PFOA and PFOS into the lake water column, as the major sources are indirect soil volatilization and direct release from human activities for PFOA and PFOS, respectively.

In Chapter 6, we developed an integrated ecological and contaminant fate model composed of CF, FW and EM modules. This integrated model was successful in simulating long-term dynamics (1953-2012) of representative PAHs in the main biotic and abiotic components in Lake Chaohu, which has undergone regime shifts in this period. Both contemporary and historical records from pelagic and sediment core samples were used to evaluate the model performance. Due to the large storage capacity of macrophytes, regime 
shifts in shallow lakes were found to exert a strong impact on the fate of less hydrophobic compounds. Sediment became the major sink after the abrupt disappearance of macrophytes, resulting in a sudden change in phenanthrene distribution in lake. On the other hand, the modelled impact of the regime shifts on more hydrophobic compounds, such as benzo(a)pyrene, was negligible for the whole environment, yet large for biotic compartments.

In Chapter 7, I proposed several remarks and perspectives. The transdisciplinary works in this thesis stand on the research fields of aquatic ecology and environmental chemistry in shallow lake ecosystems, which emphasize the interaction between eutrophication and contamination in lakes. Though the importance of this interaction has been realized for quite some time, modeling efforts on this issue remain scarce. The modeling approach in this thesis has made a step towards an integrated ecological and chemical fate model (i.e. EUTOX framework) that may fill this research gap. I also proposed a more comprehensive modeling framework (EUTOX-S), including EUTOX components and hydrodynamic models to address spatial variations. I suggested that by embracing the outcomes in aquatic ecosystem modeling (e.g. Delft3D as the hydrodynamic model, PCLake as the ecosystem model), new insights and discoveries may emerge for the research on organic contaminants in these systems that cannot be achieved by contaminant fate modeling itself. We also advocated to add the modeling approach as the third dimension in the emerging research strategy combining contemporary and paleo-observations, which together become the 'golden triangle' as the multidiscipline framework for limnologic research in the future.

In conclusion, this thesis underlines the significance of incorporating ecological knowledge in assessing the environmental behavior of HOCs in shallow lakes. Considering the valuable ecological services to human beings provided by freshwater shallow lake ecosystems and magnificent rewards in protecting them properly, intensive effort from both the scientific and the societal domain is still highly motivated. The present thesis is expected to provide implications for local ecological and environmental management and to contribute to developing a general model framework for the investigation of HOCs in shallow lakes, which are by all means indispensable. 
Acknowledgment

\section{Acknowledgment}

I want to express my immense gratitude to many of those who help me not only in my PhD project, but also in my life during all these precious years of this PhD.

First of all, I would like to thank my two promoters and also supervisors. Wolf, back in 2013, I was so grateful that you approved my application as a visiting $\mathrm{PhD}$ student from China. Now, I am even more grateful to you for becoming my $\mathrm{PhD}$ supervisor in NIOO. I still remember our first appointment, also my first day in NIOO, was on a cozy Monday in the deep European autumn. I was totally surprised to notice how tall you are when you were waiting for me at the reception. Then, I gradually found out the proportionate relation between your height and intelligence. What was even more surprising to me is how easygoing and young-hearted you have been when you are already a professor. Because of you, my world to the ecological modeling as well as the scientific research was widely broadened, and after all these years I realize how much I have learned in your group. As it is approaching to the end of $\mathrm{PhD}$, I would say that my 'complex' feeling is becoming even more complicated.

Bart, deeply thanks for being one of my promoters. Back in 2015, I was really exciting when I realized that the author for one of the most inspiring paper I have read was just sitting in the building across the street in Wageningen. It was one of my wisest decision to walk across the street and to talk with you about my research. Since then, all the work done with you was enjoyable. Besides the fruitful outcomes, I am more grateful to have the chance to learn from you in both professional knowledge and scientific writing. Thanks for your detailed comments and edits in the manuscripts we worked together, and for your patience in helping me to improve the level of these studies.

I also want to express my gratitude to my Chinese supervisor, Prof Fuliu Xu from Peking University. You opened the gate of science to me when I was still a fresh and naïve graduate. You provided me with all the wisdom, freedom and possibilities to do research, and you were fully in favor of the idea for me to visiting other labs in Europe to broaden my view and to enhance my experiences. I have no chance to finish this PhD thesis in the Netherlands without your support.

Annette and Sui, as two of my best friends, I deeply appreciate that you become my paranymphs. With you two sitting aside, I will definitely feel more confident and supportive when I am standing in front of the opponents during 
the defense. Annette, from where can I start? I had my very first meal in the Netherlands at your home with Karspar, when I was a total stranger in town and had no idea what life would be like here. It was a raining Sunday, typical Dutch weather in autumn, but I felt warm with your kindness and hospitality. I would not start this $\mathrm{PhD}$ without your 'catalyst' suggestion during the 'last' meeting with Wolf. It was really nice to work with you in NIOO, and now I am expecting more opportunities to work together again. Sui, thank you for being so supportive in my life, and no matter how far we are in the world, we can always talk to each other as we have just met yesterday. I cannot imagine a better friend than you. 祝福你平安喜乐!

Jan and Luuk (and also Annette), I feel myself the luckiest PhD student to have all three of you in the group when I was in NIOO. Jan, sometimes I feel you are a big brother to me. The discussions we had were interesting, and some were really inspiring, which I can still remember clearly until now. You are one of the smartest person I have met, and it is great that you are staying in science. Met je blije bakkus! Luuk, you would be the most 'rocky' scientist in history I suppose. I saw two versions of you, one sitting quietly in front the computer and working on the theoretical ecological models, and the other holding a Base and standing on the stage under all the lights and the screaming. I cannot not imagine to combine these two personalities into one until I knew you. I am really proud to have you as one of my colleagues in NIOO.

I want to thank all my colleagues at NIOO, but unfortunately I cannot mention everybody by name. Jan Janse, as the father of PCLake, you are in fact the key to my $\mathrm{PhD}$ research, and all the results I could have are attributed to your fantastic work on developing such a delicate ecosystem model. Kim, Michiel and Tania, you would be the best roommates for work! It was a great time to spend together here in NIOO with all our chats and jokes. Jing and Steven, thank you for being so hospitality during our stay at your house. Sincerely happy for your marriage, and now with a baby angel that makes a house full of joy. Jenny and Davide, I was really happy to meet you two in NIOO, and also later in US when we spend the Christmas together in your family. I am proud to witness your relationship changed from friends and now husband and wife. Sven, thank you so much for helping me in manuscript revisions and thesis reading. Manqi and Peiyu, thank you so much for all the helps from you two. Thank you Libin, Wei, Bart, Thijs, Mandy, Karen, Antonella, Laura, Nico, Dennis, Lisette, Liesbeth, Dedmer, Yani, Laiye, Cong, Haikun, Minggang and Xiaobu, Yu, Paolo, Ruth, Marta, Stijn, and many others for providing a heart-warming and relaxing atmosphere in NIOO, in which I could happily grow during all these years. 
Acknowledgment

I also want to thank all my colleagues at UFZ in Germany. Karsten, thank you for being my host when I tried to apply for the Humboldt postdoctoral fellowship. I was really lucky to know you during the AEMON workshop, and I foresee a very exciting and fruitful work in the coming two years in your group. Also thanks to Bertram, Martin, Marieke, Matthias, Qing, Chenxi, Xin, Valerie, Tallent, Muhammad, Michael, Aline, Yanping, Xiangqian, Xiaoqiang, and many others. Ich habe Glück und ich bin Glücklich mit Ihnen $\mathrm{zu}$ arbeiten!

I would like to offer my gratitude to the members of the thesis committee, Prof. Dr C. Kroeze, Prof. Dr J. de Boer, Prof. Dr Ir A.J. Hendriks, and Dr M.H.S. Kraak, for your time to evaluate my thesis.

For my beloved family, I will not reach that far without all of you, who are always so supportive and encouraging. My dear Mum, you are the strongest person I have ever known. You support the family when it reaches the edge and you help us all to go through the hard time. For all of these years, you had a tough life, for which I cannot even give a hand. Without you, I would have no chance to continue my study abroad, and you have defined what a 'Mother' could be. Thank you! I am proud to be your son!

Minghui, you are the biggest discovery during my PhD in NIOO, and I feel the luckiest man in the world to marry you. Life is then always like somewhere over the rainbow, and I cannot wait to spend it with you. Thank you for showing up in my life! Olivia, I sometimes cannot even believe that such a perfect baby like you is our daughter. You are my little angel and I cannot be more thankful for you to come to my life. Yanzhi, you are the best mother-in-law. You are so dedicating and considerable, and I am really grateful for you.

My dear dad, I devote this thesis to you. It has been more than three years since your sickness, and at some moments, both in day or night, you cannot imagine how desperate I am to wish you wake up and speak, not too much, just a few words to me. I miss you so much. You were once my world, but it collapsed abruptly when I was still not strong enough to support you. But now, I am proud to become a father like you, and I have made all the endeavor to become a man for our family. I cannot wait to tell you all those amazing events occurred in our family, like now you have become a grandpa. I know, you must be aware in mind, so that I keep silent and stay with you until the moment you come back to us. You are strong, as you have always been.

Xiangzhen, 24 September 2018 


\section{About the author}

Xiangzhen Kong was born on October 22 ${ }^{\text {nd }}, 1987$ in Hai'an, a 'tiny' county in the eastern coastal area of China with a population of 865,500 (2017). He spent first two years of his life there. Then, he moved to Nanjing, the capital city of Jiangsu Province, together with his parents, where he took education in primary, junior and high school. At the age of eighteen, in 2006, he started his bachelor studies in Applied Physics at Hohai University in Nanjing. During his bachelor, he developed great interests in mathematical modeling,

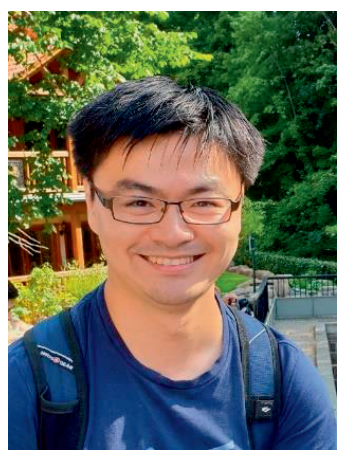
and he joined the mathematical club in the campus and won several prizes with his teammates in both national and international mathematical contests in modeling. For his bachelor thesis, he explored the method to determine triglyceride in human serum based on spectroscopic using advanced statistical modeling, which resulted in a first-author publication in a peer-reviewed scientific journal. In 2010, he started his first PhD at Peking University in China under the supervision of Prof. Dr Fuliu Xu. In this project, he investigated the long-term ecological dynamics of the fifth largest freshwater shallow lake (Chaohu) in China using both palaeolimnology and ecosystem modeling. During 2013-2015, he received a scholarship from China Scholarship Council to support his visit to the group of Prof. Dr Wolf M. Mooij in Netherlands Institute of Ecology (NIOO-KNAW) in Wageningen, The Netherlands. In 2016, he went back to China and received his first PhD degree at Peking University. Then, he officially started the current PhD in Wolf's group, which was about fate modeling of hydrophobic organic compounds (HOCs) in shallow lake ecosystems. The results of Kong's $\mathrm{PhD}$ research in Wageningen on fate modeling of HOCs are presented in this thesis. The supervision team was completed by Prof. Dr Albert A. Koelmans from the Aquatic Ecology and Water Quality Group at Wageningen University \& Research. He got married in June 2015 with Minghui, who he met at NIOO. In October 2017, their lovely daughter Olivia was born. In his spare time, he likes to do sports such as tennis, hiking and running. Kong is currently working as a postdoc in the group of Dr Karsten Rinke at Helmholtz Center for Environmental Research (UFZ) in Magdeburg, Germany, under the support from Alexander von Humboldt Foundation. 
List of publications

\section{List of publications}

Kong X., Liu W., He W., Xu F., Koelmans A.A. \& Mooij W.M. (2018): Multimedia fate modeling of perfluorooctanoic acid (PFOA) and perfluorooctane sulphonate (PFOS) in the shallow lake Chaohu, China. Environmental Pollution, 237, 339-347.

Kong X., He W., Qin N., Liu W., Yang B., Yang C, Xu F., Mooij W.M. \& Koelmans A.A. (2017): Integrated ecological and chemical food web accumulation modeling explains $\mathrm{PAH}$ temporal trends during regimes shifts in a shallow lake. Water Research, 119, 73-82.

Kong X., He W., Qin N., He Q., Yang B., Ouyang H., Wang Q., Yang C., Jiang Y. \& Xu F. (2014): Modeling the multimedia fate dynamics of $\gamma$-hexachlorocyclohexane in a large Chinese lake. Ecological Indicators, 41, 65-74.

Xu F., Qin N., Zhu Y., He W., Kong X., Barbour M.T., He Q., Wang Y., Ouyang H. \& Tao S. (2013): Multimedia fate modeling of polycyclic aromatic hydrocarbons (PAHs) in Lake Small Baiyangdian, Northern China. Ecological Modelling, 252, 246-257.

Kong X., He W., Qin N., He Q., Yang B., Ouyang H., Wang Q., Yang C., Jiang Y. $\& \mathrm{Xu} \mathrm{F}$. (2012): Simulation of the fate and seasonal variations of $\alpha$ hexachlorocyclohexane in lake chaohu using a dynamic fugacity model. Scientific World Journal, doi:10.1100/2012/691539.

Robson B.J., Arhonditsis G.B., Baird M.E., Brebion J., Edwards K.F., Geoffroy L., Hebert M., van Dongen-Vogels V., Jones E.M., Kruk C., Mongin M., Shimoda Y., Skerratt J.H., Trevathan-Tackett S.M., Wild-Allen K., Kong X. \& Steven A. (2018): Towards evidence-based parameter values and priors for aquatic ecosystem modelling. Environmental Modeling \& Software, 100, 74-81.

Janssen A.B.G., Victor de Jager; Jan H. Janse; Kong X.; Sien Liu; Qinghua Ye; Wolf Mooij. (2017): Spatial identification of critical nutrient loads of large shallow lakes: implications for Lake Taihu (China). Water Research, 119, 276287

Janssen A.B.G., Arhonditsis G.B., Beusen A., Bolding K., Bruce L., Bruggeman J., Couture R.M., Downing A., Elliott, J.A., Frassl M., Gal G., Gerla D., Hipsey M., Hu F., Ives S., Janse J.H., Jeppesen E., Jöhnk K., Kneis D., Kong X., Kuiper J.J., Lehmann M., Lemmen C., Özkundakci D., Petzoldt T., Rinke K., Robson B., Sachse R., Schep S., Schmid M., Scholten H., Teurlincx S., Trolle D., Troost T., van Dam A., van Gerven L.P.A., Weijerman M., Wells S. \& Mooij W.M. (2015): 
Exploring, exploiting and evolving diversity of aquatic ecosystem models: a community perspective. Aquatic Ecology, 49, 513-548.

Kong X., He Q., Yang B., He W., Xu F., Janssen A.B.G., Kuiper J.J., van Gerven, L.P.A., Qin, N., Jiang Y., Liu, W., Yang C., Bai Z., Zhang M., Kong F., Janse J.H. \& Mooij W.M. (2017): Hydrological regulation drives regime shifts: evidence from paleolimnology and ecosystem modelling of a large shallow Chinese lake. Global Change Biology, 23, 737-754.

Kong X., He W., Liu W., Yang B., Xu F., Jørgensen S.E. \& Mooij W.M. (2016): Changes in food web structure and ecosystem functioning of a large shallow Chinese lake during 1950s, 1980s and 2000s. Ecological Modelling, 319, 31-41.

Kong X., Dong L., He W., Wang Q., Mooij W.M. \& Xu F. (2015): Estimation of the long-term nutrient budget and thresholds of regime shift for a large shallow lake in China. Ecological Indicators, 52, 231-244.

Kong X., Jørgensen S.E., He W., Qin N. \& Xu F. (2013): Predicting the restoration effects by a structural dynamic approach in Lake Chaohu, China. Ecological Modelling, 266, 73-85.

Kong X., He W., Qin N., He Q., Yang B., Ouyang H., Wang Q. \& Xu F. (2013): Comparison of transport pathways and potential sources of PM10 in two cities around a large Chinese lake using the modified trajectory analysis. Atmospheric Research, 122, 284-297.

Kong X., Zhu W., Zhao Z., Li X., Wang H., Chen R., Chen C., Zhu F. \& Guo X. (2012): Fluorescence spectroscopic determination of triglyceride in human serum with window genetic algorithm partial least squares. Journal of Chemometrics, 26, 25-33. 
Training and Education Statement

PE\&RC Training and Education Statement

With the training and education activities listed below the PhD candidate has complied with the requirements set by the C.T. de Wit Graduate School for Production Ecology and Resource Conservation (PE\&RC) which comprises of a minimum total of 32 ECTS (= 22 weeks of activities)

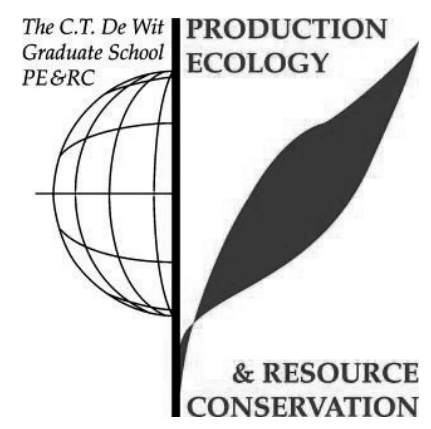

\section{Review of literature (4.5 ECTS)}

- Multimedia fate model for persistent organic pollutants in lake ecosystems (2015; presented in discussion group in Department of Aquatic Ecology, NIOO)

\section{Writing of project proposal (4 ECTS)}

- Modelling implications of emerging contaminants in aquatic ecosystems (2015)

\section{Post-graduate courses (6.1 ECTS)}

- Modelling critical transitions in nature and society; SENSE (2014)

- Microbiome Analysis in the Cloud; University of Maryland School of Medicine (2017)

- Advanced Molecular Genetics Bioinformatics \& Computational Genomics; Virginia Commonwealth University (2017)

- Introduction to Genomic Databases; Virginia Commonwealth University (2017)

\section{Laboratory training and working visits (4 ECTS)}

- Hydrodynamic modelling for lakes and reservoirs; Helmholtz Centre of Environmental Research, Germany (2016)

Invited review of (unpublished) journal manuscript (2 ECTS)

- Ecological Engineering: Phosphorus dynamic models (2015)

- Science of the Total Environment: Nutrient dynamics in a sub-lake (2017)

Competence strengthening / skills courses (2 ECTS) 
Training and Education Statement

- Responsible scientific conduct; Virginia Commonwealth University (2017)

PE\&RC Annual meetings, seminars and the PE\&RC weekend (1.2 ECTS)

- PE\&RC Day (2014-2015)

- Symposium nutrient pollution in water systems: sustainable solutions for Europe, China and the world (2016)

- PE\&RC Seminar (2016)

Discussion groups / local seminars / other scientific meetings (7.5 ECTS)

- NIOO Food web ecology group (2014-2015)

- NIOO Research group meetings (2014-2015)

- NIOO seminars (2013-2015)

International symposia, workshops and conferences (10.1 ECTS)

- International Society for Ecological Modelling (ISEM) meeting (2013)

- Netherlands Annual Ecology Meeting $(2014,2015)$

- $\quad 3^{\text {rd }}$ Aquatic Ecosystem Modelling Network (AEMON) workshop (2015)

- $\quad 10^{\text {th }}$ INTECOL International Wetlands Conference (2016)

Supervision of MSc students (1 ECTS)

- Photosynthetic and cellular toxicity of cadmium in Chlorella vulgaris 


\section{Colophon}

The research presented in this thesis was conducted at the Department of Aquatic Ecology at the Netherlands Institute of Ecology (NIOO-KNAW), and the Aquatic Ecology and Water Quality Management Group at Wageningen University \& Research.

This research received financial support from the National Science Foundation of China (NSFC) (41603088, 41030529, and 41271462), the National Project for Water Pollution Control (2012ZX07103-002) and the National Foundation for Distinguished Young Scholars (40725004).

This is NIOO Thesis 159 .

Printed by: Digiforce | Proefschriftmaken.nl

Cover design: Minghui Fei (feimh@njau.edu.cn) 
